\title{
MICHELE VITOLO
}

\section{ATIVIDADE INVERTASICA DE CÉLULAS INTACTAS DE LEVEDURA (Saccharomyces cerevisiae) OBTIDAS POR CULTIVO CONTÍNUO}

Tese de Doutoramento apresentada ao Departamento de Bioquímica do Instituto de Química da Univeridade de São Paulo

Orientador:

Prof. Dr. WALTER BORZANI 
Dedico esta tese a minha querida esposa Mārcia Cristina. 
Minha eterna gratidão ao Prof.or. WALTER BORZANI, que pôs a minha disposiçāo todo o seu talento e sua vasta experiência em pesquisa, propiciando-me inaudita segurança, sem a qual teria sido impossivel conduzir a bom termo esta tese.

Agradecimento especial aos meus queridos pais, ERSILIO e ENRICHETTA, pelo estimulo aos estudos e pelo enorme carinho e amor que sempre me deram.

"O homem $\bar{e}$ a medida de todas as coisas".

(Protāgoras). 
A Profa. Dra. MARINA LIA RIBEIRO VAIRO pela precio sa e imprescindivel colaboração nos ensaios de cultivo continuo.

AOs SRS. ARMANDO CAMOLEZE FILHO e JOSE EDUARDO DA CRUz pelo brilhante trabalho na elaboraçäo dos desenhos.

Ao Prof.Dr. Bruno Carlos de Almeida Cunha por todo - apoio que me tem dado.

A Biblioteca do Instituto de Ruimica da USP, pela revisão das referencias bibliogrä́ficas.

Ao Prof.or. Eugênio Aquarone a quem devo o convite para ingressar na Universidade de são Paulo.

Ao Departamento de Engenharia Quimica da Escola Politēcnica da USP em associaçāo com o IPT, que possibilitaram e facilitaram a execução dos ensaios de cultivo continuo.

Ao Quimico Luiz H. Koshimizu, Enga . Agron. Maria Regina de Melo cruz, ao Eng! Quimico Enrique Ildefonso $v$. Gómez e ao Engọ celso L.B. Netto, sem cuja colaboração teria sido impossivel realizar os experimentos de cultivo continuo.

Ao Sr. Euclides Gomes da Silva pelo apoio técnico no preparo dos ensaios de cultivo continuo.

A todos aqueles que direta ou indiretamente me auxiliaram na execução deste trabalho. 
1. INTRODUÇAOO 1

1.1 Generalidades 1

1.2 Resumo da teoria do processo continuo de fermentação

$\begin{array}{ll}1.3 \text { Objetivo do trabalho } & 11\end{array}$

1.4 A escolha do tipo de fermentação 12

$\begin{array}{lll}1.5 & \text { Escolha do mosto de fermentação } & 13\end{array}$

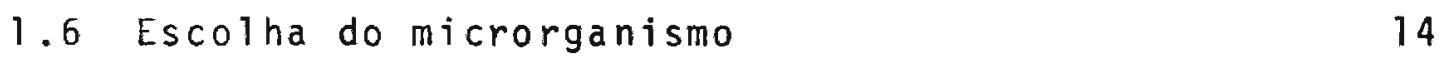

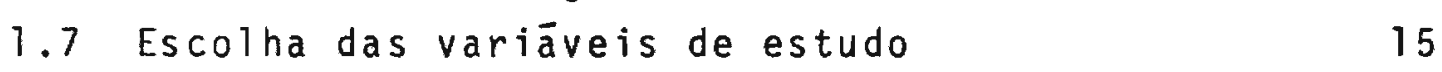

$\begin{array}{lll}1.8 & \text { Anátise dos resultados } & 17\end{array}$

2. MATERIAL E METODOS 20

$\begin{array}{ll}2.1 & \text { Preparo do mosto } \\ & 20\end{array}$

2.1 .1 Clarificação $\quad 20$

2.1.2 Esterilização 20

2.1 .3 Acerto do $\mathrm{pH} \quad 21$

2.1 .4 Suplementação 21

$\begin{array}{lll}2.2 & \text { Preparo do inōculo } & 21\end{array}$

2.3 Descrição do equipamento 22

2.4 Descrição de um ensaio típico 22

2.4.1 Condições experimentais 24

2.4.2 Tratamento das amostras 24

2.5 Técnicas analiticas 26

$\begin{array}{lll}2.5 .1 & \text { Medida do } \mathrm{pH} & 26\end{array}$

2.5.2 Medida da concentração celular 26

2.5.3 Medida da concentração de açūcares
redutores totais (ART)

2.5.4 Medida da atividade invertāsica 29 2.5.4.1 Solução de sacarose 30 
2.5.4.2 Medida da atividade invertásica da amostra

2.5.4.3 Prova em branco

2.5.4.4 Correção da atividade invertásica medida em 2.5.4.2

2.5.4.5 Cälculo da atividade invertās ca

2.5.5 Anāise de fatores que podem interferir no método analitico de medida da concen tração de ART

2.5.5.1 Interferēncia da presença de çelulas

2.5.5.2 Medida do consumo de ART pelas células

2.5.6 Efeito do tipo de armazenamento da suspensão de cēlulas sobre a atividade invertásica

3. RESULTADOS

3.1 Curva de calibração

3.2 Erro experimental na dosagem do ART pelo método de Somogyi

3.3 Interferéncia da presença de cēlulas na determinação do ART

3.4 Influência do consumo de açúcares pelas células na determinação do ART

3.5 Ensaios em cultivo continuo 43

3.5.1 Ensaio no 1

3.5 .2 Ensaio no 2

3.5 .3 Ensaio no 3

3.5 .4 Ensaio ne 4

3.5 .5 Ensaio no 5

3.5 .6 Ensaio n! 6

3.5 .7 Ensaio ne 7

83

3.5.8 Ensaio ne 8

3.5.9 Ensaio no 9 
3.5.10 Ensaio do inōculo 98

3.5 .11 Ensaio nọ $10 \quad 100$

3.5 .12 Ensaio no 11

$\begin{array}{lll}3.6 & \text { Ensajo em cultivo descontinuo } & 117\end{array}$

$\begin{array}{lll}3.6 .1 & \text { Ensaio no } 12 & 117\end{array}$

$\begin{array}{ll}\text { 4. DISCUSSAOO DOS RESULTADOS } & 121\end{array}$

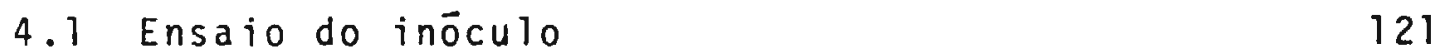

4.2 Erro experimental na dosagem do ART pelo méto do de Somogyi

123

4.3 Interferēncia da presença de cēlulas na deter minação do ART

4.4 Influéncia do consumo de açūcares pelas cēlulas na determinação do ART

4.5 Ensaios em cultivo continuo

4.5.1 Ensaios com borbulhamento de ar e com mosto não suplementado

4.5.1.1 Ensaio nọ 1

124

4.5.1.2 Ensaio nọ 2

130

4.5.1.3 Ensaio n! 3

137

4.5.1.4 Ensajo no 4

142

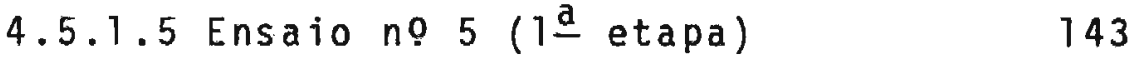

4.5.1.6 Ensaio no 10 (1 1 a etapa) 144

4.5.1.7 Comentārios sobre o ittem 4.5.1 145

4.5.2 Ensaios com borbulhamento de ar e com mosto suplementado

4.5.2.1 Ensajo no 5

4.5.2.2 Ensaio nọ 6

159

4.5.2.3 Ensaio no 7

166

4.5.2.4 Ensaio nọ $10 \quad 167$

4.5.2.5 Ensaio nọ 11

4.5.2.6 Comentärios sobre o item $4.5 .2 \quad 174$

4.5.3 Ensaio com mosto não suplementado e sem borbulhamento de ar 
p.

4.5.4 Ensaio com mosto suplementado e sem borbuthamento de ar

4.6 Ensaio descontínuo com melaço suplementado e com borbulhamento de ar

4.7 Anālise geral dos ensaios de fermentação contînua

4.7.1 Ensaios em regime estacionārio

4.7.2 Ensaios em regime transiente

4.7.3 Considerações finais

5. CONCLUSOES

6. RESUMO 
NOMENCLATURA

Apresentamos, a seguir, o significado dos símbolos e abreviaturas utilizados no decorrer desta tese.
$a, b$
- coeficientes linear e angular da curva de cali- bração.
AR
- Açücares redutores calculados como glicose.
ART
- Açūcares redutores totais calculados como glico se.
$c^{\prime}$
- Concentração de ART.
$C_{0}$
- Concentração de um ingrediente qualquer no mos- to de alimentação.
C
- Concentração de um ingrediente qualquer no tan- que de fermentação.
CV - Coeficiente de variação.
D - Vazão especîfica de alimentação da dorna.
F - Vazão de alimentação da dorna.
f - Fator de diluiçäo da suspensão de cēlulas
m - Massa de cēlulas secas, cuja atividade invertā- sica foi medida.
$m^{\prime} \quad$ - Massa celular ümida.
N - Frequéncia do agitador.
P.O.M. - Período de oscilaçäo mëdio da atividade invertä sica ao longo do ensaio.
$r$
- Coeficiente de correlaçäo linear. 


$\begin{array}{ll}r_{c r i t} & \text { - Coeficiente de correlação linear crítico. } \\ S & \text { - Desvio-padrão. } \\ S_{0} & \text { - Concentração de AR no mosto de alimentação. } \\ S_{0}^{\prime} & \text { - Concentração de ART no mosto de alimentação. } \\ S^{\prime} & \text { - Concentração de AR no tanque de fermentação. } \\ S^{\prime} & \text { - Concentração de ART no tanque de fermentação. } \\ \left(S^{\prime}-S\right) & - \text { Concentração de sacarose no tanque de fermentação } \\ \frac{d S}{d t} & - \text { Velocidade de variação da concentração de AR no } \\ & \text { mosto em fermentação. } \\ \left(\frac{d S}{d t}\right)_{c} & - \text { Velocidade de consumo de AR. } \\ \left(\frac{d S}{d t}\right)_{P} & - \text { Velocidade de formação de AR a partir da sacarose. }\end{array}$
$\frac{d\left(S^{\prime}-S\right)}{d t}$ - Velocidade de variação da concentração de sacaro- se no mosto em fermentação.

$\frac{d\left(S^{\prime}-S\right)_{c}}{d t}-$ Velocidade de consumo de sacarose.

t $\quad-$ Tempo

$v \quad$ - Atividade invertāsica específica das cétulas intactas de levedura.

$V \quad$ - Volume de mosto no tanque de fermentação.

$V_{I} \quad$ - Volume da amostra contendo a massa celular seca.

$x \quad$ - Massa de glicose

$x^{\prime} \quad$ - Massa de AR (medida como glicose) produzida pela invertase existente em dada massa de células secas.

$x$

- Concentração de microrganismo no mosto em fermen tação.

$\frac{d X}{d t} \quad$ - Velocidade de variaçäo da concentração celular no mosto em fermentação. 


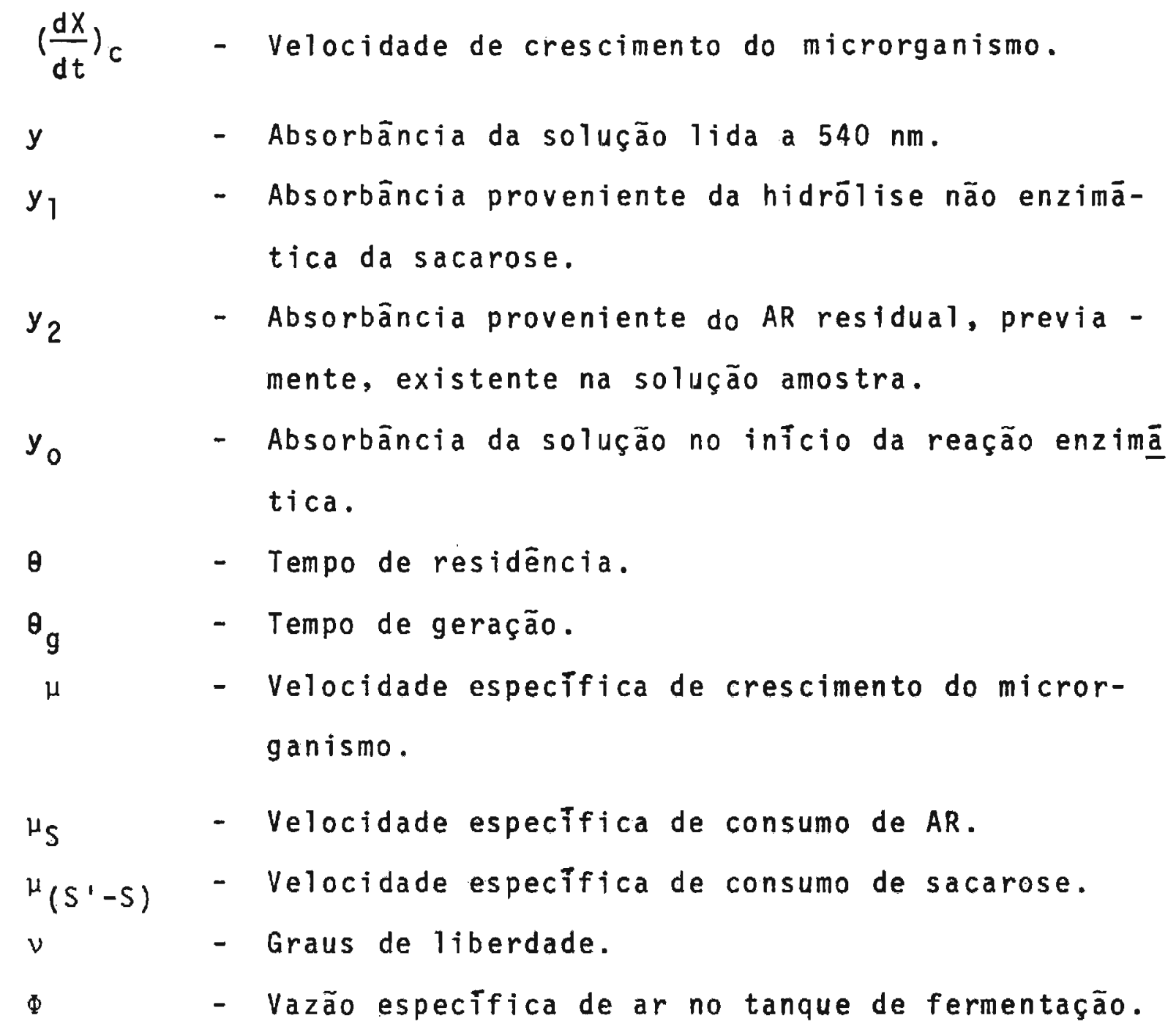




\section{INTRODUÇAO}

\subsection{GENERALIDADES}

A invertase ( $\beta$-fructofuranosideofrutohidrolase, EC. 3.2.1.26) è uma enzima encontrada em vārias espécies de organismos (60), sendo, no entanto, a levedura a fonte principal, sobretudo as espēcies $\underline{S}$. cerevisiae e $\underline{S}$. carlsbergensis.

Historicamente a invertase foi uma das prime $\underline{\mathfrak{i}}$ ras enzimas a ser obtida na forma de extrato bruto (60) e, jā em meados deste sēculo, encontrava-se disponível no comér cio (52).

Segundo SKINNER (54) o comércio de invertase no mercado Norte-Americano durante a década passada movimentou cifras da ordem de US $\$ 200.000$, que, quando comparadas com o mercado global de enzimas (aproximadamente de US $\$ 50$ milhões), são bastante modestas.

Por outro 1ado, o Brasil importou $2800 \mathrm{~kg}$ em 1980 e $8792 \mathrm{~kg}$ em 1981, despendendo, respectivamente US $\$ 31.420$ e US $\$ 74.670^{*}$. Considerando a importação brasileira de enzimas em 1980 e confrontando-a com os valores acima referentes ao mesmo ano, verifica-se que a invertase ocupou o 49 lugar em termos de quantidade e 089 em divisas (61).

* Informação pessoal obtida junto à Novo Industri do Brasil. 
Ao lado das perspectivas econōmicas, que são alentadoras, deve ser realçada a importäncia que os estudos sobre a invertase sempre tiveram para o desenvolvimento da Bioquĩmica. Atualmente particular atenção vem sendo prestada a estudos relacionados com a biossintese e transporte da invertase, importantes subsidios para esclarecer os mecanismos que levam à formaçāo de uma estrutura rica em macromolēculas, como è o caso da parede celular.

Foi demonstrada a existēncia de dois tipos de invertase na cēlula de $\underline{S}$. cerevisiae. Uma situada no inte rior do citoplasma e desprovida de manana, e outra na região da parede celular contendo este polissacarideo (29). Ainda existem muitas controvērsias sobre as interrelaçōes entre essas duas invertases (1) (34) (50).

A maneira pela qual a invertase è transferida para fora do citoplasma, tambëm näo estä bem esclarecida.S $\underline{e}$ gundo FARKAS et al (26) durante a gemulação, fase do ciclo ce lular de intensa atividade metabōlica, a invertase é deposita da, preferencialmente, na parede celular da gémula em crescimento. Conforme LAMPEN et al (38), a parte protēica da enzi ma seria formada no retículo endoplasmático e, a seguir, glicosilada, à medida que fosse transferida para a gêmula. Esta transferéncia parece ser intermediada por vesículas e a glico silaçāo ocorreria ao nível da plasmalema (6) (45) (53) (56).

Apesar das incōgnitas existentes em relaçäo aos eventos referidos, parece claro que deve existir um certo grau de correlação entre os eventos da gemulação e os do transporte, localização e biossíntese da invertase e, por extensão, com a biogēnese da parece celular. 
o resumo apresentado a seguir foi baseado nas referéncias (8) (9) (14) (28) (33) (51) e toma como ponto de partida uma cêlula que ainda não gemulou.

Uma vez atingido o tamanho adequado e, certamente, estabelecidas as melhores condições fisiolōgicas, a cēlula num dado momento passa a apresentar uma diminuta protuberāncia num ponto qualquer de sua superficie. E o primōrdio da gêmula. Concomitantemente verifica-se uma aceleração do consumo de carboidratos de reserva (trealose e glicogénio), seguida da sintese de polissacarídeos estruturais. Alēm disso ocorre, tambēm, o aparecimento de um grande número de vesículas, as quais conteriam os materiais necessários para a formação da estrutura da gēmula, inclusive a glucanase que seria responsāvel pelo enfraquecimento local da parede celular da cēlula-mãe, por onde se extrudaria a gēmula.

No instante em que a parede celular da célulamäe è rompida, começam a ser formadas, de modo contínuo, a pa rede celular e a plasmalema da célula-filha. O material cons tituinte da nova parede celular, principalmente glicana e manana, vai sendo inserido na porção distal da gēmula.

A glicana, que è o constituinte estrutural da parede, na verdade $\bar{e}$ o nome genērico de dois polissacarídeos da glicose, que se encontram associados. Um deles é linear, apresentando ligaçōes osídicas do tipo $B_{1 \rightarrow 3}$ e algumas do tipo $B_{] \rightarrow 6}$, enquanto que o outro é ramificado, sendo as ligaçōes osidicas da cadeia principal do tipo $\beta_{1 \rightarrow 6}$ e, nos pontos de ra mificação, do tipo $\beta_{1 \rightarrow 3}$.

Por sua vez, a manana, que se entrelaça com as moléculas de glicana e cuja estrutura é variāvel de acordo 
com a espēcie da levedura, é um polímero da manose contendo N-acetilgi icosamina e fosfato e que está associada a um peptideo. A manana estaria parte dispersa na parede celular e parte no espaço periplásmico, fazendo parte, neste ūitimo caso, da estrutura de enzimas como invertase e fosfatase àcida. Existem evidências de que as mananas destas duas re giōes são muito semelhantes e que estas macromoléculas são sintetisadas no citoplasma pela ação da manano-sintetase e, a seguir, são transportadas para a periferia em vesĩculas.

Toda a troca de materiais entre a gémula e a cēlula-mãe se dā através de um pequeno canal formado entre ambas. Quando o broto atinge um tamanho próximo da célula inicial, começa a se formar um septo de quitina na base do canal. A formação deste septo primärio requer a concorrēn cia de trés elementos: uma enzima na forma de zimógeno loca lizada na plasmalema (quitina-sintetase), uma protease (at vador) e um peptídeo de $P M=8500$ (inibidor).

Uma vez terminada a consolidação do septo prị mário, começam a se formar os septos secundārios, sendo um voltado para a cēlula-filha e o outro para a cēlula-mãe, cujos componentes são anālogos aos da parede celular.

Atingindo o tamanho adequado a cēlula-filha se destaca da cēlula-mãe.

Apesar de todas as dūvidas existentes, a verdade é que a invertase acaba se instalando na parede celular e/ou no espaço peripläsmico. Como foi visto, estas regiões são passiveis de intensas e variadas modificaçoes, que pode riam causar tanto mudanças conformacionais na estrutura das 
moléculas de invertase, como provocar posicionamentos distintos das mesmas. Isto tudo, em ūltima anālise, refletir-seia, a grosso modo, sobre a atividade invertásica total da célula intacta do $\underline{\mathrm{S}}$. cerevisiae, conforme será visto nos resultados apresentados mais adiante.

\subsection{RESUMO DA TEORIA DO PROCESSO CONTINUO DE FERMENTAÇÃO}

Em um processo fermentativo continuo a dorna é constantemente alimentada com mosto, o qual é fermentado e re tirado a uma vazão igual à de alimentação, o que permite um fluxo contínuo de produto e um volume constante de meio no tanque.

Neste processo podem se estabelecer, no sistema, dois tipos de regime: transiente e estacionärio. Todas as vezes que as condiçōes de cultivo não se adaptarem às neces sidades fisiolōgicas do microrganismo, tem-se o estabelecimento de regime transiente, onde as propriedades do sistema variam com o decorrer do tempo. Caso contrário obtém-se o reg me estacionārio que, aliás, é um dos objetivos principais do uso industrial do processo continuo de fermentação.

Na presente anālise sō serão apresentadas as deduções das equações que foram realmente aplicadas no cālcu10 de certos parāmetros üteis para a discussão dos resultados obtidos, a partir de uma dorna alimentada com mosto esterilizado e sem recirculação de microrganismos. Maiores informações poderão ser encontradas nos textos de AIBA (2) e BORZANI. LIMA E AQUARONE (10). 
ra 1 .

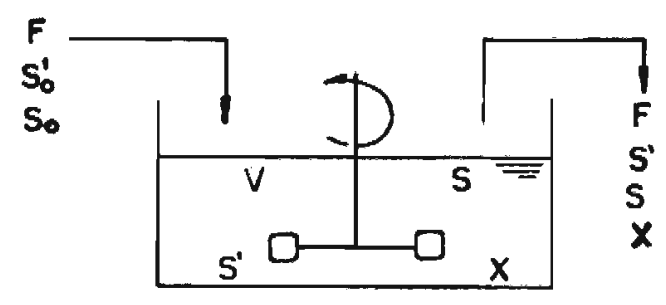

FIgURA 1. Representação esquemātica de um sistema de fermentação contînua.

Suponhamos que o fermentador seja homogēneo, contendo um volume $V$ de mosto, sendo alimentado, com mosto esterilizado, a uma vazão $F$, sendo $S_{0}$ e $S_{0}^{\prime}$, respectivamente, as concentraçōes de AR e ART no mosto de alimentação.

No interior da dorna o mosto é fermentado pelo microrganismo, presente na concentração $X$, e retirado a uma vazão F. Sejam S e S', respectivamente, as concentraçōes de AR e ART no meio existente na dorna. Como se estā admitindo agitação perfeita do sistema, então a composição do efluente é idēntica à do meio dentro da dorna.

o balanço material do microrganismo, em um intervalo de tempo $d t$, pode ser escrito como:

$$
\begin{aligned}
& \begin{array}{c}
\text { Variação da massa } \\
\text { de microrganismos } \\
\text { no tanque }
\end{array}=\left[\begin{array}{c}
\text { Variação da massa } \\
\text { de microrganismos } \\
\text { devido à reprodu- } \\
\text { ção celular }
\end{array}-\left[\begin{array}{c}
\text { Massa de micror- } \\
\text { ganismos retira- } \\
\text { da no efluente }
\end{array}\right.\right. \\
& V \cdot d X=V(d X)_{c}-F X d t
\end{aligned}
$$




$$
\frac{d X}{d t}=\frac{(d X) c}{d t}-D X
$$

onde $D=\frac{F}{V}$ representa a vazão especifica de alimentação.

Dividindo ( $1-I I)$ por $X$, temos:

$$
\frac{1}{x} \cdot \frac{d x}{d t}=\frac{1}{x} \cdot \frac{(d x)_{c}}{d t}-D
$$

Mas por definição: $\mu=\frac{1}{x} \cdot \frac{(d x)_{c}}{d t}$

onde $\mu$ representa a velocidade específica de reprodução.

Assim (1-III) pode ser escrita:

$$
\frac{1}{x} \cdot \frac{d X}{d t}=\mu-D
$$

Porēm, em regime estacionārio, tem-se $\frac{d X}{d t}=0$

$\log 0 \mu=D$

A relação (1-V) mostra que no sistema de um só tanque homogēneo, sem recirculação de microrganismos, a velocidade específica de crescimento $\vec{e}$, no regime estacionario, igual à vazão específica de alimentação.

A equação que exprime o balanço material de AR do sistema é:

$$
V d S=F S_{0} d t+V(d S)_{p}+V(d S)_{c}-F S d t
$$

Rearranjando temos:

$$
\frac{d S}{d t}=D\left(S_{0}-S\right)+\frac{(d S)_{p}}{d t}+\frac{(d S)_{c}}{d t}
$$


ou

$$
\frac{(d S)_{c}}{d t}=\frac{d S}{d t}-D\left(S_{0}-S\right)-\frac{(d S)_{p}}{d t}
$$

A equação para expressar o balanço da sacarose no sistema é:

$$
\operatorname{vd}\left(S^{\prime}-S\right)=F \cdot d t\left(S_{0}^{\prime}-S_{0}\right)+V \cdot d\left(S^{\prime}-S\right)_{c}-F \cdot d t\left(S^{\prime}-S\right)
$$

rearranjando temos:

$$
\frac{d\left(S^{\prime}-S\right)_{C}}{d t}=\frac{d\left(S^{\prime}-S\right)}{d t}-D\left[\left(S_{0}^{\prime}-S_{0}\right)-\left(S^{\prime}-S\right)\right]_{(1-I X)}
$$

Lembremos, tambèm, que:

$$
\frac{d\left\langle S^{\prime}-S\right\rangle_{C}}{d t}=-\frac{(d S)_{p}}{d t}
$$

Quando o sistema atinge o estado estacionärio tem-se:

$$
\begin{aligned}
& \frac{d S}{d t}=0 \\
& \frac{d\left(S^{\prime}-S\right)}{d t}=0
\end{aligned}
$$

Substituindo $(1-X I)$ e $(1-X I I)$, respectivamente, em $(1-V I I)$ e $(1-I X)$, tem-se:

$$
\frac{(d S)_{c}}{d t}=-D\left(S_{0}-S\right)-\frac{(d S)_{p}}{d t}
$$

e

$$
\frac{d\left(S^{\prime}-S\right)_{c}}{d t}=-D\left[\left(S_{0}^{\prime}-S_{0}\right)-\left(S^{\prime}-S\right)\right]
$$


Considerando, agora, as equações $(1-X)$ e $(1-X I V)$ podemos escrever que:

$$
\frac{(d S)_{p}}{d t}=D\left|\left(S_{0}^{\prime}-S_{0}\right)-\left(S^{\prime}-S^{\prime}\right)\right|
$$

Finalmente, substituindo $(1-X V)$ na $(1-X I I I)$ obtém-se:

$$
\frac{(d S)_{c}}{d t}=D\left(S^{\prime}-S_{0}^{\prime}\right)
$$

As velocidades especificas de consumo de $A R\left({ }_{S}^{\mu}\right)$ e de sacarose $\left({ }^{\mu} S^{\prime}-S\right)$ são definidas do seguinte modo:

$$
\begin{aligned}
\mu_{S} & =\frac{1}{x} \frac{(d S)_{c}}{d t} \\
\mu_{S}{ }^{\prime}-S & =\frac{1}{x} \cdot \frac{d\left(S^{\prime}-S\right)_{c}}{d t}
\end{aligned}
$$

No caso em que se deseja saber a quantidade de determinado in grediente após certo tempo no reator, procede-se do seguinte modo:

Seja o sistema representado na figura 2

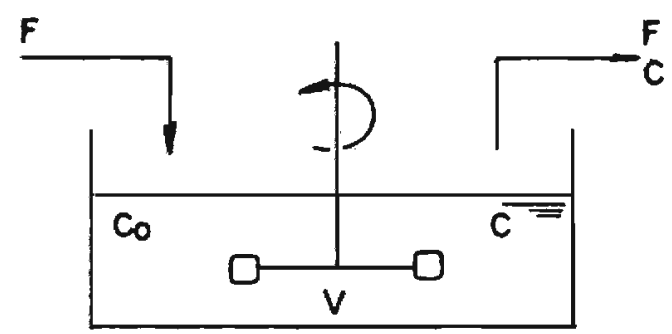

FIGURA 2. Representação esquemātica de um reator em regime de alimentação continua. 
onde: $C_{0}=$ concentração inicial do ingrediente na dorna $c=$ concentração do mesmo ingrediente apōs o tempo $t$ $V=$ volume do mosto.

Considerando um intervalo de tempo dt e desconsiderando o eventual consumo do ingrediente pelas cēlulas, temos:

$$
V \cdot d C=-F C d t
$$

$\log 0$

$$
\ln C=\ln C_{0}-D t
$$

Sabendo que o tempo de residência $(\theta) \bar{e} \circ$ inverso de $D$, e aplicando $(1-X X)$ pode-se saber, com boa aproxi mação, a quantidade do ingrediente após um tempo determinado $(t)$.

Na discussão dos resultados obtidos utilizouse o tempo de geração $\left(\theta_{g}\right)$ definido como sendo o tempo para haver duplicação da massa de células existentes no meio de cultivo. Por conseguinte demonstra-se que (10):

$$
\theta_{g}=\frac{\ln 2}{\mu}
$$

Para determinar as velocidades especificas de crescimento celular $(\mu)$, consumos de $\operatorname{AR}\left(\mu_{S}\right)$ e de sacarose $\left(\mu_{S^{\prime}-S}\right)$, atravēs, respectivamente,das equações $(1-$ IV $),(1-V I I)$ e $(1-I X)$ em regime transiente, onde $\frac{d X}{d t}$, $\frac{d S}{d t}$ e $\frac{d\left(S^{\prime}-S\right)}{d t}$ não são nulos, foi utilizado para o cálculo destas variáveis o método algébrico preconizado por Le DUY e ZAJIC (64). No apêndice apresenta-se uma tabela para ilustrar os cálculos feitos na aplicação do método referido. 
No ünico ensaio em que se utilizou processo fermentativo descontinuo, que foi o ensaio no 12 , as equações utilizadas para calcular os parāmetros acima referidos foram:

$$
\begin{aligned}
& \frac{(d S)_{c}}{d t}=\frac{d S}{d t}-\frac{(d S)_{p}}{d t} \\
& \frac{d\left(S^{\prime}-S\right)_{C}}{d t}=\frac{d\left(S^{\prime}-S\right)}{d t}=-\frac{(d S)_{p}}{d t}
\end{aligned}
$$

\subsection{OBJETIVO DO TRABALHO}

Hā, na literatura, muitos trabalhos que procu raram estudar vārios aspectos do comportamento da levedura cultivada por processo continuo, podendo ser citados, a tîtu 10 de exemplo, estudos relacionados com a composição da pare de celular (40) e com a repressão-desrepressão de enzimas (18).

Nosso primeiro objetivo foi o de verificar,em cultivo continuo, a influência de alguns fatores na ativida de invertásica de leveduras intactas no intuito de, posteriormente, estabelecer condições que conduzissem a células ricas em invertase.

Com o decorrer dos experimentos, porēm, notou-se que a atividade invertásica especifica das cēlulas in tactas oscilava ao longo do ensaio, independentemente de se estar em regime transiente ou estacionārio. Como não foi encontrada nenhuma publicação que fizesse menção a esse com- 
portamento oscilatório, procurou-se apresentar uma explicação deste fenōmeno.

\subsection{A ESCOLHA DO TIPO DE FERMENTAÇAO}

E muito dificil, ao se estudar um sistema qual quer, evitar que algum fator estranho ao mesmo acarrete perturbaçōes indesejāveis que, por sua vez, poderão conduzir a erros de interpretação dos resultados.

O grau da perturbação dependerā do tipo da técnica escolnida para o estudo programado e do seu tempo de aplicação.

No caso particular de microrganismos, que são sistemas altamente complexos, cuidados especiais devem ser tomados a este respeito.

Assim, quando a finalidade é avaliar a influência do meio ambiente sobre a fisiologia microbiana ou sobre a biossintese de determinada substāncia, è comum o emprego das técnicas: sincronismo celular (43), centrifugação fracionada (30), eletroforese bidimensional em gel de alta resolú ção (27) e cultivo contínuo (2)(10).

\section{Segundo ELLIOTT (22) a técnica do sincronismo} celular pode não ser a mais adequada para o estabelecimento do padrão de biossintese de macromoléculas, pois para obter - referido sincronismo as condições metabólicas da célula sofrem profundas alterações. Este autor sugere, para tal fim, - emprego da centrifugação fracionada e a eletroforese bidimensional. 
o cultivo contínuo, por sua vez, é um bom meio para se acompanhar as mudanças fisiológicas decorrentesde per turbações externas, pois nesse sistema as cēlulas podem ser mantidas em um ambiente com propriedades constantes (13)(16).

Segundo DEAN (19) e TODA (57) o cultivo continuo permite verificar o comportamento da atividade de enzimas frente às variaçōes ambientais como pH, vazão específica de al imentação (D), oxigenação, etc.

Assim sendo, o cultivo contínuo em estágio úni co mostra-se bastante adequado para abordar, convenientemente, os objetivos deste trabalho.

Realizou-se, tambēm, um ensaio por processo descontinuo com o intuito de acompanhar o comportamento da atividade invertásica e do crescimento celular em regime fran camente transiente.

\subsection{ESCOLHA DO MOSTO DE FERMENTAÇÃO}

Para o cultivo, continuo ou descontínuo, de $\underline{s}$. cerevisiae, assim como de muitos outros microrganismos, podem ser usados tanto meios sintéticos, cuja composição é conhecida, como meios provenientes de residuos industriais.

A escolha do meio, sem dúvida alguma, estará na dependencia do tipo de estudo a ser realizado. Quando se deseja estudar os sutis e complexos mecanismos que ocorrem no metabolismo celular, o uso de meio de cultura bem conhecido é uma condição necessária. Por outro lado, quando o estudo esta voltado para fins industriais, onde os problemas de cus- 
to tornam-se relevantes, o emprego de meio de cultura mais barato torna-se necessārio, passando os residuos industriais a terem maior importäncia.

Levando em conta que se pretendia verificar a possivel aplicação industrial dos resultados deste trabalho, optou-se, por conseguinte, pela escolha do melaço de cana-deaçūcar como matēria prima.

Alēm disso, segundo PEREGo (47), o melaço,que è o resíduo da fabricação do açücar a partir do caldo de cana, $\vec{e}$ um meio rapidamente transformado pela Tevedura, não contēm substāncias inibidoras, seu $\mathrm{pH}$ relativamente baixo diminui os riscos de contaminação, $\vec{e}$ de fācil manipulaçāo e pode ser armazenado durante o ano todo.

1.6 ESCOLHA DO MICRORGANISMO

Algumas das razōes que levaram à escolha do

S. cerevisiae foram:

a) o grande nümero de estudos existentes sobre esta especie de levedura, tornando-a um dos mais bem conheci dos microrganismos (37) (48);

b) a facilidade de seu isolamento e sua manutenção;

c) suas exigēncias nutricionais são relativamente poucas;

d) apresenta bom crescimento em meios preparados a partir de residuos industriais;

e) seu amplo uso em processos industriais; 
f) sua reconhecida capacidade de produzir enzimas extracitoplasmáticas (invertase e fosfatase ācida), sendo, por exemplo, a principal fonte de invertase;

g) o. fato de apresentar a invertase situada na região pe rifērica da cēlula, permitindo que a atividade desta enzima seja medida com relativa facilidade.

Deve ser destacado, outrossim, que este microrganismo estā sendo muito utilizado nos processos fermenta tivos para a produçäo de etanol. Como neste processo hā crescimento celular ponderável, poder-se-ia, então, desviar parte da massa de cēlulas formada para a extração da invertase. Ficaria assim aberta a possibilidade de acoplar a produção de etanol com a de invertase.

\subsection{ESCOLHA DAS VARIAVEIS DE ESTUDO}

Sempre que se procura utilizar microrganismos como agentes de transformaçāo, defrontamo-nos com dois fatos que, embora intimamente relacionados, exibem características distintas.

Um deles estā relacionado com o metabolismo celular, regido por mecanismos prōprios e dependentes da constituição genētica da cēlula. O outro relaciona-se com as condiçōes do ambiente no qual a célula é obrigada a viver e que podem ser propositalmente variadas ou, então, que se alteram como consequēncia da prōpria atividade celular. 
A resposta da cēlula às variaçōes ambientais aparece na forma de modificações morfo-fisiolögicas, que im plicam no aumento ou diminuição da atividade de pelo menos uma enzima (19)(57). Assim, pela medida da variação da ativi dade de uma enzima adequadamente escolhida, pode-se ter uma idéia da intensidade do efeito causado pela mudança ambiental.

No presente trabalho escolheu-se a invertase como enzima marcadora, sobretudo pela sua localização propícia na célula de levedura e pela relativa facilidade em se medir sua atividade.

Por outro lado, as medidas das concentrações de AR, ART e de cēlulas, tambēm se constituem em importantes indicadores da resposta da cēlula às variaçōes das condições ambientais, neste caso em termos de balanços globais de massa.

Existem muitos parämetros do sistema fermenta tivo que podem ser variados e seus efeitos avaliados.

Neste trabalho foram escolhidas as seguintes variāveis:

a) vazäo especīfica de alimentação da dorna: 0,10 a 0,11$014-0,23$ a $0,26 \mathrm{~h}^{-1}$;

b) vazāo especīfica de borbulhamento de ar: 0-1-2 l/l.min;

c) frequência do agitador: 500-700 $\mathrm{min}^{-1}$;

d) adição ou não de nutrientes: $\left(\mathrm{NH}_{4}\right)_{2} \mathrm{SO}_{4}, \mathrm{MgSO}_{4} \cdot 7 \mathrm{H}_{2} \mathrm{O}$ e $\mathrm{Na}_{2} \mathrm{HPO}_{4} \cdot 12 \mathrm{H}_{2} \mathrm{O}$. 
os niveis de variação fixados para os parāmetros selecionados, foram suficientes para provocar efeitos mensurā veis na cêlula de levedura.

A tabela I-I representa, de maneira resumida,al gumas das condições em que foram realizados os ensaios de cultivo continuo.

\subsection{ANALISE DOS RESULTADOS}

Mediram-se as concentraçōes de cëlulas $(X)$, açū cares redutores (S), açūcares redutores totais (S') e a ativi dade invertāsica especīfica (v) em funçäo do tempo, a partir de amostras do conteūdo da dorna retiradas periódicamente.

Atravēs de um balanço material adequado, deduziram-se equações que permitiram calcular as velocidades espe cīficas de consumo de açūcares redutores $\left({ }_{S}^{\mu}\right)$ e de sacarose $\left({ }^{\mu} S^{\prime}-S\right)$, assim como a velocidade específica de formação de cēlulas $(\mu)$. Em consequēncia, tambēm, foi possível calcular o tempo de geração $\left(\theta_{g}\right)$ celular nos värios ensaios.

De posse destes parāmetros, conduziu-se a anā $\underline{i}$ se dos resultados de modo que se pudesse obter, entre outras, conclusões relacionadas com:

a) condiçōes de maior produção de cēlulas ricas em invertase;

b) correlação entre as vārias velocidades específicas;

c) o verdadeiro significado dos valores de $v$ medidos; 
d) condições favorāveis à obtenção de regimes transiente e estacionārio;

e) a explicação da oscilação de $v$ com o tempo;

f) O significado da periodicidade das oscilações de $v$ em relação ao tipo de regime estabelecido na dorna;

g) o acoplamento entre a decomposição da sacarose e a assimilação dos açūcares redutores, intermediada pela ação da invertase localizada na periferia da célula;

h) a eventual relação entre $v$ e a produtividade em células, nos regimes estacionärio e transiente;

i) os efeitos causados por perturbações (por degrau e por impulso) sobre o sistema de cultivo. 


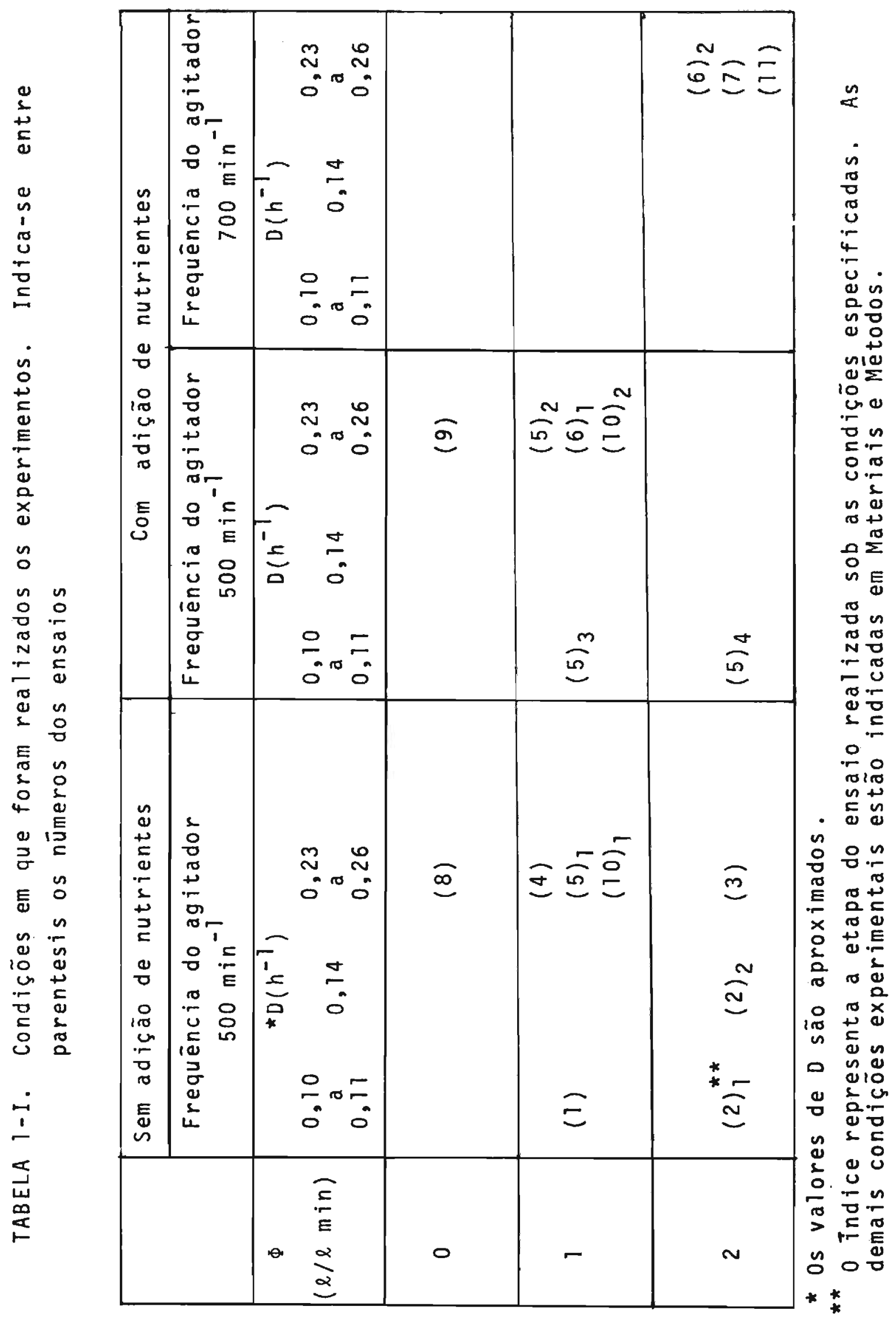




\section{MATERIAL E METODOS}

\subsection{PREPARO DO MOSTO}

Em todos os ensaios utilizou-se mosto de melaço de cana-de-açūcar clarificado, esterilizado e não hidrolisado, preparado da seguinte maneira:

\section{1 .1 Clarificação}

A melaço de cana-de-açūcar diluĩdo em àgua potāvel (proporção volumētrica $1: 1$ ) adicionou-se $\mathrm{NaH}_{2} \mathrm{PO}_{4} \cdot \mathrm{H}_{2} \mathrm{O}$ $(2,25 \mathrm{~g} / \ell$ de mistura $)$, sendo a mistura distribuida em balões de 12 \& e sucessivamente aquecida a $100^{\circ} \mathrm{C}$ por 15 min e a $115-$ $120^{\circ} \mathrm{C}$ por igual periodo. Em seguida a mistura foi deixada em repouso por no minimo $48 \mathrm{~h}$, para permitir a sedimentação de ma teriais precipitados. Findo este periodo, o mosto clarifica do foi retirado por sifonação.

\subsubsection{Esterilização}

0 mosto clarificado foi diluído de tal modo a apresentar uma concentração de ART da ordem de $30 \mathrm{~g} / \ell$ e acres cido de solução 4,0 $\mathrm{N}$ de $\mathrm{NaOH}$ suficiente para obter $\mathrm{pH}$ ao redor de 7,0. A seguir o mosto diluido foi distribuido da seguinte forma: 1,2l, divididos em frações de $200 \mathrm{ml}$, em erlenmeyers de le (paea preparar o inōculo); 2,5 \& na dorna e o 
volume restante em balões de $12 \ell(10 \ell$ em cada balão), proce dendo-se então à esterilização em autoclave a $120^{\circ} \mathrm{C}$ por 30 min.

\subsubsection{Acerto do $\mathrm{pH}$}

0 pH do mosto utilizado na fermentação foi ajustado em 4,0, pela adição de quantidades adequadas de solu ção $4,0 \mathrm{~N}$ de $\mathrm{H}_{2} \mathrm{SO}_{4}$. A fração de mosto $(1,2$ l) usada para pre parar o inōculo teve seu pH ajustado em 4,5 .

\section{1 .4 Suplementação}

Nos casos em que se utilizou mosto enriquecido, a suplementação foi feita adicionando-se, a cada balão, $\mathrm{Na}_{2} \mathrm{HPO}_{4} \cdot 12 \mathrm{H}_{2} \mathrm{O}(2,4 \mathrm{~g} / \mathrm{l}), \mathrm{MgSO}_{4} \cdot 7 \mathrm{H}_{2} \mathrm{O}(0,075 \mathrm{~g} / \mathrm{l})$ e $\left(\mathrm{NH}_{4}\right)_{2} \mathrm{SO}_{4}$ $(5,1 \mathrm{~g} / \ell)$, conforme preconizado por WHITE (62).

\subsection{PREPARO DO INOCULO}

Em todos os ensaios o microrganismo utilizado foi o $\underline{S}$. cerevisiae, isolado de fermento prensado comercial e mantido em meio glicosado sölido (extrato de levedura $3,0 \mathrm{~g} / \mathrm{l}$, peptona $5,0 \mathrm{~g} / \mathrm{l}, \mathrm{g} 1 \mathrm{icose} 10,0 \mathrm{~g} / \mathrm{l}$ e agar-agar 15,0 $g / \ell)$.

A partir da cultura pura, o microrganismo foi inoculado em tubos contendo $10,0 \mathrm{ml}$ de caldo glicosado (o qual diferiu do meio anterior apenas por não conter agar-agar) e incubado em estufa a $30^{\circ} \mathrm{C}$ por $48 \mathrm{~h}$.

Cada tubo, por sua vez, serviu de inóculo para um erlenmeyer de 1l, contendo $200 \mathrm{~m} 1$ de mosto idéntico ao que 
foi utilizado nos ensaios. Os erlenmeyers inoculados foram incubados a $30^{\circ} \mathrm{C}$ por $22 \mathrm{~h}$ em incubador rotativo (New Brunswick Scientific Co., Inc.) com frequéncia de $200 \mathrm{~min}^{-1} \mathrm{e}$ excentricidade de $3 \mathrm{~cm}$. A dorna de fermentaçāo foi inoculada com o conteūdo de 3 erlenmeyers (volume de $600 \mathrm{ml}$ ).

\subsection{DESCRIÇAO DO EQUIPAMENTO (Ver Figura 2-I)}

UtiTizou-se fermentador "Microferm" com dorna de 7 e de capacidade nominal, fabricado pela New Brunswick Scientific Co. Inc., com controles de temperatura, frequēncia do agitador, pH e vazão de ar.

A adiçāo contínua de mosto à dorna foi feita através de alimentador de vazão constante (bomba Biolafitte, série nọ 2920). A retirada continua de mosto foi feita através de um tubo, cuja extremidade inferior foi nivelada com a superficie do mosto na dorna e a extremidade superior foi conectada a uma batão de 2 l ligado a uma bomba de vácuo.

A adiçāo de antiespumante, quando necessäria, foi feita mediante a adaptação de um dispositivo adequado (Fig. 2-I).

\subsection{DESCRIÇAO DE UM ENSAIO TIPICO}

Inoculou-se a dorna com $600 \mathrm{ml}$ de inōculo, de xando-se o sistema durante $6 \mathrm{~h}$ nas condiçöes experimentais es colhidas. Apōs este período foi iniciada a alimentação conti nua de mosto. 


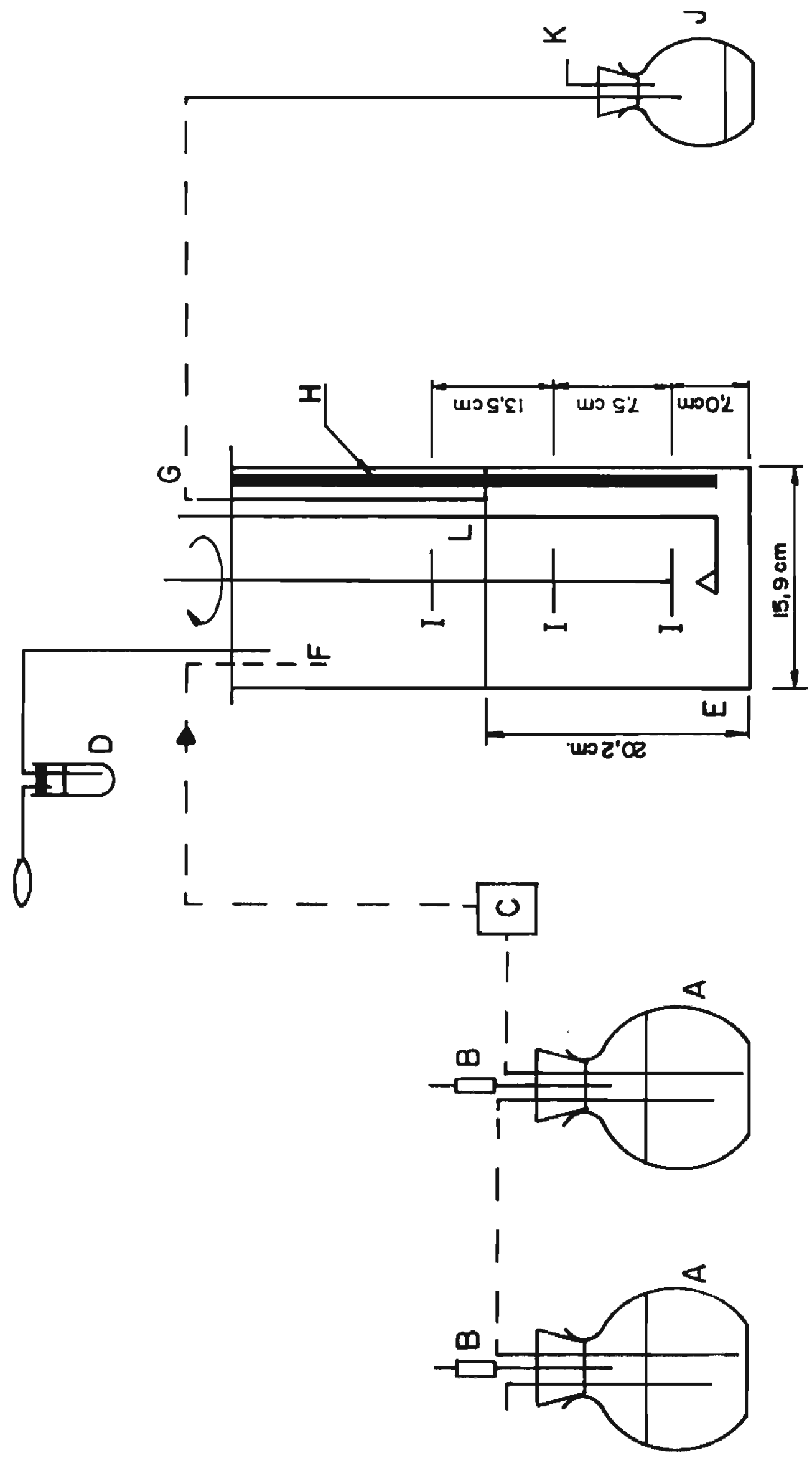

E:-isten

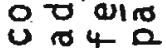

$\alpha \sigma$

$\sim$ 눈틍

- and

Q 0 읕

$0 \geq=$

n

din s

- 0 ○

ro arr...

r n

$\times, \frac{0}{0}$

$10+0$

○ $\quad$ r

- i... 웅

बir

E

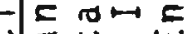

$\omega+$

당

일

튼

- S.下.

$>$ io us

눙 a 응

- No n

깅요

$+E$

o a n 0

이응

nL

乞ㄴㅇㅇㅇ

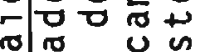

nt) 00

CE 든

(d) $d$

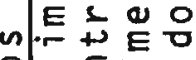

읕ㄷㄷㅏ

Eबw n

- , $\frac{0}{0}$

○ण

N ... . . E E

- 0 .

- ro a व̃

- 0

$\supset$ on 4 O [ro

草

엄 둔

幺 능

- u

웅

L $1 E \alpha$

에 山

F...

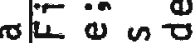

幽

है, 屯兄。

כ片

을 음

40

+ nu!

in 0

믈ㄷ…

त a $\frac{5}{n}$

N d

두 0 옹

o 0 .

5 \% 世

(

แUU? 
0 andamento da fermentação foi acompanhado por amostragem periōdica do mosto em fermentação no interior da dorna. A cada hora mediu-se o volume de efluente para contro le da vazão de alimentação.

\subsubsection{Condições Experimentais}

Os fatores seguintes tiveram seus valores fixa dos em todos os ensaios realizados:

temperatura de fermentação: $(30,0 \pm 0,5)^{\circ} \mathrm{C}$

$\mathrm{pH}$ do mosto: 4,0

antiespumante: UCON ou dimetilpolisiloxano

volume de mosto na dorna: 3 l

volume de inōculo: $600 \mathrm{ml}$

idade do inōculo: $22 \mathrm{~h}$

As demais condições experimentais estão especí ficadas na tabela $1-I$ e nos ensaios correspondentes no capitu 10 de Resultados.

\subsubsection{Tratamento das amostras}

As amostras, a menos das colhidas a intervalos de tempo de $10 \mathrm{~min}$, cujo volume variou de 10 a $50 \mathrm{ml}$, foram tratadas como indicado na figura 2-II. Os pormenores desse tratamento são descritos no îtem 2.5.

No caso de amostras colhidas a cada 10min, pro cedeu-se ao seguinte tratamento: filtrou-se 15,0 mi da amostra atravēs de membrana "Millipore" (diāmetro dos poros= $1,2 \mu \mathrm{m})$, lavando-se, em seguida, o material celular com 2 por 


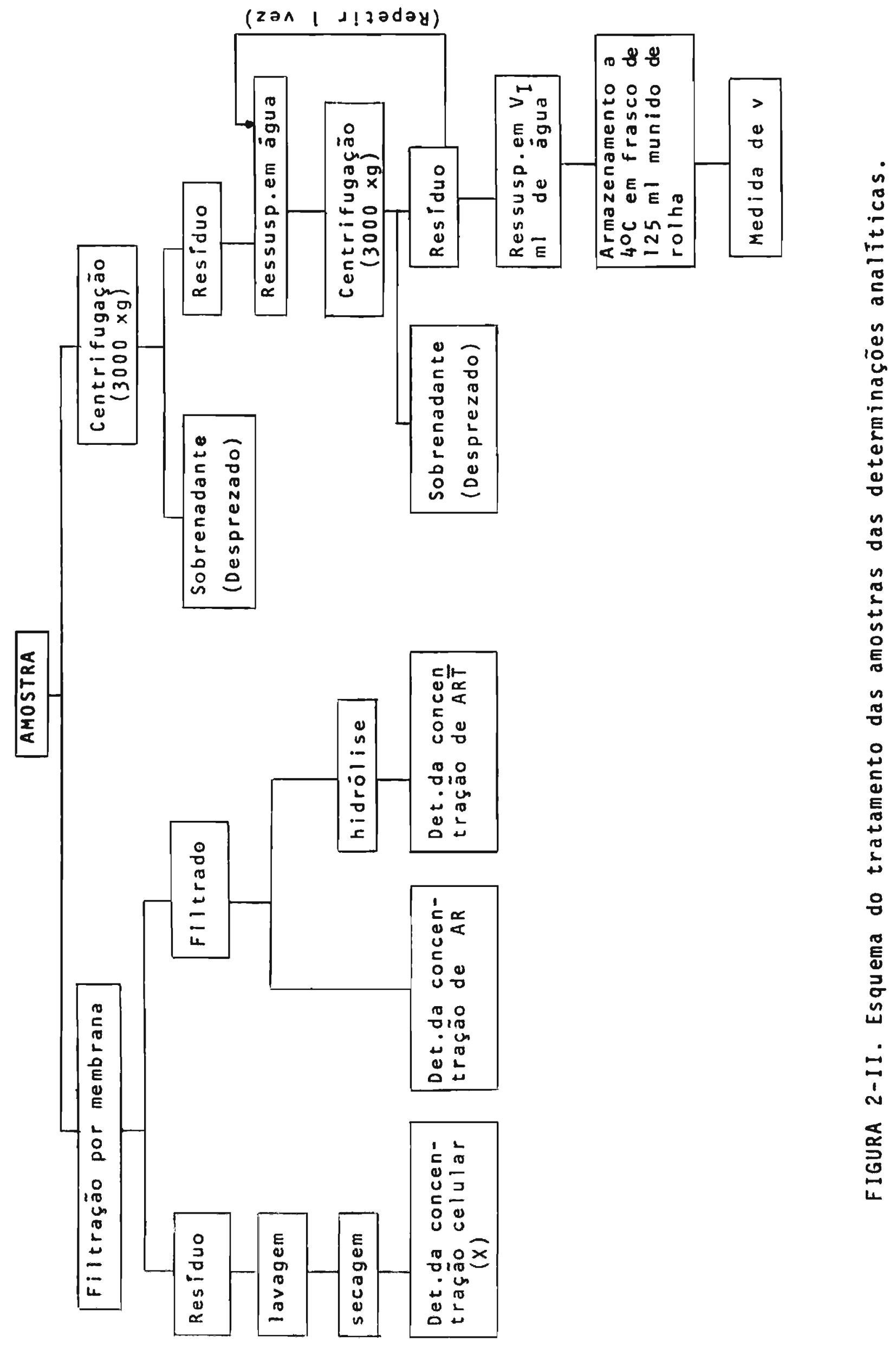


ções de $25 \mathrm{ml}$ de àgua destilada; uma vez escoada toda a àgua, as cēlulas foram transferidas, com o auxîlio de uma espátula, para um frasco munido de rolha de borracha, de massa conhecida; por diferença de pesagens, determinou-se a massa de células úmidas da amostra. Os frascos foram guardados em geladeira até o momento da medida da atividade invertāsica: o material úmido de cada amostra foi suspenso em $200 \mathrm{ml}$ de àgua destilada, sendo esta suspensão adequadamente diluída. Desta ultima, tomou-se $0,5 \mathrm{~m} 1$ procedendo-se conforme descrito em 2.5 .4 .

\subsection{TECNICAS ANALITICAS}

\subsubsection{Medida do $\mathrm{pH}$}

$0 \mathrm{pH}$ foi medido em potenciômetro (Micronal, B221).

\subsubsection{Medida da concentração celular (11)}

A amostra, tão logo colhida, foi filtrada em membrana "Millipore" (diāmetro do poro $=1,2 \mu \mathrm{m}$ ) para separar as células em suspensão. O resíduo da filtração foi lavado com $50 \mathrm{~m} 7$ de água destilada e posto a secar em estufa a $105^{\circ} \mathrm{C}$ por $2 \mathrm{~h}$.

A concentração celular obtida foi expressa em gramas de matéria seca por litro de amostra. 


\subsubsection{Medida da concentração de açūcares redutores}

\section{totais (ART)}

Em balão de $100 \mathrm{~m} 1$ foram colocados $5,0 \mathrm{ml}$ do efluente isento de células e $25,0 \mathrm{ml}$ de uma solução de HCl ( $100 \mathrm{ml}$ de $\mathrm{HCl}$ concentrado em $800 \mathrm{ml}$ de àgua destilada). Em seguida o balão foi mergulhado em banho de āgua a $65-70^{\circ} \mathrm{C}$ por 15 min para hidrolisar a sacarose do mosto. Findo este perío do resfriou-se o balào em água corrente (25).

A concentração de ART no hidrolisado foi deter minada pelo método de SOMOGYI (55), descrito a seguir:

\section{a) Reagentes}

o método de Somogyi utiliza trēs soluções cujas composiçōes são:

\section{Solução I}

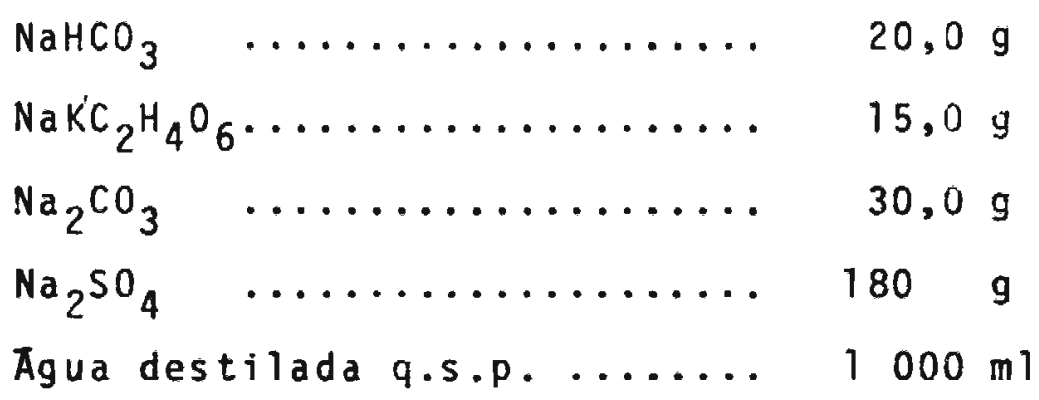

\section{Solução II}

Preparada pela dissolução, a frio, de $46,0 \mathrm{~g}$ de $\mathrm{Na}_{2} \mathrm{SO}_{4}$ em $100 \mathrm{ml}$ de uma solução de $\mathrm{CuSO}_{4} \cdot 5 \mathrm{H}_{2} \mathrm{O}$ de concentra çāo igual a $40,0 \mathrm{~g} / \ell$; eleva-se o volume a $200 \mathrm{ml}$ com àgua des tilada. 
Sol ução I I I

$$
\begin{aligned}
& \left(\mathrm{NH}_{4}\right)_{6} \mathrm{Mo}_{7} \mathrm{O}_{24} \cdot 4 \mathrm{H}_{2} \mathrm{O} \ldots \ldots \ldots \ldots \ldots \ldots \ldots .50,0 \mathrm{~g} \\
& \mathrm{H}_{2} \mathrm{SO}_{4} \quad(\mathrm{~d}=1,84) \ldots \ldots \ldots \ldots \ldots \ldots . \ldots \ldots, 42,0 \mathrm{ml} \\
& \mathrm{Na}_{2} \mathrm{HAsO}_{4} \cdot 7 \mathrm{H}_{2} \mathrm{O} \quad \ldots \ldots \ldots \ldots \ldots \ldots \ldots \ldots, 6,0 \mathrm{~g} \\
& \text { Aqua destilada q.s.p. ............ } 1000 \mathrm{ml}
\end{aligned}
$$

As soluções devem ficar em repouso por, no minimo, $30 \mathrm{~h}$ e deven ser guardadas en frasco escuro a $30^{\circ} \mathrm{C}$.

\section{b) Doseamento}

As soluções preparadas segundo descrito foram calibradas a partir de soluções de jlicose em āgua destilada, cujas concentrações distribuiram-se no intervalo de 20 a 200 $\mathrm{mg} / \ell$.

0 doseamento propriamente dito $\vec{e}$ descrito a seguir.

Em tubo de Folin-Wu colocaram-se 1,0 m1 de uma mistura das soluçōes I e II na razão volumētrica de 4:1 (mistura reativa), preparada no momento do uso, e 1,0 ml da amostra hidrolisada, adequadamente diluîda. Em seguida o tubo foi colocado em banho de ägua fervente durante 10 min exatos e, logo apös, resfriado em banho de gelo e ägua. A seguir adicionou-se 2,0 ml da soluçäo III e agitou-se vigorosamente para expulsar os gases formados, completando-se em seguida o volume de $25,0 \mathrm{ml}$ com àgua destilada. Em paralelo preparouse uma prova em branco, onde a amostra foi substituida por $1,0 \mathrm{~m} 1$ de àgua destilada.

Is to feito, mediu-se a absorbāncia da solução em espectrofotōmetro colleman Jr. (comprimento de onda $=540$ 
nm) usando, como referência, a solução obtida na prova em branco.

Muito embora os açúcares redutores obtidos pela hidrōlise do mosto de melaço sejam principalmente glicose e frutose, os resultados das determinações serão sempre expressos em gramas de açücares redutores totais, calculados como glicose, por litro de mosto, uma vez que a glicose sempre foi o padrão utilizado nas calibrações das soluções de reagentes.

Nos casos em que foi necessāria a determinação dos açücares redutores (AR) existentes na amostra, bastou to mar $1,0 \mathrm{ml}$ de uma soluçäo adequadamente diluída de efluente isento de cêlulas e proceder conforme descrito neste item.

Para avaliar o erro cometido ao usar-se o méto do de Somogyi, preparou-se uma solução de glicose $(10 \mathrm{~g} / \mathrm{h})$, a qual foi diluída 100 vezes. Desta diluição tomou-se alíquota de $1,0 \mathrm{ml}$ e procedeu-se ao doseamento. Repetiu-se a medida cinco vezes.

\subsubsection{Medida da atividade invertāsica}

Antes da medida da atividade procedia-se a uma diluição adequada da suspensão de cēlulas,a fim de garantir a condição de saturação da enzima pelo substrato durante a reação. O tempo de reação fixado sempre esteve dentro do in tervalo de 1 a 3 min, durante o qual a velocidade de formação de ART foi constante. Isto foi assegurado determinandose, em cada ensaio, a curva do aumento da concentração de ART com o tempo tomando-se por base a amostra correspondente 
à suspensão celular ma is ativa obtida em processo continuo. A medida do aumento da concentração do ART foi acompanhada, de minuto em minuto, durante 6 minutos. O sistema montado foi igual ao descrito em 2.5.4.2 a menos do tempo de reação que se prolongou por $6 \mathrm{~min}$. Informaçōes complementares serão for necidas no capitulo RESULTADOS.

\subsubsection{Solução de sacarose}

A solução de sacarose, de concentração $100 \mathrm{~g} / \ell$, foi preparada dissolvendo-se no momento do uso, em tubo de Folin-Wu, $0,25 \mathrm{~g}$ de sacarose p.a. (marca Reagen) em $2,5 \mathrm{ml}$ de tampão acetato $\mathrm{pH}=4,6$. Agitou-se até dissolução total. O tempo decorrido entre a adição do tampão sobre a sacarose e o momento do uso foi sempre de 5 min exatos.

A solução-tampão acetato de $\mathrm{pH}=4,6$ foi prepara da da seguinte maneira (7): foram misturados $260 \mathrm{ml}$ de solu ção $0,010 \mathrm{M}$ de ácido acético e $240 \mathrm{~m} 1$ de solução $0,010 \mathrm{M}$ de acetato de sódio. Após a homogeneização da mistura o pH foi ajustado a 4,6 e o volume completado a 1 e com āgua destilada.

\subsubsection{Medida da atividade invertāsica da $\underline{\text { amostra }}$}

0 tubo de'Folin-Wu contendo a solução de sacarose foi colocado em banho de ägua a $37^{\circ} \mathrm{C}$ por $10 \mathrm{~min}$. Em seguida adicionou-se $0,5 \mathrm{ml}$ da suspensão diluĩda de células e a mistura permaneceu a $37^{\circ} \mathrm{C}$ durante um tempo fixo $(1,2$ ou 3 minutos). A reação foi interrompida pela adição de $1,0 \mathrm{~m} 1$ da mistura reativa (ver item 2.5.3), seguida da imediata 
imersão em banho de água fervente por $10 \mathrm{~min}$. Apōs resfriamento do tubo em āgua corrente, adicionou-se $2,0 \mathrm{ml}$ da solução III (ver ittem 2.5.3) e agitou-se energicamente. A seguir o volume foi completado a $25,0 \mathrm{ml}$ com água destilada. A absorbāncia foi lida em espectrofotōmetro (comprimento de onda igual a $540 \mathrm{~nm})$. Esta determinação foi feita sempre em duplicata.

\subsubsection{Prova em Branco}

Em tubo de Folin-Wu colocaram-se $0,5 \mathrm{ml}$ de tampão-acetato e $1,0 \mathrm{ml}$ da mistura reativa. Em seguida o tubo foi mergulhado em banho de āgua fervente, procedendo-se, como em 2.5.4.2.

\subsubsection{Correção da atividade invertāsica medida em 2.5.4.2}

Os seguintes pontos devem ser considerados para se poder chegar ao valor corrigido da atividade invertāsica:

\section{a) Concentração de AR existentes na suspensão aquosa de cềlulas}

Esta determinação é necessāria porque as lavagens a que foram submetidas as cēlulas (ver figura 2-II) não garantem eliminação completa dos açücares provenientes do mós to. Em tubo de Folin-Wu colocaram-se $0,5 \mathrm{~m} 1 \mathrm{da}$ suspensão diluîda de cēlulas e $1,0 \mathrm{ml}$ da mistura reativa. O tubo for deixado em banho de āgua fervente por $10 \mathrm{~min}$. A seguir foi 
resfriado, acrescido de $2,0 \mathrm{ml}$ da solução III e o volume com pletado a $25,0 \mathrm{ml}$ com água destilada.

b) Concentração de AR formados durante a ação da invertase por hidrōlise não enzimätica da sacarose

Durante o intervalo de tempo em que a sacarose sofre a ação da invertase da levedura há, concomitantemente, hidrōlise não enzimātica da sacarose com a consequente produção de AR. A concentração de AR produzidos pela hidrōlise não enzimática deve, obviamente, ser medida. Para tanto, pro cedia-se do seguinte modo: dois tubos de folin-Wu contendo $2,5 \mathrm{ml}$ da solução de sacarose foram deixados em banho de āgua a $37^{\circ} \mathrm{C}$ por $10 \mathrm{~min}$. Em seguida adicionou-se a um dos tubos $1,0 \mathrm{~m} 1$ da mistura reativa, e, apōs homogeneização, o tubo foi mergulhado em banho de ägua fervente, procedendo-se conforme 2.5.4.2. O outro tubo foi deixado a $37^{\circ} \mathrm{C}$ durante mais $3 \mathrm{~min}$, sofrendo a seguir tratamento anālogo ao anterior.

\section{c) Determinação da concentração de ART formados durante os 10 min de permanência da solução de sacarose a $37^{\circ} \mathrm{C}$}

Para esta determinação procedeu-se tal como des crito em 2.5.4.2, exceto que a mistura reativa $(1,0 \mathrm{ml})$ foi adicicnada ao tubo de Folin-Wu imediatamente após a adição da amostra contendo as células $(0,5 \mathrm{ml})$. Este tubo serā considerado como sendo o "tubo de tempo zero". 


\subsubsection{Cálculo da atividade enzimätica \\ Para o cálculo da atividade enzimática}

procedeu-se como descrito a seguir (Figura 2-III).

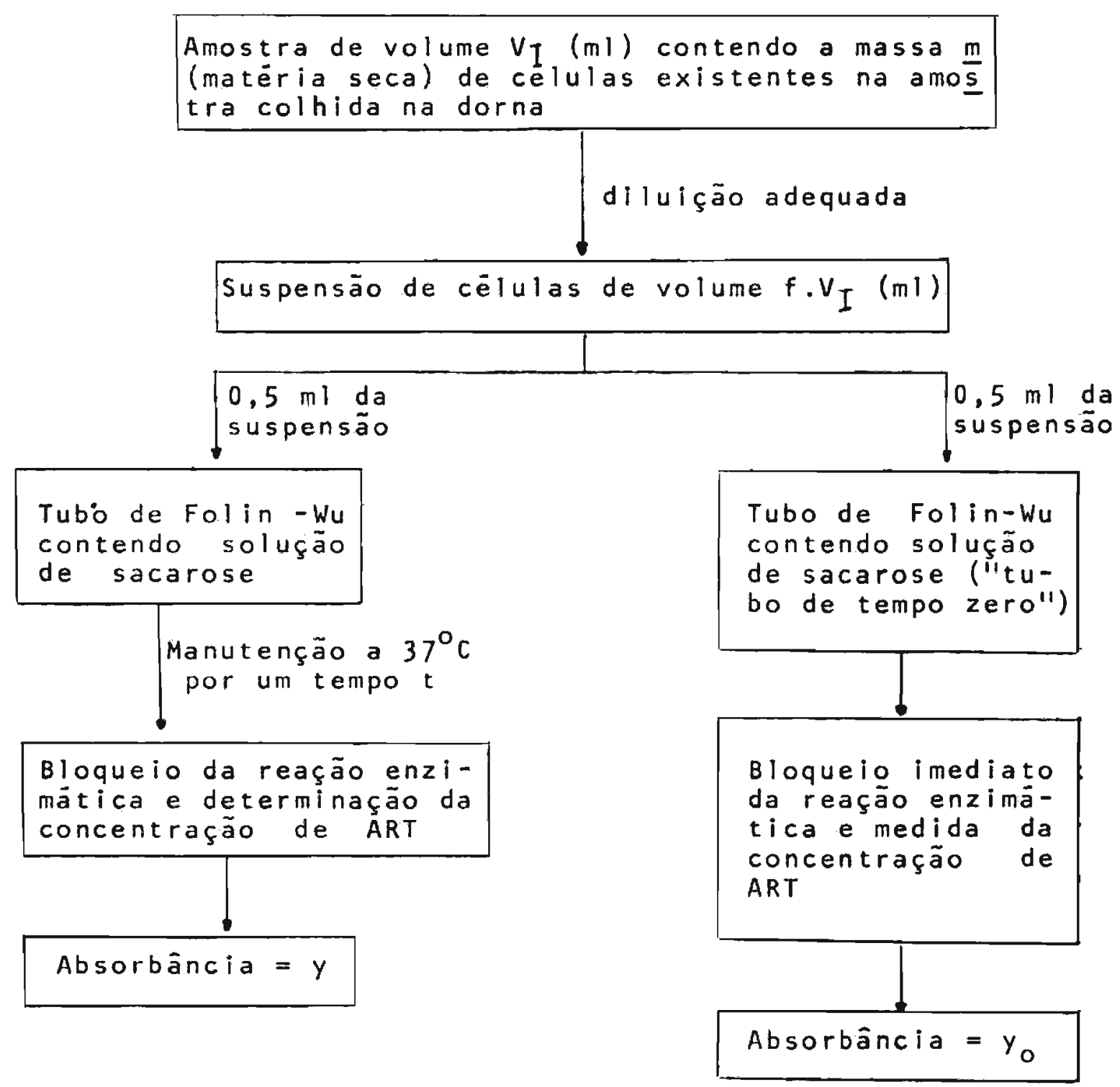

FIgURA 2. III. Esquema da tēcnica utilizada para medida da atividade enzimätica de amostras contendo células intactas de levedura. 
Da leitura y deve-se subtrair a absorbância de vida à hidrōlise não enzimātica da sacarose $\left(y_{1}\right)$ e tambēm aquela devida à existência de AR na amostra em questão $\left(y_{2}\right)$. Chega-se assim a uma absorbāncia dada por:

$$
y-\left(y_{1}+y_{2}\right)
$$

Desse ūitimo valor deve ser ainda subtraĩda a absorbāncia obtida nos "tubos de tempo zero" que, analogamente ao que foi exposto anteriormente, serā:

$$
y_{0}-\left(y_{1}+y_{2}\right)
$$

O valor corrigido da absorbanncia para o cālcu10 da atividade enzimātica será:

$$
Y=y-y_{0}
$$

Sendo $x$ a massa de ART correspondente à absorbância $Y$, e sendo $Y=a+b x$ a equação da curva de calibração, tem-se :

$$
x=\frac{y-y_{0}-a}{b}
$$

Levando em conta o mëtodo utilizado na medida da atividade enzimática (ver fig. 2-III), a massa de ART que seria produzida pela massa m de cēlulas serä:

$$
x^{\prime}=2 f V_{I} \frac{y-y_{0}-a}{b}
$$

Sendo a atividade enzimātica ( $v$ ) definida como 
a massa de ART produzida na unidade de tempo, pela unidade de massa de cēlulas (matēria seca), tem-se:

$$
v=\frac{2 f \cdot v_{I}}{m \cdot t} \cdot \frac{y-y_{0}-a}{b}
$$

A equação (2-IV) sõ não foi aplicada nas amostras que, durante o ensaio no 11, foram colhidas de 10 em 10 min durante um período de $3 \mathrm{~h}$. Por razōes de ordem tēcnica não foi possivel determinar a massa de cēlulas secas dessas amostras, sendo por isso utilizados os valores das massas de cēlulas ümidas (m') no cālculo de v. Assim, nesses casos, tem-se:

$$
v=\frac{2 f \cdot v_{I}}{m^{\prime} \cdot t} \cdot \frac{y-y_{0}-a}{b}
$$

\subsubsection{Anālise de fatores que podem interferir no mētodo analitico de medida da concentração de ART}

Preparou-se uma suspensão de levedura (fermento Fleischmann) em āgua destilada de concentração igual a $0,33 \mathrm{~g}$ de matéria seca por 1 itro. Aliquotas desta suspensão foram tomadas para avaliar a interferéncia dos fatores indicados a seguir.

\subsubsection{Interferēncia da presença de cēlulas}

A tubos contendo volumes conhecidos $(0,4$ $\mathrm{ml} ; 0,6 \mathrm{ml}$ e $0,8 \mathrm{ml})$ de solução de glicose $(0,2 \mathrm{~g} / \ell)$ adicionou-se $0,5 \mathrm{~m} 1$ de suspensäo de Tevedura e tampão-acetato $\langle\mathrm{pH}=$ 
4,6) suficiente para completar $3,0 \mathrm{ml}$. Apōs homogeneização, determinou-se a concentração de AR em cada tubo. Tratamento anālogo, a menos da adição da suspensão de levedura, foi dado, em paralelo, a outros tubos (provas em branco).

\subsubsection{Medida do consumo de ART pelas cēlulas}

A tubos de ensaio adictonou-se: a) 5,0 ml de solução de sacarose, previamente submetida à hidrōlise ācida (100 ml de āgua destilada $+10 \mathrm{~g}$ de sacarose $+10 \mathrm{ml}$ de $\mathrm{HCl}$ concentrado foram aquecidos em banho de água a $70^{\circ} \mathrm{C}$ por $15 \mathrm{~min}$ ) $\mathrm{com} \mathrm{pH}=4,6$ e mantida a $37^{\circ} \mathrm{C}$, por $10 \mathrm{~min}$; $1,0 \mathrm{~m} 1$ de suspensão de levedura, tambēm previamente mantida a $37^{\circ} \mathrm{C}$ por $10 \mathrm{~min}$.

De tempos em tempos, sempre a $37^{\circ} \mathrm{C}$, retiravase um tubo que, apōs receber $2,0 \mathrm{ml}$ de solução $0,010 \mathrm{M}$ de $\mathrm{NaOH}$, era centrifugado $(1100 \times g)$ durante $10 \mathrm{~min}$. Determinava-se a concentraçāo do ART no sobrenadante.

\subsubsection{Efeito do tipo de armazenamento da suspensão de} cēlulas sobre a atividade invertāsica

Tão logo a amostra foi retirada do fermenta dor e apōs as operações de lavagem foi feita a medida da ati vidade invertásica. A seguir foi acondicionada em erlenmeyer de $125 \mathrm{~m} 1$ munido de rolha e guardada em geladeira. Após $24 \mathrm{~h}$ (tempo que corresponderia ao momento de anālise da amos tra conforme nosso esquema de trabalho) mediu-se novamente a atividade invertāsica. O restante da suspensão foi mantida nas mesmas condições durante sete dias, quando se refez a 
a medida da atividade.

Alēm disso, mediante o uso de microscōpio bi nocular convencional observou-se a morfologia das cêlutas de levedura em suspensão, tão logo a amostra foi obtida e sete dias apōs. 


\section{RESULTADOS}

\subsection{Curva de Calibração}

Uma curva tîpica de calibração do espectrọ fotōmetro para determinação da concentração de ART estā indi cada na tabela 3.1 e representada na figura 3.1 .

0 coeficiente de correlação (r) para todas as curvas de calibração utilizadas na determinação do AR e ART esteve entre 0,9990 e 0,9998 .

TABELA 3.1 Calibração do espectrofotōmetro ( $\lambda=540 \mathrm{~nm}$ ) para determinação da concentração de açūcares redutores.

\begin{tabular}{ccc}
\hline $\begin{array}{c}\text { Massa de } \mathrm{glicose} \\
\times(\mathrm{mg})\end{array}$ & \multicolumn{2}{c}{ Absorbäncia $(y)$} \\
\cline { 2 - 3 } & Leituras & Mädia \\
\hline 0,04 & $0,100-0,100$ & 0,100 \\
0,08 & $0,195-0,200$ & 0,198 \\
0,16 & $0,295-0,295$ & 0,295 \\
0,20 & $0,390-0,395$ & 0,393 \\
\hline
\end{tabular}




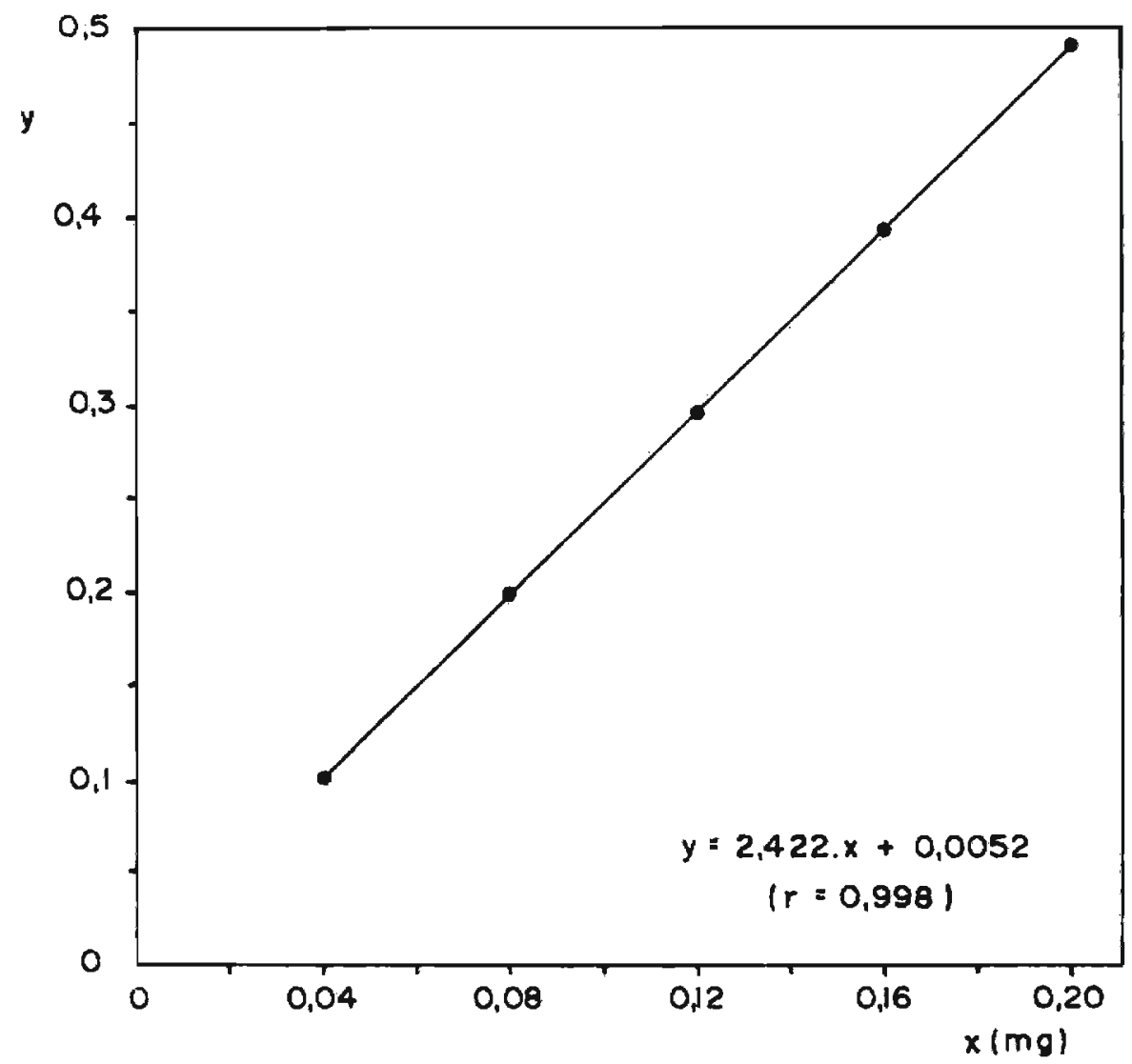

FIGURA 3.I. Curva de calibração do espectrofotōmetro para medidas das concentrações de açūcares redutores. $(x=$ massa de glicose; $y=$ absorbāncia; $r=$ coeficiente de correlação). 
3.2 Erro experimental na dosagem do ART pelo método de Somogyi

a) Resultados

Os valores obtidos encontram-se na tabela 3.2 .

b) Comentärios

A equação da curva de calibração utilizada è a seguin te:

$$
y=1,963 x+0,0044 \quad(r=0,996)
$$

o valor médio da concentração de glicose, desvio-padrão e coeficiente de variação são, respectivamente, $9,71 \mathrm{~g} / \mathrm{l}, 0,26 \mathrm{~g} / \mathrm{l}$ e $2,7 \%$.

Pela aplicação do teste " $t$ " e consideran do 4 graus de 7 iberdade e $95 \%$ de confiança, obtēm-se o inter valo para a média dos valores: $(9,71 \pm 0,36) \mathrm{g} / \mathrm{l}$.

TABELA 3.2 Avaliação do erro experimental na determinação da concentração de ART

\begin{tabular}{cc}
\hline Absorbäncia & $\begin{array}{c}\text { Concentração de } \\
\text { glicose, } c \\
(g / \ell)\end{array}$ \\
\hline 0,190 & 9,45 \\
0,190 & 9,45 \\
0,195 & 9,71 \\
0,200 & 9,96 \\
0,200 & 9,96 \\
\hline$c=9,71 \mathrm{~g} / \mathrm{l}$ & $\mathrm{s}=0,26 \mathrm{~g} / \ell \quad \mathrm{CV}=2,7 \%$ \\
\hline
\end{tabular}


3.3 Interferēncia da presença de cēlulas na determinação do ART

a) Condições experimentais

Tanto a suspensão de cēlutas como os tubos contendo so lução de glicose foram mantidos a $37^{\circ} \mathrm{C}$ por 10 minutos, antes de serem misturados

b) Resultados

os valores obtidos encontram-se na tabela 3.3 .

c) Comentārios

Como o objetivo do ensaio era verificar se a presença de cēlulas causava alguma interferéncia, a aliquota para a dosagem era retirada imediatamente apōs a homogeneização da mistura das células com a solução de glicose. A rapidez teve o objetivo de eliminar qualquer perda de glicose em conseqüéncia da presença de cểulas intactas de levedura.

A equação da curva de calibração usada nos eāiculos foi:

$$
y=1,963 x+0,0044 \quad(r=0,996)
$$

TABELA 3.3 Interferēncia da presença de cēlulas na determinação da concentraçäo de ART

\begin{tabular}{cccccc}
\hline $\begin{array}{c}\text { Concentraçäo } \\
\text { de } \begin{array}{c}\text { glicose } \\
\text { esperada } \\
(\mathrm{g} / \mathrm{l})\end{array}\end{array}$ & \multicolumn{4}{c}{ Concentraçāo determinada $(\mathrm{g} / \mathrm{l})$} \\
\cline { 2 - 6 } & $\frac{N a \text { ausēncia de cēls. }}{\text { Medidas }}$ & Mèdia & $\frac{N a \text { presença de cēls. }}{\text { Medidas }}$ & Média \\
\hline 0,0270 & $0,0255-0,0265$ & 0,0260 & $0,0260-0,0260$ & 0,0260 \\
0,0400 & $0,0420-0,0420$ & 0,0420 & $0,0408-0,0412$ & 0,0410 \\
0,0540 & $0,0555-0,0565$ & 0,0560 & $0,0560-0,0560$ & 0,0560 \\
\hline
\end{tabular}


3.4 Influēncia do consumo de açūcares pelas cēlulas na determinação do ART

a) Condiçōes experimentais

A amostragem foi feita de 10 em 10 min na primeira hora e, a partir da segunda hora, de 20 em 20 min, até completar $3 \mathrm{~h}$.

b) Resultados

Os valores obtidos encontram-se na tabela 3.4 .

c) Comentārios

O objetivo deste ensaio foi o de se avaliar algum consu mo de ART por parte das cēlulas de levedura, já que elas estão intactas e viáveis. Os valores de $\bar{c}$, s e c.v. são, respectiva mente $28,9 \mathrm{~g} / \mathrm{\ell}, 1,18 \mathrm{~g} / \mathrm{l}$ e $4,1 \%$

A equação da curva de calibração usada nos cálculos foi

$$
y=1,963 x+0,0044 \quad(r=0,996)
$$

TABELA 3.4 Concentração de ART da solução de sacarose hidrolisada em contato com leveduras viāveis

\begin{tabular}{|c|c|c|}
\hline \multirow{2}{*}{$\begin{array}{l}\text { Tempo decorrido } \\
\text { apos adição da } \\
\text { levedura (min) }\end{array}$} & \multicolumn{2}{|c|}{$\begin{aligned} \text { Concentração de } & \text { ART no sobrenadante, } \\
& \text { c }(g / \ell)\end{aligned}$} \\
\hline & Medidas & Mëdia \\
\hline $\begin{array}{l}0 \\
10 \\
20 \\
30 \\
40 \\
50 \\
60 \\
80 \\
100 \\
120 \\
140 \\
160 \\
180\end{array}$ & $\begin{array}{l}27,0-27,2 \\
26,9-27,3 \\
29,8-30,4 \\
29,1-29,1 \\
29,5-29,7 \\
30,0-30,2 \\
29,7-30,5 \\
29,9-30,3 \\
28,0-28,2 \\
28,4-28,8 \\
27,0-27,2 \\
28,9-29,3 \\
28,6-29,6\end{array}$ & $\begin{array}{l}27,1 \\
27,1 \\
30,1 \\
29,1 \\
29,6 \\
30,1 \\
30,1 \\
30,1 \\
28,1 \\
28,6 \\
27,1 \\
29,1 \\
29,1\end{array}$ \\
\hline $\bar{c}=28,9 \mathrm{~g} / \mathrm{l}$ & $\mathrm{s}=1,18 \mathrm{~g} / \mathrm{l}$ & $=4,1 \%$ \\
\hline
\end{tabular}




\subsection{Ensaios em cultivo contínuo}

\subsubsection{Ensaio no 1}

\section{a) Condiçōes experimentais}

Nutrientes adicionados ao mosto: nenhum

$$
\begin{aligned}
& S_{0}^{\prime}=29,9 \mathrm{~g} / \mathrm{l} \\
& S_{0}=23,7 \mathrm{~g} / \mathrm{l}
\end{aligned}
$$

Volume final de mosto na dorna $=2,95 \&$

$$
\begin{aligned}
F & =312 \mathrm{ml} / \mathrm{h} \\
D & =0,11 \mathrm{~h}^{-1} \\
\Phi & =1 \text { l/ } / \mathrm{min} \\
N & =500 \mathrm{~min}^{-1}
\end{aligned}
$$

\section{b) Resultados}

Os valores obtidos nas determinaçōes de $X$, AR, ART e $v$ encontram-se na tabela 3.5 e nas figuras 3 . IIa e 3 IIb.

A equação utilizada para o cālculo do AR e ART foi:

$$
y=0,00341 x+0,015
$$

Para o cālculo do ART proveniente da atividade enzimātica a equação usada foi:

$$
y=2,304 x+0,0014 \quad(r=0,997)
$$

\section{c) Comentärios}

Neste ensaio as amostras foram colnidas de 3 em 3 h. Na preparação do mosto constatou-se hidrōlise de sacarose como conseqüéncia da esterilização, pois, antes dela, 
os valores de AR e ART eram, respectivamente, $7,6 \mathrm{~g} / \mathrm{l}$ e 29,6 g/l. Isto sucedeu devido ao fato do $\mathrm{pH}$ do mosto ter sido ajustado em 4,0 antes da esterilização.

Da figura 3 . I Ib constata-se que os periodos de oscilação de $v$ (considerando dois minimos consecutivos) a par tir do instante $t=12 \mathrm{~h}$ são: $6 \mathrm{~h}, 12 \mathrm{~h} ; 9 \mathrm{~h} ; 6 \mathrm{~h}$ e $6 \mathrm{~h}$, sendo 0 período mëdio de $7,8 \mathrm{~h}$.

0 coeficiente de variação dos valores de $v$ è $23,5 \%(\bar{v}=0,149 \mathrm{gART} / \mathrm{g}$ c $\bar{e} 1$.min e $s=0,035 \mathrm{gART} / \mathrm{g}$ c $\bar{e} 1 . \mathrm{min})$.

Os dados referentes à formação de ART em função do tempo na medida a que se refere o îtem 2.5 .4 relativa a amostra mais ativa obtida durante o processo continnuo, são mostrados na tabela 3.6 e na figura 3 . IIb (gräfico $A_{1}$ ). Este procedimento serā mantido doravante.

Procedeu-se ao exame microscōpico das cēlulas existentes na suspensão aquosa tão logo foj preparada e apōs 7 dias de armazenamento em geladeira, não sendo observadas modi ficaçōes morfolōgicas. 
TABELA 3.5 Resultados obtidos no ensaio nọ 1.

\begin{tabular}{|c|c|c|c|c|c|c|}
\hline \multirow{2}{*}{$\begin{array}{c}t \\
(h)\end{array}$} & \multirow{2}{*}{$\begin{array}{c}x \\
(g / \ell)\end{array}$} & \multirow{2}{*}{$\begin{array}{c}S \\
(g / l)\end{array}$} & \multirow{2}{*}{$\begin{array}{c}S^{\prime} \\
(g / \ell)\end{array}$} & \multicolumn{3}{|c|}{$v(g A R T / g$ cél.min) } \\
\hline & & & & $1^{a}{ }^{\mathrm{Me}}$ & das 2 a & Média \\
\hline-6 & 0,072 & 13,9 & 26,5 & - & - & - \\
\hline-3 & 0,77 & 19,0 & 23,7 & 0,180 & - & - \\
\hline${ }^{\star} 0$ & 1,66 & 16,2 & 17,2 & 0,268 & 0,268 & 0,268 \\
\hline 3 & 1,95 & 14,5 & 15,8 & 0,221 & 0,221 & 0,221 \\
\hline 6 & 2,26 & 13,3 & 14,6 & 0,139 & 0,146 & 0,143 \\
\hline 9 & 2,50 & 13,0 & 14,6 & 0,114 & 0,174 & 0,114 \\
\hline 12 & 2,75 & 12,6 & $14, i$ & 0,099 & 0,093 & 0,096 \\
\hline 15 & 2,74 & 12,2 & 13,1 & 0,114 & 0,104 & 0,109 \\
\hline 18 & 2,83 & 11,6 & 12,3 & 0,101 & 0,101 & 0,101 \\
\hline 21 & 2,95 & 10,8 & 11,6 & 0,112 & 0,112 & 0,112 \\
\hline 24 & 3,00 & 10,4 & 11,0 & 0,129 & 0,138 & 0,134 \\
\hline 27 & 3,07 & 9,5 & 9,9 & 0,164 & 0,154 & 0,159 \\
\hline 30 & 3,12 & 9,7 & 10,3 & 0,138 & 0,142 & 0,140 \\
\hline 33 & 3,14 & 9,6 & 9,7 & 0,142 & 0,151 & 0,146 \\
\hline 36 & 3,19 & 8,6 & 9,7 & 0,166 & 0,157 & 0,162 \\
\hline 39 & 3,33 & 8,4 & 8,6 & 0,155 & 0,160 & 0,158 \\
\hline 42 & 3,32 & 7,9 & 8,2 & 0,182 & 0,190 & 0,186 \\
\hline 45 & 3,38 & 7,8 & 8,7 & 0,178 & 0,187 & 0,183 \\
\hline 48 & 3,40 & 7,0 & 7,5 & 0,186 & 0,186 & 0,186 \\
\hline 51 & 3,46 & 5,4 & 5,8 & 0,179 & 0,183 & 0,181 \\
\hline 54 & 3,70 & 2,9 & 3,0 & 0,191 & 0,199 & 0,195 \\
\hline
\end{tabular}


TABELA 3.6 Variação da concentração de ART pela ação de cēlulas recolhidas no instante $t=0 \mathrm{~h}$ do Ensaio no 1 (ver item 2.5.4).

\begin{tabular}{|c|c|c|c|}
\hline \multirow{3}{*}{$\begin{array}{c}t \\
(\mathrm{~min})\end{array}$} & \multicolumn{3}{|c|}{ Concentraçāo de ART, $c^{\prime}(g / l)$} \\
\hline & \multicolumn{2}{|c|}{ Medidas } & \multirow{2}{*}{ Mëdia } \\
\hline & $1 \stackrel{a}{a}$ & $2 \underline{a}$ & \\
\hline 1 & 0,043 & 0,045 & 0,044 \\
\hline 2 & 0,089 & 0,089 & 0,089 \\
\hline 3 & 0,131 & 0,134 & 0,133 \\
\hline 4 & 0,176 & 0,180 & 0,178 \\
\hline 5 & 0,221 & 0,223 & 0,222 \\
\hline 6 & 0,270 & 0,264 & 0,267 \\
\hline
\end{tabular}



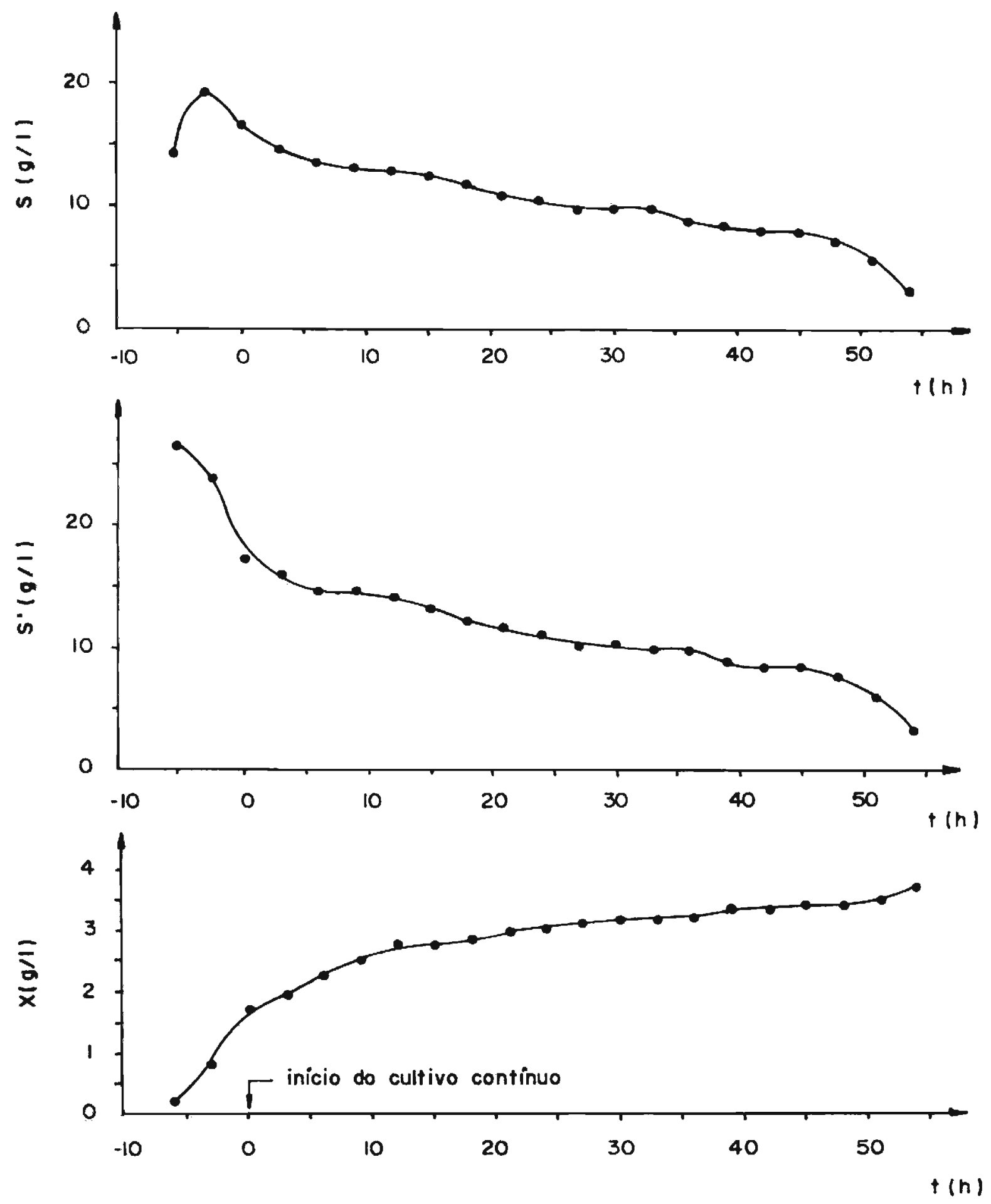

FIGURA 3. IIa. Variação, com o tempo, das concentrações de ART ( $\left.S^{\prime}\right)$, de AR (S) e de cēlulas (X) no ensaionọ 1 . 


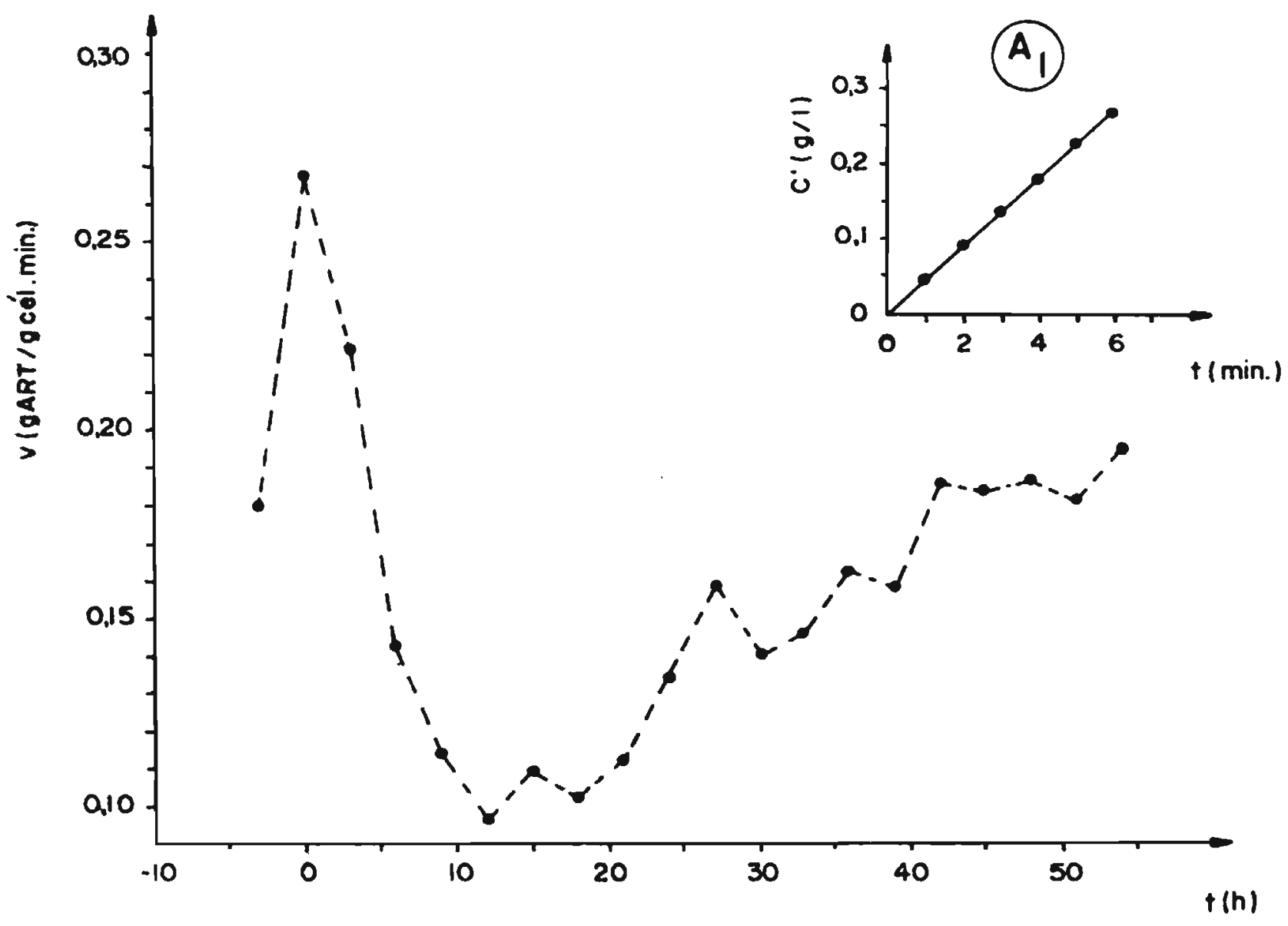

FIGURA 3.IIb. Variação, com o tempo, da atividade invertāsica (v) no ensaio no 1 . A curva do grä́fico $A_{j}$ mostra a variação da concentração de ART ( $\left.c^{\prime}\right)$, com 0 tempo, na medida a que se refere o item 2.5.4, utilizando celulas colhidas no instante $t=0 \mathrm{~h}$ (Equação da curva: $c^{\prime}=0,045 t-0,002 ; r=0,996$ ). 


\section{5 .2 Ensaio no 2}

\section{a) Condições experimentais}

Nutrientes adicionados ao mosto: nenhum

$$
\begin{aligned}
& S_{0}^{\prime}=28,4 \mathrm{~g} / \mathrm{l} \\
& S_{0}=7,5 \mathrm{~g} / \ell \\
& V_{0} \text { ume final de mosto na dorna }=3,10 \mathrm{l} \\
& \Phi=2 \mathrm{l} / \mathrm{l} \cdot \mathrm{min} \\
& \mathrm{N}=500 \mathrm{~min}^{-1} \\
& F(1 \text { a etapa })=339 \mathrm{ml} / \mathrm{h} \\
& D(1 \text { a etapa })=0,11 \mathrm{~h}^{-1} \\
& F(2 \text { - etapa })=423 \mathrm{~m}^{1 / \mathrm{h}} \\
& D(2 \text { a etapa })=0,14 \mathrm{~h}^{-1}
\end{aligned}
$$

\section{b) Resultados}

Ds valores obtidos nas determinações de $X, A R, A R T$ e $v$ encontram-se na tabela 3.7 e nasfiguras 3 . IIIa,b. A equação usada para o cálculo do AR e ART foi:

$$
y=0,00341 x+0,015
$$

e para o cālculo do ART proveniente da atividade enzimātica a equação usada foi:

$$
y=2,293 x+0,015 \quad(r=0,997)
$$

\section{c) Comentārios}

A amostragem foi fejta de 3 em $3 \mathrm{~h}$.

Para evitar a hidrōlise da sacarose durante a esterilizaçäo, acertou-se o pH do mosto em 7,0. Nestas condi- 
ções, os valores de AR e ART não foram afetados pela esterili zação. Este procedimento foi mantido nos ensaios seguintes.

Após $44 \mathrm{~h}$ de processo continuo aumentou-se a vazäo de alimentação para $423 \mathrm{ml} / \mathrm{h}$, valor este mantido atē o final do ensaio. Isto foi feito na tentativa de acelerar o estabelecimento do regime estacionário.

Para efeito de cālculos este ensaio será considerado em duas etapas. Os valores de $X$, AR, ART e $v$ correspondentes $\bar{a} t=44 \mathrm{~h}$ e $t=45,5 \mathrm{~h}$ foram desprezados.

Da figura 3 .IIIb constata-se que os periodos de oscillação de $v$ na $1 \stackrel{a}{a}$ etapa são: 12h; $12 \mathrm{~h}$ e $12 \mathrm{~h}$, sendo o perío do médio de $12 \mathrm{~h}$. Na 2 a etapa são: $12 \mathrm{~h}$ e $9 \mathrm{~h}$, sendo o período médio de $10,5 \mathrm{~h}$.

0 coeficiente de variação de $v$ na 1 a etapa é $14,7 \%$ $(\bar{v}=0,163 \mathrm{gART} / \mathrm{g}$ cél. min e $\mathrm{s}=0,024 \mathrm{gART} / \mathrm{g}$ cél. min) e na

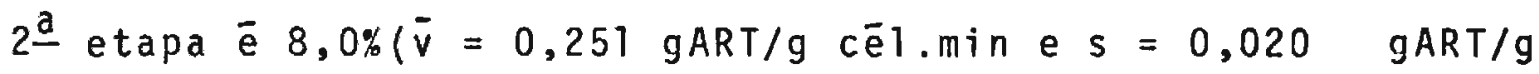
cè $1 \cdot \min )$.

A tabela 3.8 e a figura 3 .IIIb (gräfico $A_{1}$ ) mostram os dados referentes à formação de ART em função do tempo para a amostra de cêlulas mais ativa obtida durante o processo contínuo (ver item 2.5.4). 
TABELA 3.7 Resultados obtidos no ensaio no 2.

\begin{tabular}{|c|c|c|c|c|c|c|c|}
\hline \multirow{3}{*}{$\left(h^{-1}\right)$} & \multirow{3}{*}{$\begin{array}{c}t \\
(h)\end{array}$} & \multirow{3}{*}{$\begin{array}{c}x \\
(g / 2)\end{array}$} & \multirow{3}{*}{$\begin{array}{c}S \\
(g / \ell)\end{array}$} & \multirow{3}{*}{$\begin{array}{c}S^{\prime} \\
(g / \ell)\end{array}$} & \multicolumn{3}{|c|}{$v(g A R T / g$ cēl. min) } \\
\hline & & & & & \multicolumn{2}{|c|}{ Medidas } & \multirow[b]{2}{*}{ Média } \\
\hline & & & & & $1 \underline{a}$ & 2 a & \\
\hline \multirow{8}{*}{0} & -6 & 0,58 & 8,5 & 22,4 & 0,609 & 0,584 & 0,596 \\
\hline & -3 & 1,23 & 18,1 & 20,9 & 0,200 & 0,189 & 0,195 \\
\hline & ${ }^{\star} 0$ & 1,95 & $14 ., 2$ & 13,0 & 0,261 & 0,245 & 0,253 \\
\hline & 2 & 2,02 & 12,2 & 15,0 & 0,165 & 0,179 & 0,172 \\
\hline & 5 & 2,22 & 12,2 & 14,5 & 0,177 & 0,177 & 0,177 \\
\hline & 8 & 2,44 & 12,2 & 14,9 & 0,167 & 0,155 & 0,161 \\
\hline & 11 & 2,81 & 11,5 & 13,7 & 0,150 & 0,150 & 0,150 \\
\hline & 14 & 3,05 & 11,2 & 13,7 & 0,119 & 0,119 & 0,119 \\
\hline \multirow[t]{14}{*}{0,11} & 17 & 3,30 & 10,3 & 12,9 & 0,132 & 0,145 & 0,139 \\
\hline & 20 & 3,51 & 9,7 & 12,6 & 0,161 & 0,157 & 0,159 \\
\hline & 23 & 3,72 & 8,9 & 10,6 & 0,164 & 0,156 & 0,160 \\
\hline & 26 & 3,87 & 8,1 & 10,2 & 0,131 & 0,139 & 0,135 \\
\hline & 29 & 4,06 & 8,4 & 10,3 & 0,166 & 0,155 & 0,160 \\
\hline & 32 & 4,38 & 8,3 & 9,4 & 0,194 & 0,194 & 0,194 \\
\hline & 35 & 4,46 & 7,6 & 8,9 & 0,180 & 0,185 & 0,183 \\
\hline & 38 & 4,60 & 6,9 & 8,6 & 0,165 & 0,180 & 0,173 \\
\hline & 41 & 4,73 & 6,6 & 7,5 & 0,207 & 0,207 & 0,207 \\
\hline & 44 & 4,89 & 6,1 & 7,4 & 0,218 & 0,218 & 0,218 \\
\hline & 45,5 & 4,89 & - & - & 0,276 & 0,258 & 0,267 \\
\hline & 47 & 4,93 & 6,5 & 7,4 & 0,229 & 0,229 & 0,229 \\
\hline & 50 & 5,30 & 7,3 & 8,0 & 0,241 & 0,247 & 0,244 \\
\hline & 53 & 5,55 & 6,7 & 8,0 & 0,261 & $0,25]$ & 0,256 \\
\hline \multirow[t]{6}{*}{0,74} & 56 & 5,54 & 6,6 & 7,6 & 0,246 & 0,246 & 0,246 \\
\hline & 59 & 5,67 & 6,5 & 7,0 & 0,222 & 0,238 & 0,230 \\
\hline & 62 & 5,91 & 6,3 & 6,9 & 0,272 & 0,265 & 0,269 \\
\hline & 64 & 5,75 & 6,1 & 7,3 & 0,287 & 0,287 & 0,287 \\
\hline & 68 & 5,99 & 5,4 & 6,3 & 0,235 & 0,256 & 0,246 \\
\hline & 71 & 6,23 & - & - & 0,291 & 0,277 & 0,284 \\
\hline
\end{tabular}

* Início do cultivo contínuo. 
TABELA 3.8 Variação da concentração de ART pela ação de cēlulas recolhidas no instante $t=64 \mathrm{~h}$ do Ensaio no 2 (ver item 2.5.4).

\begin{tabular}{cccc}
\hline \multirow{2}{*}{$\begin{array}{c}\text { Concentração de } \\
\text { (min) }\end{array}$} & \multicolumn{2}{c}{ Medidas } & $c^{\prime}(g / l)$ \\
\hline 1 & 0,082 & 0,084 & Média \\
2 & 0,162 & 0,168 & 0,083 \\
3 & 0,247 & 0,249 & 0,248 \\
4 & 0,329 & 0,333 & 0,331 \\
5 & 0,413 & 0,413 & 0,413 \\
6 & 0,495 & 0,497 & 0,496 \\
\hline
\end{tabular}




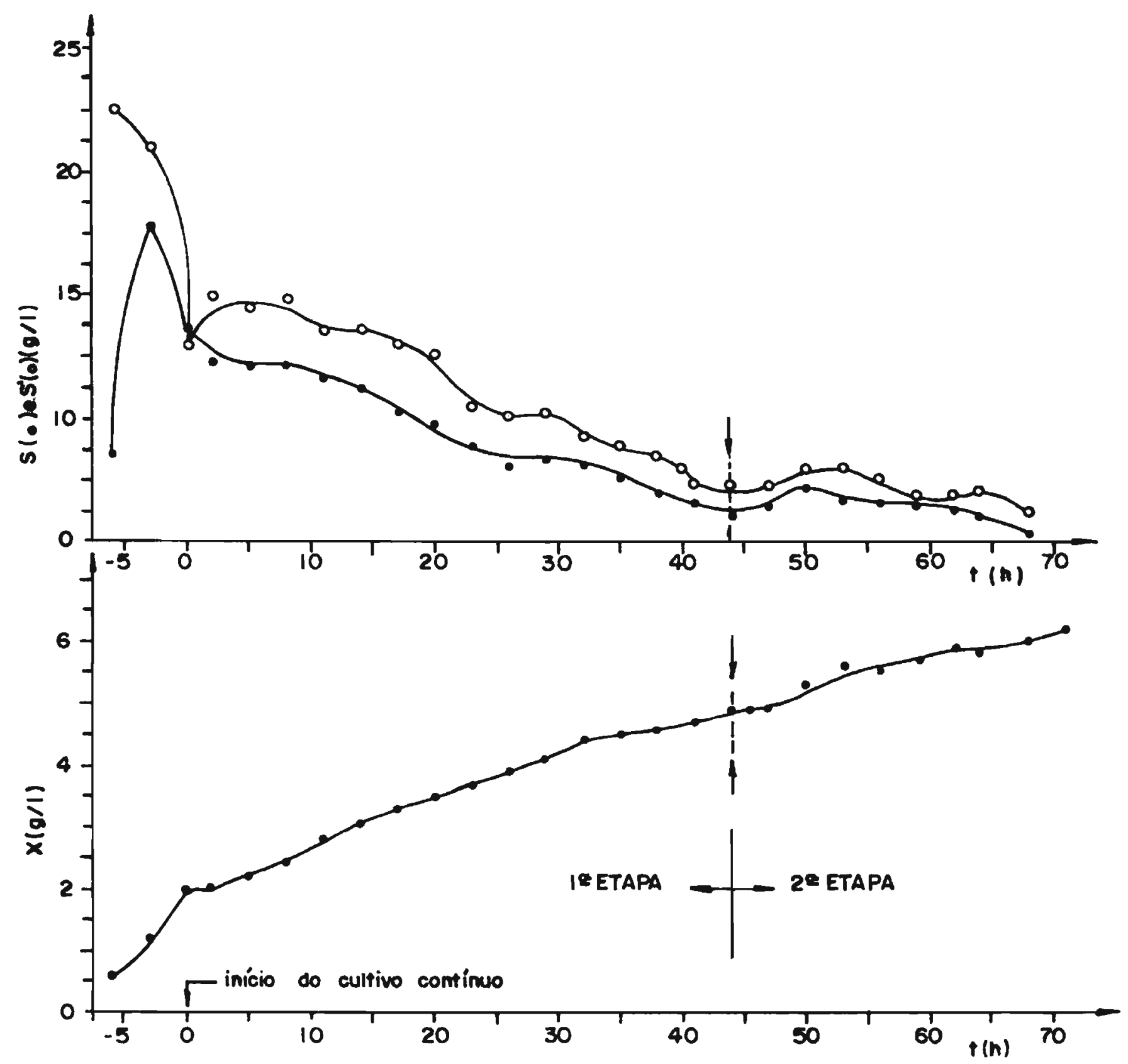

FIGURA 3. IIIa. Variação, com o tempo, das concentrações de ART (S'), de AR (S) e de células (X) no en- 

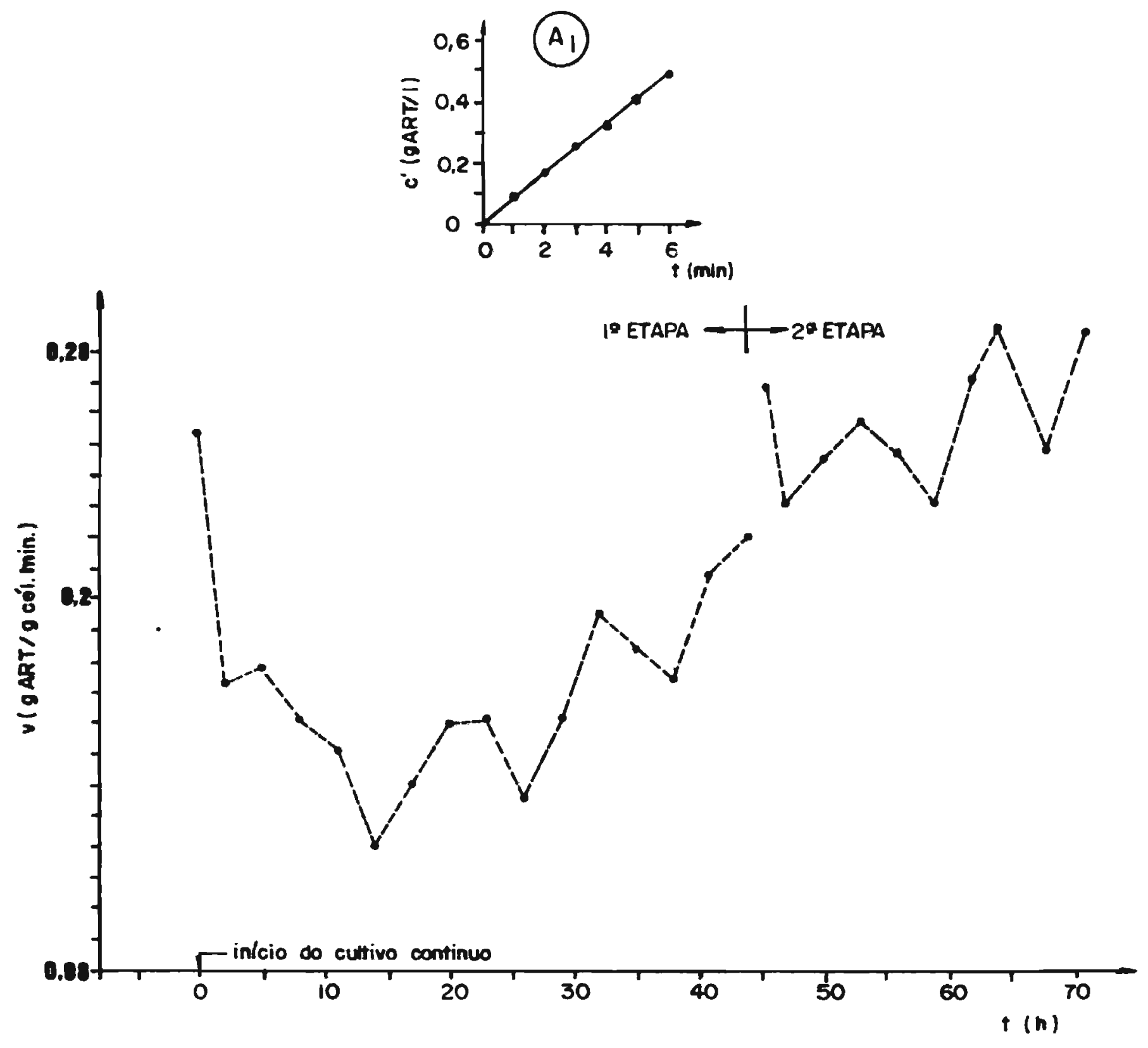

FIGURA 3.III.b. Variação, com o tempo,da atividade invertāsi ça (v) no ensaio no. 2. A curva do gráfico $A_{1}$ mostra a varia se refere o item 2.5.4, utilizando células colhidas no instan te $t=64 \mathrm{~h}$ (Equação da curva: $c^{\prime}=0,083 t-0,002 ; r=0,998$ ). 


\subsubsection{Ensaio no 3}

\section{a) Condições experimentais}

Nutrientes adicionados ao mosto: nenhum

$$
\mathrm{S}_{0}^{\prime}=30,2 \mathrm{~g} / \mathrm{l}
$$$$
\mathrm{S}_{0}=8,0 \mathrm{~g} / \mathrm{l}
$$

Volume final de mosto na dorna $=3,04 \mathrm{l}$

$F \quad=697 \mathrm{ml} / \mathrm{h}$

$D=0,23 \mathrm{~h}^{-1}$

$\phi \quad=2 \ell / \ell \cdot \min$

$\mathrm{N}=500 \mathrm{~min}^{-1}$

\section{b) Resultados}

Os valores obtidos nas determinaçöes de $X, A R, A R T$ e v acham-se na tabela 3.9 e figura 3.IV.

Para o cālculo do AR e ART utilizou-se a equação:

$$
y=0,00345 x+0,011
$$

e para a medida do ART proveniente da atividade invertāsica usou-se a equação:

$$
y=2,422 x+0,0052 \quad(r=0,998)
$$

\section{c) Comentärios}

A amostragem para a medida da atividade invertāsica foi feita de 1,5 em $1,5 \mathrm{~h}$, enquanto que para $A R, A R T$ e $X$ foi feita de 3 em $3 \mathrm{~h}$. Os valores intermediārios de $x$ foram determinados por interpolação gräfica. Tal procedimento será mantido no ensaio no 4. 
A diminuição do intervalo da amostragem teve 0 objetivo de tentar melhorar a observação do perfil oscilatō rio da função $v=f(t)$.

Da figura 3 .IV constata-se que os períodos de oscilação de v são: $3 h ; 6 h ; 4,5 h ; 6 h ; 3 h ; 3 h ; 6 h$, sendo o pe ríodo médio de $4,5 \mathrm{~h}$.

0 coeficiente de variação de $v \bar{e} 51,5 \% \quad(\vec{v}=$ 0,066 gART/g cét.min; s $=0,034$ gART/g cēt.min).

A tabela 3.10 e a figura 3 . IV (gräfico $A_{1}$ ) mostram os dados referentes à velocidade de formação de ART em funçāo do tempo para a amostra de cēlulas mais ativa obtida durante o processo contínuo.

TABELA 3.10 Variação da concentração de ART pela ação de cēlulas recolhidas no instante $t=0 \mathrm{~h}$ do ensaio no 3 (ver T́tem 2.5.4).

\begin{tabular}{cccc}
\hline$t$ & \multicolumn{2}{c}{ Concentração de ART, } & $c^{\prime}(g / l)$ \\
\cline { 2 - 4 }$(\min )$ & $1 \frac{a^{\text {Medidas }}}{2 a}$ & Média \\
\hline 1 & 0,054 & 0,054 & 0,054 \\
2 & 0,108 & 0,110 & 0,109 \\
3 & 0,161 & 0,165 & 0,163 \\
4 & 0,216 & 0,218 & 0,217 \\
5 & 0,269 & 0,275 & 0,272 \\
6 & 0,325 & 0,327 & 0,326 \\
\hline
\end{tabular}


TABELA 3.9 Resultados obtidos no ensaio no 3.

\begin{tabular}{|c|c|c|c|c|c|c|}
\hline \multirow{3}{*}{$\begin{array}{c}t \\
(h)\end{array}$} & \multirow{3}{*}{$\begin{array}{c}x \\
(g / \ell)\end{array}$} & \multirow{3}{*}{$\begin{array}{c}S \\
(g / \ell)\end{array}$} & \multirow{3}{*}{$\begin{array}{c}S^{\prime} \\
(g / \ell)\end{array}$} & \multicolumn{3}{|c|}{$v(g A R T / g \quad c \vec{e} 1 \cdot m i n)$} \\
\hline & & & & \multicolumn{2}{|c|}{ Medidas } & \multirow{2}{*}{ Mëdia } \\
\hline & & & & $1 \stackrel{a}{a}$ & $2 \underline{a}$ & \\
\hline-6 & 0,52 & 8,6 & 24,9 & 0,586 & 0,573 & 0,580 \\
\hline-3 & 1,14 & 17,9 & 21,5 & 0,230 & 0,236 & 0,233 \\
\hline$* 0$ & 1,71 & 15,4 & 16,6 & 0,321 & 0,313 & 0,317 \\
\hline 1,5 & 1,71 & - & - & 0,190 & 0,197 & 0,194 \\
\hline 3 & 1,74 & 12,9 & 18,2 & 0,173 & 0,189 & 0,181 \\
\hline 4,5 & 1,85 & - & - & 0,133 & 0,140 & 0,137 \\
\hline 6 & 1,99 & 12,7 & 18,1 & 0,090 & 0,083 & 0,086 \\
\hline 7,5 & 2,02 & - & - & 0,097 & 0,104 & 0,101 \\
\hline 9 & 2,04 & 11,4 & 18,0 & 0,054 & 0,054 & 0,054 \\
\hline 10,5 & 2,15 & - & - & 0,083 & 0,083 & 0,083 \\
\hline 12 & 2,28 & 10,5 & 18,4 & 0,060 & 0,066 & 0,063 \\
\hline 13,5 & 2,25 & - & - & 0,049 & 0,049 & 0,049 \\
\hline 15 & 2,20 & 9,6 & 19,5 & 0,042 & 0,042 & 0,042 \\
\hline 16,5 & 2,17 & - & - & 0,051 & 0,051 & 0,051 \\
\hline 18 & 2,19 & 9,1 & 18,9 & 0,060 & 0,060 & 0,060 \\
\hline 19,5 & 2,15 & - & - & 0,024 & 0,024 & 0,024 \\
\hline 21 & 2,06 & 9,3 & 19,6 & 0,038 & 0,043 & 0,041 \\
\hline 22,5 & 2,07 & - & - & 0,045 & 0,045 & 0,045 \\
\hline 24 & 2,11 & 8,9 & 20,1 & 0,059 & 0,059 & 0,059 \\
\hline 25,5 & 2,23 & - & - & 0,042 & 0,042 & 0,042 \\
\hline 27 & 2,33 & 8,8 & 19,5 & 0,062 & 0,058 & 0,060 \\
\hline 28,5 & 2,43 & - & - & 0,051 & 0,051 & 0,051 \\
\hline 30 & 2,51 & 9,5 & 19,1 & 0.060 & 0,064 & 0,062 \\
\hline 31,5 & 2,57 & - & - & $C, 049$ & 0,049 & 0,049 \\
\hline 33 & 2.54 & 9,5 & 19,0 & 0,053 & 0,061 & 0,057 \\
\hline 34,5 & 2,55 & - & - & 0,063 & 0,063 & $0,0 \in 3$ \\
\hline 36 & 2,66 & 9,2 & 18,9 & 0,070 & 0,062 & 0,066 \\
\hline 37,5 & 2,70 & - & - & 0,053 & 0,053 & 0,053 \\
\hline 39 & 2,96 & 9,4 & 18,1 & 0,073 & 0,077 & 0,075 \\
\hline
\end{tabular}

* Início do cultivo contínuo 


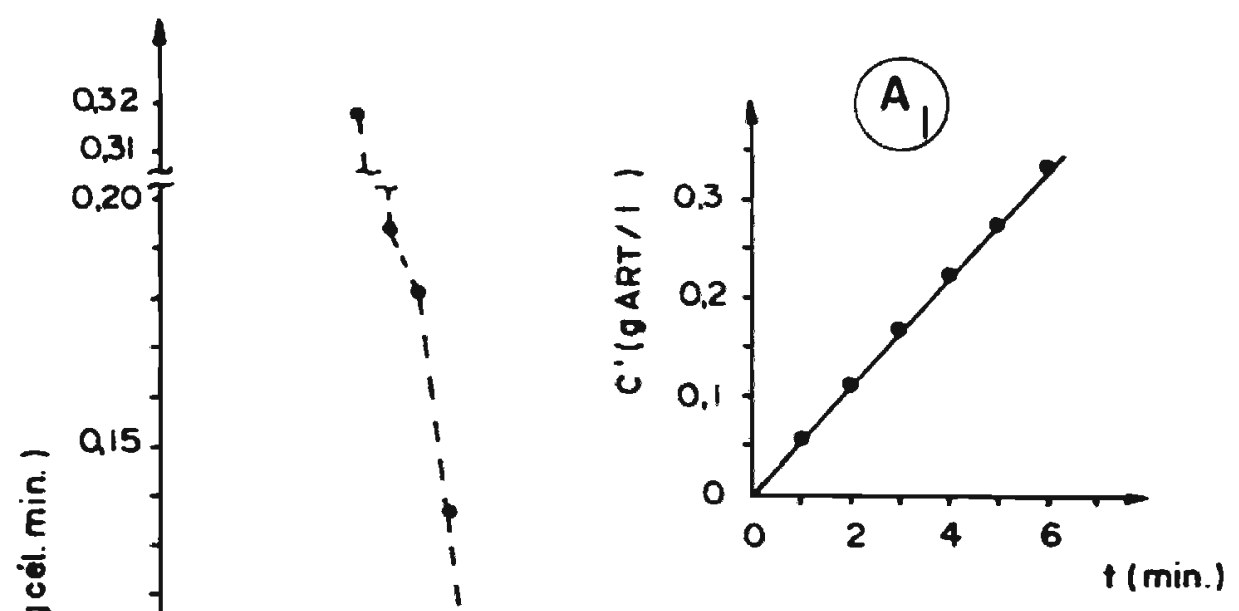




\section{5 .4 Ensaio n! 4}

\section{a) Condições experimentais}

Nutrientes adicionados ao mosto: nenhum

$S_{0}^{1}=31,2 \mathrm{~g} / 2$

$\mathrm{S}_{0}=7,6 \mathrm{~g} / \mathrm{l}$

Volume final de mosto na dorna $=3,00$ \&

$F=679 \mathrm{ml} / \mathrm{h}$

$D=0,23 \mathrm{~h}^{-1}$

$\Phi=1 \ell / \ell \cdot \min$

$N=500 \mathrm{~min}^{-1}$

\section{b) Resultados}

Os valores obtidos nas determinações de $X, A R$, ART e $v$ acham-se na tabela 3.11 e figura $3 . V$.

Para o cālculo do AR e ART utilizou-se a equaçāo:

$$
y=0,00345 x+0,011
$$

e para a medida do ART oriundo da atividade invertásica usouse a equação:

$$
y=2,307 x+0,013 \quad(r=0,995)
$$

\section{c) Comentārios}

Pela figura 4.5 constata-se que os períodos de os cilação de v no patamar, são: $3 \mathrm{~h} ; 6 \mathrm{~h} ; 6 \mathrm{~h} ; 4,5 \mathrm{~h} ; 4,5 \mathrm{~h} ; 9 \mathrm{~h}$ e 3h, sendo o período mēdio de $5,1 \mathrm{~h}$.

0 coeficiente de variação de v no patamar $\bar{e} 31,4 \%$ $(\bar{v}=0,044$ gART $/ g$ cét.min e $s=0,014$ gART/g c $\vec{e} 1 . m i n)$. 
A tabela 3.12 e a figura $3 . V$ (Gräfico $A_{1}$ ) mostram os dados referentes à formação de ART em função do tempo para a amostra de células mais ativa obtida durante o processo continuo. 
TABELA 3.11 Resultados obtidos no ensaio no 4 ,

\begin{tabular}{|c|c|c|c|c|c|c|}
\hline \multirow{3}{*}{$\begin{array}{c}t \\
(h)\end{array}$} & \multirow{3}{*}{$\begin{array}{c}x \\
(g / \ell)\end{array}$} & \multirow{3}{*}{$\begin{array}{c}S \\
(g / \ell)\end{array}$} & \multirow{3}{*}{$\begin{array}{c}S^{\prime} \\
(g / l)\end{array}$} & \multicolumn{3}{|c|}{$v(g A R T / g$ cél.min $)$} \\
\hline & & & & \multicolumn{2}{|c|}{ Medidas } & \multirow{2}{*}{ Mëdia } \\
\hline & & & & $1 \stackrel{a}{a}$ & $2=$ & \\
\hline-6 & 0,57 & 9,2 & 25,6 & 0,653 & 0,666 & 0,660 \\
\hline-3 & 1,07 & 19,8 & 22,3 & 0,308 & 0,329 & 0,319 \\
\hline$\star_{0}$ & 1,76 & 15,7 & 15,9 & 0,338 & 0,344 & 0,341 \\
\hline 1,5 & 1,60 & - & - & 0,157 & 0,157 & 0,157 \\
\hline 3 & 1,45 & 13,0 & 20,2 & 0,123 & 0,130 & 0,126 \\
\hline 4,5 & 1,26 & - & - & 0,106 & 0,106 & 0,106 \\
\hline 6 & 1,14 & 11,3 & 19,7 & 0,095 & 0,095 & 0,095 \\
\hline 7,5 & 1,25 & - & - & 0,081 & 0,090 & 0,085 \\
\hline 9 & 1,32 & 9,5 & 18,3 & 0,085 & 0,077 & 0,081 \\
\hline 10,5 & 1,25 & - & - & 0,036 & 0,036 & 0,036 \\
\hline 12 & 1,17 & 9,7 & 21,8 & 0,031 & 0,031 & 0,031 \\
\hline 13,5 & 1,15 & - & - & 0,049 & 0,049 & 0,049 \\
\hline 15 & 1,13 & 7,3 & 22,6 & 0,014 & 0,014 & 0,014 \\
\hline 16,5 & 1,10 & - & - & 0,027 & 0,034 & 0,031 \\
\hline 18 & 1,10 & 6,9 & 22,7 & 0,074 & 0,066 & 0,070 \\
\hline 19,5 & 1,10 & - & - & 0,049 & 0,049 & 0,049 \\
\hline 21 & 1,13 & 7,0 & 22,6 & 0,045 & 0,045 & 0,045 \\
\hline 22,5 & 1,13 & - & - & 0,053 & 0,062 & 0,057 \\
\hline 24 & 1,17 & 6,8 & 22,5 & 0,062 & 0,062 & 0,062 \\
\hline 25,5 & 1,15 & - & - & 0,042 & 0,042 & 0,042 \\
\hline 27 & 1,06 & 7,7 & 21,1 & 0,025 & 0,025 & 0,025 \\
\hline 28,5 & 1,10 & - & - & 0,051 & 0,051 & 0,051 \\
\hline 30 & 1,17 & 7,4 & 27,8 & 0,048 & 0,057 & 0,053 \\
\hline 31,5 & 1,20 & - & - & 0,031 & 0,031 & 0,031 \\
\hline 33 & 1,16 & 7,6 & 22,5 & 0,036 & 0,040 & 0,039 \\
\hline 34,5 & 1,18 & - & - & 0,038 & 0,043 & 0,041 \\
\hline 36 & 1,22 & 7,4 & 22,2 & 0,033 & 0,033 & 0,033 \\
\hline 37,5 & 1,23 & - & - & 0,041 & 0,046 & 0,043 \\
\hline
\end{tabular}


Continuação da Tabela 3.11

\begin{tabular}{|c|c|c|c|c|c|c|}
\hline \multirow{3}{*}{$\begin{array}{c}t \\
(n)\end{array}$} & \multirow{3}{*}{$\begin{array}{c}x \\
(g / \ell)\end{array}$} & \multirow{3}{*}{$\begin{array}{c}S \\
(g / \ell)\end{array}$} & \multirow{3}{*}{$\begin{array}{c}S^{\prime} \\
(g / l)\end{array}$} & \multicolumn{3}{|c|}{$v(g A R T / g$ cél.min $)$} \\
\hline & & & & \multicolumn{2}{|c|}{ Medidas } & \multirow{2}{*}{ Média } \\
\hline & & & & $1 \underline{a}$ & $2 \underline{a}$ & \\
\hline 39 & 1,18 & 6,5 & 22,5 & 0,045 & 0,045 & 0,045 \\
\hline 40,5 & 1,16 & - & - & 0,046 & 0,046 & 0,046 \\
\hline 42 & 1,14 & 7,1 & 22,6 & 0,044 & 0,044 & 0,044 \\
\hline 43,5 & 1,15 & - & - & 0,035 & 0,039 & 0,037 \\
\hline 45 & 1,17 & 7,2 & 23,1 & 0,031 & 0,031 & 0,031 \\
\hline 46,5 & 1,18 & - & - & 0,043 & 0,043 & 0,043 \\
\hline 48 & 1,14 & 7,3 & 23,4 & 0,035 & 0,035 & 0,035 \\
\hline 49,5 & 1,18 & - & - & 0,048 & 0,048 & 0,048 \\
\hline 51 & 1,20 & 7,0 & 22,5 & 0,060 & 0,060 & 0,060 \\
\hline
\end{tabular}

* Início do cultivo contínuo. 
TABELA 3.12 Variação da concentração de ART pela ação de cēlulas recolhidas no instante $t=0 \mathrm{~h}$ do ensaio no 4 (ver ítem 2.5.4).

\begin{tabular}{cccc}
\hline \multirow{2}{*}{$\begin{array}{c}\text { Concentração de ART, } \\
\text { (min) }\end{array}$} & \multicolumn{2}{c}{$c^{\prime}(\mathrm{g} / \mathrm{a})$} \\
\cline { 2 - 3 } 1 & 0,060 & 0,060 & Média \\
1 & 0,119 & 0,121 & 0,060 \\
3 & 0,180 & 0,180 & 0,120 \\
4 & 0,240 & 0,240 & 0,180 \\
5 & 0,298 & 0,304 & 0,240 \\
6 & 0,359 & 0,362 & 0,301 \\
& & & 0,361 \\
\hline
\end{tabular}



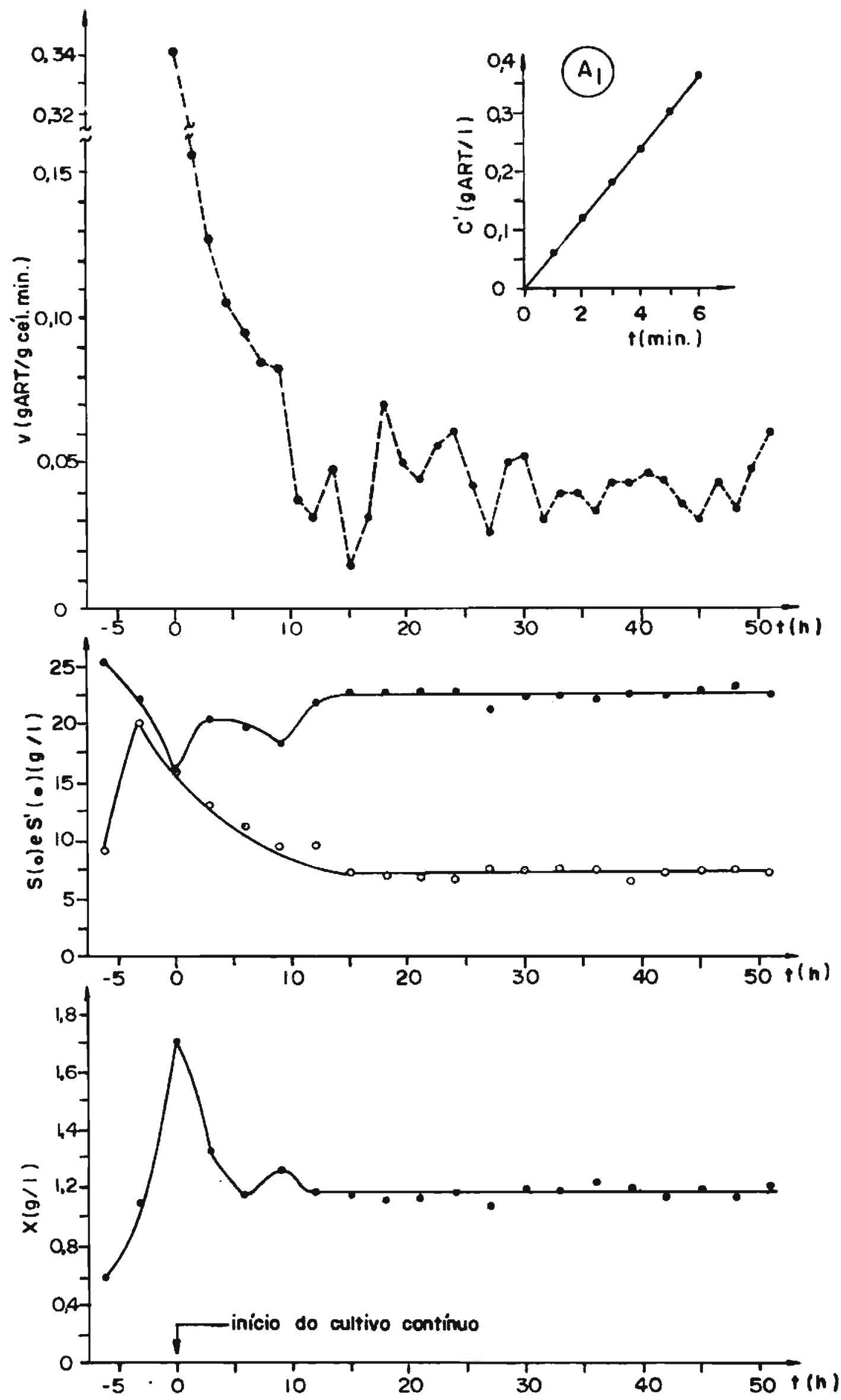

FIGURA 3.V. Variação, com o tempo, da atividade invertāsica (v) e das concentraçöes de ART ( $\left.S^{\prime}\right)$, de AR $(S)$ e de células $(X)$ no ensaio n84. A curva do gráfico Al mostra a variação da concentração de ART ( $\left.C^{\prime}\right)$ com 0 tempo na medida a que se refere 0 item 2.5 .4 ,usando célu las colhidas no instante $t=0 h$ (Eq.da curva: $c^{\prime}=0,061 t-0,004 ; r=0,99 \overline{8}$ ) 


\section{5 .5 Ensaio nọ 5}

a) Condicōes experimentais

$$
\begin{aligned}
& S_{0}^{\prime}=30,8 \mathrm{~g} / \ell \\
& S_{0}=6,5 \mathrm{~g} / \ell \\
& N=500 \mathrm{~min}^{-1} \\
& \text { Oensaio foi dividido em quatro etapas: } \\
& \text { la Etapa }(t=3 \mathrm{~h} \text { at } \bar{e} t=27 \mathrm{~h})
\end{aligned}
$$

Nutrientes adicionados ao mosto: nenhum

$$
F=689 \mathrm{~m} 1 / \mathrm{h}
$$$$
D=0,24 h^{-1}
$$$$
\Phi=1 \ell / \ell \cdot \min
$$

Volume final de mosto na dorna $=2,89 \mathrm{l}$

\section{$2 \stackrel{a}{ }$ Etapa $(t=28,5 \mathrm{~h}$ at $\overline{\mathrm{e}} \mathrm{t}=51 \mathrm{~h})$}

Nutrientes adicionados ao mosto: $\mathrm{Na}_{2} \mathrm{HPO}_{4} \cdot 12 \mathrm{H}_{2} \mathrm{O}$, $\mathrm{MgSO}_{4} \cdot 7 \mathrm{H}_{2} \mathrm{O}$ e $\left(\mathrm{NH}_{4}\right)_{2} \mathrm{SO}_{4}$ conforme referido no item 2.1.4.

$F=692 \mathrm{ml} / \mathrm{h}$

$D=0,24 \mathrm{~h}^{-1}$

$\Phi=1$ \&/l.min

Volume final de mosto na dorna $=2,89 \mathrm{l}$

3ㅡㅡ Etapa $(t=52,5 \mathrm{~h}$ atē $t=75 \mathrm{~h})$

Nutrientes adicionados ao mosto: conforme indicado na $2 \stackrel{a}{-}$ etapa

$F=291 \mathrm{ml} / \mathrm{h}$

$D=0,10 \mathrm{~h}^{-1}$ 


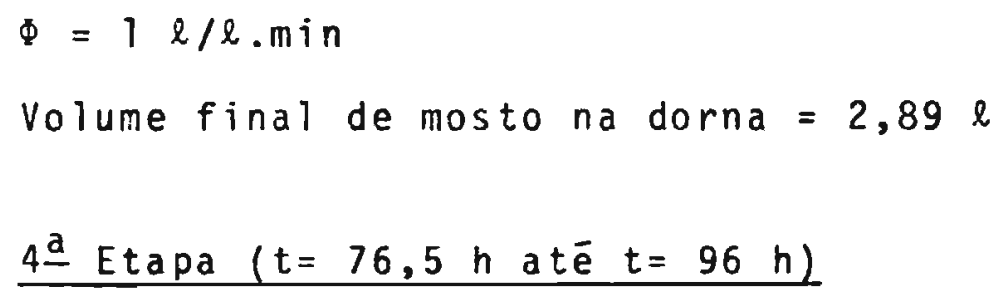

\section{b) Resultados}

Os valores obtidos nas determinações de $X, A R$, ART e $v$ encontram-se na tabela 3.13 e figuras $3 . V I a-d, 3$.VII e 3.VIII.

Para o cálculo do AR e ART utilizou-se a equação:

$$
y=0,00340 x+0,0092
$$

e para a medida do ART proveniente da atividade invertásica usou-se a equação:

$$
y=2,285 x+0,0024 \quad(r=0,998)
$$

\section{c) Comentärios}

A suplementação do mosto teve inīcio após o estabelecimento de um patamar nitido, sendo a adição de nutrientes feita por degrau a partir de $t=27 \mathrm{~h}$.

Da figura $3 . V I I$ constata-se que os periodos de oscilação de $v$ em cada etapa são:

1ㅡ etapa: $6 \mathrm{~h} ; 4,5 \mathrm{~h} ; 6 \mathrm{~h} ; 3 \mathrm{~h} ;$ período mēdio $=4,5 \mathrm{~h}$ 


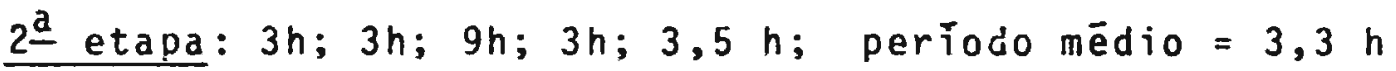

3르 etapa: $3 \mathrm{~h}$ e $9 \mathrm{~h} ; \quad$ perỉodo mēdio $=6 \mathrm{~h}$

4ㅡ etapa: $6 \mathrm{~h} ; 4,5 \mathrm{~h} ; 6 \mathrm{~h} ; \quad$ periodo mēdio $=5,3 \mathrm{~h}$

os coeficientes de variação de $v$ em cada etapa são:

I- Etapa: considerando os valores de $v$ entre $t=3 \mathrm{~h}$ e $t=27 \mathrm{~h}$,

temos: $C V=34,7 \%(\bar{v}=0,077$ gART/g cél.min e

$s=0,027 \mathrm{gART} / \mathrm{g}$ (ë) $1 . \mathrm{min})$.

2- Etapa: a) considerando os valores de $v$ entre $t=28,5 \mathrm{~h}$ e $t=51 \mathrm{~h}$,temos: $C V=92,3 \%(\bar{v}=1,19 \mathrm{gART} / \mathrm{g}$ cể.min e $s=1,10 \mathrm{gART} / \mathrm{g}(\overline{\mathrm{e}} \mathrm{l}, \mathrm{min})$;

b) considerando os valores de $v$ entre $t=40,5 \mathrm{~h}$ e $t=51 \mathrm{~h}$, temos: $C V=12,1 \%(\bar{v}=2,24 \mathrm{gART} / \mathrm{g}$ Cél.min e $\quad s=0,27 \mathrm{gART} / \mathrm{g}$ (é).min).

3․ Etapa: a) considerando os valores de $v$ entre $t=52,5 \mathrm{~h}$ e $t=75 \mathrm{~h}$, temos: $\mathrm{CV}=64,1 \%(\bar{v}=1,10 \mathrm{gART} / \mathrm{g} \mathrm{C} \overrightarrow{\mathrm{e}} \mathrm{l} . \mathrm{min}$ e $\quad s=0,71 \mathrm{gART} / \mathrm{g}(\overrightarrow{\mathrm{e}} \mathrm{l}$.min);

b) considerando os valores de $v$ entre $t=63 \mathrm{~h} \quad \mathrm{e}$ $t=75 \mathrm{~h}$, temos: $C V=20,7 \%(\bar{v}=0,596 \mathrm{gART} / \mathrm{g}$ cé l.min e $s=0,12 \mathrm{gART} / \mathrm{g}$ (ēt.min).

4- Etapa: a) considerando os valores de $v$ entre $t=76,5 \mathrm{~h}$ e $t=96 \mathrm{~h}$, temos: $\mathrm{CV}=33,1 \%(\bar{v}=1,06 \mathrm{gART} / \mathrm{g} \mathrm{c} \overline{\mathrm{e}} \mathrm{l} . \mathrm{min}$ e $\quad s=0,35 \mathrm{gART} / \mathrm{g}$ (ēl.min):

b) considerando os valores de $v$ entre $t=85,5 \mathrm{~h}$ e $t=96 \mathrm{~h}$, temos: $\mathrm{CV}=18,7 \%(\bar{v}=1,30 \mathrm{gART} / \mathrm{g}$ cét.min e $\quad s=0,24 \mathrm{gART} / \mathrm{g}$ (ēl.min).

Para a 2a․ $3 \underline{a}$ e $4 \underline{a}$ etapas a desconsideração de alguns valores de $v$ justifica-se pelo fato de que, ao se mudar 
determinado parâmetro, as cểulas demoram um certo tempo para se adaptarem às novas condições.

A tabe1a 3.14 e a figura 3.VII (ver gräf co $A_{1}$ ) mostram os dados referentes à formação de ART em função do tempo para a amostra de cēlulas mais ativa obtida durante o processo contīnuo.

TABELA 3.14 Variação da concentração de ART pela ação de célutas recolhidas no instante $t=52,5 \mathrm{~h}$ do ensajo no 5 (ver Jtem 2.5.4).

\begin{tabular}{cccc}
\hline$t$ & \multicolumn{3}{c}{ Concentração de ART, $c^{\prime}(g / \ell)$} \\
\cline { 2 - 3 }$($ min $)$ & \multicolumn{1}{c}{ Medidas } & Mëdia \\
1 & 0,147 & 0,149 & 0,148 \\
2 & 0,293 & 0,297 & 0,295 \\
3 & 0,446 & 0,440 & 0,443 \\
4 & 0,592 & 0,590 & 0,591 \\
5 & 0,737 & 0,741 & 0,739 \\
6 & 0,885 & 0,886 & 0,886 \\
\hline
\end{tabular}


TABELA 3.13 Resultados obtidos no ensaio no 5.

\begin{tabular}{|c|c|c|c|c|c|c|c|}
\hline \multirow{3}{*}{ Etapa } & \multirow{3}{*}{$\begin{array}{c}t \\
(h)\end{array}$} & \multirow{3}{*}{$\begin{array}{c}x \\
(g / \ell)\end{array}$} & \multirow{3}{*}{$\begin{array}{c}S \\
(g / \ell)\end{array}$} & \multirow{3}{*}{$\begin{array}{c}S^{\prime} \\
(g / e)\end{array}$} & \multicolumn{3}{|c|}{$v(g A R T / g$ cél.min } \\
\hline & & & & & \multicolumn{2}{|c|}{ Medidas } & \multirow{2}{*}{ Média } \\
\hline & & & & & $1 \underline{a}$ & $2 \underline{a}$ & \\
\hline \multirow[t]{10}{*}{ Desc. } & -6 & 0,67 & 9,0 & 25,4 & 0,722 & 0,733 & 0,727 \\
\hline & -3 & 1.25 & 20,5 & 22,5 & 0,400 & 0,383 & 0,392 \\
\hline & ${ }^{*} 0$ & 1,87 & 15,3 & 15,6 & 0,398 & 0,405 & 0,402 \\
\hline & 1,5 & 1,70 & - & - & 0,233 & 0,233 & 0,233 \\
\hline & 3 & 1,54 & 13,4 & 17,7 & 0,145 & 0,138 & 0,142 \\
\hline & 4,5 & 1,55 & - & - & 0,081 & 0,081 & 0,081 \\
\hline & 6 & 1,53 & 11,7 & 20,7 & 0,061 & 0,061 & 0,061 \\
\hline & 7,5 & 1,50 & - & - & 0,026 & 0,026 & 0,026 \\
\hline & 9 & 1,47 & 10,1 & 22,1 & 0,062 & 0,062 & 0,062 \\
\hline & 10,5 & 1,40 & - & - & 0,106 & 0,106 & 0,106 \\
\hline \multirow{15}{*}{ 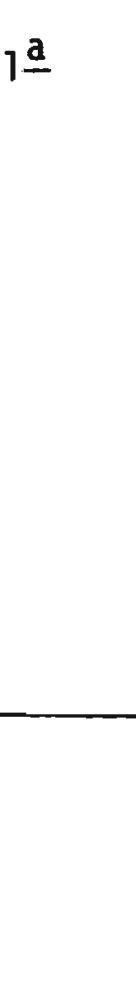 } & 12 & 1,37 & 7,9 & 21,2 & 0,092 & 0,092 & 0,092 \\
\hline & 13,5 & 1,35 & - & - & 0,085 & 0,085 & 0,085 \\
\hline & 15 & 1,39 & 7,7 & 21,2 & 0,106 & 0,091 & 0,099 \\
\hline & 16,5 & 1,38 & - & - & 0,068 & 0,068 & 0,068 \\
\hline & 18 & 1,41 & 8,2 & 27,5 & 0,066 & 0,066 & 0,066 \\
\hline & 19,5 & 1,45 & - & - & 0,064 & 0,071 & 0,068 \\
\hline & 21 & 1,58 & 7,3 & 18,5 & 0,094 & 0,094 & 0,094 \\
\hline & 22,5 & - & - & - & - & - & - \\
\hline & 24 & 1,51 & 7,4 & 20,1 & 0,055 & 0,055 & 0,055 \\
\hline & 25,5 & 1,45 & - & - & 0,072 & 0,079 & 0,076 \\
\hline & 27 & 1,43 & 7,5 & 20,8 & 0,050 & 0,050 & 0,050 \\
\hline & 28,5 & 1,55 & - & - & 0,067 & 0,067 & 0,067 \\
\hline & 30 & 1,71 & 6,1 & 20,9 & 0,061 & 0,061 & 0,061 \\
\hline & 31,5 & 1,90 & - & - & 0,095 & 0,095 & 0,095 \\
\hline & 33 & 2,11 & 6,0 & 18,2 & 0,078 & 0,078 & 0,078 \\
\hline \multirow[t]{6}{*}{$2 \underline{a}$} & 34,5 & 2,40 & - & - & 0,088 & 0,088 & 0,088 \\
\hline & 36 & 2,73 & 6,6 & 12,0 & 0,099 & 0,109 & 0,104 \\
\hline & 37,5 & 3,20 & - & - & 0,212 & 0,212 & 0,212 \\
\hline & 39 & 3,62 & 3,5 & 4,5 & 0,464 & 0,464 & 0,464 \\
\hline & 40,5 & 3,90 & - & - & 2,57 & 2,57 & 2,57 \\
\hline & 42 & 4,35 & 1,6 & 2,1 & 1,67 & 1,67 & 1,67 \\
\hline
\end{tabular}

continua 
Continuação da Tabela 3.13

\begin{tabular}{|c|c|c|c|c|c|c|c|}
\hline \multirow{3}{*}{$\begin{array}{c}\text { Etapa } \\
n Q\end{array}$} & \multirow{3}{*}{$\begin{array}{c}t \\
(h)\end{array}$} & \multirow{3}{*}{$\begin{array}{c}x \\
(g / \ell)\end{array}$} & \multirow{3}{*}{$\begin{array}{c}S \\
(g / \ell)\end{array}$} & \multirow{3}{*}{$\begin{array}{c}S^{\prime} \\
(g / l)\end{array}$} & \multicolumn{3}{|c|}{$v(g A R T / g$ cēl.min) } \\
\hline & & & & & \multicolumn{2}{|c|}{ Medidas } & \multirow{2}{*}{ Média } \\
\hline & & & & & $1 \underline{a}$ & $2-a$ & \\
\hline \multirow{6}{*}{$2 \stackrel{a}{-}$} & 43,5 & 4,60 & - & - & 2,20 & 2,20 & 2,20 \\
\hline & 45 & 4,78 & 1,5 & 2,0 & 2,10 & 2,10 & 2,10 \\
\hline & 46,5 & 5,00 & - & - & 2,50 & 2,40 & 2,45 \\
\hline & 48 & 5,17 & 1,6 & 2,0 & 2,26 & 2,26 & 2,26 \\
\hline & 49,5 & 5,30 & - & - & 2,26 & 2,26 & 2,26 \\
\hline & 51 & 5,22 & 1,4 & 1,8 & 2,39 & 2,39 & 2,39 \\
\hline \multirow{16}{*}{$3 \underline{a}$} & 52,5 & 5,70 & - & - & 2,67 & 2,52 & 2,59 \\
\hline & 54 & 6,38 & 1,3 & 1,7 & 2,25 & 2,32 & 2,28 \\
\hline & 55,5 & 7,20 & - & - & 2,04 & 2,10 & 2,07 \\
\hline & 57 & 8,24 & 1,1 & 1,7 & 1,73 & 1,73 & 1,73 \\
\hline & 58,5 & 9,20 & - & - & 1,41 & 1,41 & 1,41 \\
\hline & 60 & 10,3 & 1,3 & 1,3 & 1,03 & 1,03 & 1,03 \\
\hline & 61,5 & 10,8 & - & - & 1,10 & 1,10 & 1,10 \\
\hline & 63 & 11,2 & 1,1 & 1,5 & 0,433 & 0,433 & 0,433 \\
\hline & 64,5 & 11,8 & - & - & 0,650 & 0,650 & 0,650 \\
\hline & 66 & 11,8 & 0,91 & 1,2 & 0,647 & 0,647 & 0,647 \\
\hline & 67,5 & 12,6 & - & - & 0,731 & 0,731 & 0,731 \\
\hline & 69 & 13,1 & 0,88 & 1,5 & 0,731 & 0,731 & 0,731 \\
\hline & 70,5 & 13,3 & - & - & 0,556 & 0,556 & 0,556 \\
\hline & 72 & 13,5 & 0,86 & 1,5 & 0,386 & 0,386 & 0,386 \\
\hline & 73,5 & 13,6 & - & - & 0,610 & 0,610 & 0,610 \\
\hline & 75 & 13,6 & 0,93 & 1,6 & 0,622 & 0,622 & 0,622 \\
\hline \multirow{8}{*}{$4 \stackrel{a}{-}$} & 76,5 & 14,0 & - & - & 0,814 & 0,814 & 0,814 \\
\hline & 78 & 14,4 & 0,99 & 1,6 & 0,420 & 0,420 & 0,420 \\
\hline & 79,5 & 14,7 & - & - & 0,932 & 0,932 & 0,932 \\
\hline & 81 & 15,1 & 1,0 & 1,4 & 0,806 & 0,806 & 0,806 \\
\hline & 82,5 & 15,4 & - & - & 0,763 & 0,765 & 0,764 \\
\hline & 84 & 15,6 & 0,92 & 1,3 & 0,732 & 0,732 & 0,732 \\
\hline & 85,5 & 15,0 & - & - & 1,09 & 1,09 & 1,09 \\
\hline & \multicolumn{7}{|c|}{ Continua } \\
\hline
\end{tabular}


Continuação da Tabela 3.13

\begin{tabular}{|c|c|c|c|c|c|c|c|}
\hline \multirow{3}{*}{ Etapa } & \multirow{3}{*}{$\begin{array}{c}t \\
(h)\end{array}$} & \multirow{3}{*}{$\begin{array}{c}x \\
(g / \ell)\end{array}$} & \multirow{3}{*}{$\begin{array}{c}S \\
(g / l)\end{array}$} & \multirow{3}{*}{$\begin{array}{c}S^{\prime} \\
(g / l)\end{array}$} & \multicolumn{3}{|c|}{$v(g A R T / g$ cét.min $)$} \\
\hline & & & & & \multicolumn{2}{|c|}{ Medidas } & \multirow{2}{*}{ Mëdia } \\
\hline & & & & & $1 \underline{a}$ & $2 \underline{a}$ & \\
\hline \multirow{7}{*}{$4 \stackrel{a}{-}$} & 87 & 14,2 & 0,96 & 1,5 & 1,15 & 1,15 & 1,15 \\
\hline & 88,5 & 14,2 & - & - & 1,12 & 1,12 & 1,12 \\
\hline & 90 & 14,1 & 1,0 & 1,5 & 1,48 & 1,48 & 1,48 \\
\hline & 91,5 & 14,2 & - & - & 1,53 & 1,53 & 1,53 \\
\hline & 93 & 14,3 & 1,0 & 1,5 & 1,72 & 1,72 & 1,72 \\
\hline & 94,5 & 14,0 & - & - & 1,10 & 1,10 & 1,10 \\
\hline & 96 & 13,8 & 1,0 & 1,5 & 1,18 & 1,18 & 1,18 \\
\hline
\end{tabular}




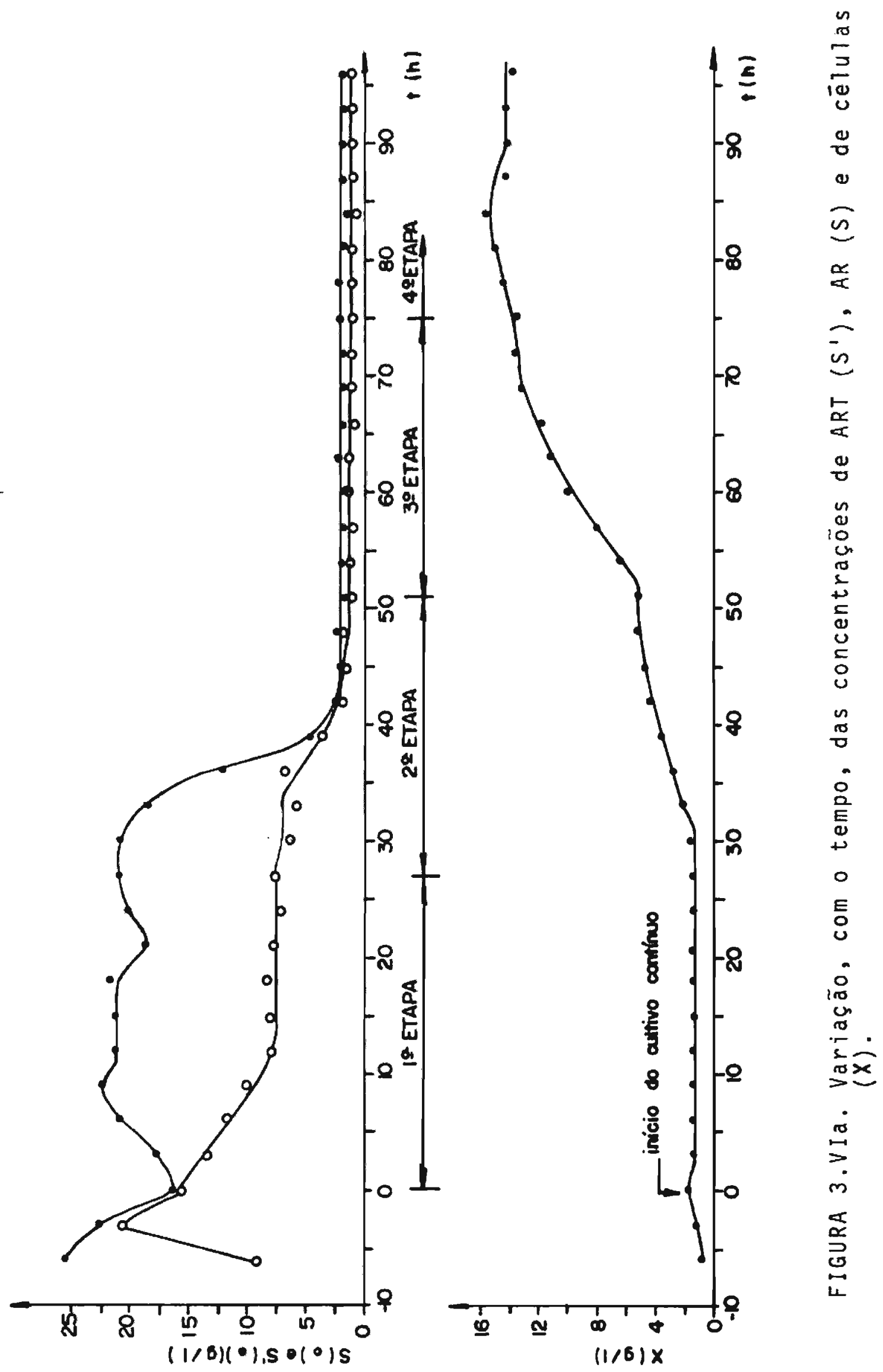




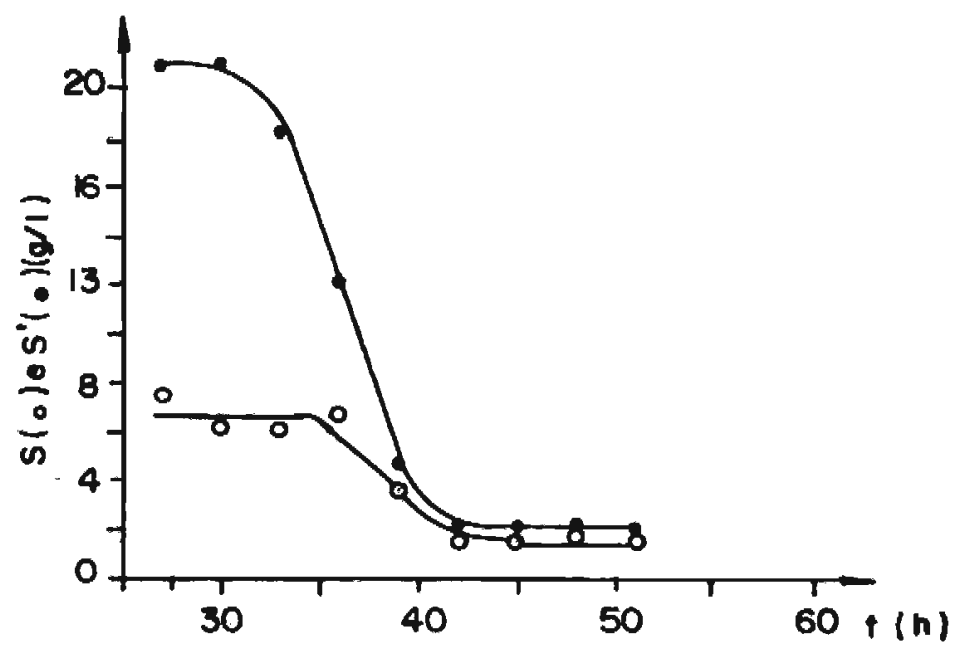

FIGURA 3.VIb. Perfil da variaçăo, com o tempo, das concentraçôes de ART ( $S^{i}$ ) e AR (S) para a 2 a etapa do en saio nọ 5 (entre os instantes $t=2 \bar{h}$ e $t=51 \mathrm{~h}$ ).

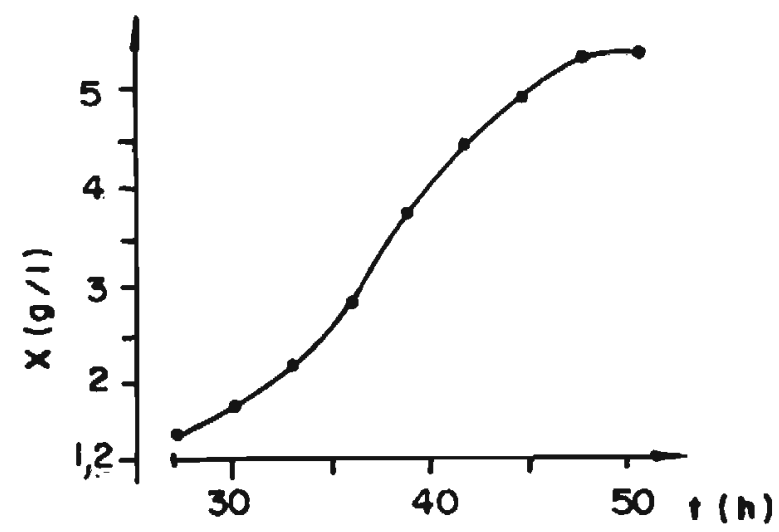

FIGURA 3.VIc. Perfil da variação, com o tempo, da concentra ção de cëlulas (X) para a 2 a etapa do ensaio no5.

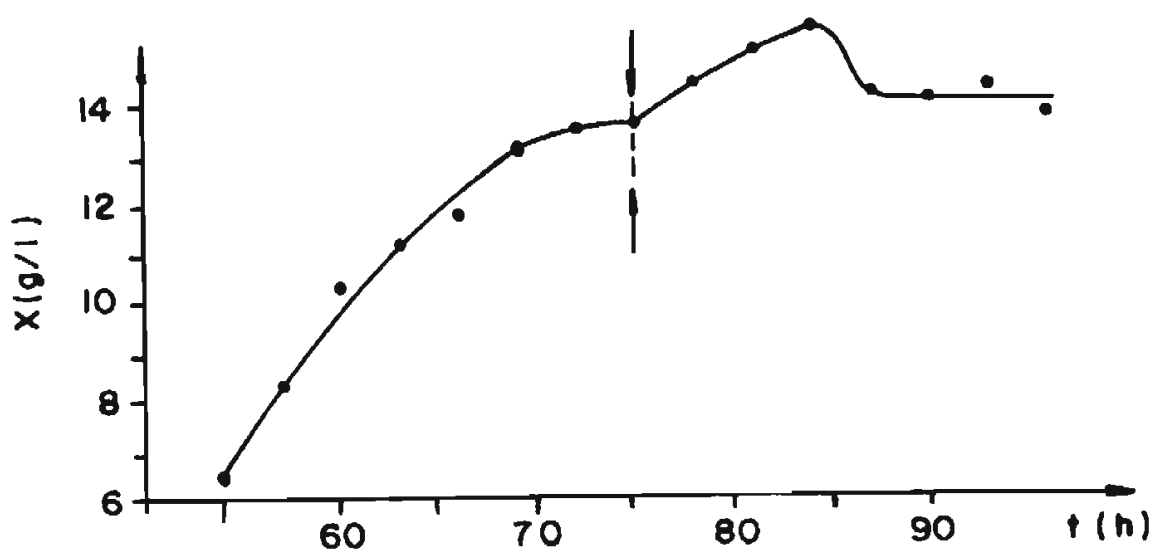

FIGURA 3.VId. Perfil da variaçäo, com o tempo, da concentração celular (X) para a 3 a e 4 a etapas do ensaio nọ 5 . 


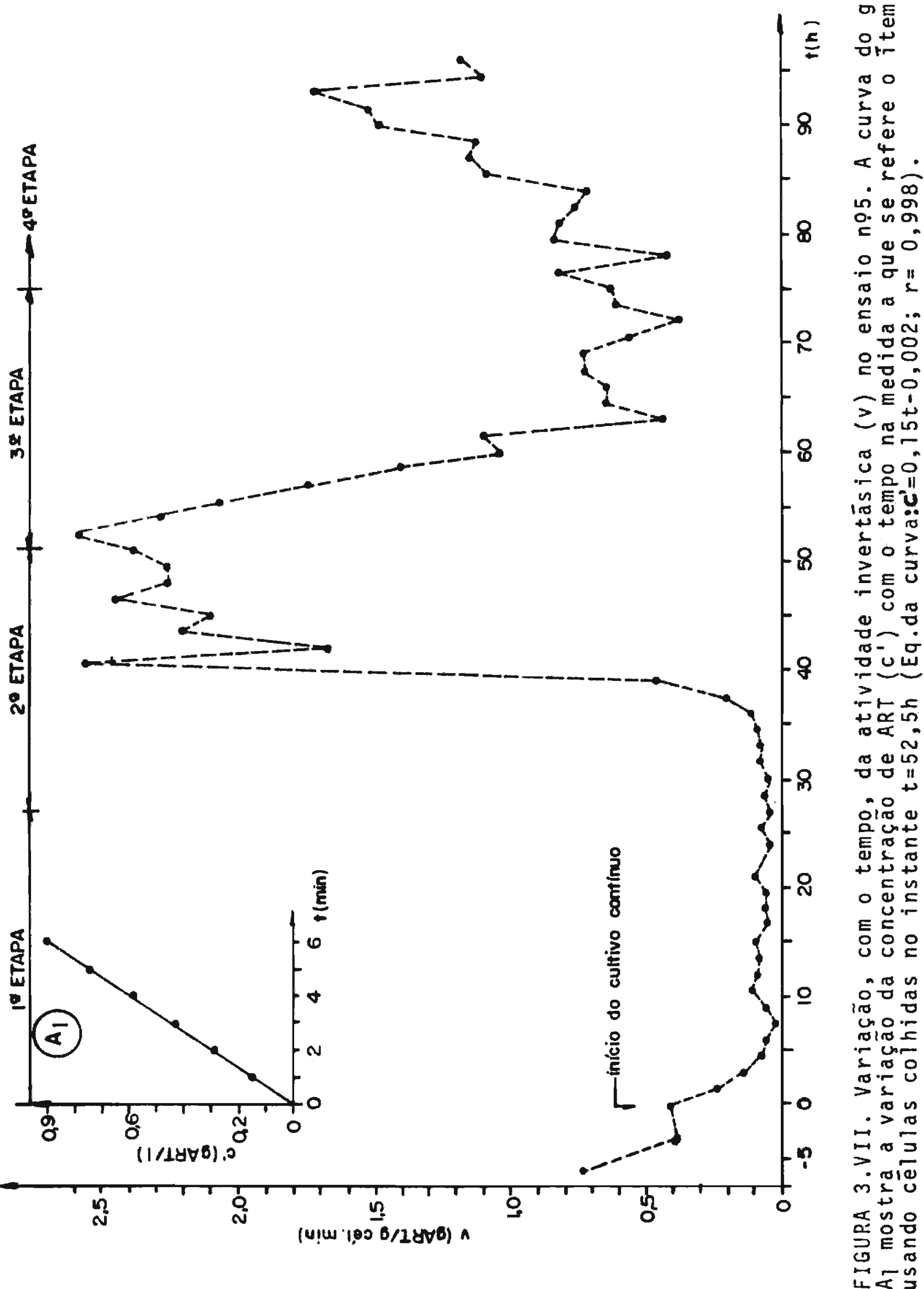




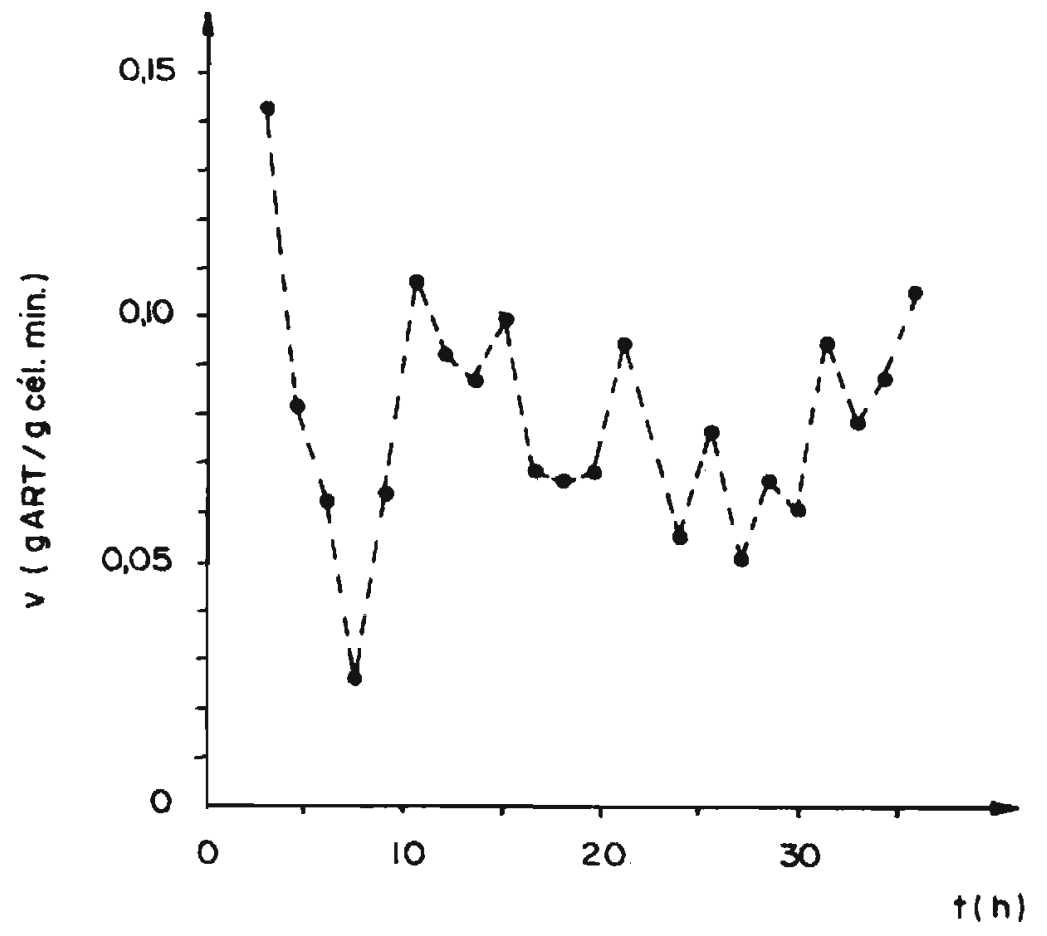

FIGURA 3.VIII. Variação, com o tempo, da atividade invertāsica ( $v$ ) no ensaio no 5 entre os instantes $t=3 \mathrm{~h}$ e $t=36 \mathrm{~h}$. 


\section{5 .6 Ensaio no 6}

\section{a) Condições experimentais}

Nutrientes adicionados ao mosto: $\mathrm{Na}_{2} \mathrm{HPO}_{4} \cdot 12 \mathrm{H}_{2} \mathrm{O}$, $\mathrm{MgSO}_{4} \cdot 7 \mathrm{H}_{2} \mathrm{O}$ e $\left(\mathrm{NH}_{4}\right)_{2} \mathrm{SO}_{4}$ conforme item 2.7.4.

$$
\begin{aligned}
& S_{0}^{1}=30,7 \mathrm{~g} / \mathrm{l} \\
& S_{0}=6,6 \mathrm{~g} / \mathrm{l}
\end{aligned}
$$

o ensaio foi dividido em duas etapas:

la etapa $(t=0 \mathrm{~h}$ at $\overline{\mathrm{e}} \mathrm{t}=45 \mathrm{~h}\rangle$

$F=711 \mathrm{~m} 1 / \mathrm{h}$

$D=0,23 \mathrm{~h}^{-1}$

$\Phi=1 \ell / \ell \cdot \mathrm{min}$

Volume final de mosto na dorna $=3,10 \ell$

$N=500 \mathrm{~min}^{-1}$

2- etapa $(t=46,5 \mathrm{~h}$ até $t=72 \mathrm{~h})$

$\mathrm{F}=704 \mathrm{ml} / \mathrm{h}$

$D=0,24 \mathrm{~h}^{-1}$

$\Phi \quad=2 \ell / \ell \cdot \min$

Volume final de mosto na dorna $=2,94 \ell$

$N=700 \mathrm{~min}^{-1}$

b) Resultados

Os valores obtidos nas determinações de $X, A R, A R T$ e $v$ encontram-se na tabela 3.15 e nas figuras $3.1 \times a-b$.

Para o cālculo do AR e ART utilizou-se a equação:

$$
y=0,00340 x+0,0092
$$


e para a medida do ART proveniente da atividade invertásica usou-se a equação:

$$
\begin{gathered}
y=2,315 x+0,0088 \quad(r=0,9994) \\
\text { c) Comentārios }
\end{gathered}
$$

Da figura 3. IXb constata-se que os períodos de oscilação de $v$ no patamar são:

la etapa: $4,5 \mathrm{~h} ; 3 \mathrm{~h} ; 3 \mathrm{~h} ; 3 \mathrm{~h} ; 5 \mathrm{~h} ; 3 \mathrm{~h} ; 5 \mathrm{~h} ; 3 \mathrm{~h} ; 6 \mathrm{~h}$ e $4,5 \mathrm{~h}$; período médio $=4,4 \mathrm{~h}$.

2- etapa: $12 \mathrm{~h}$ e $10,5 \mathrm{~h}$ periodo médio $=11,3 \mathrm{~h}$ o coeficiente de variação de $v \bar{e}:$

1 etapa: $51,7 \% \quad(\bar{v}=0,658 \mathrm{gART} / \mathrm{g}$ cél.min e

$$
s=0,34 \mathrm{gART} / \mathrm{g}(\bar{e} \mathrm{l} . \mathrm{min}) \text {. }
$$

2- etapa: $26,9 \% \quad(\bar{v}=0,633 \mathrm{gART} / \mathrm{g}$ cêl.min e

$$
s=0,17 \text { gART/g cél.min). }
$$

A tabela 3.16 e a figura 3. IXb (gráfico $A_{1}$ ) mostram os dados referentes à formação de ART em função do tempo para a amostra de cēlulas mais ativa obtida durante o processo contínuo. 
TABELA 3.15. Resultados obtidos no ensaio no 6.

\begin{tabular}{|c|c|c|c|c|c|c|c|}
\hline \multirow{3}{*}{ Etapa } & \multirow{3}{*}{$\begin{array}{c}t \\
(h)\end{array}$} & \multirow{3}{*}{$\begin{array}{c}x \\
(g / \ell)\end{array}$} & \multirow{3}{*}{$\begin{array}{c}S \\
(g / \ell)\end{array}$} & \multirow{3}{*}{$\begin{array}{c}S^{\prime} \\
(g / \ell)\end{array}$} & \multicolumn{3}{|c|}{$v(g A R T / g$ cēl.min) } \\
\hline & & & & & \multicolumn{2}{|c|}{ Medidas } & \multirow{2}{*}{ Média } \\
\hline & & & & & $1 \underline{a}$ & $2 a$ & \\
\hline \multirow[t]{15}{*}{ Desc. } & -6 & 0,84 & 8,3 & 23,4 & 0,619 & 0,602 & 0,611 \\
\hline & -3 & 1,94 & 15,6 & 16,2 & 0,238 & 0,231 & 0,235 \\
\hline & ${ }^{\star} 0$ & 3,90 & 0,93 & 1,4 & 0,440 & 0,440 & 0,440 \\
\hline & 1,5 & 4,25 & - & - & 0,856 & 0,856 & 0,856 \\
\hline & 3 & 4,28 & 1,3 & 2,0 & 1,13 & 1,13 & 1,13 \\
\hline & 4,5 & 4,60 & - & - & 0,928 & 0,928 & 0,928 \\
\hline & 6 & 4,67 & 1,6 & 2,1 & 1,38 & 1,31 & 1,34 \\
\hline & 7,5 & 4,60 & - & - & 1,30 & 1,27 & 1,29 \\
\hline & 9 & 4,47 & 2,0 & 2,5 & 1,20 & 1,20 & 1,20 \\
\hline & 10,5 & 4,35 & - & - & 1,32 & 1,40 & 1,36 \\
\hline & 12 & 4,33 & 2,3 & 2,7 & 0,929 & 0,954 & 0,941 \\
\hline & 13,5 & 4,30 & - & - & 0,985 & 1,04 & 1,01 \\
\hline & 15 & 4,15 & 2,7 & 3,2 & 0,735 & 0,735 & 0,735 \\
\hline & 16,5 & 4,00 & - & - & 0,816 & 0,816 & 0,816 \\
\hline & 18 & 3,99 & 3,1 & 3,7 & 0,666 & 0,612 & 0,639 \\
\hline \multirow[t]{16}{*}{$1 \stackrel{a}{-}$} & 19,5 & 3,90 & - & - & 0,723 & 0,709 & 0,716 \\
\hline & 21 & 3,90 & 3,2 & 4,4 & 0,543 & 0,576 & 0,529 \\
\hline & 22,5 & 3,90 & - & - & 0,516 & 0,516 & 0,516 \\
\hline & 24 & 3,87 & 3,3 & 4,2 & 0,506 & 0,478 & 0,492 \\
\hline & 25,5 & 3,85 & - & - & 0,508 & 0,508 & 0,508 \\
\hline & 27 & 3,90 & 3,8 & 4,4 & 0,391 & 0,377 & 0,384 \\
\hline & 28,5 & 3,80 & - & - & 0,401 & 0,401 & 0,401 \\
\hline & 30 & 3,76 & 4,0 & 4,3 & 0,348 & 0,334 & 0,341 \\
\hline & 31,5 & 3,80 & - & - & 0,359 & 0,344 & 0,352 \\
\hline & 33 & 3,74 & 4,0 & 4,7 & 0,350 & 0,350 & 0,350 \\
\hline & 34,5 & 3,78 & - & - & 0,346 & 0,346 & 0,346 \\
\hline & 36 & 3,74 & 3,9 & 4,6 & 0,307 & 0,321 & 0,314 \\
\hline & 37,5 & 3,70 & - & - & 0,372 & 0,372 & 0,372 \\
\hline & 39 & 3,66 & 3,7 & 4,8 & 0,366 & 0,376 & 0,371 \\
\hline & 40,5 & 3,70 & - & - & 0,343 & 0,343 & 0,343 \\
\hline & 42 & 3,57 & 4,1 & 4,9 & 0,345 & 0,355 & 0,350 \\
\hline
\end{tabular}


Continuação da Tabela 3.15

\begin{tabular}{|c|c|c|c|c|c|c|c|}
\hline \multirow{3}{*}{ Etapa } & \multirow{3}{*}{$\begin{array}{c}t \\
(h)\end{array}$} & \multirow{3}{*}{$\begin{array}{c}x \\
(g / l)\end{array}$} & \multirow{3}{*}{$\begin{array}{c}S \\
(g / l)\end{array}$} & \multirow{3}{*}{$\begin{array}{c}S^{\prime} \\
(g / \ell)\end{array}$} & \multicolumn{3}{|c|}{$v(g A R T / g$ cél.min) } \\
\hline & & & & & \multicolumn{2}{|c|}{ Medidas } & \multirow{2}{*}{ Média } \\
\hline & & & & & $1 \underline{a}$ & $2-a$ & \\
\hline \multirow{2}{*}{$1 \underline{a}$} & 43,5 & 3,55 & - & - & 0,378 & 0,378 & 0,378 \\
\hline & 45,0 & 3,29 & 4,2 & 5,1 & 0,418 & 0,429 & 0,424 \\
\hline \multirow{18}{*}{$2 \underline{a}$} & 46,5 & 3,40 & - & - & 0,341 & 0,352 & 0,347 \\
\hline & 48 & 3,69 & 4,1 & 4,8 & 0,363 & 0,383 & 0,373 \\
\hline & 49,5 & 3,80 & - & - & 0,401 & 0,430 & 0,415 \\
\hline & 51 & 3,96 & 3,2 & 3,6 & 0,535 & 0,535 & 0,535 \\
\hline & 52,5 & 4,00 & - & - & 0,624 & 0,624 & 0,624 \\
\hline & 54 & 4,07 & 2,5 & 2,5 & 0,627 & 0,627 & 0,627 \\
\hline & 55,5 & 4,10 & - & - & 0,635 & 0,622 & 0,629 \\
\hline & 57 & 4,13 & 2,7 & 3,4 & 0,555 & 0,529 & 0,542 \\
\hline & 58,5 & 4,15 & - & - & 0,501 & 0,553 & 0,527 \\
\hline & 60 & 4,20 & 2,5 & 3,2 & 0,597 & 0,649 & 0,623 \\
\hline & 61,5 & 4,30 & - & - & 0,659 & 0,659 & 0,659 \\
\hline & 63 & 4,31 & 2,6 & 3,0 & 0,708 & 0,733 & 0,720 \\
\hline & 64,5 & 4,30 & - & - & 0,734 & 0,759 & 0,747 \\
\hline & 66 & 4,25 & 2,4 & 2,9 & 0,997 & 0,946 & 0,972 \\
\hline & 67,5 & 4,30 & - & - & 0,935 & 0,935 & 0,935 \\
\hline & 69 & 4,41 & 2,4 & 3,0 & 0,618 & 0,618 & 0,618 \\
\hline & 70,5 & 4,30 & - & - & 0,810 & 0,835 & 0,822 \\
\hline & 72 & 4,31 & 2,6 & 3,1 & 0,682 & 0,682 & 0,682 \\
\hline
\end{tabular}

* Inĩcio do cultivo contínuo. 
TABELA 3.16 Variação da concentração de ART pela ação de células recolhidas no instante $t=10,5 \mathrm{~h}$ do ensaio no 6 (ver item 2.5.4).

\begin{tabular}{|c|c|c|c|}
\hline \multirow{3}{*}{$\begin{array}{c}\mathrm{t} \\
(\min )\end{array}$} & \multicolumn{3}{|c|}{ Concentração de ART, $c^{\prime}(g / l)$} \\
\hline & \multicolumn{2}{|c|}{ Medidas } & \multirow{2}{*}{ Mëdia } \\
\hline & $1 \underline{a}$ & $2 \underline{a}$ & \\
\hline 1 & 0,235 & 0,237 & 0,236 \\
\hline 2 & 0,470 & 0,476 & 0,473 \\
\hline 3 & 0,707 & 0,711 & 0,709 \\
\hline 4 & 0,946 & 0,946 & 0,946 \\
\hline 5 & 1,16 & 1,20 & 1,18 \\
\hline 6 & 1,40 & 1,44 & 1,42 \\
\hline
\end{tabular}




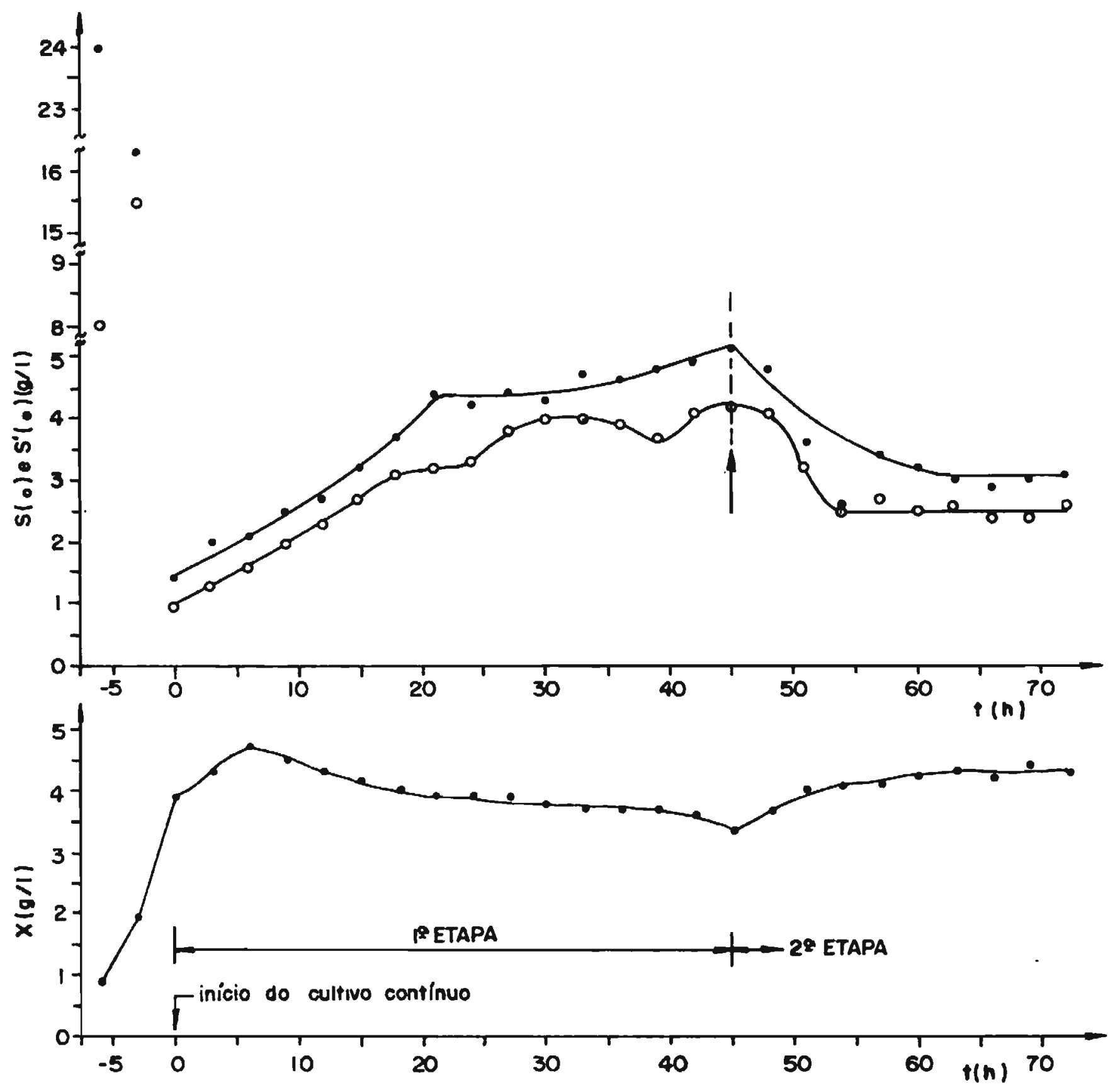

FIGURA 3. IXa. Variação, com o tempo, das concentrações de ART (S'), de AR (S) e de células $(X)$ no ensaio no 6 . 


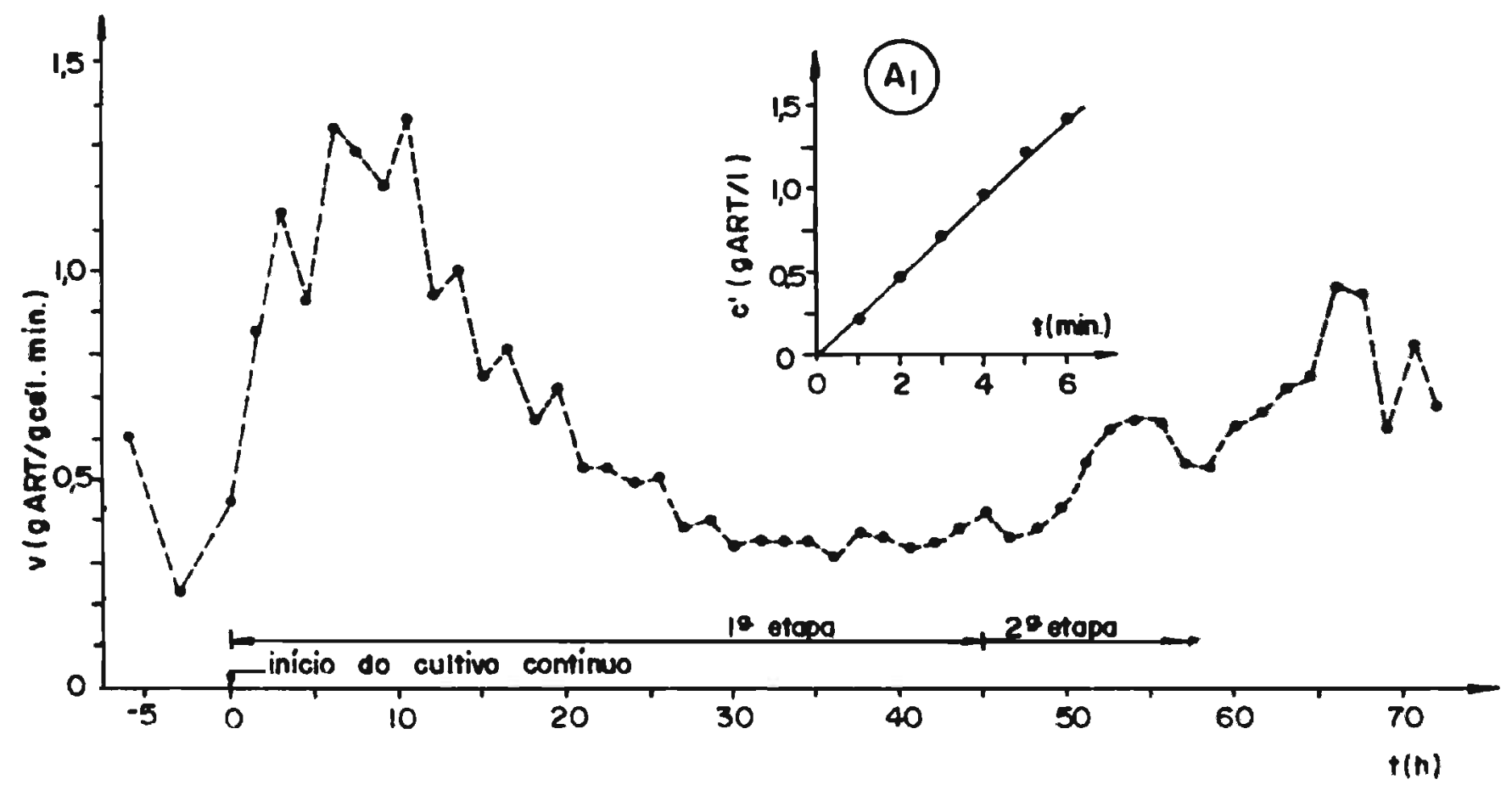

FIGURA 3.IXb. Variação, com o tempo, da atividade invertāsica (v) no ensaio, nọ 6. A curva do gráfico $A_{1}$ mostra a varíaçã̃o da concentração de ART ( $\left.c^{\prime}\right)$ com o tempo na medida a que se refe re 0 it tem 2.5.4, usando cêlulas colhidas no instante $t=10,5 \mathrm{~h}$.

( $E q$. da curva: $c^{\prime}=0,24 t-0,004 ; r=0,9998$ ). 


\section{5 .7 Ensaio n! 7}

a) Condições experimentais

Nutrientes adicionados ao mosto: $\mathrm{Na}_{2} \mathrm{HPO}_{4} \cdot 12 \mathrm{H}_{2} \mathrm{O}$, $\mathrm{MgSO}_{4} \cdot 7 \mathrm{H}_{2} \mathrm{O}$ e $\left(\mathrm{NH}_{4}\right)_{2} \mathrm{SO}_{4}$, conforme referido no item 2.1 .4 .

$$
\begin{aligned}
& \mathrm{S}_{0}^{\prime}=30,3 \mathrm{~g} / \mathrm{l} \\
& \mathrm{S}_{0}=6,6 \mathrm{~g} / \mathrm{\ell} \\
& \mathrm{F}=725 \mathrm{ml} / \mathrm{h} \\
& D=0,23 \mathrm{~h}^{-1} \\
& \Phi=2 \ell / \ell \cdot \min \\
& \text { Volume final de mosto na dorna }=3,10 \mathrm{l} \\
& N=700 \mathrm{~min}^{-1}
\end{aligned}
$$

b) Resultados

Os valores obtidos nas determinações de $X, A R$, ART e $v$ encontram-se na tabela 3.17 e na figura $3 . x$.

Para o cālculo do AR e ART utilizou-se a equação:

$$
y=0,0036 x-0,0037
$$

e para a medida do ART proveniente da atividade invertásica usou-se a equaçāo:

$$
\begin{aligned}
& y=2,226 x+0,015 \quad(r=0,998) \\
& \text { c) Comentārios }
\end{aligned}
$$

Da figura $3 . x$ constata-se que os periodos de os cilação de $v$ entre os instantes $t=15 \mathrm{~h}$ e $t=57 \mathrm{~h}$, são: $3 \mathrm{~h}$; $4 \mathrm{~h}$; $5,5 h ; 3 h ; 4,5 h ; 3 h ; 6 h ; 6 h ; 3 h$, sendo o periodo mēdio de $4,2 h$. 
0 coeficiente de variação de $v$ entre $t=15 \mathrm{~h}$ e $t=57 \mathrm{~h} \bar{e} 15,6 \%(\bar{v}=0,161 \mathrm{gART} / \mathrm{g} \quad \mathrm{e} \overline{\mathrm{e}} 1 . \mathrm{min} ; \mathrm{s}=0,025 \mathrm{gART} / \mathrm{g} \quad \bar{e} 1$. $\operatorname{min.)}$

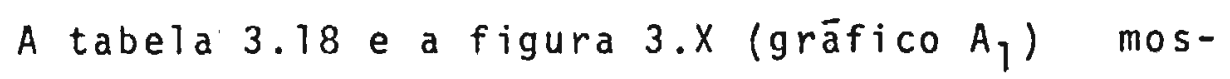
tram os dados referentes à formação de ART em função do tempo para a amostra de células mais ativa obtida durante o processo contínuo.

Com o intuito de verificar melhor o perfil da oscitação de $v$, foram feitas amostragens de meia em meia hora entre os instantes $t=48 \mathrm{~h}$ e $t=51 \mathrm{~h}$.

TABELA 3.18 Variação da concentração de ART pela ação de cēlutas recolhidas no instante $t=3 \mathrm{~h}$ do ensaio n! 7 (ver ítem 2.5.4).

\begin{tabular}{|c|c|c|c|}
\hline \multirow{3}{*}{$\begin{array}{c}t \\
(\min )\end{array}$} & \multicolumn{3}{|c|}{ Concentração de ART, $c^{\prime}(g / \ell)$} \\
\hline & \multicolumn{2}{|c|}{ Medidas } & \multirow{2}{*}{ Média } \\
\hline & $1 \underline{a}$ & $2 \underline{a}$ & \\
\hline 1 & 0,076 & 0,076 & 0,076 \\
\hline 2 & 0,151 & 0,154 & 0,153 \\
\hline 3 & 0,228 & 0,230 & 0,229 \\
\hline 4 & 0,303 & 0,307 & 0,305 \\
\hline 5 & 0,381 & 0,383 & 0,382 \\
\hline 6 & 0,458 & 0,458 & 0,458 \\
\hline
\end{tabular}


TABELA 3.17 Resultados obtidos no ensaio n? 7.

\begin{tabular}{|c|c|c|c|c|c|c|}
\hline \multirow{3}{*}{$(h)$} & \multirow{3}{*}{$\begin{array}{c}x \\
(g / \ell)\end{array}$} & \multirow{3}{*}{$\begin{array}{c}S \\
(g / l)\end{array}$} & \multirow{3}{*}{$\begin{array}{c}S^{\prime} \\
(g / \ell)\end{array}$} & \multicolumn{3}{|c|}{$v(g A R T / g$ cé 1 . min) } \\
\hline & & & & \multicolumn{2}{|c|}{ Medidas } & \multirow{2}{*}{ Média } \\
\hline & & & & $1 \underline{\mathrm{a}}$ & $2 \frac{a}{-}$ & \\
\hline-6 & 1,02 & 5,8 & 23,4 & 0,782 & 0,782 & 0,782 \\
\hline-3 & 1,36 & 14,5 & 21,4 & 0,314 & 0,314 & 0,314 \\
\hline${ }^{\star} 0$ & 3,87 & 3,9 & 4,4 & 0,193 & 0,184 & 0,188 \\
\hline 1,5 & 4,20 & - & - & 0,383 & 0,410 & 0,397 \\
\hline 3 & 4,30 & 2,8 & 3,8 & 0,444 & 0,444 & 0,444 \\
\hline 4,5 & 4,25 & - & - & 0,436 & 0,436 & 0,436 \\
\hline 6 & 4,24 & 3,2 & 3,7 & 0,383 & 0,410 & 0,397 \\
\hline 7,5 & 4,20 & - & - & 0,294 & 0,321 & 0,307 \\
\hline 9 & 4,11 & 3,9 & 4,8 & 0,259 & 0,287 & 0,273 \\
\hline 10,5 & 4,00 & - & - & 0,210 & 0,210 & 0,210 \\
\hline 12 & 4,00 & 5,1 & 5,9 & 0,234 & 0,224 & 0,229 \\
\hline 13,5 & 3,80 & - & - & 0,217 & 0,217 & 0,217 \\
\hline 15 & 3,78 & 5,1 & 6,6 & 0,238 & 0,238 & 0,238 \\
\hline 16,5 & 3,70 & - & - & 0,202 & 0,182 & 0,192 \\
\hline 18 & 3,73 & 5,7 & 6,2 & 0,191 & 0,191 & 0,191 \\
\hline 19,5 & 3,70 & - & - & 0,222 & 0,212 & 0,217 \\
\hline 21 & 3,73 & 5,0 & 6,4 & 0,201 & 0,191 & 0,196 \\
\hline 22,5 & 3,70 & - & - & 0,162 & 0,152 & 0,157 \\
\hline 24 & 3,76 & 5,2 & 6,5 & 0,179 & 0,169 & 0,174 \\
\hline 25,5 & 3,70 & - & - & 0,141 & 0,141 & 0,741 \\
\hline 27 & 3,66 & 6,2 & 6,5 & 0,174 & 0,184 & 0,179 \\
\hline 28,5 & 3,70 & - & - & 0,182 & 0,172 & 0,177 \\
\hline 30 & 3,10 & 4,3 & 5,3 & 0,152 & 0,152 & 0,152 \\
\hline 31,5 & 3,70 & - & - & 0,162 & 0,162 & 0,162 \\
\hline 33 & 3,67 & 4,8 & 7,3 & 0,132 & 0,122 & 0,127 \\
\hline 34,5 & 3,70 & - & - & 0,141 & 0,152 & 0,147 \\
\hline 36 & 3,64 & 5,1 & 6,6 & 0,144 & 0,144 & 0,144 \\
\hline 37,5 & 3,70 & - & - & 0,121 & 0,121 & 0,121 \\
\hline 39 & 3,71 & 5,0 & 7,0 & 0,121 & 0,121 & 0,121 \\
\hline \multirow[t]{2}{*}{40,5} & 3,70 & - & - & 0,121 & 0,121 & 0,121 \\
\hline & & & & \multicolumn{3}{|c|}{ Continua } \\
\hline
\end{tabular}


Continuação da Tabela 3.17

\begin{tabular}{|c|c|c|c|c|c|c|}
\hline \multirow{3}{*}{$\begin{array}{c}t \\
(h)\end{array}$} & \multirow{3}{*}{$\begin{array}{c}x \\
(g / \ell)\end{array}$} & \multirow{3}{*}{$\begin{array}{c}S \\
(g / \ell)\end{array}$} & \multirow{3}{*}{$\begin{array}{c}S^{\prime} \\
(g / l)\end{array}$} & \multicolumn{3}{|c|}{$v(g A R T / g \quad c \bar{e} 1 \cdot \min )$} \\
\hline & & & & \multicolumn{2}{|c|}{ Medidas } & \multirow[b]{2}{*}{ Média } \\
\hline & & & & ja & $2 \underline{a}$ & \\
\hline 42 & 3,71 & 5,1 & 6,5 & 0,171 & 0,161 & 0,166 \\
\hline 43,5 & 3,70 & - & - & 0,162 & 0,152 & 0,157 \\
\hline 45 & 3,70 & 5,0 & 6,5 & 0,152 & 0,152 & 0,152 \\
\hline 46,5 & 3,70 & - & - & 0,152 & 0,162 & 0,157 \\
\hline 48 & 3,72 & 4,9 & 6,3 & 0,141 & 0,141 & 0,141 \\
\hline 48,5 & 3,70 & - & - & 0,192 & 0,182 & 0,187 \\
\hline 49 & 3,70 & - & - & 0,152 & 0,141 & 0,147 \\
\hline 49,5 & 3,70 & - & - & 0,162 & 0,162 & 0,162 \\
\hline 50 & 3,70 & - & - & 0,167 & 0,167 & 0,167 \\
\hline 50,5 & 3,70 & - & - & 0,131 & 0,141 & 0,136 \\
\hline 51 & 3,65 & 5,1 & 6,4 & 0,133 & 0,143 & 0,138 \\
\hline 52,5 & 3,70 & - & - & 0,141 & 0,141 & 0,141 \\
\hline 54 & 3,73 & 4,9 & 6,5 & 0,170 & 0,180 & 0,175 \\
\hline 55,5 & 3,70 & - & - & 0,177 & 0,177 & 0,177 \\
\hline 57 & 3,69 & 5,0 & 6,6 & 0,172 & 0,162 & 0,167 \\
\hline
\end{tabular}

* Inicio do cultivo contínuo. 


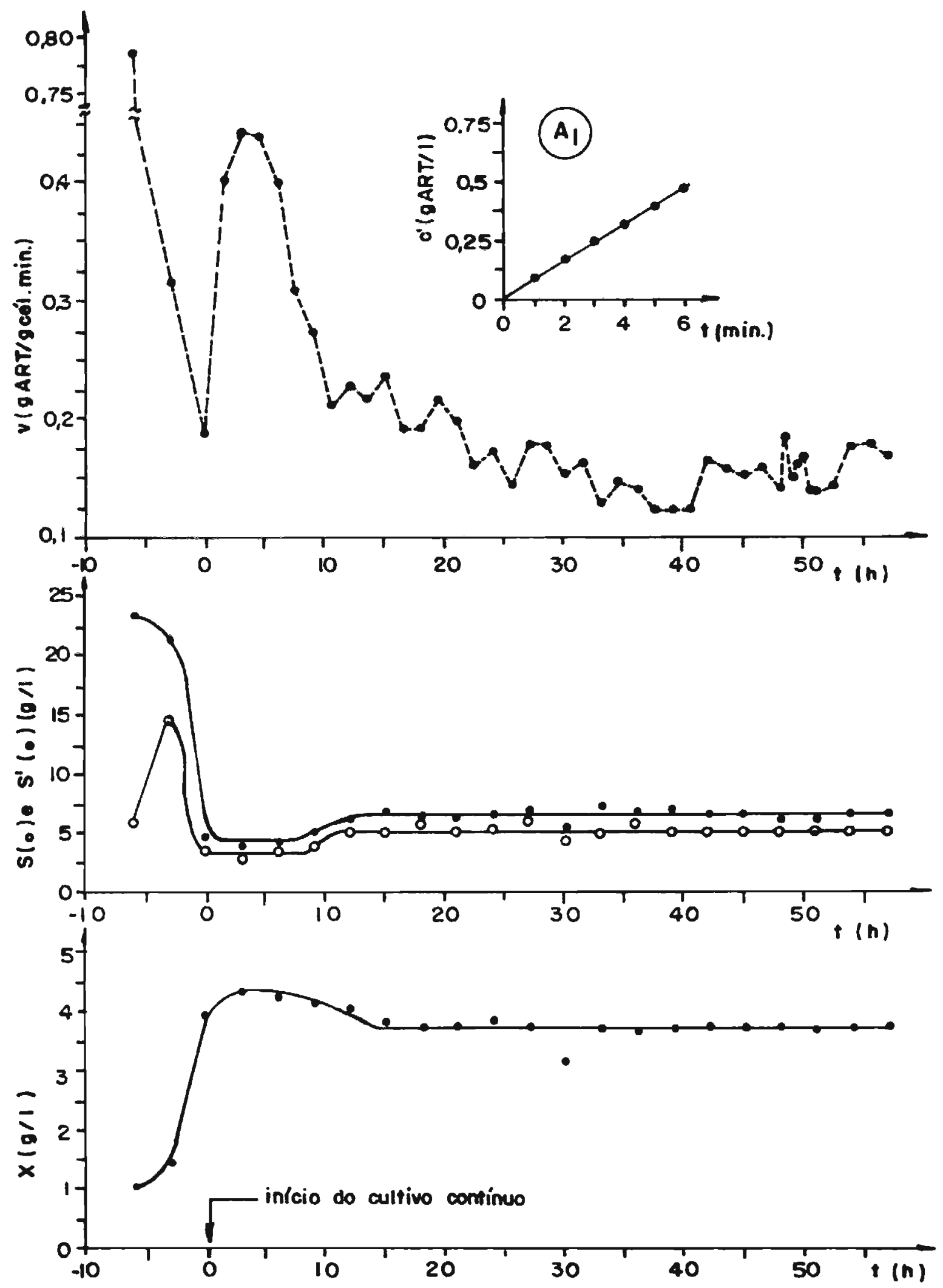

FIGURA 3.X. Variação, com o tempo, da atividade invertáśica (v), e das concentraçōes de ART (S'), de AR (S) e de células $(X)$ no ensaio no 7. A curva do gráfico Al mostra a variação da concentração de ART $\left(c^{\prime}\right)$ com o tempo na medida a que se refere o item 2.5.4, usando células colhidas no instante $t=3 \mathrm{~h}$ (Eq.da curva: $c^{\prime}=0,077 t-0,003 ; r=0,9995$ ). 


\section{a) Condiçōes experimentais}

Nutrientes adicionados ao mosto: nenhum

$$
\begin{aligned}
& S_{0}^{1}=30,8 \mathrm{~g} / \mathrm{l} \\
& S_{0}=6,3 \mathrm{~g} / \mathrm{l} \\
& F=737 \mathrm{ml}^{\mathrm{h}} \\
& D=0,24 \mathrm{~h}^{-1} \\
& \Phi \quad=0 \text { (sem borbul hamento de ar) } \\
& N \quad=500 \mathrm{~min}^{-1} \\
& \text { Volume final de mosto }=3,10 \mathrm{l}
\end{aligned}
$$

b) Resuitados

Os valores obtidos nas determinações de $X, A R$, ART e $v$ encontram-se na tabela 3.19 e na figura $3 . X I$.

Para o cālculo do AR e ART utilizou-se a equação:

$$
y=0,0036 x+0,015
$$

e para a medida do ART proveniente da atividade invertāsica usou-se a equação:

$$
y=2,407 x+0,0071 \quad(r=0,9998)
$$

\section{c) Comentários}

Da figura $3 . X I$ constata-se que os periodos de oscilação de $v$ entre os instantes $t=3 \mathrm{~h}$ e $t=45 \mathrm{~h}, \mathrm{são}: 6 \mathrm{~h} ; 12 \mathrm{~h}$; $4,5 \mathrm{~h} ; 3 \mathrm{~h} ; 7,5 \mathrm{~h} ; 4 \mathrm{~h}$, sendo o perjodo mëdio de $6,1 \mathrm{~h}$.

0 coeficiente de variação de $v$ entre $t=3 \mathrm{~h} \quad \mathrm{e}$ $\mathrm{t}=45 \mathrm{~h} \overline{\mathrm{e}} 18 \%(\bar{v}=0,081 \mathrm{gART} / \mathrm{g}$ cēel.min; $\mathrm{s}=0,015 \mathrm{~g}$ ART $/ \mathrm{g}$ cēl. min). 
A tabela 3.20 e a figura 3.XI (Gräfico $\left.A_{1}\right)$ mostram os dados referentes à formaçăo de ART em funçäo do tempo para a amostra de células mais ativa obtida durante o processo contínuo.

Com o intuito de verificar melhor o perfil da os cilação de $v$ foram feitas amostragens de meia em meia hora entre os instantes $t=42 \mathrm{~h}$ e $t=45 \mathrm{~h}$.

TABELA 3.20 Variação da concentração de ART pela ação de células colhidas no instante $t=0 h$ do ensaio no 8 (ver îtem 2.5.4).

\begin{tabular}{|c|c|c|c|}
\hline \multirow{3}{*}{$\begin{array}{c}t \\
(\min )\end{array}$} & \multicolumn{3}{|c|}{ Concentraçāo de ART, $c^{\prime}(g / l)$} \\
\hline & \multicolumn{2}{|c|}{ Medidas } & \multirow{2}{*}{ Média } \\
\hline & $1 \mathrm{a}$ & $2 \underline{a}$ & \\
\hline 1 & 0,025 & 0,025 & 0,025 \\
\hline 2 & 0,059 & 0,061 & 0,060 \\
\hline 3 & 0,090 & 0,090 & 0,090 \\
\hline 4 & 0,118 & 0,122 & 0,120 \\
\hline 5 & 0,149 & 0,151 & 0,150 \\
\hline 6 & 0,175 & 0,775 & 0,175 \\
\hline
\end{tabular}


TABELA 3.19 Resultados obtidos no ensaio no 8.

\begin{tabular}{|c|c|c|c|c|c|c|}
\hline \multirow{3}{*}{$\begin{array}{c}t \\
(h)\end{array}$} & \multirow{3}{*}{$\begin{array}{c}x \\
(g / l)\end{array}$} & \multirow{3}{*}{$\begin{array}{c}S \\
(g / l)\end{array}$} & \multirow{3}{*}{$\begin{array}{c}S^{\prime} \\
(g / l)\end{array}$} & \multicolumn{3}{|c|}{$v(g A R T / g$ cét. min) } \\
\hline & & & & \multicolumn{2}{|c|}{ Medidas } & \multirow[b]{2}{*}{ Média } \\
\hline & & & & 1 a & 2 a & \\
\hline-6 & 0,58 & 7,0 & 23,1 & 0,508 & 0,508 & 0,508 \\
\hline-3 & 1,03 & 17,6 & 20,6 & 0,232 & 0,225 & 0,229 \\
\hline${ }^{*} 0$ & 1,48 & 13,2 & 12,1 & 0,193 & 0,212 & 0,202 \\
\hline 1,5 & 1,35 & - & - & 0,160 & 0,160 & 0,160 \\
\hline 3 & 1,30 & 7,2 & 14,3 & 0,144 & 0,134 & 0,139 \\
\hline 4,5 & 1,25 & - & - & 0,095 & 0,095 & 0,095 \\
\hline 6 & 1,31 & 4,8 & 12,7 & 0,076 & 0,068 & 0,072 \\
\hline 7,5 & 1,25 & - & - & 0,079 & 0,071 & 0,075 \\
\hline 9 & 1,22 & 4,7 & 15,1 & 0,077 & 0,077 & 0,077 \\
\hline 10,5 & 1,25 & - & - & 0,075 & 0,075 & 0,075 \\
\hline 12. & 1,30 & 5,2 & 15,7 & 0,061 & 0,061 & 0,061 \\
\hline 13,5 & 1,25 & - & - & 0,070 & 0,070 & 0,070 \\
\hline 15 & 1,25 & 4,8 & 16,4 & 0,075 & 0,075 & 0,075 \\
\hline 16,5 & 1,25 & - & - & 0,075 & 0,080 & 0,078 \\
\hline 18 & 1,22 & 5,2 & 15,2 & 0,094 & 0,083 & 0,088 \\
\hline 19,5 & 1,25 & - & - & 0,092 & 0,092 & 0,092 \\
\hline 21 & 1,22 & 4,8 & 15,5 & 0,091 & 0,091 & 0,091 \\
\hline 22,5 & 1,25 & - & - & 0,081 & 0,086 & 0,083 \\
\hline 24 & 1,21 & 5,3 & 14,8 & 0,055 & 0,055 & 0,055 \\
\hline 25,5 & 1,25 & - & - & 0,097 & 0,108 & 0,103 \\
\hline 27 & 1,21 & 4,8 & 16,6 & 0,069 & 0,069 & 0,069 \\
\hline 28,5 & 1,25 & - & - & 0,061 & 0,061 & 0,061 \\
\hline 30 & 1,24 & 6,4 & 15,1 & 0,098 & 0,098 & 0,098 \\
\hline 31,5 & 1,25 & - & - & 0,058 & 0,058 & 0,058 \\
\hline 33 & 1,27 & 4,3 & 14,7 & 0,077 & 0,077 & 0,077 \\
\hline 34,5 & 1,25 & - & - & 0,108 & 0,103 & 0,105 \\
\hline 36 & 1,22 & 4,4 & 15,3 & 0,100 & 0,100 & 0,100 \\
\hline 37,5 & 1,25 & - & - & 0,086 & 0,086 & 0,086 \\
\hline 39 & 1,24 & 4,2 & 15,6 & 0,059 & 0,070 & 0,064 \\
\hline 40,5 & 1,25 & - & - & 0,070 & 0,064 & 0,067 \\
\hline
\end{tabular}


Continuação da Tabela 3.19

\begin{tabular}{|c|c|c|c|c|c|c|}
\hline \multirow{3}{*}{$\begin{array}{c}t \\
(h)\end{array}$} & \multirow{3}{*}{$\begin{array}{c}x \\
(g / \ell)\end{array}$} & \multirow{3}{*}{$\begin{array}{c}S \\
(g / \ell)\end{array}$} & \multirow{3}{*}{$\begin{array}{c}S^{\prime} \\
(g / \ell)\end{array}$} & \multicolumn{3}{|c|}{$v(g A R T / g c \vec{e} 1 . m i n)$} \\
\hline & & & & \multicolumn{2}{|c|}{ Medidas } & \multirow{2}{*}{ Média } \\
\hline & & & & $1 \underline{a}$ & $2 \underline{a}$ & \\
\hline 42 & 1,23 & 5,9 & 15,5 & 0,108 & 0,708 & 0,108 \\
\hline 42,5 & 1,25 & - & - & 0,092 & 0,092 & 0,092 \\
\hline 43 & 1,25 & - & - & 0,081 & 0,070 & 0,075 \\
\hline 43,5 & 1,25 & - & - & 0,086 & 0,086 & 0,086 \\
\hline 44 & ], 25 & - & - & 0,081 & 0,075 & 0,078 \\
\hline 44,5 & 1,25 & - & - & 0,075 & 0,075 & 0,075 \\
\hline 45 & 1,24 & 4,0 & 15,1 & 0,104 & 0,104 & 0,104 \\
\hline
\end{tabular}

* Início do cultivo contínuo. 

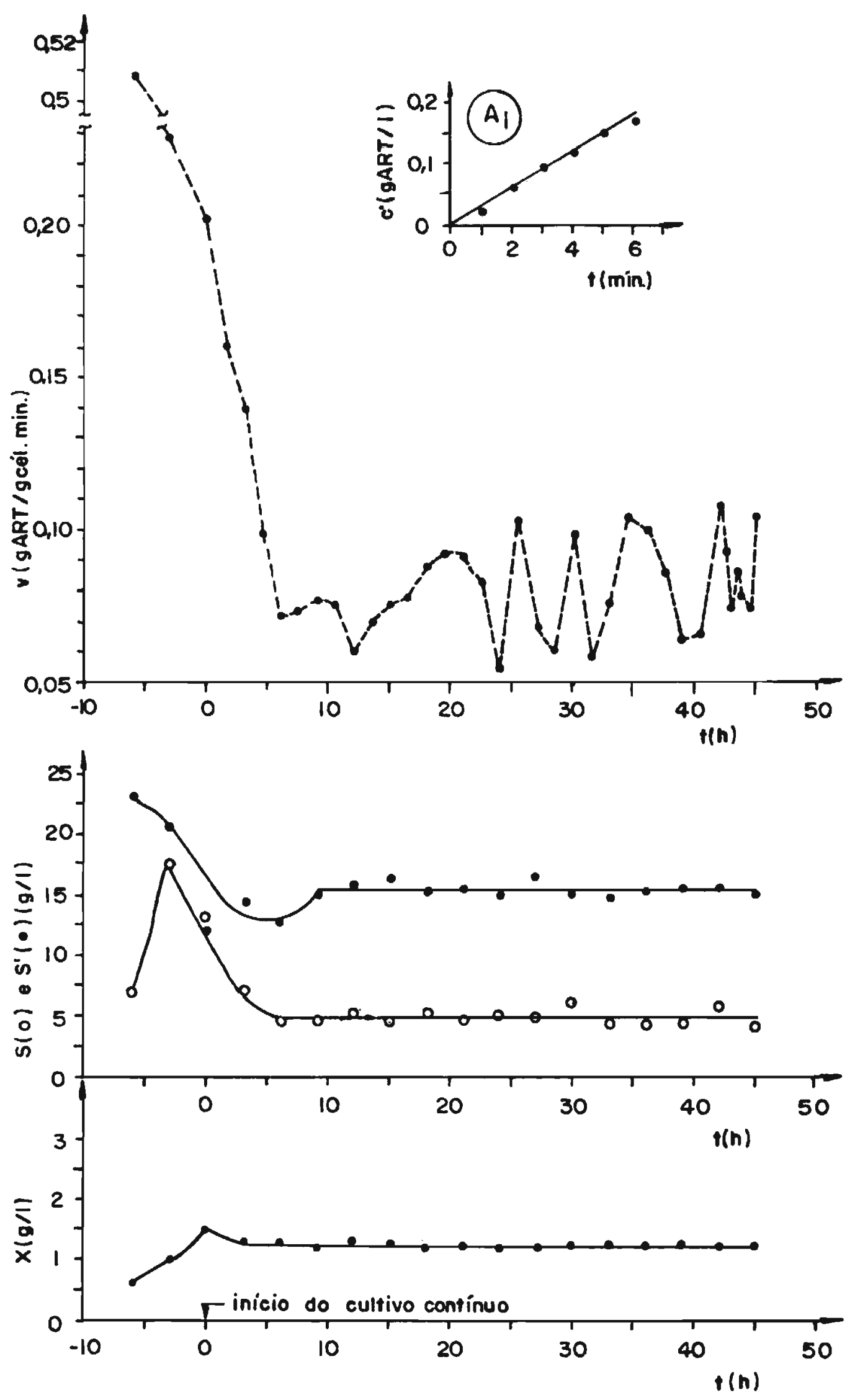

FIGURA 3.XI. Variação, com o tempo, da atividade invertāsica ( $v$ ) no das concentraçós de ART (S'), de AR (S) e de células concentração de $A \dot{R}^{A}$ (curva do gräfico $A_{1}$ mostra a variação da re o Ttem 2.5.4, usando cêlulas colhidas no instante $t=0 \mathrm{~h}$ (Eq.da curva: $\left.c^{\prime}=0,03 t-0,002 ; r=0,998\right)$. 


\section{5 .9 Ensaio no 9}

\section{a) Condições experimentais}

Nutrientes adicionados ao mosto: foram adicionados nutrientes conforme referido no jtem 2.1 .4 .

$$
\begin{aligned}
& S_{0}^{1}=28,4 \mathrm{~g} / \mathrm{l} \\
& S_{0}=6,1 \mathrm{~g} / \mathrm{l} \\
& \Phi=0 \text { (sem borbulhamento de ar) } \\
& F=770 \mathrm{ml} / \mathrm{h} \\
& D=0,26 \mathrm{~h}^{-1} \\
& V_{0 l}=6 \text { final de mosto na dorna }=3,0 \mathrm{l} \\
& N=500 \mathrm{~min}^{-1}
\end{aligned}
$$

\section{b) Resultados}

Os valores obtidos nas determinações de $X, A R$, ART e $v$ encontram-se na tabela 3.21 e figura $3 . X 11$.

Para o cālculo do AR e ART usou-se a equação:

$$
y=0,0036 x+0,015
$$

e para a medida do ART proveniente da atividade invertásica usou-se a equação:

$$
y=2,378 x+0,013(r=0,997)
$$

\section{c) Comentārios}

Da figura $3 . X I I$ nota-se que os periodos de oscila ção de $v$ entre os instantes $t=9 \mathrm{~h}$ e $t=51 \mathrm{~h}, 5 \mathrm{a}_{0}: 6 \mathrm{~h} ; 7 \mathrm{~h} ; 3,5 \mathrm{~h}$; $7,5 h ; 3 h ; 3 h ; 3 h ; 4,5 h ; 3,5 h$, sendo o período mēdio de $4,6 h$. 
0 coeficiente de variação de $v$ entre $t=9 \mathrm{~h}$ e $t=$ $51 \mathrm{~h} \overline{\mathrm{e}} 26,8 \%(\bar{v}=0,099 \mathrm{gART} / \mathrm{g}$ cēl.min e $\mathrm{s}=0,027 \mathrm{gART} / \mathrm{g} \quad$ cè 1 . min.).

A tabela 3.22 e a figura $3 . X I I$ (Gräfico $A_{1}$ ) mostram os dados referentes à velocidade de formação de ART em função do tempo para a amostra de cêlulas mais ativa obtida durante o processo contīnuo.

Com o intuito de evidenciar melhor o perfil da oscilação de $v$ foram feitas amostragens de meia em meia hora entre os instantes $t=48 \mathrm{~h}$ e $t=51 \mathrm{~h}$.

TABELA 3.22 Variação da concentração de ART pela ação de células colhidas no instante $t=1,5 \mathrm{~h}$ do ensaio nọ 9 (ver îtem 2.5.4).

\begin{tabular}{|c|c|c|c|}
\hline \multirow{3}{*}{$\begin{array}{c}t \\
(\min )\end{array}$} & \multicolumn{3}{|c|}{ Concentração de ART, $c^{\prime}(g / \ell)$} \\
\hline & \multicolumn{2}{|c|}{ Medidas } & \multirow{2}{*}{ Mëdia } \\
\hline & $1 \stackrel{a}{a}$ & $2 \underline{a}$ & \\
\hline 1 & 0,107 & 0,107 & 0,107 \\
\hline 2 & 0,213 & 0,215 & 0,214 \\
\hline 3 & $0,3] 9$ & 0,323 & 0,321 \\
\hline 4 & 0,427 & 0,429 & 0,428 \\
\hline 5 & 0,533 & 0,537 & 0,535 \\
\hline 6 & 0,640 & 0,644 & 0,642 \\
\hline
\end{tabular}


TABELA 3.21 Resultados obtidos no ensaio no 9.

\begin{tabular}{|c|c|c|c|c|c|c|}
\hline \multirow{3}{*}{$\begin{array}{c}t \\
(h)\end{array}$} & \multirow{3}{*}{$\begin{array}{c}x \\
(g / \ell)\end{array}$} & \multirow{3}{*}{$\begin{array}{c}S \\
(g / \ell)\end{array}$} & \multirow{3}{*}{$\begin{array}{c}S^{\prime} \\
(g / \ell)\end{array}$} & \multicolumn{3}{|c|}{$v(g A R T / g$ cél.min $)$} \\
\hline & & & & \multicolumn{2}{|c|}{ Medidas } & \multirow{2}{*}{ Média } \\
\hline & & & & & $2^{\underline{a}}$ & \\
\hline-6 & 0,7 & 7,6 & 22,5 & 0,422 & 0,432 & 0,427 \\
\hline-3 & 1,4 & 13,6 & 17,3 & 0,177 & 0,177 & 0,177 \\
\hline${ }^{\star}{ }_{0}$ & 2,34 & 2,5 & 2,3 & 0,332 & 0,332 & 0,332 \\
\hline 1,5 & 2,15 & - & - & 0,497 & 0,497 & 0,497 \\
\hline 3 & 2,13 & 3,7 & 4,6 & 0,351 & 0,344 & 0,347 \\
\hline 4,5 & 1,85 & - & - & 0,268 & 0,252 & 0,260 \\
\hline 6 & 1,85 & 4,3 & 7,4 & 0,222 & 0,215 & 0,218 \\
\hline 7,5 & 1,70 & - & - & 0,118 & 0,118 & 0,118 \\
\hline 9 & 1,71 & 3,8 & 8,9 & 0,117 & 0,126 & 0,122 \\
\hline 10,5 & 1,60 & - & - & 0,108 & 0,108 & 0,108 \\
\hline 12 & 1,67 & 3,9 & 9,6 & 0,087 & 0,095 & 0,091 \\
\hline 13,5 & 1,60 & - & - & 0,053 & 0,061 & 0,057 \\
\hline 15 & 1,63 & 3,2 & 11,3 & 0,115 & 0,123 & 0,119 \\
\hline 16,5 & 1,60 & - & - & 0,134 & 0,134 & 0,134 \\
\hline 18 & 1,63 & 4,3 & 10,5 & 0,124 & 0,124 & 0,124 \\
\hline 19,5 & 1,60 & - & - & 0,091 & 0,099 & 0,095 \\
\hline 21 & 1,62 & 3,6 & 10,9 & 0,098 & 0,090 & 0,094 \\
\hline 22,5 & 1,60 & - & - & 0,113 & 0,113 & 0,113 \\
\hline 24 & 1,63 & 3,8 & 10,7 & 0,046 & 0,046 & 0,046 \\
\hline 25,5 & 1,60 & - & - & 0,056 & 0,056 & 0,056 \\
\hline 27 & 1,68 & 3,4 & 11,1 & 0,103 & 0,111 & 0,107 \\
\hline 28,5 & 1,60 & - & - & 0,152 & 0,152 & 0,152 \\
\hline 30 & 1,59 & 3,4 & 10,8 & 0,126 & 0,126 & 0,126 \\
\hline 31,5 & 1,60 & - & - & 0,051 & 0,057 & 0,051 \\
\hline 33 & 1,54 & 3,3 & 10,9 & 0,085 & 0,094 & 0,090 \\
\hline 34,5 & 1,60 & - & - & 0,064 & 0,064 & 0,064 \\
\hline 36 & 1,51 & 3,3 & 11,0 & 0,105 & 0,096 & 0,101 \\
\hline 37,5 & 1,60 & - & - & 0,091 & 0,091 & 0,091 \\
\hline 39 & 1,51 & 3,0 & 9,9 & 0,096 & 0,096 & 0,096 \\
\hline
\end{tabular}


Continuação da Tabela 3.21

\begin{tabular}{|c|c|c|c|c|c|c|}
\hline \multirow{2}{*}{$\begin{array}{c}t \\
(h)\end{array}$} & \multirow{2}{*}{$\begin{array}{c}X \\
(g / \ell)\end{array}$} & \multirow{2}{*}{$\begin{array}{c}S \\
(g / l)\end{array}$} & \multirow{2}{*}{$\begin{array}{c}S^{\prime} \\
(g / \ell)\end{array}$} & \multicolumn{3}{|c|}{$v(g A R T / g \quad c \overrightarrow{e l} \cdot m i n)$} \\
\hline & & & & $\begin{array}{l}\text { Medi } \\
1 \underline{a} \\
\end{array}$ & $2^{a}$ & Mëdia \\
\hline 40,5 & 1,60 & - & - & 0,082 & 0,082 & 0,082 \\
\hline 43,5 & 1,56 & 3,7 & 11,0 & 0,129 & 0,129 & 0,129 \\
\hline 45 & 1,63 & 3,7 & 11,1 & 0,115 & 0,115 & 0,115 \\
\hline 46,5 & 1,60 & - & - & 0,117 & 0,117 & 0,117 \\
\hline 48 & 1,63 & 3,7 & 11,0 & 0,072 & 0,080 & 0,076 \\
\hline 48,5 & 1,60 & - & - & 0,064 & 0,064 & 0,064 \\
\hline 49 & 1,60 & - & - & 0,082 & 0,091 & 0,086 \\
\hline 49,5 & 1,60 & - & - & 0,091 & 0,091 & 0,091 \\
\hline 50 & 1,60 & - & - & 0,126 & 0,108 & 0,117 \\
\hline 50,5 & 1,60 & - & - & 0,117 & 0,108 & 0,113 \\
\hline 51 & 1,58 & 3,0 & 11,1 & 0,137 & 0,137 & 0,137 \\
\hline
\end{tabular}

* Início do cultivo contínuo. 

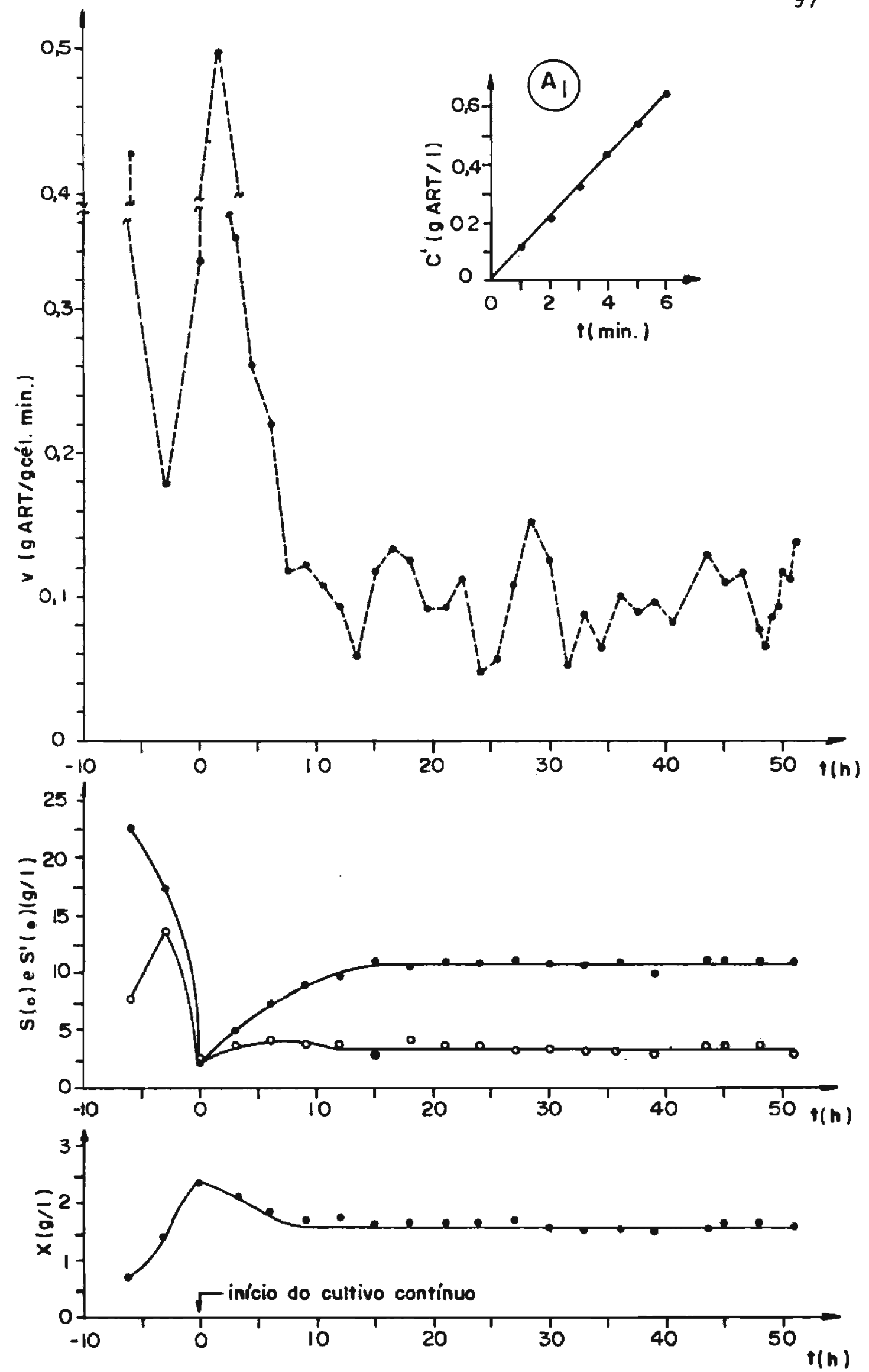

FIGURA 3.XII. Variação, com o tempo, da atividade invertāsjca (v) e das concentrações de ART ( $S^{\prime}$ ), de AR (S) e de células (X) no en saio nọ. A curva do gräfico A mostra a variação da concentração de ART ( $c^{\prime}$ ) com o tempo na medida a que se refere o item $2.5,4, u-$ sando celulas colhidas no instante $t=1,5 \mathrm{~h}$ (Eq.da curva: $c^{\prime}=0,108 \mathrm{t}-$ $-0,003 ; r=0,9995)$. 


\subsubsection{Ensaio do Inōculo}

a) Condiçöes experimentais

Conforme descrito no item 3.2. Outrossim, deve ser mencionado que o inōculo foi preparado com meio não suple mentado e com meio acrescido dos seguintes nutrientes: $\mathrm{Na}_{2} \mathrm{HPO}_{4} \cdot 12 \mathrm{H}_{2} \mathrm{O} 2,4 \mathrm{~g} / \mathrm{\ell} ; \mathrm{MgSO}_{4} \cdot 7 \mathrm{H}_{2} \mathrm{O} 0,075 \mathrm{~g} / \mathrm{\ell}$ e $\left(\mathrm{NH}_{4}\right)_{2} \mathrm{SO}_{4}$ $5,1 \mathrm{~g} / \mathrm{l}$.

\section{b) Resultados}

Os valores obtidos nas determinaçōes de $X$ e $v$ encontram-se na tabela 3.23 .

Para a medidado ART, proveniente da atividade invertásica usou-se a equação:

$$
y=2,407 x+0,0071 \quad(r=0,9998)
$$

\section{c) Comentārios}

Neste ensaio foram utilizados 10 frascos de $1 \ell$, dos quajs retiraram-se amostras de $10 \mathrm{ml}$ para a medida da concentração celular e da atividade invertäsica. 0 tempo total de processo foi de $22 \mathrm{~h}$.

$$
\text { o objetivo deste ensaio foi o de se ter uma }
$$

idëia de como o inóculo se encontrava ao ser introduzido na dorna. 


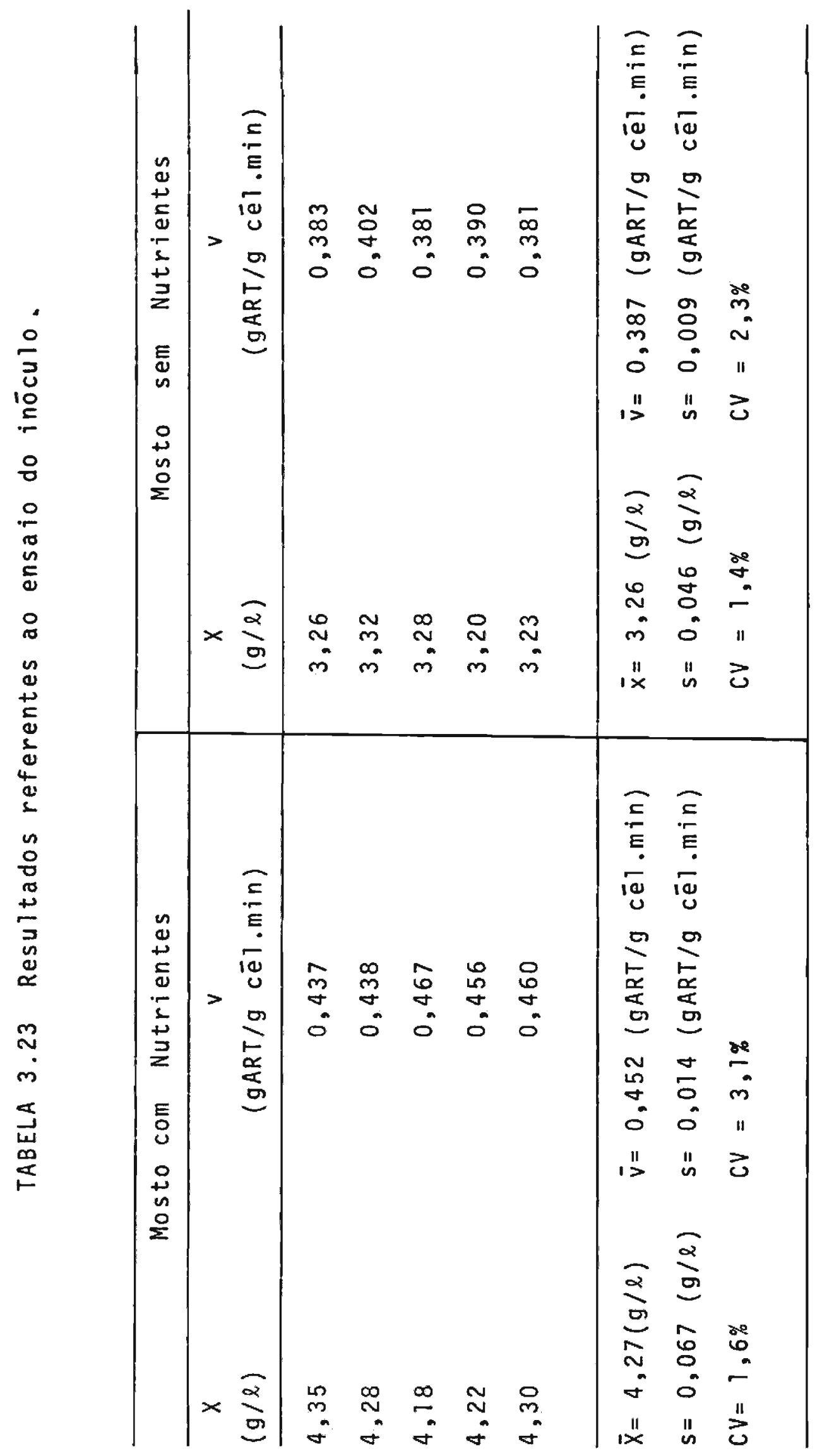




\section{5 .11 Ensaio no 10}

a) Condições experimentais

$$
\begin{aligned}
& S_{0}^{\prime}=31,5 \mathrm{~g} / \mathrm{l} \\
& S_{0}=6,6 \mathrm{~g} / \mathrm{l} \\
& F=713 \mathrm{ml} / \mathrm{h} \\
& D=0,23 \mathrm{~h}^{-1}
\end{aligned}
$$

Volume final de mosto na dorna $=3,10$ l

$\Phi=1 \ell / \ell \cdot \min$

$N=500 \mathrm{~min}^{-1}$

b) Resultados

Os valores obtidos nas determinações de $X, A R$, ART e $v$ encontram-se na tabela 3.24 e figuras 3 .XIIIa-b.

Para o cālculo do AR e ART utilizou-se a equação:

$$
y=0,0036 x+0,015
$$

e para a medida do ART, proveniente da atividade invertāsica usou-se a equação:

$$
y=2,382 x+0,027 \quad(r=0,998)
$$

\section{c) Comentārios}

0 processo continuo entre os instantes $t=0 \mathrm{~h}$ e $t=19 \mathrm{~h}$ foi executado com mosto não suplementado, sendo as con dições de ensaio muito prōximas daquelas do ensaio nọ 4. Apōs - instante $t=19 \mathrm{~h}$ foram adicionados, de uma só vez à dorna (perturbação por impulso), os sais: $\mathrm{Na}_{2} \mathrm{HPO}_{4} \cdot 12 \mathrm{H}_{2} \mathrm{O} \quad 2,4 \mathrm{~g} / \ell$, $\mathrm{MgSO}_{4} \cdot 7 \mathrm{H}_{2} \mathrm{O} \quad 0,075 \mathrm{~g} / \ell$ e $\left(\mathrm{NH}_{4}\right)_{2} \mathrm{SO}_{4} 5,1 \mathrm{~g} / \ell$. A operação foi 
repetida mais très vezes a intervalos de $12 \mathrm{~h}$. Este ensaio, para efeito de anālise, serā subdividido em 5 etapas (considerando apenas o processo contínuol a saber:

1 etapa $(t=0 h$ atē $t=19 h):$ o coeficiente de variação de $\underline{v} \bar{e}$ $63,2 \%\langle\bar{v}=0,038 \mathrm{gART} / \mathrm{g}$ cēl.min; s=0,024 gART/g cēl. min), sendo os perīodos de oscilação de $v$ iguais a: $4,5 \mathrm{~h} ; 4 \mathrm{~h} ; 6 \mathrm{~h}$ (período mēdio $=4,8 \mathrm{~h}$ ).

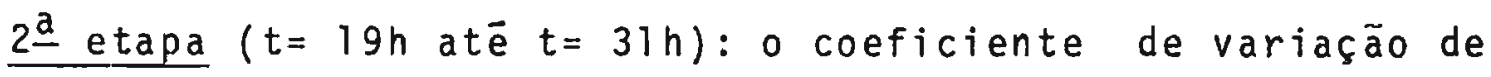
$v \bar{e} 44,7 \%(\bar{v}=0,038 \mathrm{gART} / \mathrm{g}$ céel.min e $s=0,017$ gART/g c cél.min).

$3 \underline{a}$ etapa $(t=31 \mathrm{~h}$ ate $t=43 \mathrm{~h}):$ o coeficiente de variação de $v \bar{e} 51,1 \%(\bar{v}=0,045 \mathrm{gART} / \mathrm{g}$ cée $1 . \mathrm{min}$ e $s=0,023$ gART/g cēit.min).

4 a etapa $(t=43 h$ até $t=55 h):$ o coeficiente de variação de $v \bar{e} 36,3 \%(\bar{v}=0,055 \mathrm{gART} / \mathrm{g}$ cé $1 . \mathrm{min}$ e $\mathrm{s}=0,021$ gART/g cé̀ 1 min).

5ㅡ etapa $(t=55 h$ até $t=66 h):$ o coeficiente de variação de $v \bar{e} 51.5 \% \quad(\bar{v}=0,036 \mathrm{gART} / \mathrm{g}$ cêl.min e $s=0,020$ gART/g cềl.min).

Ressalte-se, outrossim, que cada impulso foi efetuado 3 min após ter sido retirada a ūitima amostra de cada etapa.

Considerando o tempo global de fermentação contínua, obtēm-se os seguintes períodos de oscilação de $v: 4,5 \mathrm{~h}$; $4 h ; 6 h ; 5 h ; 6 h ; 3 h ; 5,5 h ; 9 h ; 3 h ; 4,5 h ; 4,5 h ; 3 h ; 3 h$, sendo 0 periodo mëdio de $4,7 \mathrm{~h}$. 


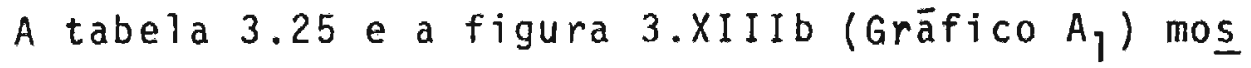
tram os dados referentes à formação de ART em função do tem po para a amostra de cêlulas mais ativa obtida durante o pro cesso continuo.

TABELA 3.25 Variação da concentração de ART pela ação de células colhidas no instante $t=0 h$ do ensaio no 10 (ver item 2.5.4).

\begin{tabular}{|c|c|c|c|}
\hline \multirow{3}{*}{$\begin{array}{c}t \\
(\min )\end{array}$} & \multicolumn{3}{|c|}{ Concentração de ART, $c^{\prime}(g / \ell)$} \\
\hline & \multicolumn{2}{|c|}{ Medidas } & \multirow{2}{*}{ Média } \\
\hline & $1 \underline{a}$ & $2 \underline{a}$ & \\
\hline 1 & 0,035 & 0,035 & 0,035 \\
\hline 2 & $0,0.67$ & 0,067 & 0,067 \\
\hline 3 & 0,099 & 0,102 & 0,101 \\
\hline 4 & 0,135 & 0,135 & 0,135 \\
\hline 5 & 0,169 & 0,167 & 0,168 \\
\hline 6 & 0,206 & 0,204 & 0,205 \\
\hline
\end{tabular}


TABELA 3.24. Resultados obtidos no ensaio no 10.

\begin{tabular}{|c|c|c|c|c|c|c|c|}
\hline \multirow{3}{*}{ Etapa } & \multirow{3}{*}{$\begin{array}{c}t \\
(h)\end{array}$} & \multirow{3}{*}{$\begin{array}{c}x \\
(g / \ell)\end{array}$} & \multirow{3}{*}{$\begin{array}{c}S \\
(g / \ell)\end{array}$} & \multirow{3}{*}{$\begin{array}{c}S^{\prime} \\
(g / \ell)\end{array}$} & \multicolumn{3}{|c|}{$v(g A R T / g \quad c \vec{e} 1 . m i n)$} \\
\hline & & & & & \multicolumn{2}{|c|}{ Medidas } & \multirow[b]{2}{*}{ Mēdia } \\
\hline & & & & & $1 \underline{a}$ & 2 a & \\
\hline \multirow{2}{*}{ Desc. } & -6 & 0,60 & 6,1 & 25,4 & 0,511 & 0,523 & 0,517 \\
\hline & -3 & 1,07 & 17,7 & 22,5 & 0,232 & 0,225 & 0,229 \\
\hline \multirow{13}{*}{$1 \underline{a}$} & ${ }^{*} 0$ & 1,63 & 15,0 & 15,5 & 0,210 & 0,202 & 0,206 \\
\hline & 1,5 & 1,45 & - & - & 0,063 & 0,072 & 0,068 \\
\hline & 3 & 1,34 & 11,8 & 19,7 & 0,078 & 0,078 & 0,078 \\
\hline & 4,5 & 1,27 & - & - & 0,083 & 0,083 & 0,083 \\
\hline & 6 & 1,33 & 9,1 & 20,8 & 0,027 & 0,027 & 0,027 \\
\hline & 7,5 & 1,27 & - & - & 0,037 & 0,037 & 0,037 \\
\hline & 9 & 1,27 & 7,7 & 21,5 & 0,014 & 0,014 & 0,014 \\
\hline & 10,5 & 1,27 & - & - & 0,014 & 0,014 & 0,014 \\
\hline & 12 & 1,22 & 6,8 & 21,9 & 0,026 & 0,026 & 0,026 \\
\hline & 13,5 & 1,27 & - & - & 0,047 & 0,047 & 0,047 \\
\hline & 15 & 1,24 & 6,2 & 21,7 & 0,020 & 0,020 & 0,020 \\
\hline & 16,5 & 1,27 & - & - & 0,022 & 0,022 & 0,022 \\
\hline & 19 & 1,29 & 7,6 & 21,8 & 0,057 & 0,052 & 0,054 \\
\hline \multirow{7}{*}{$2 \underline{a}$} & 21 & 1,32 & 6,0 & 21,4 & 0,016 & 0,016 & 0,016 \\
\hline & 22,5 & 1,35 & - & - & 0,023 & 0,023 & 0,023 \\
\hline & 24 & 1,39 & 5,9 & 20,3 & 0,058 & 0,058 & 0,058 \\
\hline & 25,5 & 1,50 & - & - & 0,051 & 0,070 & 0,061 \\
\hline & 27 & 1,70 & 5,9 & 18,8 & 0,037 & 0,037 & 0,037 \\
\hline & 28,5 & 1,80 & - & - & 0,043 & 0,043 & 0,043 \\
\hline & 30 & 1,82 & 6,2 & 16,9 & 0,019 & 0,019 & 0,019 \\
\hline \multirow{7}{*}{$3 \stackrel{a}{-}$} & 31,5 & 1,80 & 6,9 & 17,3 & 0,043 & 0,050 & 0,047 \\
\hline & 33 & 1,85 & 7,0 & 16,5 & 0,034 & 0,041 & 0,038 \\
\hline & 34,5 & 1,80 & - & - & 0,020 & 0,020 & 0,020 \\
\hline & 36 & 1,82 & 6,2 & 17,1 & 0,019 & 0,019 & 0,019 \\
\hline & 39 & 1,96 & 4,7 & 16,6 & 0,039 & 0,039 & 0,039 \\
\hline & 40,5 & 2,00 & - & - & 0,053 & 0,053 & 0,053 \\
\hline & 42 & 2,04 & 7,5 & 14,9 & 0,065 & 0,072 & 0,069 \\
\hline
\end{tabular}


Continuação da Tabela 3.24

\begin{tabular}{|c|c|c|c|c|c|c|c|}
\hline \multirow{3}{*}{ Etapa } & \multirow{3}{*}{$\begin{array}{c}t \\
(h)\end{array}$} & \multirow{3}{*}{$\begin{array}{c}x \\
(g / l)\end{array}$} & \multirow{3}{*}{$\begin{array}{c}S \\
(g / \ell)\end{array}$} & \multirow{3}{*}{$\begin{array}{c}S^{\prime} \\
(g / l)\end{array}$} & \multicolumn{3}{|c|}{$v(g A R T / g$ cél.min $)$} \\
\hline & & & & & \multicolumn{2}{|c|}{ Medidas } & \multirow{2}{*}{ Mēdia } \\
\hline & & & & & $1 \stackrel{a}{a}$ & $2 \underline{a}$ & \\
\hline \multirow{8}{*}{$4 \stackrel{a}{-}$} & 43,5 & 2,10 & - & - & 0,083 & 0,070 & 0,077 \\
\hline & 45 & 2,17 & 5,7 & 13,9 & 0,016 & 0,016 & 0,016 \\
\hline & 46,5 & 2,20 & - & - & 0,054 & 0,054 & 0,054 \\
\hline & 48 & 2,21 & 5,8 & 14,2 & 0,054 & 0,048 & 0,051 \\
\hline & 49,5 & 2,20 & - & - & 0,079 & 0,073 & 0,076 \\
\hline & 51 & 2,23 & 5,4 & 11,8 & 0,053 & 0,059 & 0,057 \\
\hline & 52,5 & 2,20 & - & - & 0,041 & 0,041 & 0,041 \\
\hline & 54 & 2,11 & 6,9 & 13,6 & 0,083 & 0,083 & 0,083 \\
\hline \multirow{8}{*}{$5 \stackrel{a}{a}$} & 55,5 & 2,00 & - & - & 0,060 & 0,060 & 0,060 \\
\hline & 57 & 1,90 & 7,3 & 15,9 & 0,019 & 0,019 & 0,019 \\
\hline & 58,5 & 1,85 & - & - & 0,034 & 0,034 & 0,034 \\
\hline & 60 & 1,85 & 7,3 & 16,8 & 0,019 & 0,019 & 0,019 \\
\hline & 61,5 & 1,90 & - & - & 0,041 & 0,041 & 0,041 \\
\hline & 63 & 2,02 & 4,7 & 15,4 & 0,017 & 0,017 & 0,017 \\
\hline & 64,5 & 2,10 & - & - & 0,054 & 0,059 & 0,057 \\
\hline & 66 & 2,20 & 6,4 & 13,4 & 0,067 & 0,067 & 0,067 \\
\hline
\end{tabular}

* Início do cultivo contínuo 


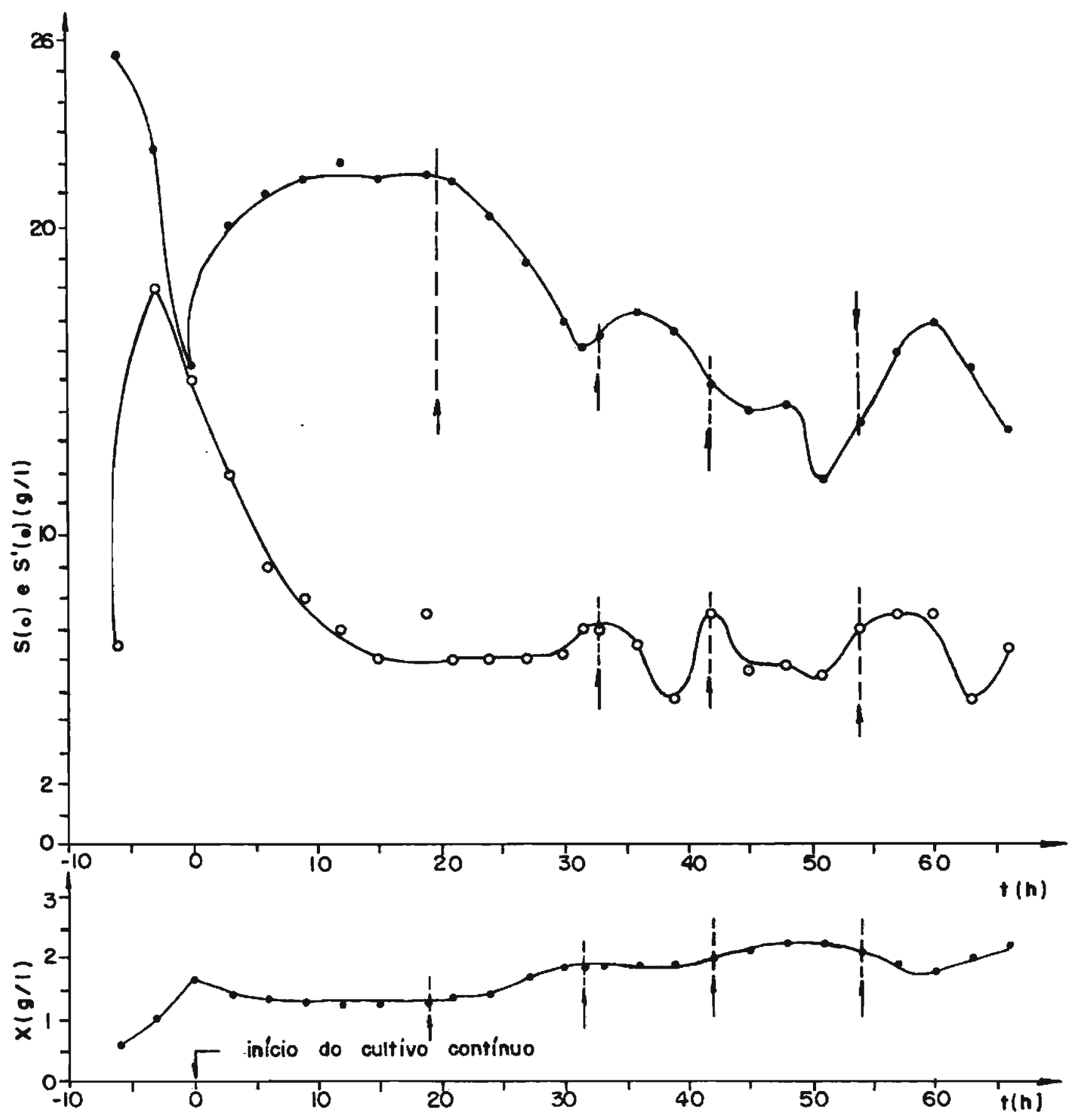

FIGURA 3.XIIIa. Variação, com o tempo, das concentrações de ART (S'), de AR (S) e de células (X) no ensaio no 10 . As setas indicam os momentos em que foram realizadas as perturbações por impuiso. 


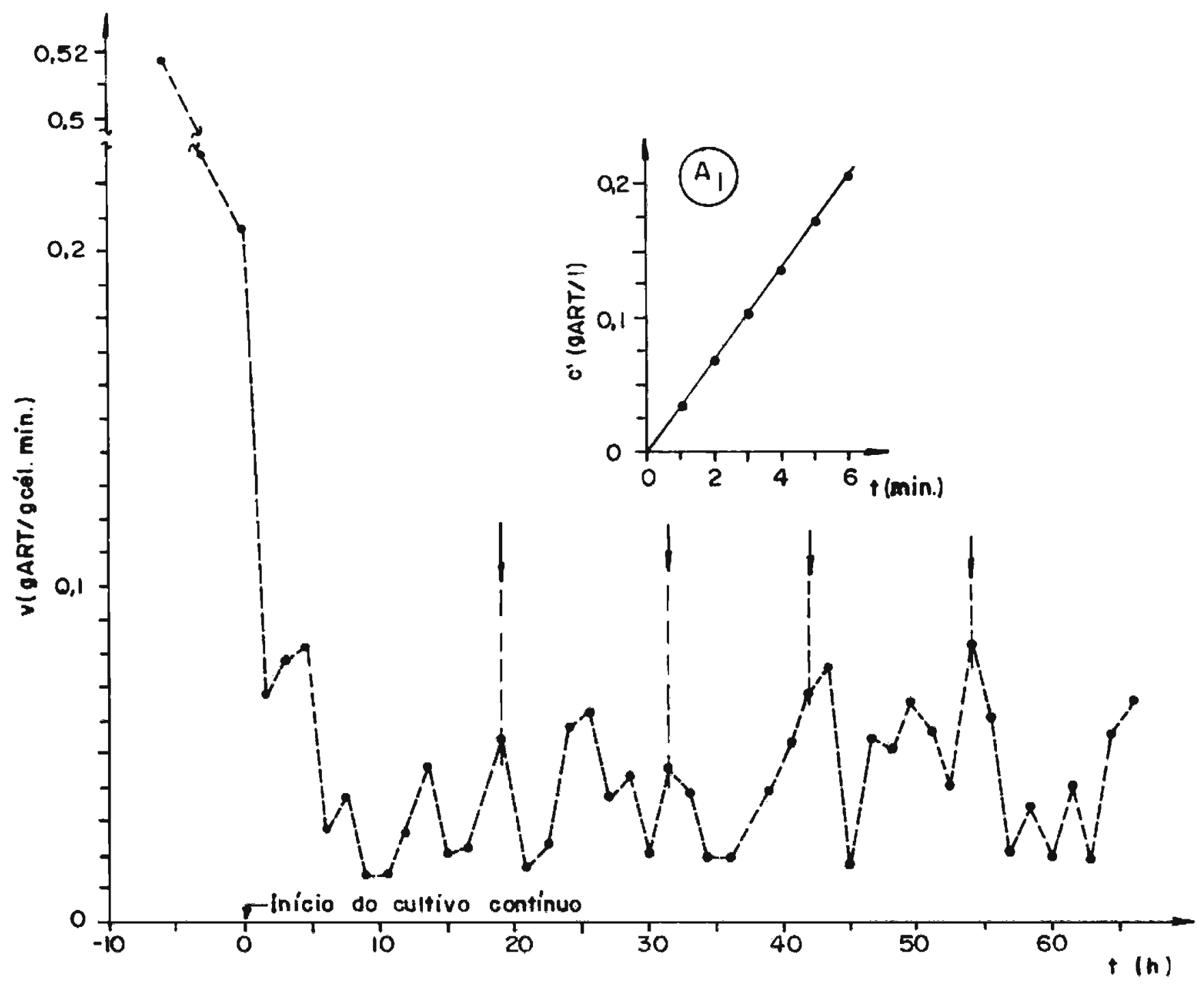

FIGURA 3.XIIIb. Variaçäo, com o tempo, da atividade invertāsi ca ( $v$ ) no ensaio nolo. A curva do gráfico $A \vec{T}$ mostra a variação da concentração de ART ( $\left.c^{\prime}\right)$ com o tempo na medida a que se refere 0 t tem 2.5 .4 , usando células coinidas no instante $t=0 \mathrm{~h}$ ( $\mathrm{Eq}$. da curva: $c^{\prime}=0,034 \mathrm{t}-0,0008$; $r=0,9998)$. As setas indicam os momentos em que foram rea1izadas as perturbações por impulso. 


\subsubsection{Ensaio n! 11}

\section{a) Condições experimentais}

Nutrientes adicionados ao mosto: $\mathrm{Na}_{2} \mathrm{HPO}_{4} \cdot 12 \mathrm{H}_{2} \mathrm{O}$ $2,4 \mathrm{~g} / \ell ; \mathrm{MgSO}_{4} \cdot 7 \mathrm{H}_{2} \mathrm{O} 0,075 \mathrm{~g} / \mathrm{l}$ e $\left(\mathrm{NH}_{4}\right)_{2} \mathrm{SO}_{4}$ $5,1 \mathrm{~g} / 2$.

$$
\begin{aligned}
& S_{0}^{\prime}=29,5 \mathrm{~g} / \mathrm{l} \\
& \mathrm{S}_{0}=5,7 \mathrm{~g} / \mathrm{l} \\
& F=729 \cdot \mathrm{ml} / \mathrm{h} \\
& D=0,24 \mathrm{~h}^{-1} \\
& \Phi=2 \mathrm{l} / \mathrm{l} \cdot \mathrm{min}
\end{aligned}
$$

Volume final de mosto na dorna $=3,10 \mathrm{l}$ $N=700 \mathrm{~min}^{-1}$

\section{b) Resultados}

Os valores obtidos nas determinações de $X, A R$, ART e $v$ encontram-se nas tabelas 3.26 e 3.27 e nas figuras 3.XIV, 3.XV e 3.XVI.

$$
\begin{aligned}
& \text { Para o cālculo do AR e ART utilizou-se a equação: } \\
& y=0,0036 x+0,015 \quad(3, \text { XIII })
\end{aligned}
$$

e para a medida do ART, proveniente da atividade invertásica usou-se a equação:

$$
\begin{aligned}
& y=2,248 x+0,039 \quad(r=0,9994) \\
& \text { c) Comentārios }
\end{aligned}
$$

Da figura $3 . X V$ constata-se que os períodos de os cilação de $v$ entre os instantes $t=15 \mathrm{~h}$ e $t=60 \mathrm{~h}$, são: $3 \mathrm{~h} ; 6 \mathrm{~h}$; 
$7 \mathrm{~h} ; 8 \mathrm{~h} ; 6 \mathrm{~h} ; 9 \mathrm{~h}$, sendo o perỉodo médio de $6,5 \mathrm{~h}$.

0 coeficiente de variação de $v$ entre os instantes $t=15 \mathrm{~h}$ e $t=60 \mathrm{~h} \bar{e} 36,7 \%(\bar{v}=0,148 \mathrm{gART} / \mathrm{g}$ c $\bar{e} 1 . \mathrm{min}$ e $\mathrm{s}=$ $0,054 \mathrm{gART} / \mathrm{g}$ (è) $\mathrm{lmin}$ ).

Entre os instantes $t=48 \mathrm{~h}$ e $t=51 \mathrm{~h}$ de processo continuo foram feitas amostragens de $10 \mathrm{em} 10 \mathrm{~min}$, conforme descrito em 2.4.2. O objetivo disto foi acompanhar o valor da atividade invertāsica em intervalos de tempo menores. 0 intervalo utilizado correspondeu ao menor tempo possivel entre a retirada e a lavagem de duas amostras consecutivas nas nossas condições de trabalho. Ressalte-se, outrossim, que os valores de $v$ determinados neste caso näo podem ser comparados aos demais valores de $v$ do ensaio, pois para a sua determinação foi utilizada a massa de cēlulas úmidas.

A partir do instante $t=75 \mathrm{~h}$ suspendeu-se a alimentação de mosto $\bar{a}$ dorna, deixando-se em regime descontīnuo atè o final do ensaio. o objetivo desta ültima etapa foi verificar se, após longo periodo de processo contínuo, as con diçōes iniciais, tanto de concentraçäo de cēlulas quanto de atividade invertásica, seriam restabelecidas.

Neste ensaio as amostragens foram feitas de 3 em $3 \mathrm{~h}$. Contudo, durante dois periodos näo consecutivos de $9 \mathrm{~h}$ de duração $(t=18 \mathrm{~h} \overline{\mathrm{a}} t=27 \mathrm{~h}$ e $t=66 \mathrm{~h} \overline{\mathrm{a}} \mathrm{t}=75 \mathrm{~h})$ foram co1 hidas amostras de 1,5 em $1,5 \mathrm{~h}$ com o objetivo de obter dados do perfil da oscilação de $v$ comparāveis aos de outros ensaios.

o gräfico 3.XVIA mostra o perfil da oscilaçäo de v para amostras colhidas de 10 em $10 \mathrm{~min} 0$ gräfico 3.XVIB e a tabela 3.28 mostram os dados referentes ä formação de ART 
em função do tempo para a amostra de cētulas mais ativa obtida entre os instantes $t=48 \mathrm{~h}$ e $t=51 \mathrm{~h}$.

O gräfico $3 . X V I C$ e a tabela 3.29 mostram os dados referentes à formação de ART em função do tempo para a amostra de cēlulas mais ativa obtida durante o processo contínuo. 
TABELA 3.26 Resultados obtidos no ensaio no 11 .

\begin{tabular}{|c|c|c|c|c|c|c|}
\hline \multirow{2}{*}{$\begin{array}{c}t \\
(h)\end{array}$} & \multirow{2}{*}{$\begin{array}{c}x \\
(g / \ell)\end{array}$} & \multirow{2}{*}{$\begin{array}{c}S \\
(g / \ell)\end{array}$} & \multirow{2}{*}{$\begin{array}{c}S^{\prime} \\
(g / \ell)\end{array}$} & \multicolumn{3}{|c|}{$v(g / A R T / g$ cēl.min $)$} \\
\hline & & & & $\begin{array}{l}\text { Medi } \\
1 \underline{a}\end{array}$ & $2 a$ & Mèdia \\
\hline-6 & 1,02 & 6,8 & 22,7 & 0,284 & 0,274 & 0,279 \\
\hline-3 & 1,72 & 15,2 & 17,1 & 0,175 & 0,182 & 0,179 \\
\hline$*^{0} 0$ & 3,84 & 2,5 & 2,9 & 0,366 & 0,377 & 0,372 \\
\hline 3 & 4,46 & 1,6 & 2,0 & 1,02 & 1,02 & 1,02 \\
\hline 6 & 4,23 & 2,5 & 2,7 & 0,791 & 0,791 & 0,791 \\
\hline 9 & 3,94 & 3,8 & 4,4 & 0,497 & 0,511 & 0,504 \\
\hline 12 & 3,69 & 4,5 & 4,7 & 0,283 & 0,283 & 0,283 \\
\hline 15 & 3,59 & 3,8 & 4,6 & 0,219 & 0,219 & 0,219 \\
\hline 18 & 3,46 & 4,6 & 5,3 & 0,216 & 0,227 & 0,222 \\
\hline 19,5 & 3,40 & - & - & 0,231 & 0,220 & 0,226 \\
\hline 21 & 3,51 & 4,5 & 5,0 & 0,150 & 0,150 & 0,150 \\
\hline 22,5 & 3,40 & - & - & 0,166 & 0,155 & 0,160 \\
\hline 24 & 3,37 & 4,1 & 5,6 & 0,145 & 0,134 & 0,140 \\
\hline 25,5 & 3,40 & - & - & 0,187 & 0,198 & 0,193 \\
\hline 27 & 3,32 & 4,2 & 6,0 & 0,228 & 0,228 & 0,228 \\
\hline 30 & 3,35 & 4,5 & 6,6 & 0,102 & 0,091 & 0,096 \\
\hline 33 & 3,67 & 4,5 & 6,7 & 0,164 & 0,153 & 0,159 \\
\hline 36 & 3,34 & 4,6 & 6,4 & 0,113 & 0,124 & 0,119 \\
\hline 39 & 2,95 & 4,5 & 6,4 & 0,128 & 0,128 & 0,128 \\
\hline 42 & 3,17 & 5,1 & 6,1 & 0,179 & 0,179 & 0,179 \\
\hline 43,5 & 3,40 & - & - & 0,141 & 0,133 & 0,137 \\
\hline 45 & 3,47 & 4,1 & 6,2 & 0,120 & 0,130 & 0,125 \\
\hline 47 & 3,47 & 4,8 & 6,2 & 0,130 & 0,130 & 0,130 \\
\hline 51 & 3,40 & 4,0 & 5,8 & 0,122 & 0,111 & 0,117 \\
\hline 54 & 3,50 & 4,4 & 6,9 & 0,150 & 0,150 & 0,150 \\
\hline 57 & 3,17 & 4,9 & 7,1 & 0,055 & 0,055 & 0,055 \\
\hline 60 & 3,26 & 4,7 & 7,5 & 0,025 & 0,025 & 0,025 \\
\hline 63 & 3,03 & 4,3 & 7,0 & 0,027 & 0,027 & 0,027 \\
\hline
\end{tabular}


Continuação da Tabela 3.26

\begin{tabular}{lcccccc}
\hline & & & & \multicolumn{3}{c}{$v(g$ ART/g cél.min $)$} \\
\cline { 5 - 7 }$(\mathrm{h})$ & $(\mathrm{g} / \mathrm{l})$ & $(\mathrm{g} / \mathrm{l})$ & $(\mathrm{g} / \mathrm{l})$ & \multicolumn{2}{c}{ Medidas } & Mēdia \\
& & & & $\mathrm{a}$ & $2-$ & \\
\hline 66 & 2,98 & 5,0 & 6,6 & 0,102 & 0,102 & 0,102 \\
67,5 & 3,00 & - & - & 0,126 & 0,126 & 0,126 \\
69 & 2,96 & 4,9 & 6,6 & 0,078 & 0,090 & 0,084 \\
70,5 & 2,95 & - & - & 0,128 & 0,116 & 0,122 \\
72 & 2,81 & 4,9 & 8,3 & 0,108 & 0,108 & 0,108 \\
73,5 & 2,65 & - & - & 0,059 & 0,072 & 0,066 \\
75 & 2,52 & 6,8 & 9,7 & 0,076 & 0,076 & 0,076 \\
78 & 3,77 & 0,9 & 1,4 & 0,759 & 0,759 & 0,759 \\
81 & 4,38 & 0,9 & 1,3 & 0,746 & 0,746 & 0,746
\end{tabular}

* Início do cultivo contínuo 
TABELA 3.27 Atividade invertāsica de amostras obtidas a intervalos de $10 \mathrm{~min}$, durante o ensaio n911.

\begin{tabular}{|c|c|c|c|c|}
\hline \multirow{3}{*}{$\begin{array}{c}\mathrm{t} \\
(\min )\end{array}$} & \multirow{3}{*}{$\begin{array}{c}m^{\prime} \\
(g)\end{array}$} & \multicolumn{3}{|c|}{$v(g A R T / g$ cél.min $)$} \\
\hline & & \multicolumn{2}{|c|}{ Medidas } & \multirow{2}{*}{ Mēdia } \\
\hline & & $1 \stackrel{a}{-}$ & $2^{a}$ & \\
\hline * 0 & 0,25 & 0,032 & 0,032 & 0,032 \\
\hline 10 & 0,23 & 0,027 & 0,027 & 0,027 \\
\hline 20 & 0,23 & 0,032 & 0,030 & 0,031 \\
\hline 30 & 0,19 & 0,044 & 0,042 & 0,043 \\
\hline 40 & 0,24 & 0,030 & 0,029 & 0,030 \\
\hline 50 & 0,20 & 0,031 & 0,031 & 0,031 \\
\hline 60 & 0,24 & 0,030 & 0,030 & 0,030 \\
\hline 70 & 0,20 & 0,029 & 0,031 & 0,030 \\
\hline 80 & 0,20 & 0,034 & 0,034 & 0,034 \\
\hline 90 & 0,24 & 0,031 & 0,029 & 0,030 \\
\hline 100 & 0,21 & 0,043 & 0,041 & 0,042 \\
\hline 110 & 0,20 & 0,040 & 0,040 & 0,040 \\
\hline 720 & 0,21 & 0,034 & 0,032 & 0,033 \\
\hline 130 & 0,21 & 0,033 & 0,033 & 0,033 \\
\hline 140 & 0,20 & 0,044 & 0,044 & 0,044 \\
\hline 150 & 0,24 & 0,031 & 0,031 & 0,031 \\
\hline 160 & $0,20$. & 0,047 & 0,047 & 0,047 \\
\hline 170 & 0,23 & 0,036 & 0,036 & 0,036 \\
\hline
\end{tabular}

$m^{\prime}=$ massa de cēlulas ümidas

* = instante correspondente a $t=48 \mathrm{~h}$ de cultivo contínuo 
TABELA 3.28 Variação da concentração de ART pela ação de células colnidas no instante $t=51 \mathrm{~h}$ do ensaio no 11 (ver itens 2.5.4 e 2.4.2)

\begin{tabular}{|c|c|c|c|}
\hline \multirow{3}{*}{$\stackrel{t}{t}$} & \multicolumn{3}{|c|}{ Concentração de ART, $c^{\prime}(g / \ell)$} \\
\hline & \multicolumn{2}{|c|}{ Medidas } & \multirow[t]{2}{*}{ Mēdia } \\
\hline & $1 \underline{a}$ & $2 \underline{a}$ & \\
\hline 1 & 0,024 & 0,024 & 0,024 \\
\hline 2 & 0,047 & 0,047 & 0,047 \\
\hline 3 & 0,070 & 0,072 & 0,071 \\
\hline 4 & 0,094 & 0,094 & 0,094 \\
\hline 5 & 0,117 & 0,119 & 0,118 \\
\hline 6 & 0,139 & 0,143 & 0,141 \\
\hline
\end{tabular}

TABELA 3.29 Variação da concentração de ART pela ação de células colhidas no instante $t=3 \mathrm{~h}$ do ensaio no 11 (ver item 2.5.4)

\begin{tabular}{|c|c|c|c|}
\hline \multirow{3}{*}{$\begin{array}{c}t \\
(m i n)\end{array}$} & \multicolumn{3}{|c|}{ Concentração de ART, $c^{\prime}(g / \ell)$} \\
\hline & \multicolumn{2}{|c|}{ Medidas } & \multirow{2}{*}{ Mēdia } \\
\hline & $1 \underline{\underline{a}}$ & $2 \underline{a}$ & \\
\hline 1 & 0,182 & 0,184 & 0,183 \\
\hline 2 & 0,368 & 0,364 & 0,366 \\
\hline 3 & 0,552 & 0,544 & 0,548 \\
\hline 4 & 0,731 & 0,737 & 0,731 \\
\hline 5 & 0,910 & 0,918 & 0,914 \\
\hline 6 & 1,09 & 1,11 & 1,10 \\
\hline
\end{tabular}




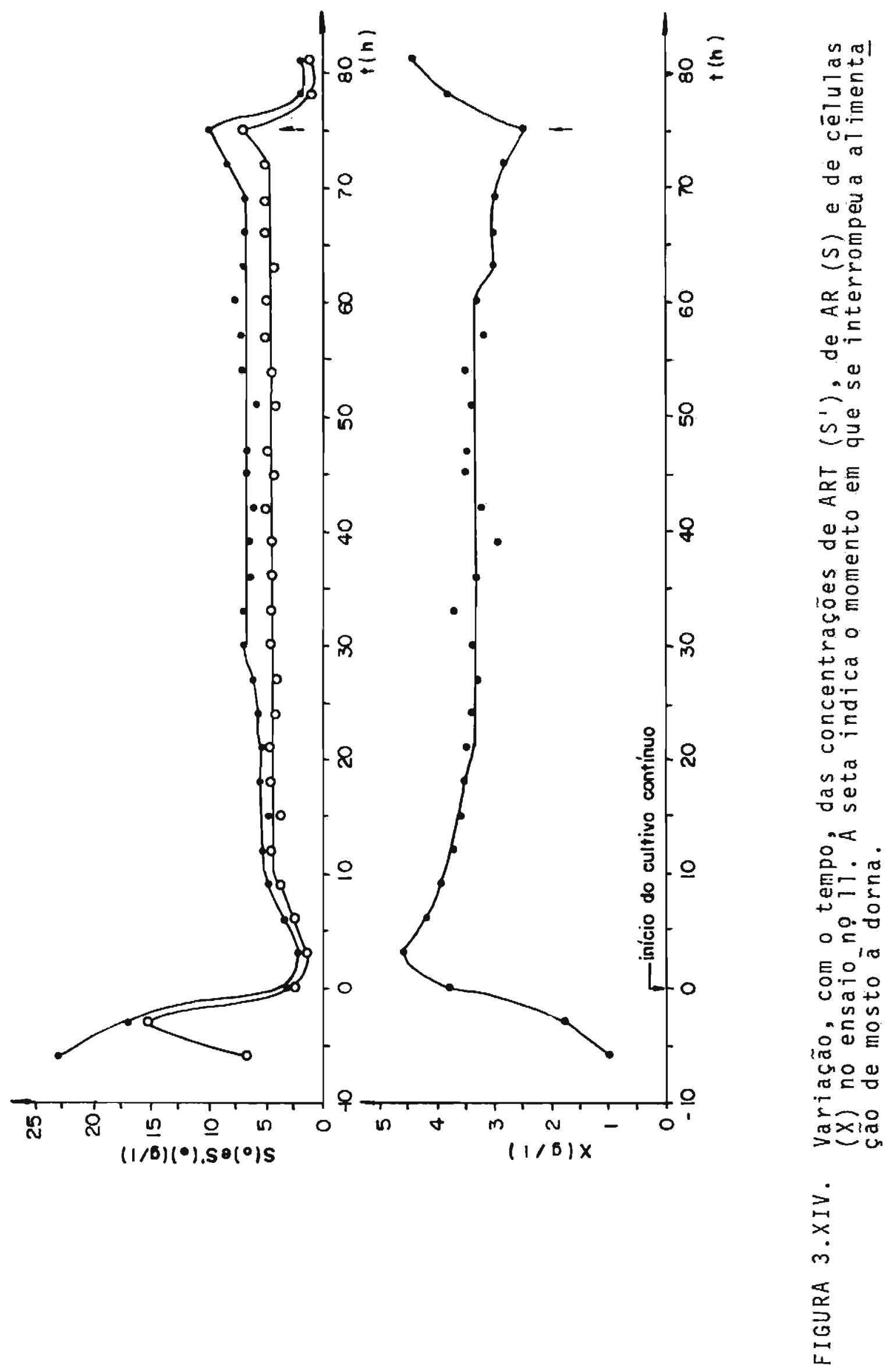




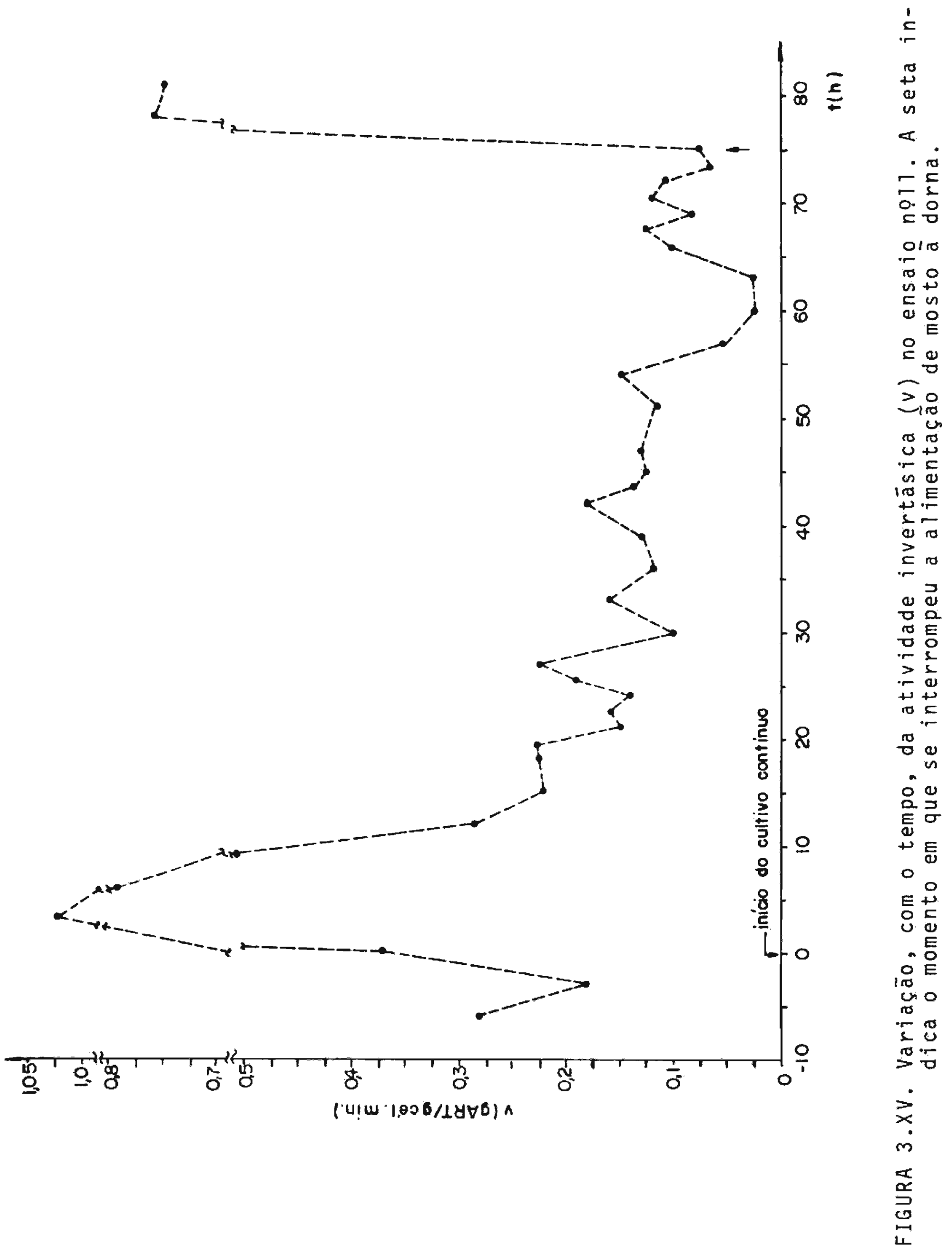




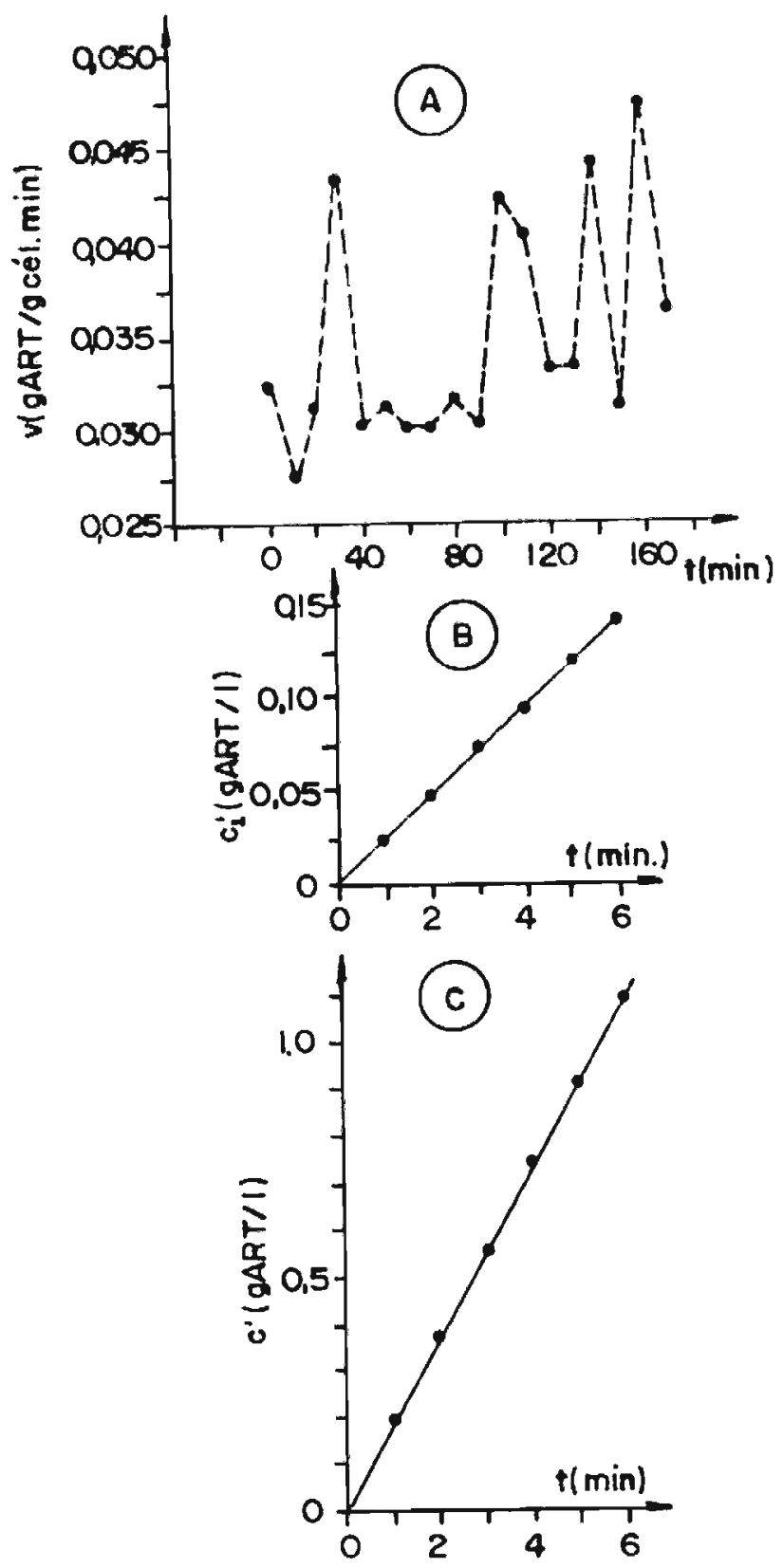

FIGURA 3.XVI. O gräfico A mostra o perfil da oscilação de v pa ra as amostras colhidas de 10 em $10 \mathrm{~min}$ entre os instantes $t=48 \mathrm{~h}$ e $t=51 \mathrm{~h}$. O gráfico B mostra a variaçāo da concentraçāo de ART ( $\left.c^{\prime} 1\right)$ com o tempo usando cēlulas colhidas no instante $t=51 \mathrm{~h}$, sen do a amostragem feita de 10 em $10 \mathrm{~min}$ (Eq.da cur va: $\left.c^{\prime} j=0,024 t+0,0003 ; r=0,998\right)$. 0 gräfico $\bar{c}$ mostra a varjação da concentração de ART ( $\left.c^{\prime}\right)$ com o tempo usando cēlulas colhidas no instante $t=$ $3 h$ (Eq.da curva: $\left.c^{\prime}=0,184 t-0,005 ; r=0,9990\right)$. 


\subsection{Ensaio en cultivo descontínuo}

3.6.1 Ensaio no 12
a) Condições experimentais

Nutrientes adicionados ao mosto: $\mathrm{Na}_{2} \mathrm{HPO}_{4} \cdot 12 \mathrm{H}_{2} \mathrm{O}$

$$
\begin{aligned}
& 2,4 \mathrm{~g} / \ell ; \mathrm{MgSO}_{4} \cdot 7 \mathrm{H}_{2} \mathrm{O} 0,075 \mathrm{~g} / \ell \text { e }\left(\mathrm{NH}_{4}\right)_{2} \mathrm{SO}_{4} \\
& 5,1 \mathrm{~g} / \mathrm{l} . \\
& \mathrm{S}_{0}^{\prime}=30,4 \mathrm{~g} / \ell \\
& \mathrm{S}_{0}=6,2 \mathrm{~g} / \mathrm{l} \\
& \Phi=2 \mathrm{l} / \mathrm{l} \cdot \mathrm{min} \\
& \mathrm{N}=500 \mathrm{~min}^{-1} \\
& \mathrm{~F}=0 \text { (cultivo descontinuo) } \\
& \text { b) Resultados }
\end{aligned}
$$

Os valores obtidos nas determinações de $X$, $A R$, ART e $v$ encontram-se na tabela 3.30 e figura $3 . X V I I$.

Para o cālculo do AR e ART utilizou-se a equação:

$$
y=0,0034 x-0,0039
$$

e para a medida do ART proveniente da atividade invertásica usou-se a equação:

$$
\begin{aligned}
& y=2,111 x+0,045 \quad(r=0,994) \\
& \text { c) Comentārios }
\end{aligned}
$$

A figura 3.XVII e a tabela 3.31 mostram os dados referentes à formação de ART em função do tempo para a amostra de células mais ativa obtida durante o processo des continuo. 
TABELA 3.30 Resultados obtidos no ensaio no 12.

\begin{tabular}{|c|c|c|c|c|c|c|}
\hline \multirow{3}{*}{$\begin{array}{c}t \\
(h)\end{array}$} & \multirow{3}{*}{$\begin{array}{c}x \\
(g / \ell)\end{array}$} & \multirow{3}{*}{$\begin{array}{c}S \\
(g / l)\end{array}$} & \multirow{3}{*}{$\begin{array}{c}S^{\prime} \\
(g / \ell)\end{array}$} & \multicolumn{3}{|c|}{$v(g A R T / g$ cét.min $)$} \\
\hline & & & & \multicolumn{2}{|c|}{ Medidas } & \multirow{2}{*}{ Média } \\
\hline & & & & $T \underline{a}$ & $2 \underline{a}$ & \\
\hline 0 & 0,84 & 10,3 & 25,0 & 0,529 & 0,558 & 0,544 \\
\hline 0,5 & 0,95 & - & - & 0,647 & 0,631 & 0,639 \\
\hline 1 & 1,20 & 17,6 & 22,5 & 0,481 & 0,481 & 0,481 \\
\hline 1,5 & 1,30 & - & - & 0,943 & 0,852 & 0,890 \\
\hline 2 & 1,43 & 15,5 & 21,3 & 0,278 & 0,278 & 0,278 \\
\hline 2,5 & 1,95 & - & - & 0,184 & 0,184 & 0,184 \\
\hline 3 & 2,53 & 16,3 & 17,6 & 0,141 & 0,141 & 0,141 \\
\hline 3,5 & 2,85 & - & - & 0,115 & 0,115 & 0,115 \\
\hline 4 & 3,17 & 11,6 & 11,7 & 0,103 & 0,094 & 0,100 \\
\hline 4,5 & 3,80 & - & - & 0,110 & 0,110 & 0,110 \\
\hline 5 & 4,20 & 4,6 & 5,1 & 0,205 & 0,205 & 0,205 \\
\hline 5,5 & 4,50 & - & - & 0,640 & 0,640 & 0,640 \\
\hline 6 & 4,86 & 1,2 & 1,5 & 0,744 & 0,744 & 0,744 \\
\hline 6,5 & 5,00 & - & - & 0,664 & 0,664 & 0,664 \\
\hline 7 & 5,16 & - & - & 0,697 & 0,681 & 0,690 \\
\hline 7,5 & 5,25 & - & - & 0,734 & 0,723 & 0,728 \\
\hline 8 & 5,34 & - & - & 0,655 & 0,688 & 0,672 \\
\hline
\end{tabular}


TABELA 3.31 Variação da concentração de ART pela ação de células colhidas no instante $t=1,5 \mathrm{~h}$ do ensaio no 12 (ver item 2.5.4)

\begin{tabular}{|c|c|c|c|}
\hline \multirow{3}{*}{$\begin{array}{c}t \\
(\min )\end{array}$} & \multicolumn{3}{|c|}{ Concentração de ART, $c^{\prime}(g / \ell)$} \\
\hline & \multicolumn{2}{|c|}{ Medidas } & \multirow{2}{*}{ Média } \\
\hline & $1 \underline{a}$ & $2 \stackrel{a}{-}$ & \\
\hline 1 & 0,047 & 0,047 & 0,047 \\
\hline 2 & 0,092 & 0,094 & 0,093 \\
\hline 3 & 0,140 & 0,140 & 0,140 \\
\hline 4 & 0,189 & 0,185 & 0,187 \\
\hline 5 & 0,232 & 0,234 & 0,233 \\
\hline 6 & 0,278 & 0,282 & 0,280 \\
\hline
\end{tabular}



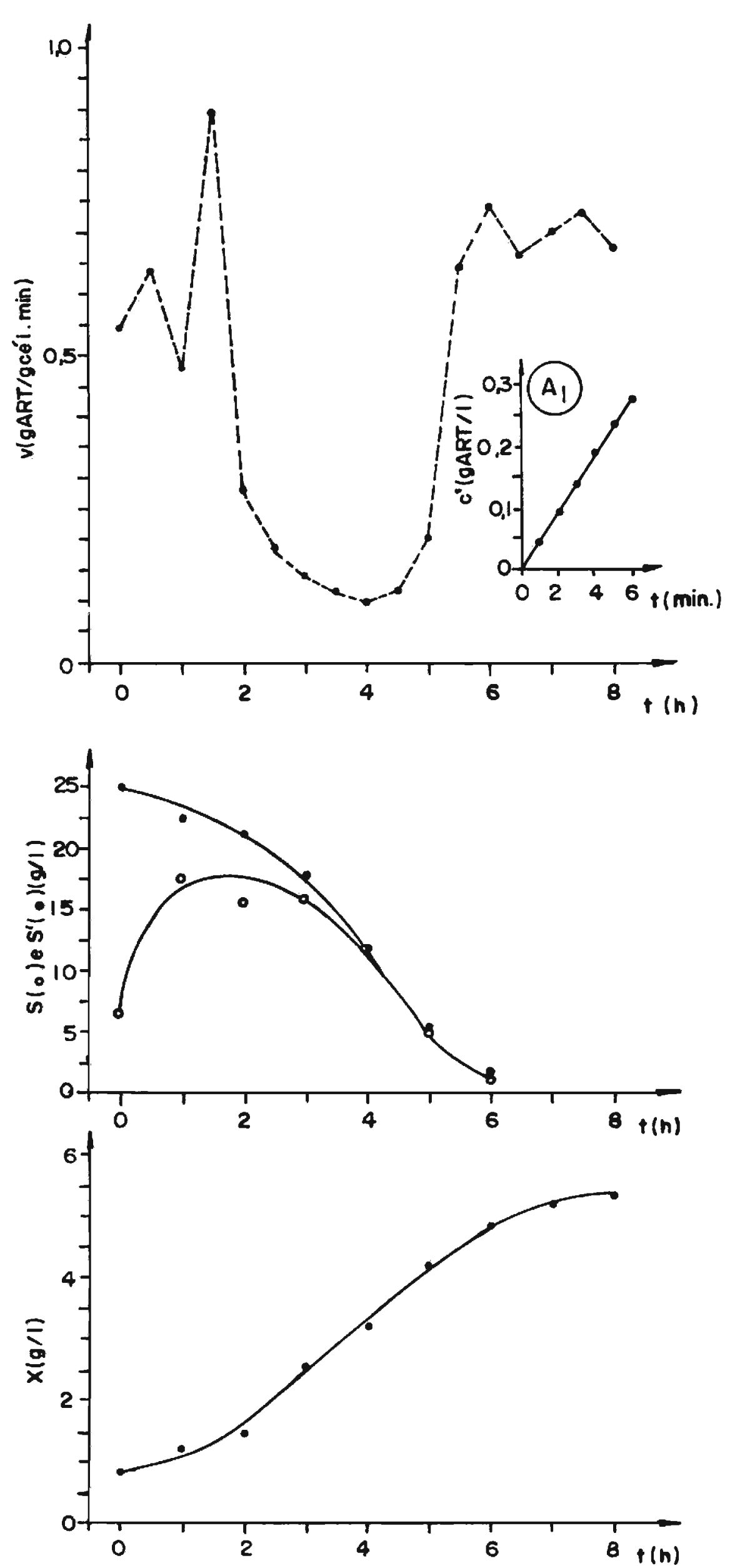

FIGURA 3. XVII. Variação, com o tempo, da atividade invertásica (V) e das concentrações de ART ( $S^{\prime}$ ), de $A R$ (S) e de células (X) no ensaio nQ12. A curva do gräfico A] mostra a variaçäo da concentração de ART ( $c^{\prime}$ ) com o tempo na medida a que se refere o Ttem 2.5.4, usando células colhidas no instante $t=1,5 \mathrm{~h}$ (Eq.da curva: $c^{\prime}=0,047 t-0,002$; $r=0,9998$ ). 


\subsection{ENSAIO DO INOCULO}

Pela anālise da tabela 3.23 verifica-se que o inōculo preparado com meio suplementado apresenta uma concentração celular mēdia $(\bar{x})$ e uma atividade invertásica específica média $(\bar{v})$, respectivamente 1,3 e 1,2 vezes superior às do inōculo preparado em meio de cultura não suplementado. Este resultado vem de encontro ao fato, jā bem estabelecido, de que cēlulas crescidas em meio enriquecido têm sua atividade metabō lica incrementada.

Outrossim, verifica-se que os coeficientes de variação para $\bar{x}$ de cēlulas crescidas em meio suplementado e não suplementado são, respectivamente, $1,6 \%$ e $1,4 \%$, enquanto que para $\bar{v}$ tem-se, respectivamente, $3,1 \%$ e $2,3 \%$. Isto indica que as diferenças encontradas entre os ensaios com e sem nutri entes são devidas, apenas, à diferente constituição dos meios de cultura.

Seria interessante, neste momento, verificar se os valores de $X$ e de $v$, medidos logo apōs a inoculação da dorna nos vārios ensaios fermentativos realizados, guardam alguma relação com os mostrados acima. Para tanto elaborou-se a tabela 4.1, que mostra os valores de $x$ e de $v$ medidos na amos tra colhida no instante $t=-6 \mathrm{~h}$ em cada um dos ensaios realiza dos. Para facilitar a anālise, os doze ensaios foram dividi dos em dois grupos, conforme o mosto utilizado tenha ou não 
TABELA 4.1 Determinação da concentração celular $(X)$ e da atividade invertāsica específica ( $V$ ) de amos tras colhidas no instante $t=-6 \mathrm{~h}$ para todos os ensaios de cultivo contínuo.

\begin{tabular}{|c|c|c|c|c|c|c|c|}
\hline \multicolumn{4}{|c|}{ Mosto não Suplementado } & \multicolumn{4}{|c|}{ Mos to Suplementado } \\
\hline $\begin{array}{c}\text { Ensaio } \\
\text { ne }\end{array}$ & $\begin{array}{c}x \\
(g / l)\end{array}$ & (gART/g & $\begin{array}{l}v \\
\text { cêp } 1 \cdot \min )\end{array}$ & $\begin{array}{c}\text { Ensaio } \\
\text { no }\end{array}$ & $\begin{array}{c}x \\
(g / \ell)\end{array}$ & (gART /g & $\begin{array}{l}v \\
\text { cél.min) }\end{array}$ \\
\hline 1 & - & & - & 6 & 0,84 & & 611 \\
\hline 2 & 0,58 & 0 , & 596 & 7 & 1,02 & & 782 \\
\hline 3 & 0,52 & 0 , & 580 & 9 & 0,70 & & 427 \\
\hline 4 & 0,57 & 0 , & 660 & 11 & 1,02 & & 279 \\
\hline 5 & 0,67 & 0 , & 727 & 12 & 0,84 & & 544 \\
\hline 8 & 0,58 & 0 , & 508 & & & & \\
\hline 10 & 0,60 & 0 , & 517 & & & & \\
\hline & $\bar{x}=0,5$ & $9(g / l)$ & & & $\bar{x}=0$, & $8(g / \ell)$ & \\
\hline & $s=0,0$ & $49(g / l)$ & & & $s=0$, & $4(g / l)$ & \\
\hline C & $V=8,3$ & $\%$ & & & $V=15$ & & \\
\hline
\end{tabular}


sido suplementado. De imediato nota-se que $\bar{x}$ para o grupo em que se usou mosto suplementado é cerca de 1,5 vezes supe rior ao $\bar{X}$ do outro grupo. Este resultado está bem próximo ao apurado através da tabela 3.23 .

Com relação à atividade invertāsica específica os dados obtidos são discrepantes, ressaltando-se que, a menos do ensajo no 11 , os valores de $v$ para o instante $t=$ $-6 \mathrm{~h}$, são superiores aos mostrados na tabela 3.23 . No momen to não temos explicação para este fato. Mais adiante propor-se-à uma hipōtese para tentar explicar a oscilação de $v$ com o tempo, que foi observada durante os ensajos de cultivo continuo e, a partir dela, talvez se possa tirar alguma idéia que permita compreender melhor o resultado ora encontrado.

\subsection{ERRO EXPERIMENTAL NA DOSAGEM DO ART PELO METODO DE SOMOGYI}

Pela tabela 3.2 verifica-se que o coeficiente de variação das medidas da concentração de ART é igual a $2,7 \%$, inferior portanto ao 1 imite tolerado para o erro expe rimental en mëtodos espectrofotomētricos, que ē de 5\% (46).

\subsection{INTERFERENCIA DA PRESENÇA DE CELULAS NA DETERMINAÇAOO DO ART}

A tabela 3.3 mostra claramente que a presen ça de células na concentração de $0,33 \mathrm{~g} / \ell$ não interfere na determinação do ART. 


\subsection{INFLUENCIA DO CONSUMO DE AÇOCARES PELAS CELULAS NA DETERMINAÇAOO DO ART}

Da tabela 3.4 depreende-se que a influencia do consumo de açūcares pelas células na determinação do ART não è mensurāvel pelo método analitico utilizado.

\subsection{ENSAIOS EM CULTIVO CONTINUO}

\subsubsection{Ensaios com borbulhamento de ar e com mosto não} suplementado

\subsubsection{Ensaio nọ 1}

Examinando as figuras 3 . I I e 4 .I I depre ende-se que as condições experimentais utilizadas ( $F=312$ $\mathrm{ml} / \mathrm{h} ; \mathrm{D}=0,11 \mathrm{~h}^{-1} ; \Phi=1 \mathrm{\ell} / \mathrm{\ell} \cdot \mathrm{min} \mathrm{e} N=500 \mathrm{~min}^{-1}$ ) conduziram a um regime transiente durante $54 \mathrm{~h}$ de processo contínuo.

As figuras $4 . I$ e $4 . I$, cujos dados são apresen tados na tabela 4.2, mostram o comportamento de $\mu_{S}, \mu, \mu_{\left(S^{\prime}-S\right)}$ e $\mu X$ em função do tempo.

Comparando os perfis de $\mu_{S}, \mu\left(S^{\prime}-S\right)$ e $v$ entre sí a partir do instante $t=10 \mathrm{~h}$, nota-se claramente que são diferentes. 0 que mais chama a atenção $\bar{e}$ a diferença entre as curvas de $\mu\left(S^{\prime}-S\right)$ e $v$ que, teoricamente, deveriam apresentar alguma correlação, jă que a cểula, para se multiplicar nas condições do ensaio, necessita converter a sacarose do mosto em açūcares fermentescīveis, somente podendo fazé-lo mediante a ação da invertase que ela possui em sua parede celular. 
Ajustando-se retas pelo método dos mínimos quadrados aos pontos dos grāficos $\mu x=f(t)$ e $v=f(t)$ a partir de $t=15 \mathrm{~h}$, obtém-se respectivamente, os seguintes coeficientes de correlação $(r): 0,81$ e 0,96 . os valores criticos de $r$ (99\% de probabilidade) são, respectivamente, 0,39 e $0,66(32)$. Destes dados depreende-se que tanto a atividade invertásica específica como a produtividade em células são funções crescentes do tempo a partir de $t=15 \mathrm{~h}$.

Outrossim, destaca-se que o valor de $v$, apōs apresentar acentuada variação entre os instantes $t=0 \mathrm{~h}$ e $t=12 \mathrm{~h}$, passa a oscilar, sendo o período de oscilação mé dio de $7,8 \mathrm{~h}$ (Fig. 3.IIb). 
TABELA 4.2 Velocidades especificas de consumo de AR, de con sumo de sacarose, de crescimento celular e produtividade em células para o ensaio no 1.

\begin{tabular}{|c|c|c|c|c|c|c|c|}
\hline $\begin{array}{c}t \\
\text { (h) }\end{array}$ & $\begin{array}{c}x \\
(g / \ell)\end{array}$ & $\begin{array}{c}S \\
(g / \ell)\end{array}$ & $\begin{array}{c}S^{\prime} \\
(g / \ell)\end{array}$ & $\begin{array}{r}\left(S^{\prime}-S\right) \\
\left(h^{-1}\right)\end{array}$ & $\begin{array}{c}{ }^{\mu} S \\
\left(h^{-1}\right)\end{array}$ & $\begin{array}{c}\mu \\
\left(h^{-1}\right)\end{array}$ & $\begin{array}{c}\mu X \\
(g / \ell \cdot h)\end{array}$ \\
\hline 0 & 1,70 & 16,4 & 17,8 & 1,313 & 1,235 & 0,135 & 0,230 \\
\hline 1 & 1,75 & 15,6 & 17,0 & 1,275 & 1,248 & 0,149 & 0,261 \\
\hline 2 & 1,85 & 14,8 & 16,2 & 1,206 & 1,135 & 0,160 & 0,296 \\
\hline 3 & 1,95 & 14,3 & 15,5 & 1,145 & 1,037 & 0,157 & 0,306 \\
\hline 4 & 2,05 & 13,8 & 15,0 & 1,089 & 0,960 & 0,155 & 0,318 \\
\hline 5 & 2,15 & 13,5 & 14,9 & 1,008 & 0,833 & 0,153 & 0,329 \\
\hline 6 & 2,25 & 13,3 & 14,5 & 0,940 & 0,760 & 0,150 & 0,338 \\
\hline 7 & 2,35 & 13,1 & 14,5 & 0,915 & 0,730 & 0,149 & 0,350 \\
\hline 8 & 2,45 & 13,0 & 14,5 & 0,876 & 0,683 & 0,143 & 0,350 \\
\hline 9 & 2,53 & 12,9 & 14,5 & 0,839 & 0,656 & 0,136 & 0,344 \\
\hline 10 & 2,60 & 12,8 & 14,5 & 0,848 & 0,655 & 0,135 & 0,351 \\
\hline 11 & 2,68 & 12,8 & 14,4 & 0,872 & 0,685 & 0,130 & 0,348 \\
\hline $12^{-}$ & 2,73 & 12,7 & 14,2 & 0,895 & 0,733 & 0,124 & 0,339 \\
\hline 13 & 2,78 & 12,6 & 13,5 & 0,895 & 0,758 & 0,119 & 0,331 \\
\hline 14 & 2,80 & 12,4 & 13,0 & 0,885 & 0,757 & 0,110 & 0,308 \\
\hline 15 & 2,80 & 12,3 & 13,2 & 0,881 & 0,739 & 0,106 & 0,297 \\
\hline 16 & 2,80 & 12,2 & 12,8 & 0,869 & 0,748 & 0,110 & 0,308 \\
\hline 17 & 2,82 & 12,0 & 12,5 & 0,851 & 0,790 & 0,115 & 0,324 \\
\hline 18 & 2,85 & 11,6 & 12,3 & 0,822 & 0,796 & 0,117 & 0,333 \\
\hline 19 & 2,88 & 11,3 & 11,8 & 0,797 & 0,765 & 0,115 & 0,331 \\
\hline 20 & 2,90 & 11,0 & 11,5 & 0,771 & 0,733 & וו1 & 0,322 \\
\hline 21 & 2,91 & 10,8 & 11,4 & 0,772 & 0,742 & 0,111 & 0,323 \\
\hline 22 & 2,93 & 10,5 & 11,1 & 0,778 & 0,758 & 0,118 & 0,346 \\
\hline 23 & 2,98 & 10,3 & 10,9 & 0,776 & 0,747 & 0,118 & 0,352 \\
\hline 24 & 3,00 & 10,1 & 10,7 & 0,782 & 0,744 & 0,113 & 0,339 \\
\hline 25 & 3,02 & 10,0 & 10,5 & 0,781 & 0,730 & 0,119 & 0,359 \\
\hline 26 & 3,08 & 9,9 & 10,4 & 0,783 & 0,736 & 0,119 & 0,367 \\
\hline 27 & 3,10 & 9,8 & 10,3 & 0,789 & 0,730 & 0,111 & 0,344 \\
\hline
\end{tabular}


Continuação da Tabela 4.2

\begin{tabular}{|c|c|c|c|c|c|c|c|}
\hline $\begin{array}{c}t \\
(h)\end{array}$ & $\begin{array}{c}x \\
(g / l)\end{array}$ & $\begin{array}{c}S \\
(g / 2,)\end{array}$ & $\begin{array}{c}S^{\prime} \\
(g / \ell)\end{array}$ & $\begin{array}{r}\mu\left(S^{\prime}-S\right) \\
\left(h^{-1}\right)\end{array}$ & $\begin{array}{c}\mu_{S} \\
\left(h^{-1}\right)\end{array}$ & $\begin{array}{c}\mu \\
\left(h^{-1}\right)\end{array}$ & $\begin{array}{c}\mu x \\
(g / i . h)\end{array}$ \\
\hline 28 & 3,11 & 9,8 & 10,0 & 0,782 & 0,707 & 0,109 & 0,339 \\
\hline 29 & 3,12 & 9,8 & 10,0 & 0,768 & 0,693 & 0,112 & 0,349 \\
\hline 30 & 3,15 & 9,8 & 10,0 & - & - & 0,111 & 0,350 \\
\hline 31 & 3,15 & 9,8 & 10,0 & 0,739 & 0,665 & 0,106 & 0,334 \\
\hline 32 & 3,15 & 9,8 & 10,0 & 0,702 & 0,628 & 0,106 & 0,334 \\
\hline 33 & 3,15 & 9,8 & 10,0 & 0,660 & 0,634 & 0,106 & 0,334 \\
\hline 34 & 3,15 & 9,5 & 10,0 & 0,646 & 0,707 & 0,111 & 0,350 \\
\hline 35 & 3,18 & 9,0 & 10,0 & 0,641 & 0,720 & 0,114 & 0,363 \\
\hline 36 & 3,20 & 8,7 & 9,9 & 0,687 & 0,712 & 0,114 & 0,365 \\
\hline 37 & 3,23 & 8,6 & 9,7 & 0,736 & 0,734 & 0,118 & 0,381 \\
\hline 38 & 3,28 & 8,5 & 9,3 & 0,759 & 0,776 & 0,117 & 0,384 \\
\hline 39 & 3,30 & 8,3 & 8,7 & 0,757 & 0,810 & 0,117 & 0,386 \\
\hline 40 & 3,35 & 8,0 & 8,6 & 0,732 & 0,764 & 0,113 & 0,379 \\
\hline 41 & 3,35 & 8,0 & 8,5 & 0,725 & 0,712 & 0,106 & 0,355 \\
\hline 42 & 3,35 & 8,0 & 8,3 & 0,720 & 0,708 & 0,106 & 0,355 \\
\hline 43 & 3,35 & 8,0 & 8,3 & 0,707 & 0,695 & 0,106 & 0,355 \\
\hline 44 & 3,35 & 8,0 & 8,3 & 0,681 & 0,668 & 0,110 & 0,369 \\
\hline 45 & 3,38 & 8,0 & 8,3 & 0,641 & 0,671 & 0,110 & 0,372 \\
\hline 46 & 3,38 & 7,7 & 8,3 & 0,636 & 0,707 & 0,109 & 0,368 \\
\hline 47 & 3,40 & 7,5 & 8,0 & 0,658 & 0,760 & 0,109 & 0,371 \\
\hline 48 & 3,40 & 7,0 & 7,7 & 0,690 & 0,841 & 0,109 & 0,371 \\
\hline 49 & 3,42 & 6,6 & 7,2 & 0,711 & 0,859 & 0,112 & 0,383 \\
\hline 50 & 3,44 & 6,2 & 6,6 & 0,714 & 0,912 & 0,115 & 0,396 \\
\hline 51 & 3,48 & 5,5 & 6,0 & 0,688 & 0,938 & 0,125 & 0,435 \\
\hline 52 & 3,57 & 4,8 & 5,1 & 0,659 & 0,952 & 0,130 & 0,464 \\
\hline 53 & 3,65 & 4,0 & 4,3 & 0,641 & 0,989 & 0,131 & 0,478 \\
\hline 54 & 3,75 & 3,0 & 3,3 & 0,623 & 0,879 & 0,129 & 0,484 \\
\hline
\end{tabular}



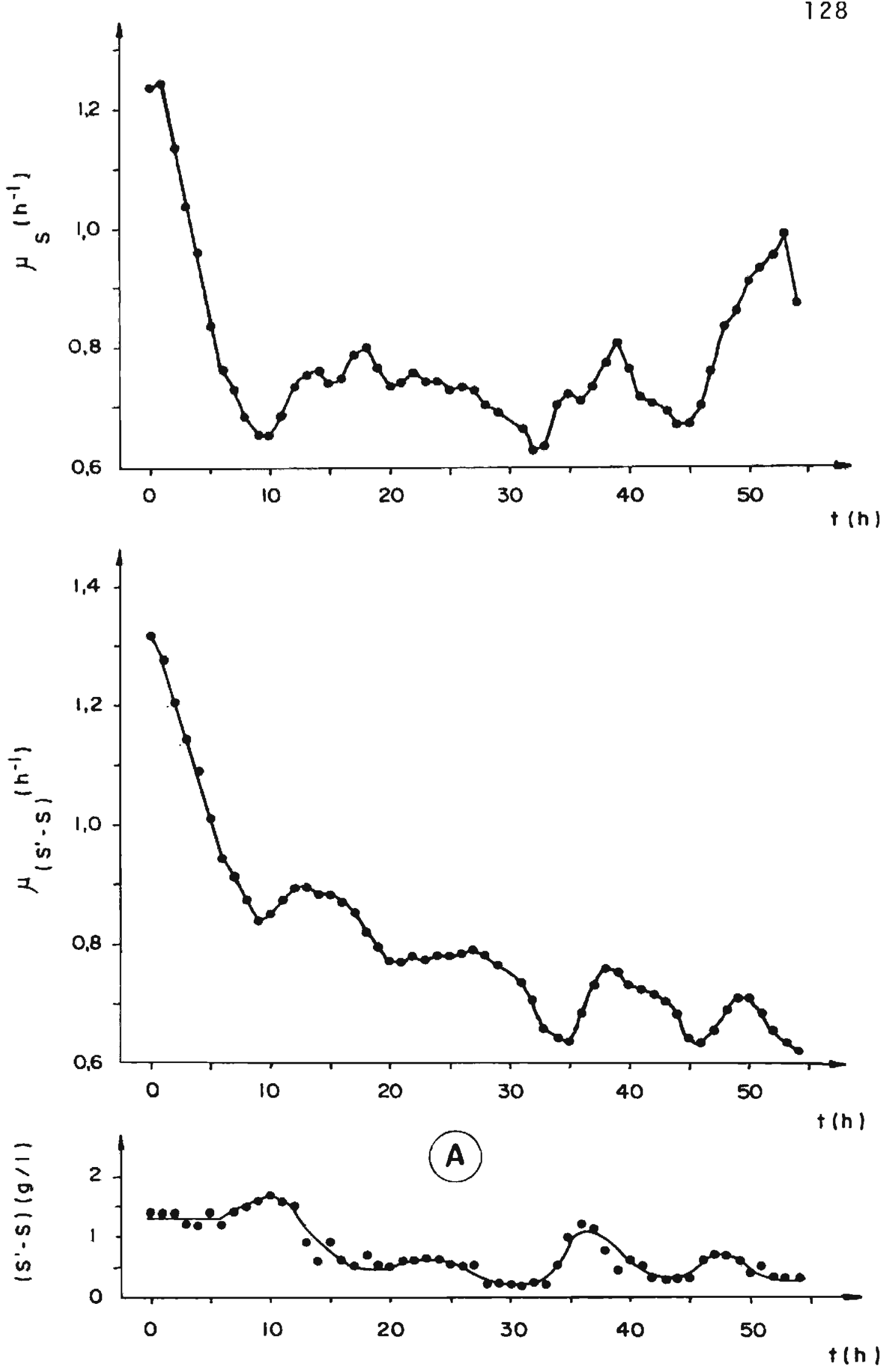

FIGURA 4.I. Variação, com o tempo, das velocidades especỉficas de consumo de sacarose ( $\mu\left(S^{\prime}-s\right)$ ) e de $A R$ ( $\left.\mu s\right)$ no ensaio nọ. 0 gräfico A mostra o perfil da curva para interpolar os valores de ( $\left.S^{\prime}-S\right)$ utilizados para calcular $\mu\left(S^{\prime}-S\right)$. O perfil da curva usado para interpolar os valores de S para calcular ${ }_{\mathrm{S}} \mathrm{e}$ mostrado na figura 3. IIa. 

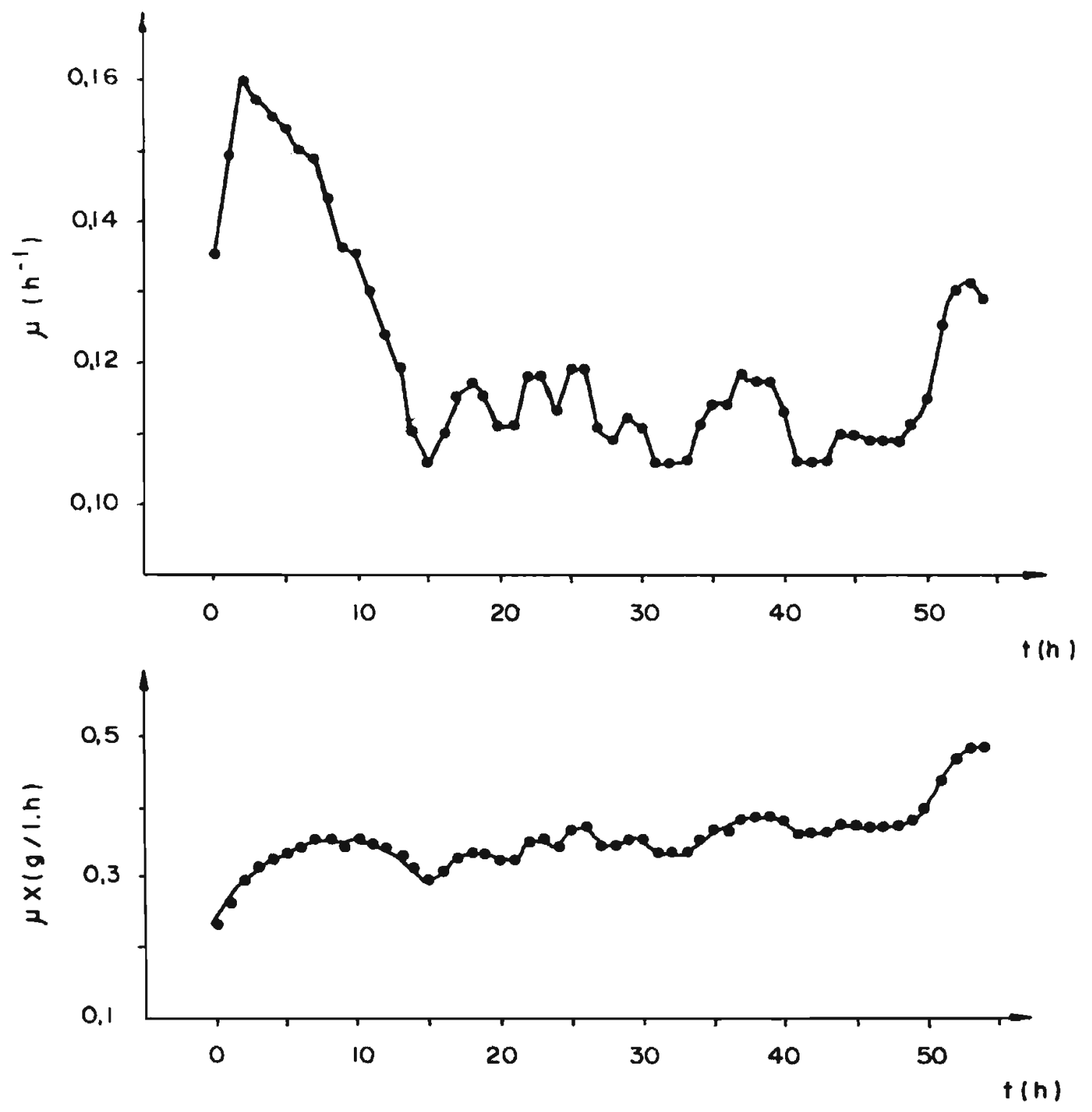

FIGURA 4.II. Variação, conı o tempo, da velocidade especîfica de crescimento celular $(\mu)$ e da produtivida de em células $(\mu X)$ no ensaio nọ 1. 


\subsubsection{Ensaio no 2}

Conforme descrito anteriormente este ensaio $\bar{e}$ constituĩdo por duas etapas, cujas condições de trabalho foram:

\section{1ㄹ etapa :}

$$
\begin{aligned}
& F=339 \mathrm{ml} / \mathrm{h} \\
& D=0,11 \mathrm{~h}^{-1} \\
& \Phi=2 \mathrm{l} / \mathrm{l} \cdot \mathrm{min} \\
& N=500 \mathrm{~min}^{-1}
\end{aligned}
$$

\section{2a etapa:}

$$
\begin{aligned}
& F=423 \mathrm{ml} / \mathrm{h} \\
& D=0,14 \mathrm{~h}^{-1} \\
& \Phi=2 \ell / \ell \cdot \mathrm{min} \\
& N=500 \mathrm{~min}^{-1}
\end{aligned}
$$

Pela anālise das figuras 3 .III e 4.IV ve rifica-se que em ambas as etapas obteve-se regime transiente.

$$
\text { A tabela } 4.3 \text { e as figuras } 4 . \text { III e } 4 . \text { IV }
$$
mostram o comportamento de $\mu_{S}, \mu\left(S^{\prime}-S\right), \mu$ e $\mu X$ em função do tempo.

Comparando os gräficos de $\mu_{S}, \mu_{\left(S^{\prime}-S\right)} e$ $v$ entre sij, nota-se que apresentam perfis diferentes. Aqui, tambem,verifica-se a dissemelhança entre as curvas dos gräfi 
cos de $v$ e $\mu\left(S^{\prime}-S\right)$, tal como sucedeu no ensaio no 1 .

Para analisar um pouco melhor os regimes trans $j$ entes obtidos, tentamos ajustar aos pontos de $\mu X=f(t)$ e $v=f(t)$ em cada etapa, as correspondentes retas de minimo quadrado. Assim, para a primeira etapa, mais precisamente entre os instantes $t=14 \mathrm{~h}$ e $t=43 \mathrm{~h}$, os coeficientes de correlação (r) obtidos para $\mu X$ e $v$ säo, respectivamente, 0,91 e 0,86, sen do que os coirespondentes valores de $r$ criticos (99\% de probabilidade) são, respectivamente, 0,49 e 0,76 (32).

Por outro 1 ado, para a 2 a etapa, compreendida entre os instantes $t=46 \mathrm{~h}$ e $t=68 \mathrm{~h}$, os coeficientes de correla ção para $\mu X$ e $v$ são, respectivamente 0,86 e 0,64 , sendo os correspondentes vatores críticos de $r$ (99\% de probabilidade), respectivamente, iguais a 0,55 e 0,79 (32).

Pelos dados obtidos conclui-se que na la etapa do ensaio tanto $\mu X$ como $\vee$ são funções crescentes com 0 tempo. No entanto para a 2 a etapa não se pode estabelecer tal correla ção para v ao nîvel de $99 \%$ de probabilidade.

Para finalizar deve ser realçado que a partir do instante $t=14 \mathrm{~h}$ o valor de $v$ começa a oscilar, assim suce dendo atē o final do processo (Fig. 3.III). o período mëdio de oscilação de v para a 1a etapa ē $12 \mathrm{~h}$ e para a 2 a etapa $10,5 \mathrm{~h}$. 
TABELA 4.3 Velocidades especîficas de consumo de AR, de consumo de sacarose, de crescimento celular e produtividade em cēlulas para o ensaio no 2.

\begin{tabular}{|c|c|c|c|c|c|c|c|}
\hline $\begin{array}{c}t \\
(h)\end{array}$ & $\begin{array}{c}x \\
(g / \ell)\end{array}$ & $\begin{array}{c}S \\
(g / \ell)\end{array}$ & $\begin{array}{c}S^{\prime} \\
(g / \ell)\end{array}$ & $\begin{array}{c}\mu\left(s^{\prime}-s\right) \\
\left(h^{-1}\right)\end{array}$ & $\begin{array}{c}\mu_{S} \\
\left(h^{-1}\right)\end{array}$ & $\begin{array}{c}\mu \\
\left(h^{-1}\right)\end{array}$ & $\begin{array}{c}\mu X \\
(g / \ell \cdot h)\end{array}$ \\
\hline 0 & 2,00 & 14,3 & 14,8 & 0,45 & 0,73 & 0,120 & 0,240 \\
\hline 1 & 2,02 & 13,0 & 14,8 & 0,66 & 0,74 & 0,122 & 0,246 \\
\hline 2 & 2,05 & 12,5 & 14,8 & 0,82 & 0,72 & 0,134 & 0,275 \\
\hline 3 & 2,12 & 12,3 & 14,8 & 0,87 & 0,70 & 0,141 & 0,299 \\
\hline 4 & 2,18 & 12,2 & 14,8 & 0,89 & 0,70 & 0,135 & 0,294 \\
\hline 5 & 2,23 & 12,1 & 14,8 & 0,89 & 0,69 & 0,137 & 0,306 \\
\hline 6 & 2,30 & 12,1 & 14,7 & 0,88 & 0,69 & 0,143 & 0,329 \\
\hline 7 & 2,38 & 12,0 & 14,6 & 0,87 & 0,68 & 0,146 & 0,347 \\
\hline 8 & 2,47 & 12,0 & 14,5 & 0,86 & 0,70 & 0,144 & 0,356 \\
\hline 9 & 2,55 & 11,8 & 14,3 & 0,84 & 0,71 & 0,141 & 0,360 \\
\hline 10 & 2,63 & 11,7 & 14,0 & 0,81 & 0,68 & 0,148 & 0,389 \\
\hline 11 & 2,75 & 11,6 & 13,8 & 0,76 & 0,64 & 0,150 & 0,413 \\
\hline 12 & 2,85 & 11,5 & 13,7 & 0,71 & 0,61 & 0,145 & 0,413 \\
\hline 13 & 2,95 & 3 & 13,6 & 0,68 & 0,59 & 0,144 & 0,425 \\
\hline 14 & 3,05 & 11,2 & 13,5 & 0,64 & 0,57 & 0,140 & 0,427 \\
\hline 15 & 3,13 & 10,9 & 13,4 & 0,59 & 0,57 & 0,137 & 0,429 \\
\hline 16 & 3,22 & 10,6 & 13,3 & 0,57 & 0,52 & 0,136 & 0,438 \\
\hline 17 & 3,30 & 10,5 & 13,2 & 0,56 & 0,54 & 0,137 & 0,452 \\
\hline 18 & 3,40 & 10,1 & 13,0 & 0,56 & 0,58 & 0,136 & 0,462 \\
\hline 19 & 3,48 & 9,8 & 12,8 & 0,57 & 0,59 & 0,127 & 0,442 \\
\hline 20 & 3,52 & 9,5 & 12,5 & 0,62 & 0,63 & 0,130 & 0,458 \\
\hline 21 & 3,62 & 9,3 & 11,8 & 0,65 & 0,66 & 0,135 & 0,489 \\
\hline 22 & 3,70 & 9,0 & 11,3 & 0,62 & 0,64 & 0,128 & 0,474 \\
\hline 23 & 3,75 & 8,8 & 10,8 & 0,58 & 0,60 & 0,123 & 0,461 \\
\hline 24 & 3,80 & 8,6 & 10,6 & 0,56 & 0,58 & 0,126 & 0,479 \\
\hline 25 & 3,87 & 8,4 & 10,4 & 0,54 & 0,55 & 0,126 & 0,488 \\
\hline 26 & 3,92 & 8,3 & 10,3 & 0,54 & 0,53 & 0,127 & 0,498 \\
\hline 27 & 4,00 & 8,3 & 10,3 & 0,53 & 0,51 & 0,120 & 0,480 \\
\hline 28 & 4,00 & 8,3 & 10,3 & 0,52 & 0,54 & 0,120 & 0,480 \\
\hline 29 & 4,08 & $B, 3$ & 10,2 & 0,52 & 0,51 & 0,126 & 0,514 \\
\hline 30 & 4,13 & 8,25 & 10,1 & 0,53 & $\begin{array}{l}0,54 \\
\text { Continua }\end{array}$ & 0,127 & 0,525 \\
\hline
\end{tabular}


Continuação da Tabela 4.3

\begin{tabular}{cccccccc}
\hline$t$ & $x$ & $S$ & $S^{\prime}$ & $\mu\left(S^{\prime}-S\right)$ & $\mu_{S}$ & $\mu$ & $\mu X$ \\
$(h)$ & $(g / l)$ & $(g / l)$ & $(g / l)$ & $\left(h^{-1}\right)$ & $\left(h^{-1}\right)$ & $\left(h^{-1}\right)$ & $(g / \ell \cdot h)$
\end{tabular}

\begin{tabular}{|c|c|c|c|c|c|c|c|}
\hline 31 & 4,22 & 8,1 & 9,8 & 0,53 & 0,55 & 0,130 & 0,549 \\
\hline 32 & 4,30 & 8,0 & 9,5 & 0,53 & 0,54 & 0,138 & 0,593 \\
\hline 33 & 4,40 & 7,9 & 9,3 & 0,53 & 0,54 & 0,133 & 0,585 \\
\hline 34 & 4,50 & 7,8 & 9,2 & 0,51 & 0,52 & 0,128 & 0,576 \\
\hline 35 & 4,56 & 7,7 & 8,8 & 0,48 & 0,51 & 0,121 & 0,552 \\
\hline 36 & 4,60 & $\dot{7}, 5$ & 8,8 & 0,45 & 0,48 & 0,119 & 0,547 \\
\hline 37 & 4,64 & 7,4 & 8,7 & 0,42 & 0,47 & 0,119 & 0,552 \\
\hline 38 & 4,68 & 7,0 & 8,6 & 0,42 & 0,50 & 0,116 & 0,543 \\
\hline 39 & 4,70 & 6,8 & 8,4 & 0,46 & 0,52 & 0,117 & 0,550 \\
\hline 40 & 4,75 & 6,6 & 8,2 & 0,50 & 0,55 & 0,118 & 0,561 \\
\hline 41 & 4,78 & 6,5 & 7,5 & 0,50 & 0,56 & 0,117 & 0,559 \\
\hline 42 & 4,82 & 6,3 & 7,3 & 0,47 & 0,52 & 0,117 & 0,564 \\
\hline 43 & 4,85 & 6,3 & 7,3 & 0,46 & 0,51 & 0,116 & 0,563 \\
\hline $44^{*}$ & 4,88 & 6,1 & 7,2 & 0,56 & 0,59 & 0,117 & 0,571 \\
\hline 45 & 4,92 & 6,2 & 7,0 & 0,55 & 0,56 & 0,116 & 0,571 \\
\hline 46 & 4,94 & 6,3 & 7,3 & 0,56 & 0,56 & 0,143 & 0,706 \\
\hline 47 & 4,98 & 6,5 & 7,4 & 0,57 & 0,55 & 0,145 & 0,722 \\
\hline 48 & 5,02 & 6,8 & 7,6 & 0,58 & 0,53 & 0,149 & 0,748 \\
\hline 49 & 5,10 & 7,2 & 7,8 & 0,56 & 0,52 & 0,155 & 0,791 \\
\hline 50 & 5,20 & 7,3 & 8,0 & 0,50 & - & 0,153 & 0,796 \\
\hline 51 & 5,27 & 7,2 & 8,1 & 0,47 & 0,50 & 0,149 & 0,785 \\
\hline 52 & 5,33 & 7,0 & 8,2 & 0,47 & 0,52 & 0,152 & 0,810 \\
\hline 53 & 5,43 & 6,8 & 8,1 & 0,49 & 0,53 & 0,153 & 0,831 \\
\hline 54 & 5,50 & 6,8 & 8,0 & 0,51 & 0,54 & 0,152 & 0,836 \\
\hline 55 & 5,60 & 6,7 & 7,8 & 0,51 & 0,54 & 0,149 & 0,834 \\
\hline 56 & 5,63 & 6,6 & 7,5 & 0,51 & 0,54 & 0,142 & 0,799 \\
\hline 57 & 5,66 & 6,6 & 7,3 & 0,52 & 0,55 & 0,145 & 0,821 \\
\hline 58 & 5,72 & 6,5 & 7,2 & 0,52 & 0,55 & 0,147 & 0,841 \\
\hline 59 & 5,78 & 6,5 & 7,1 & 0,50 & 0,52 & 0,144 & 0,832 \\
\hline 60 & 5,80 & 6,5 & 6,9 & 0,47 & 0,50 & 0,141 & 0,818 \\
\hline
\end{tabular}


Continuação da Tabela 4.3

\begin{tabular}{|c|c|c|c|c|c|c|c|}
\hline $\begin{array}{c}t \\
(h)\end{array}$ & $\begin{array}{c}x \\
(g / \ell)\end{array}$ & $\begin{array}{c}S \\
(g / \ell)\end{array}$ & $\begin{array}{c}S^{\prime} \\
(g / \ell)\end{array}$ & $\begin{array}{c}\mu\left(s^{\prime}-s\right) \\
\left(h^{-1}\right)\end{array}$ & $\begin{array}{c}\mu_{S} \\
\left(h^{-1}\right)\end{array}$ & $\begin{array}{c}\mu \\
\left(h^{-1}\right)\end{array}$ & $\begin{array}{c}\mu X \\
(g / \ell \cdot h)\end{array}$ \\
\hline 61 & 5,83 & 6,4 & 7,0 & 0,45 & 0,49 & 0,144 & 0,840 \\
\hline 62 & 5,88 & 6,3 & 7,1 & 0,44 & 0,48 & 0,143 & 0,841 \\
\hline 63 & 5,90 & 6,3 & 7,2 & 0,43 & 0,48 & 0,145 & 0,856 \\
\hline 64 & 5,97 & 6,1 & 7,3 & 0,42 & 0,48 & 0,145 & 0,866 \\
\hline 65 & 6,00 & 6,0 & 7,2 & 0,43 & 0,49 & 0,141 & 0,846 \\
\hline 66 & 6,02 & 5,8 & 7,1 & 0,45 & 0,52 & 0,143 & 0,861 \\
\hline 67 & 6,07 & 5,6 & 6,8 & 0,47 & 0,54 & 0,196 & 1,19 \\
\hline 68 & 7,00 & 5,4 & 6,5 & 0,41 & 0,48 & 0,211 & 1,48 \\
\hline
\end{tabular}

* Instante no qual a vazão específica foi aumentada para $0,14 \mathrm{~h}^{-1}$. 

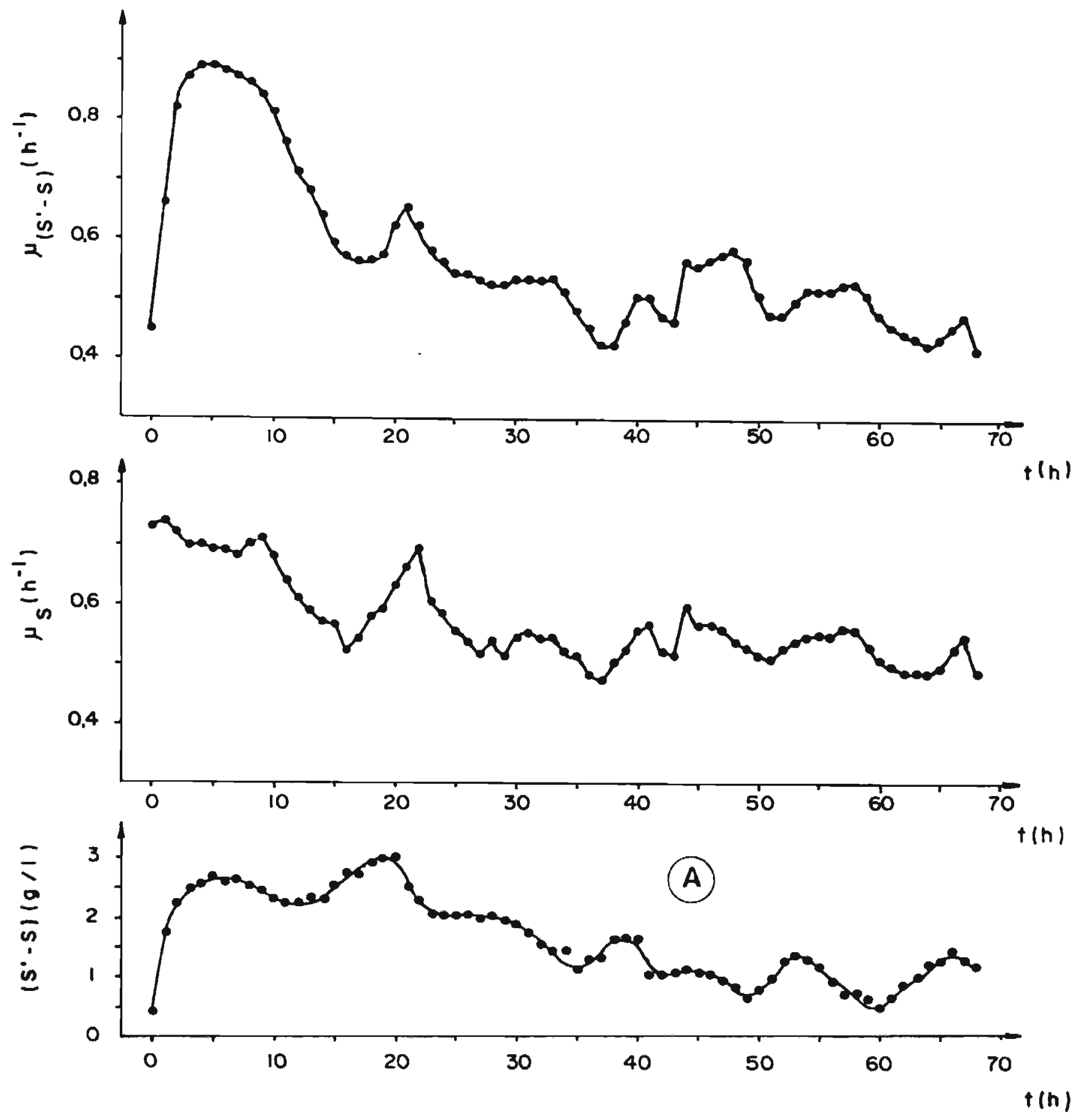

FIGURA 4.III. Varjação, com o tempo, das velocidades especificas de consumo de sacarose ( $\mu\left(S^{\prime}-S\right)$ ) e de $A R$ ( $\mu S)$ no ensaio nọ 2. 0 gräfico A mostra o perfil da curva para interpolar os valores de ( $\left.S^{\prime}-\mathrm{S}\right)$ utilizados para calcular $\left(\mu\left(S^{\prime}-s\right)\right)$. 0 perfil da curva usado para interpolar os valores de $S$ para calcular $\mu_{S} \bar{e}$ mostrado na figura 3. III. 


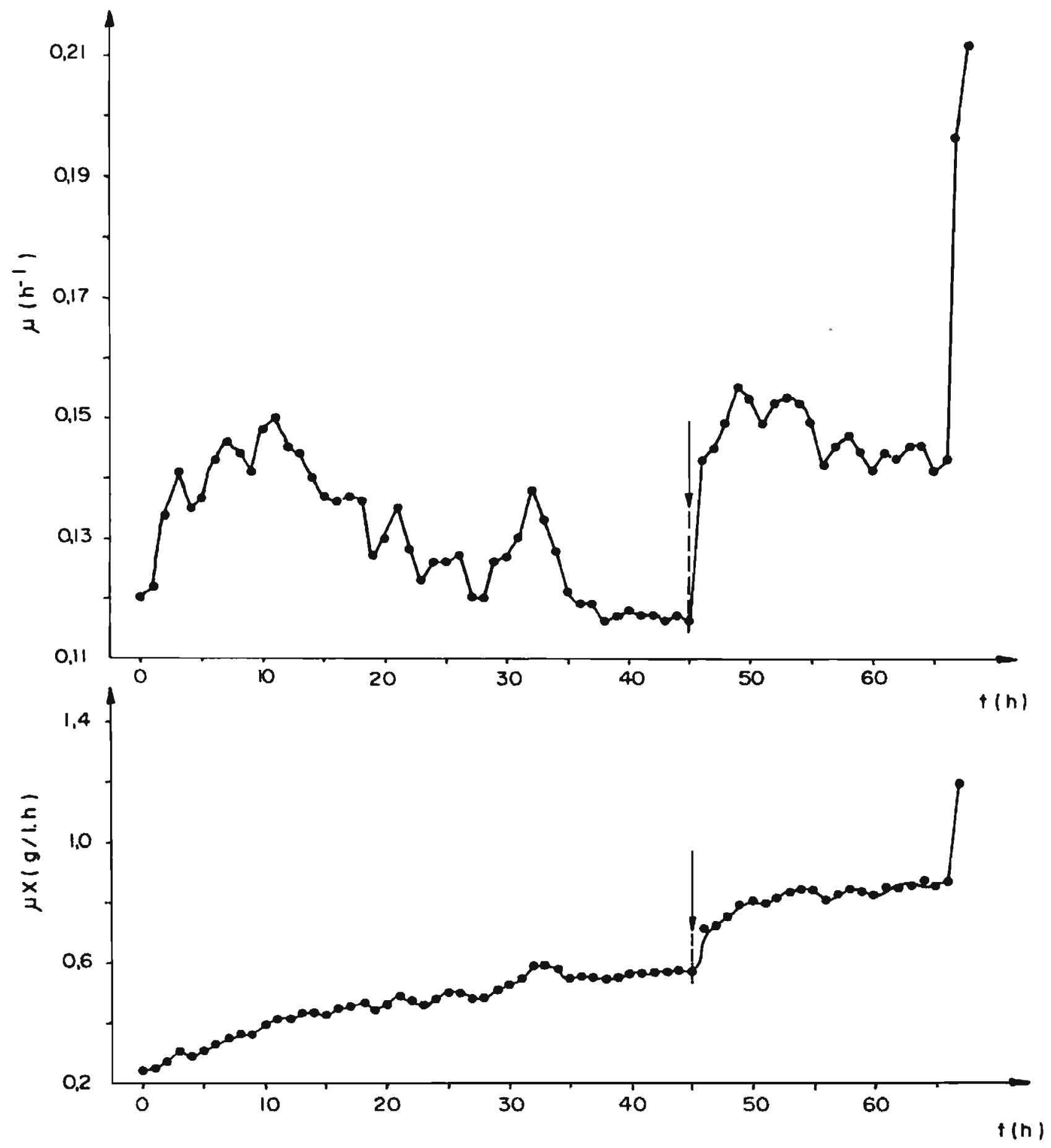

FIgURA 4.IV. Variação, com o tempo, da velocidade especîfica de crescimento celular ( $\mu$ ) e da produtivida de em cēlulas $(\mu X)$ no ensaio no 2 . 


\subsubsection{Ensaio no 3}

Pela anālise das figuras 3 .IV e 4 .VI nota-se que as condiçōes de ensaio utilizadas ( $F=697 \mathrm{ml} / \mathrm{h}$; $D=0,23 \mathrm{~h}^{-1} ; \Phi=2 \mathrm{l} / \mathrm{l} \cdot \mathrm{min}$ e $N=500 \mathrm{~min}^{-1}$ ) permitiram obter regime transiente.

$$
\text { A tabela } 4.4 \text { e as figuras } 4 . V \text { e } 4 . V I
$$

mostram o comportamento de $\mu_{S}, \mu^{\mu}\left(S^{\prime}-S\right), \mu$ e $\mu X$ em função do tempo.

A figura 3.IV mostra que a partir do instante $t=6 \mathrm{~h}$ o valor de $v$ começa a oscilar, sendo 0 período médio de oscilação igual a $4,5 \mathrm{~h}$. 
TABELA 4.4 Velocidades especificas de consumo de AR, de con sumo de sacarose, de crescimento celular e produtividade em cétulas para o ensaio no 3.

\begin{tabular}{|c|c|c|c|c|c|c|c|}
\hline $\begin{array}{c}t \\
(h)\end{array}$ & $\begin{array}{c}x \\
(g / 2)\end{array}$ & $\begin{array}{c}S \\
(g / \ell)\end{array}$ & $\begin{array}{c}S^{\prime} \\
(g / \ell)\end{array}$ & $\begin{array}{c}\mu\left(S^{\prime}-S\right) \\
\left(h^{-1}\right)\end{array}$ & $\begin{array}{c}{ }^{\mu} S \\
\left(h^{-1}\right)\end{array}$ & $\begin{array}{c}\mu \\
\left(h^{-1}\right)\end{array}$ & $\begin{array}{l}\mu X \\
(g / \ell \cdot h)\end{array}$ \\
\hline 0 & 1,70 & 15,1 & 16,8 & 2,43 & 1,52 & 0,236 & 0,401 \\
\hline 1 & 1,71 & 15,0 & 17,3 & 2,26 & 1,47 & 0,245 & 0,419 \\
\hline 2 & 1,75 & 14,5 & 17,7 & 2,08 & 1,50 & 0,241 & 0,422 \\
\hline 3 & 1,75 & 14,0 & 17,8 & 2,03 & 1,52 & 0,244 & 0,427 \\
\hline 4 & 1,80 & 13,5 & 18,1 & 1,89 & 1,44 & 0,249 & 0,448 \\
\hline 5 & 1,82 & 13,1 & 18,2 & 1,89 & 1,46 & 0,257 & 0,468 \\
\hline 6 & 1,90 & 12,7 & 18,2 & 1,76 & 1,42 & 0,264 & 0,502 \\
\hline 7 & 1,95 & 12,2 & 18,3 & 1,69 & 1,42 & 0,268 & 0,523 \\
\hline 8 & 2,05 & 11,8 & 18,3 & 1,58 & 1,32 & 0,267 & 0,547 \\
\hline 9 & 2,10 & 11,5 & 18,3 & 1,51 & 1,31 & 0,247 & 0,519 \\
\hline 10 & 2,12 & 11,0 & 18,3 & 1,44 & 1,28 & 0,242 & 0,513 \\
\hline 11 & 2,15 & 10,8 & 18,3 & 1,35 & 1,22 & 0,242 & 0,520 \\
\hline 12 & 2,17 & 10,3 & 18,5 & 1,24 & 1,13 & 0,235 & 0,510 \\
\hline 13 & 2,17 & 10,1 & 18,8 & 1,16 & 1,05 & 0,230 & 0,499 \\
\hline 14 & 2,17 & 9,8 & 19,2 & 1,12 & 1,04 & 0,230 & 0,499 \\
\hline 15 & 2,17 & 9,6 & 19,3 & 1,21 & 1,12 & 0,230 & 0,499 \\
\hline 16 & 2,17 & 9,4 & 19,3 & 1,24 & 1,15 & 0,230 & 0,499 \\
\hline 17 & 2,17 & 9,3 & 19,3 & 1,25 & 1,15 & 0,230 & 0,499 \\
\hline 18 & 2,17 & 9,2 & 19,3 & 1,26 & 1,15 & 0,230 & 0,499 \\
\hline 19 & 2,17 & 9,2 & 19,3 & 1,28 & 1,15 & 0,230 & 0,499 \\
\hline 20 & 2,17 & 9,2 & 19,3 & 1,28 & 1,15 & 0,230 & 0,499 \\
\hline 21 & 2,17 & 9,2 & 19,3 & 1,28 & 1,15 & 0,230 & 0,499 \\
\hline 22 & 2,17 & 9,2 & 19,3 & 1,28 & 1,15 & 0,230 & 0,499 \\
\hline 23 & 2,17 & 9,2 & 19,3 & 1,28 & 1,15 & 0,230 & 0,499 \\
\hline 24 & 2,17 & 9,2 & 19,3 & 1,28 & 1,15 & 0,242 & 0,525 \\
\hline 25 & 2,22 & 9,2 & 19,3 & 1,26 & 1,13 & 0,248 & 0,551 \\
\hline 26 & 2,25 & 9,2 & 19,3 & 1,24 & 1,11 & 0,259 & 0,585 \\
\hline 27 & 2,35 & 9,2 & 19,3 & 1,19 & 1,06 & 0,262 & 0,616 \\
\hline 28 & 2,40 & 9,2 & 19,3 & 1,16 & 1,04 & 0,251 & 0,602 \\
\hline 29 & 2,45 & 9,2 & 19,3 & 1,14 & 1,02 & 0,250 & 0,613 \\
\hline
\end{tabular}


Continuação da Tabela 4.4

\begin{tabular}{lcccccccc}
\hline$t$ & $X$ & $S$ & $S^{\prime}$ & $\begin{array}{c}\mu \\
\left(S^{1}-S\right)\end{array}$ & $\begin{array}{c}\mu_{S} \\
\left(h^{-1}\right)\end{array}$ & $\begin{array}{c}\mu \\
\left(h^{-1}\right)\end{array}$ & $\left(h^{-1}\right)$ & $(g / l . h)$ \\
\hline 3$)$ & $(g / l)$ & $(g / l)$ & $(g / l)$ & $\left(h^{-}\right)$ & & & \\
\hline 30 & 2,50 & 9,2 & 19,3 & 1,12 & 1,00 & 0,244 & 0,610 \\
31 & 2,52 & 9,2 & 19,3 & 1,11 & 0,99 & 0,240 & 0,605 \\
32 & 2,55 & 9,2 & 19,3 & 1,09 & 0,98 & 0,242 & 0,617 \\
33 & 2,58 & 9,2 & 19,3 & 1,08 & 0,97 & 0,240 & 0,619 \\
34 & 2,60 & 9,2 & 19,3 & 1,07 & 0,96 & 0,236 & 0,614 \\
35 & 2,61 & 9,2 & 19,3 & 1,07 & 0,96 & 0,249 & 0,650 \\
36 & 2,70 & 9,2 & 19,3 & 1,06 & 0,95 & 0,256 & 0,691 \\
37 & 2,75 & 9,2 & 19,2 & 1,11 & 1,00 & 0,257 & 0,707 \\
38 & 2,85 & 9,2 & 18,8 & 1,19 & 1,08 & 0,274 & 0,781 \\
39 & 3,00 & 9,2 & 18,2 & 1,09 & 0,99 & 0,269 & 0,807 \\
\hline
\end{tabular}




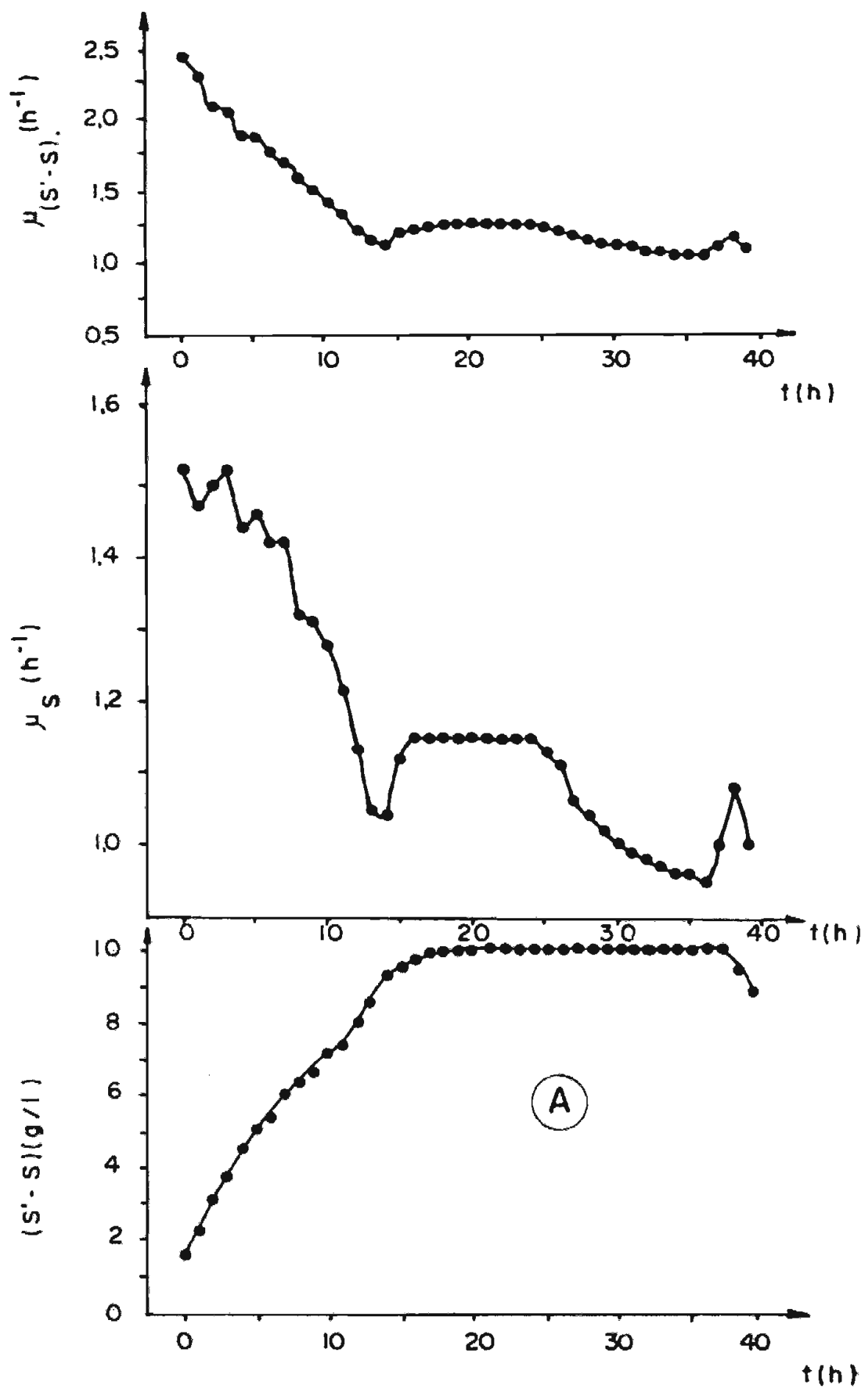

FIGURA 4.V. Variação, com o tempo, das velocidades especificas de consumo de sacarose $\left(\mu\left(S^{\prime}-S\right)\right.$ ) e de AR ( $\left.\mu S\right)$ no ensaio no3. O grä́fico A mostra o perfil da curva para interpolar os valores de $\left(S^{\prime}-S\right)$ usados para calcular ( $\mu\left(S^{\prime}-S\right)$ ). 0 perfil da curva usado para interpolar ds vaiores de $S$ para calcular $\mu_{S}$ é mostrado na figura 3 .IV. 


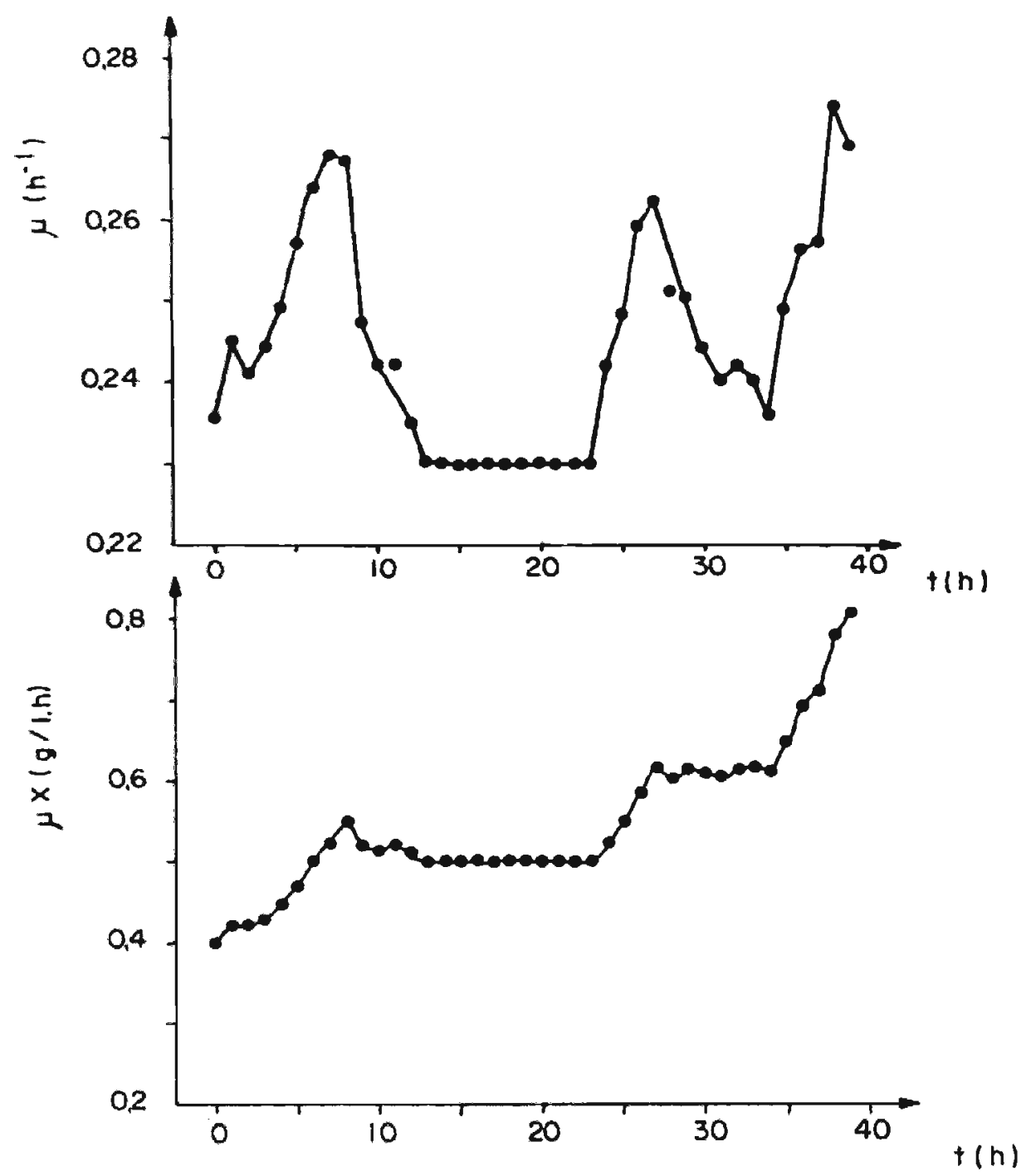

FIGURA 4.VI. Variação, com o tempo, da velocidade específi ca de crescimento celular ( $\mu$ ) e da produtivi= dade em células $(\mu X)$ no ensaio no 3 . 


\subsubsection{Ensaio no 4}

Pela figura $3 . V$ nota-se claramente que, o processo fermentativo continuo realizado nas seguintes condições:

$$
\begin{aligned}
& F=679 \mathrm{ml} / \mathrm{h} \\
& D=0,23 \mathrm{~h}^{-1} \\
& \Phi=1 \mathrm{\ell} / \mathrm{l} \cdot \mathrm{min} \\
& N=500 \mathrm{~min}^{-1}
\end{aligned}
$$

permitiu o estabelecimento de regime estacionário a partir do instante $t=12 \mathrm{~h}$.

O patamar obtido se manteve durante $39 \mathrm{~h}$, com os seguintes valores médios:

$$
\begin{aligned}
& \bar{x}=1,16 \mathrm{~g} / \mathrm{l} \\
& \overline{\mathrm{s}}=6,8 \mathrm{~g} / \mathrm{l} \\
& \overline{\mathrm{v}}=0,044 \mathrm{gART} / \mathrm{g} \mathrm{c} \overline{\mathrm{e}} 1 . \mathrm{min} \\
& \overline{\mathrm{s}}^{\prime}=22,6 \mathrm{~g} / \ell
\end{aligned}
$$

As velocidades especificas de crescimento celular, de consumo de Ar e consumo de sacarose são, respectivamente, iguais a $0,23 \mathrm{~h}^{-1}, 1,71 \mathrm{~h}^{-1}$ e $1,26 \mathrm{~h}^{-1}$. A produtividade em cēlulas foi de $0,27 \mathrm{~g} / \mathrm{l} . \mathrm{h}$.

Outrossim deve ser destacado que durante todo o periodo de duração do patamar o valor de v oscilou,sen do o periodo mëdio de oscilação igual a 5,1 h. 


\section{$4.5 .1 .5 \quad$ Ensaio ne 5}

Conforme indicado no item 3.5 .5 este en saio foi dividido em 4 etapas, das quais a la etapa será analisada neste momento.

Entre os instantes $t=0 \mathrm{~h}$ e $t=27 \mathrm{~h}$ as condiçöes de ensaio foram anălogas às do ensaio nọ 4, sendo mais precisamente:

$$
\begin{aligned}
& F=689 \mathrm{ml} / \mathrm{h} \\
& D=0,24 \mathrm{~h}^{-1} \\
& \Phi=1 \ell / \ell \cdot \mathrm{min} \\
& N=500 \mathrm{~min}^{-1}
\end{aligned}
$$

Conforme se pode depreender da figura 3.VI o regime permanente foi reproduzido e mantido durante $24 \mathrm{~h}$, com os seguintes valores mëdios:

$$
\begin{aligned}
& \overline{\mathrm{X}}=1,40 \mathrm{~g} / \mathrm{l} \\
& \overline{\mathrm{s}}=7,8 \mathrm{~g} / \mathrm{l} \\
& \overline{\mathrm{S}}^{\prime}=21,0 \mathrm{~g} / \mathrm{l} \\
& \overline{\mathrm{v}}=0,077 \mathrm{gART} / \mathrm{g} \text { cé } 1 . \mathrm{min}
\end{aligned}
$$


Deve ser notado que, embora a perturbação do sistema tenha sido feita no instante $t=27 \mathrm{~h}$, o patamar se pro longou até 0 instante $t=30 \mathrm{~h}$. A explicação reside no fato de que o sistema precisa de um certo tempo para responder às novas condições.

As velocidades especificas de crescimento celular, de consumo de AR e consumo de sacarose são, respectiva mente, iguais a $0,24 \mathrm{~h}^{-1}, 1,63 \mathrm{~h}^{-1}$ e $1,82 \mathrm{~h}^{-1}$. A produtivida de em cêlulas foi de $0,34 \mathrm{~g} / \ell . \mathrm{h}$.

Observando a figura 3 .VIII observa-se que o valor de voscila ao longo do patamar, sendo o periodo de oscilação mēdio de $4,5 \mathrm{~h}$.

\subsubsection{Ensaio no 10}

Este ensaio foi dividido em 5 etapas, de acordo com o descrito no $\mathbf{i}$ tem 3.5 .11 , das quais se analisará

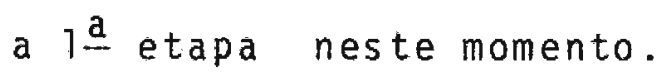

Entre os instantes $t=0 \mathrm{~h}$ e $t=19 \mathrm{~h}$ o sistema foi mantido sob condições operacionais anālogas às dos ensaios no 4 e no 5 ( 1 a etapa), sendo:

$$
\begin{aligned}
& F=713 \mathrm{ml} / \mathrm{h} \\
& D=0,23 \mathrm{~h}^{-1} \\
& \Phi=1 \mathrm{\ell} / \mathrm{\ell} \cdot \mathrm{min} \\
& N=500 \mathrm{~min}^{-1}
\end{aligned}
$$

Pela figura 3.XIII infere-se que o regime per manente foi mantido durante $16 \mathrm{~h}$, com os seguintes valores mēdios: 


$$
\begin{aligned}
& \bar{x}=1,25 \mathrm{~g} / \mathrm{l} \\
& \overline{\mathrm{S}}=6,5 \mathrm{~g} / \mathrm{l} \\
& \overline{\mathrm{S}}^{\prime}=21,5 \mathrm{~g} / \mathrm{l} \\
& \overline{\mathrm{v}}=0,038 \mathrm{gART} / \mathrm{g} \mathrm{c} \overline{\mathrm{e}} \mathrm{T} . \mathrm{min}
\end{aligned}
$$

As velocidades especificas de crescimento celular, de consumo de AR e consumo de sacarose são, respectiva mente, iguais a $0,23 \mathrm{~h}^{-1}, 1,75 \mathrm{~h}^{-1}$ e $1,68 \mathrm{~h}^{-1}$. A produtivida de em células foi de $0,29 \mathrm{~g} / \mathrm{l} . \mathrm{h}$.

Da figura 3.XII depreende-se que o valor de $\checkmark$ oscila ao longo do patamar, sendo o período médio de oscila ção de $4,8 \mathrm{~h}$.

\subsubsection{Comentārios sobre o item 4.5.1}

Analisando o grupo de ensaios realizados com borbulhamento de ar e com mosto não suplementado pode-se dizer:

a) O regime transiente foi obtido nas quatro condições seguintes:

1) $F=312 \mathrm{ml} / \mathrm{h} ; D=0,11 \mathrm{~h}^{-1}$ e $\Phi=1 \mathrm{l} / \mathrm{l} \cdot \mathrm{min}$.

2) $F=339 \mathrm{ml} / \mathrm{h} ; D=0,11 \mathrm{~h}^{-1}$ e $\Phi=2 \mathrm{l} / \mathrm{l} \cdot \mathrm{min}$.

3) $F=423 \mathrm{ml} / \mathrm{h} ; D=0,14 \mathrm{~h}^{-1}$ e $\Phi=2 \mathrm{l} / \mathrm{l} \cdot \mathrm{min}$.

4) $F=697 \mathrm{ml} / \mathrm{h} ; D=0,23 \mathrm{~h}^{-1}$ e $\Phi=2$ l/l.min.

Em todos estes casos a frequéncia do agitador foi de $500 \mathrm{~min}^{-1}$.

b) O regime estacionārio foi obtido nas seguintes condições:

1) $F=679 \mathrm{ml} / \mathrm{h} ; D=0,23 \mathrm{~h}^{-1}$ e $\Phi=1 \mathrm{l} / \mathrm{l} \cdot \mathrm{min}$. 
2) $F=689 \mathrm{ml} / \mathrm{h} ; \quad D=0,24 \mathrm{~h}^{-1}$ e $\Phi=1 \ell / \ell \cdot \mathrm{min}$.

3) $F=713 \mathrm{ml} / \mathrm{h} ; \quad D=0,23 \mathrm{~h}^{-1}$ e $\Phi=1 \mathrm{l} / \mathrm{l} \cdot \mathrm{min}$.

Em todos estes casos a frequéncia do agitador foi de $500 \mathrm{~min}^{-1}$.

-

c) Em todos os ensaios a atividade invertāsica específica de células intactas de levedura apresenta uma variação acentuada durante as primeiras horas de processo continuo.

Na tabela 4.5 nota-se um comportamento distin to entre as variaçōes de $v$ e $X$ num mesmo intervalo de tempo no início do cultivo continuo, de acordo com as condições ope racionais empregadas. No caso das condições para regime tran siente (ensaios nos 1,2 e 3 ) a variação de $X$ é positiva e a de $v$ negativa, ao passo que nas condiçōes para regime estacio nārio ambas apresentam variação negativa. E notōrio, também, que no primeiro caso a variação de $v \bar{e}$ menos acentuada do que no segundo.

Sabendo que a invertase só pode provir da célula e que a enzima, uma vez formada, fica presa à parede celular, então as referidas variações, provavelmente, refletem mudanças no metabolismo celular.

d) Tanto em regime transiente como estacionário os valores de v oscilam.

e) Em regime transiente $v, \mu\left(S^{\prime}-S\right)$ e $\mu_{S}$, aparentemente, não se correlacionam. 
TABELA 4.5 Variaçōes globais de $X$ e $v$ no inicio do processo fermentativo continuo dos ensaios $1,2,3,4,5$ ( 1 a etapa) e 10 ( 1 a etapa).

\begin{tabular}{|c|c|c|c|c|c|c|c|}
\hline \multirow[t]{2}{*}{$\begin{array}{c}\text { Ensaio } \\
\text { no }\end{array}$} & \multirow{2}{*}{$\begin{array}{c}\text { Intervalo } \\
\text { de tempo } \\
\text { (n) }\end{array}$} & \multirow[t]{2}{*}{$\begin{array}{c}x \\
(g / \ell)\end{array}$} & \multirow{2}{*}{$\begin{array}{c}v \\
(g A R T / \\
g \quad c \bar{l} 1 . m i n)\end{array}$} & \multirow{2}{*}{$\begin{array}{l}\Delta x \\
(g / 2)\end{array}$} & \multirow{2}{*}{$\begin{array}{c}\Delta v \\
(g A R T / \\
g(c \bar{e} 1 . m i n)\end{array}$} & \multicolumn{2}{|c|}{$\begin{array}{l}\text { Variação } \\
\text { Percentual }\end{array}$} \\
\hline & & & & & & $\Delta x$ & $\Delta v$ \\
\hline \multirow[t]{2}{*}{1} & 0 & 1,66 & 0,268 & \multirow[t]{2}{*}{1,09} & \multirow[t]{2}{*}{$-0,172$} & \multirow[t]{2}{*}{39,6} & \multirow[t]{2}{*}{$-64,2$} \\
\hline & 12 & 2,75 & 0,096 & & & & \\
\hline \multirow[t]{2}{*}{2} & 0 & 1,95 & 0,253 & \multirow{2}{*}{1,10} & \multirow{2}{*}{$-0,134$} & \multirow{2}{*}{36,1} & \multirow[t]{2}{*}{$-52,9$} \\
\hline & 14 & 3,05 & 0,119 & & & & \\
\hline \multirow{2}{*}{3} & 0 & 1,71 & 0,317 & \multirow{2}{*}{0,28} & \multirow{2}{*}{$-0,231$} & \multirow{2}{*}{14,1} & \multirow{2}{*}{$-72,9$} \\
\hline & 6 & 1,99 & 0,086 & & & & \\
\hline \multirow[b]{2}{*}{4} & 0 & 1,76 & 0,341 & \multirow[b]{2}{*}{$-0,51$} & \multirow[b]{2}{*}{$-0,305$} & \multirow[b]{2}{*}{$-29,0$} & \multirow[b]{2}{*}{$-89,4$} \\
\hline & 10,5 & 1,25 & 0,036 & & & & \\
\hline \multirow[t]{2}{*}{$5(1 \stackrel{a}{)})$} & 0 & 1,87 & $0,4.02$ & \multirow[t]{2}{*}{$-0,37$} & \multirow[t]{2}{*}{$-0,376$} & \multirow[t]{2}{*}{$-19,8$} & \multirow[t]{2}{*}{$-93,5$} \\
\hline & 7,5 & 1,50 & 0,026 & & & & \\
\hline \multirow[t]{2}{*}{$10(1-\underline{a})$} & 0 & 1,63 & 0,202 & \multirow[t]{2}{*}{$-0,18$} & \multirow[t]{2}{*}{$-0,130$} & \multirow[t]{2}{*}{$-11,0$} & \multirow{2}{*}{$-64,4$} \\
\hline & 1,5 & 1,45 & 0,072 & & & & \\
\hline
\end{tabular}


f) Em regime transiente o período de oscilação mëdio (P.O.M.) da atividade invertāsica específica è superior ao obtido em regime estacionārio, indicando que $\checkmark$ varia mais rápido neste tipo de regime do que naquele. Assim, no caso dos ensaios no 1,2 (1aㅡ etapa), 2 ( 2 a etapa) e 3 , onde se obtiveram regimes transientes, o P.0.M. apresentou CV igual a $38 \%$ enquan to que nos ensaios em regime estacionārio (ensaios no 4,5 (1 a etapa) e 10 ( 1 a etapa) o CV foi cerca de $6 \%$.

\subsubsection{Ensaios com borbulhamento de ar e com mosto su-} plementado

\section{5 .2 .1 Ensaio no 5}

A primeira etapa deste ensaio $(t=0 \mathrm{~h}$ ate $t=27 \mathrm{~h}) \quad j \vec{a}$ foj analisada no $\vec{i}$ tem 5.4 .1 , restando, por ora, discutir um pouco a respeito das demais.

\section{A) 2 a etapa}

Teve inicio no instante $t=28,5 \mathrm{~h}$ e prolongouse até $t=51 \mathrm{~h}$. Em relação à etapa anterior, a ünica modificação realizada foi introduzir na dorna mosto enriquecido, conforme descrito em 3.5.5, causando uma perturbação por degrau no sistema.

A utilização das condições indicadas a seguir permitiram o estabelecimento de regime transiente, o qual resulta nítido da observação das figuras 3.VI e 4.VIII $(\mu=f(t)):$ 


$$
\begin{aligned}
& F=692 \mathrm{ml} / \mathrm{h} \\
& D=0,24 \mathrm{~h}^{-1} \\
& \Phi=1 \mathrm{\ell} / \mathrm{\ell} \cdot \mathrm{min} \\
& N=500 \mathrm{~min}^{-1}
\end{aligned}
$$

As figuras 4.VII e 4.VIII, cujos dados são apresentados na tabela 4.6, mostram o comportamento de $\mu_{S}$, $\mu\left(S^{\prime}-S\right), \mu$ e $\mu X$ em função do tempo.

Merece destaque a similaridade dos perfis de $\mu_{S}$ e ${ }^{\prime}\left(s^{\prime}-s\right)$, que parecem mostrar o acoplamento, provavelmente intermediado pela ação da invertase ligada à parede celular da levedura, entre a decomposição da sacarose e a retirada dos açūcares redutores formados do mosto em fermentação.

$$
\text { Por outro lado, confrontando-se } v \text { e } \mu\left(S^{\prime}-s\right)
$$
constata-se que estas duas velocidades especificas apresentam comportamento oposto, sobretudo a partir do instante $t=35 \mathrm{~h}$ onde $v$ cresce e $\mu\left(S^{\prime}-S\right)$ decresce.

Confrontando $v=f(t)$ com $\mu X=f(t)$ nota-se que ambas são nitidamente funçōes crescentes, embora não tenha sido possivel associar aos pontos experimentais uma reta de mínimo quadrado estatisticamente significativa.

Da figura 4.VII observa-se que $v$ apresentou um aumento abrupto $8 \mathrm{~h}$ apōs a perturbação, evidenciando a fase de adaptação sofrida pelas cēlulas de levedura diante das novas condiçōes ambientais. A partir desta fase de adaptação os valores de voscilaram, sendo o P.0.M de $3,3 \mathrm{~h}$. 


\section{B) 3 a etapa}

Caracterizou-se pela manutenção das condições da etapa anterior, a menos da vazão específica de alimentação que foi reduzida a $0,10 \mathrm{~h}^{-1}$. As figuras 3.VI e 4.X ( $\mu=$ $f(t))$ mostram o estabelecimento de regime transiente no sistema.

As figuras 4 .IX e 4.X, cujos dados aparecem na tabela 4.7, mostram os perfis de $\mu_{S}, \mu, \mu\left(S^{\prime}-S\right)$ e $: \mu X$ em função do tempo.

Tal como na etapa precedente, $\mu_{S}$ e $\mu_{\left(S^{\prime}-S\right)}$ em funçāo do tempo apresentam comportamento similar. Contudo, comparando-se simultaneamente $v, \mu x, \mu_{S} e \mu\left(S^{\prime}-S\right)$ ao longo desta etapa nota-se que inexiste correlação estatistica mente significativa.

No entanto, caso se leve em conta o periodo de ensaio compreendido entre os instantes $t=52,5 \mathrm{~h}$ e $t=63 \mathrm{~h}$, - qual pode ser considerado como sendo a fase de adaptação da levedura às novas condições, observa-se que $v$, Hs e $\mu\left(S^{\prime}-S\right)$ são funções decrescentes com o tempo, enquanto que $\mu X \bar{e}$ função crescente.

Ajustando-se as retas de minimo quadrado aos pontos situados entre os instantes referidos para $v$, " $S$, $\mu\left(S^{t}-S\right)$ e $\mu X$, obtém-se, respectivamente, os seguintes coeficientes de correlação: 0,$98 ; 0,93 ; 0,91$ e 0,98 . 0s respectivos valores críticos de $r$ com $99 \%$ de probabilidade são: 0,83 e 0,76 (32).

Outrossim deve-se mencionar que entre os instantes $t=63 \mathrm{~h}$ e $t=75 \mathrm{~h}$ os valores de $v$ oscilam, sendo $o$ P.O.M. igual a $6 \mathrm{~h}$. 
C) 4 a

Esta foi realizada nas mesmas condições que a anterior, exceto que o ar foi borbulhado a uma vazão de 2 $\ell / \ell \cdot \min$.

As figuras $3 . V I$ e $4 . X(\mu=f(t))$ mostran que 0 regime estabelecido na dorna foi o transiente, embora menos acentuado que nas etapas anteriores. Ressalte-se que a partir de $t=90 \mathrm{~h}$ o sistema tendeu para regime estacionārio.

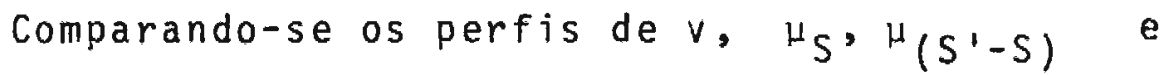
$\mu X$, mostrados nas figuras 4.IX e $4 . X$, verifica-se a inexistência de correlação entre eles, exceptuando-se,talvez, $\mu_{S}$ e $\mu\left(s^{\prime}-s\right)$, quando comparados entre si.

Não se encontrou explicação plausivel para a pronunciada variação ocorrida ao redor do instante $t=86 \mathrm{~h}$ nas curvas de $\mu X, \mu$ e X.

Para firalizar, deve ser salientado que durante toda esta etapa os valores de $v$ oscilam, sendo o P.o.M., igual a $5,3 \mathrm{~h}$. 
TABELA 4.6 Velocidades específicas de consumo de $A R$, de consumo de sacarose, de crescimento celular e produtividade em cēlulas para o ensaio no 5 (2a etapa).

\begin{tabular}{|c|c|c|c|c|c|c|c|}
\hline $\begin{array}{c}t \\
(h)\end{array}$ & $\begin{array}{c}x \\
(g / \ell)\end{array}$ & $\begin{array}{c}S \\
(g / \ell)\end{array}$ & $\begin{array}{c}S^{\prime} \\
(g / \ell)\end{array}$ & $\begin{array}{c}\mu\left(s^{\prime}-s\right) \\
\left(h^{-1}\right)\end{array}$ & $\begin{array}{c}\mu_{S} \\
\left(h^{-1}\right)\end{array}$ & $\begin{array}{c}\mu \\
\left(h^{-1}\right)\end{array}$ & $\begin{array}{c}\mu X \\
(g / \ell \cdot h)\end{array}$ \\
\hline 27 & 1,43 & 7,5 & 20,8 & 1,84 & 1,67 & 0,303 & 0,433 \\
\hline 28 & 1,52 & 7,5 & 20,8 & 1,73 & 1,57 & 0,303 & 0,461 \\
\hline 29 & 1,62 & 7,5 & 20,8 & 1,68 & 1,54 & 0,299 & 0,484 \\
\hline 30 & 1,71 & 7,5 & 20,6 & 1,74 & 1,60 & 0,307 & 0,525 \\
\hline 31 & 1,85 & 7,5 & 20,1 & 1,76 & 1,64 & 0,318 & 0,588 \\
\hline 32 & 2,00 & 7,5 & 19,5 & 1,89 & 1,80 & 0,305 & 0,610 \\
\hline 33 & 2,11 & 7,4 & 18,5 & 2,25 & 2,19 & 0,318 & 0,671 \\
\hline 34 & 2,33 & 7,3 & 16,2 & 2,42 & 2,40 & 0,324 & 0,755 \\
\hline 35 & 2,50 & 7,1 & 14,1 & 2,38 & 2,48 & 0,320 & 0,800 \\
\hline 36 & 2,73 & 6,5 & 12,0 & 2,23 & 2,51 & 0,330 & 0,901 \\
\hline 37 & 3,00 & 5,5 & 9,5 & 2,12 & 2,54 & 0,343 & 1,03 \\
\hline 38 & 3,35 & 4,5 & 7,1 & 1,93 & 2,37 & 0,333 & 1,12 \\
\hline 39 & 3,62 & 3,5 & 4,5 & 1,71 & 2,18 & 0,317 & 1,15 \\
\hline 40 & 3,91 & 2,5 & 3,3 & 1,54 & 1,97 & 0,308 & 1,20 \\
\hline 41 & 4,15 & 2,0 & 2,5 & 1,41 & 1,77 & 0,293 & 1,22 \\
\hline 42 & 4,35 & 1,6 & 2,1 & 1,31 & 1,63 & 0,284 & 1,24 \\
\hline 43 & 4,53 & 1,6 & 2,0 & 1,26 & 1,53 & 0,276 & 1,25 \\
\hline 44 & 4,68 & 1,5 & 2,0 & 1,22 & 1,48 & 0,267 & 1,25 \\
\hline 45 & 4,78 & 1,5 & 2,0 & 1,19 & 1,44 & 0,266 & 1,27 \\
\hline 46 & 4,93 & 1,5 & 2,0 & 1,15 & 1,40 & 0,267 & 1,32 \\
\hline 47 & 5,05 & 1,5 & 2,0 & 1,13 & 1,36 & 0,264 & 1,33 \\
\hline 48 & 5,17 & 1,5 & 2,0 & 1,10 & 1,33 & 0,256 & 1,32 \\
\hline 49 & 5,22 & 1,5 & 2,0 & 1,09 & 1,32 & 0,246 & 1,28 \\
\hline 50 & 5,23 & 1,5 & 2,0 & 1,09 & 1,32 & 0,243 & 1,27 \\
\hline 51 & 5,25 & 1,5 & 2,0 & 1,08 & 1,31 & 0,243 & 1,28 \\
\hline
\end{tabular}



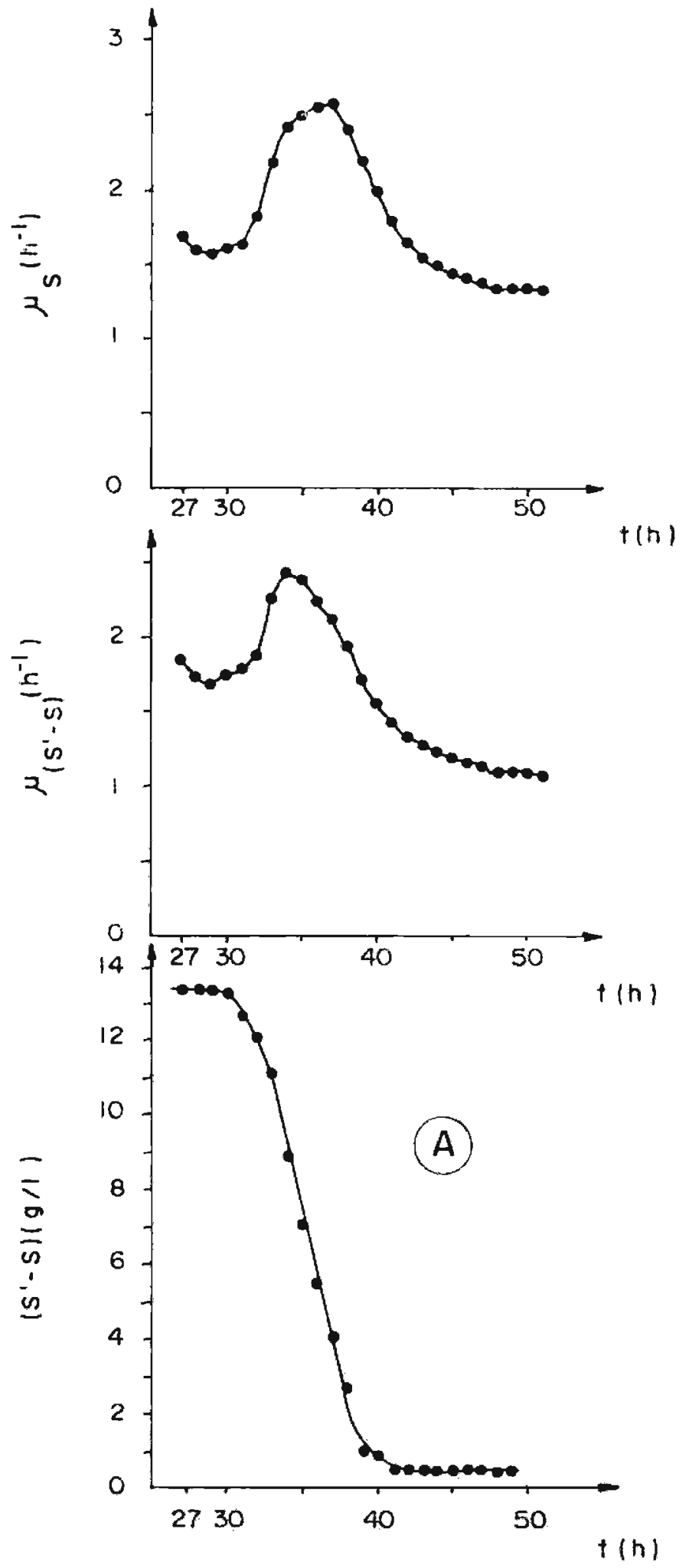

FIGURA 4.VII. Variação, com o tempo, das velocidades especīficas de consurio de sacarose ( $\mu\left(S^{\prime}-S\right)$ ) e de AR ( $S_{S}$ ) referentes a 2 a etapa do ensaio nọ. O gräfico A mostra o perfil da curva para interpolar os valores de ( $S^{\prime}-S$ ) utilizados para calcular $\mu\left(S^{\prime}-5\right.$. O per$f i l$ da curva usado para interpolar os valores de $S$ para calcular its $\bar{E}$ mostrado na figura 3 .VI do $\bar{i}-$ tem 3.5 .5 . 

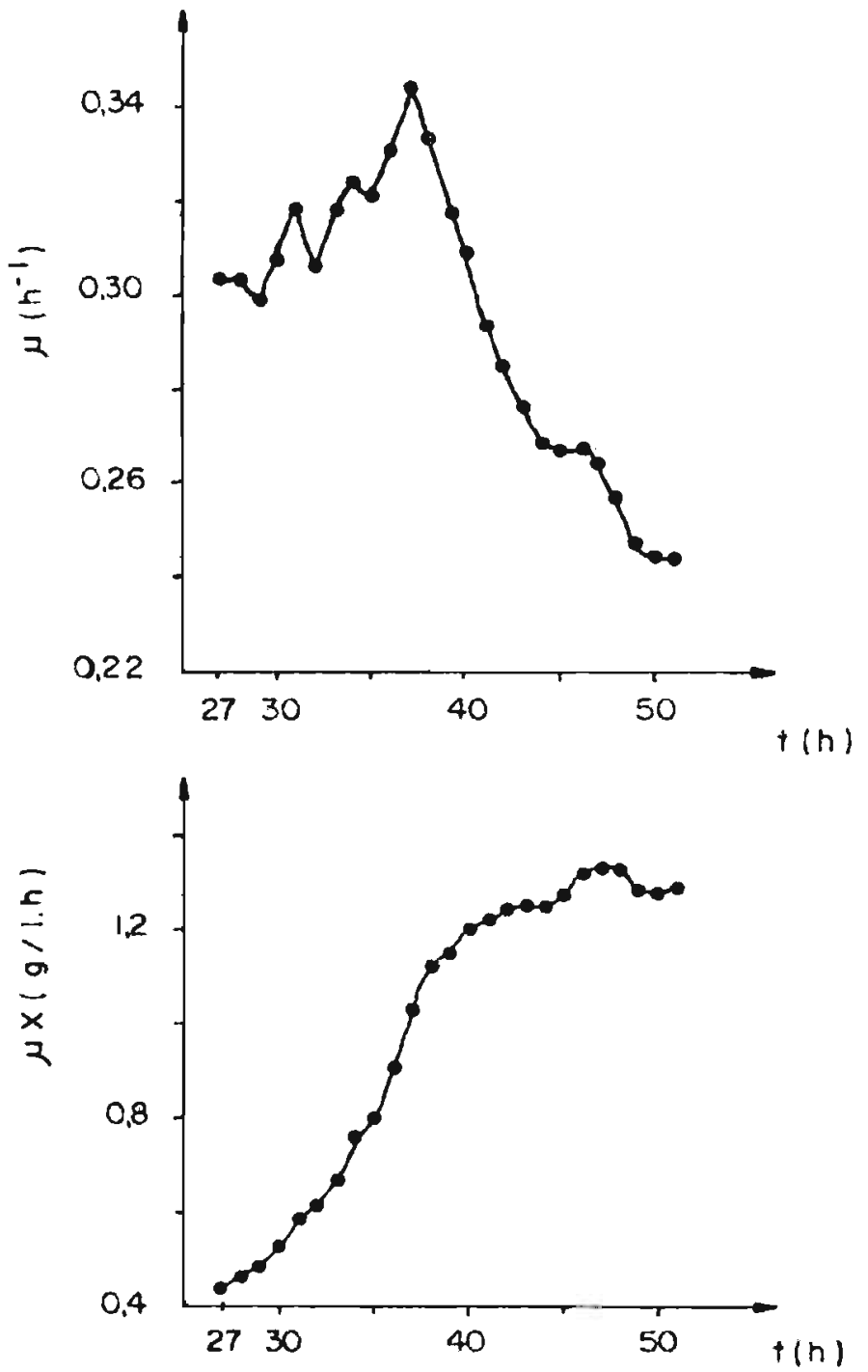

FIGURA 4.VIII. Variaçäo, com o tempo, da velocidade especifi ca de crescimento celular ( $\mu$ ) e da produtivi= dade em células ( $\mu X$ ) referentes a 2 a etapa do ensaio n! 5 . 
TABELA 4.7 Velocidades especificas de consumo de AR, de consumo de sacarose, de crescimento celular e produtividade em células para o ensaio nọs (3a e $4 \stackrel{a}{-}$ etapas).

\begin{tabular}{|c|c|c|c|c|c|c|c|}
\hline$(h)$ & $\begin{array}{c}x \\
(g / \ell)\end{array}$ & $\begin{array}{c}S \\
(g / \ell)\end{array}$ & $\begin{array}{c}S^{\prime} \\
(g / l)\end{array}$ & $\begin{array}{c}\mu\left(S^{1}-s\right) \\
\left(h^{-1}\right)\end{array}$ & $\begin{array}{l}{ }^{\mu_{S}} \\
\left(h^{-1}\right)\end{array}$ & $\begin{array}{l}\mu \\
\left(h^{-1}\right)\end{array}$ & $\begin{array}{c}\mu X \\
(g / \ell \cdot h)\end{array}$ \\
\hline 54 & 6,4 & 1,02 & 1,49 & 0,372 & 0,458 & 0,209 & 1,34 \\
\hline 55 & 7,1 & 1,02 & 1,49 & 0,336 & 0,413 & 0,192 & 1,36 \\
\hline 56 & 7,7 & 1,02 & 1,49 & 0,309 & 0,381 & 0,178 & 1,37 \\
\hline 57 & 8,3 & 1,02 & 1,49 & 0,287 & 0,353 & 0,166 & 1,38 \\
\hline 58 & 8,8 & 1,02 & 1,49 & 0,271 & 0,333 & 0,157 & T. 38 \\
\hline 59 & 9,3 & 1,02 & 1,49 & 0,256 & 0,375 & 0,154 & 1,43 \\
\hline 60 & 9,8 & 1,02 & 1,49 & 0,243 & 0,299 & 0,148 & 1,45 \\
\hline 61 & 10,3 & 1,02 & 1,49 & 0,232 & 0,286 & 0,144 & 1,48 \\
\hline 62 & 10,7 & 1,02 & 1,49 & 0,223 & 0,274 & 0,139 & 1,49 \\
\hline 63 & 11,1 & 1,02 & 1,49 & 0,215 & 0,264 & 0,136 & 1,51 \\
\hline 64 & 11,5 & 1,02 & 1,49 & 0,207 & 0,255 & 0,135 & 1,55 \\
\hline 65 & 11,9 & 1,02 & 1,49 & 0,200 & 0,246 & 0,127 & 1,51 \\
\hline 66 & 12,2 & 1,02 & 1,49 & 0,196 & 0,241 & 0,125 & 1,52 \\
\hline 67 & 12,5 & 1,02 & 1,49 & 0,191 & 0,234 & 0,126 & 1,58 \\
\hline 68 & 12,8 & 1,02 & 1,49 & 0,186 & 0,229 & 0,120 & 1,54 \\
\hline 69 & 13,0 & 1,02 & 1,49 & 0,183 & 0,225 & 0,115 & 1,50 \\
\hline 70 & 13,2 & 1,02 & 1,49 & 0,181 & 0,222 & 0,113 & 1,49 \\
\hline 71 & 13,4 & 1,02 & 1,49 & 0,179 & 0,220 & 0,109 & 1,46 \\
\hline 72 & 13,5 & 1,02 & 1,49 & 0,177 & 0,218 & 0,107 & 1,44 \\
\hline 73 & 13,6 & 1,02 & 1,49 & 0,176 & 0,216 & 0,106 & 1,44 \\
\hline 74 & 13,6 & 1,02 & 1,49 & 0,175 & 0,216 & 0,102 & 1,39 \\
\hline $75^{\star}$ & 13,6 & 1,02 & 1,49 & 0,175 & 0,216 & 0,111 & 1,51 \\
\hline 76 & 13,9 & 1,02 & 1,49 & 0,166 & 0,205 & 0,116 & 1,61 \\
\hline 77 & 14,2 & 1,02 & 1,49 & 0,163 & 0,201 & 0,117 & 1,66 \\
\hline 78 & 14,5 & 1,02 & 1,49 & 0,160 & 0,197 & 0,114 & 1,65 \\
\hline 79 & 14,7 & 1,02 & 1,49 & 0,158 & 0,194 & 0,113 & 1,66 \\
\hline 80 & 14,9 & 1,02 & 1,49 & 0,155 & 0,191 & 0,112 & 1,67 \\
\hline 81 & 15,1 & 1,02 & 1,49 & 0,153 & 0,188 & 0,110 & 1,66 \\
\hline
\end{tabular}


Continuação da Tabela 4.7

\begin{tabular}{lcccccccc}
\hline$t$ & $x$ & $S$ & $S^{\prime}$ & $\mu\left(S^{1}-S\right)$ & $\mu_{S}$ & $\mu$ & $\mu X$ \\
$(h)$ & $(g / l)$ & $(g / \ell)$ & $(g / \ell)$ & $\left(h^{-1}\right)$ & $\left(h^{-1}\right)$ & $\left(h^{-1}\right)$ & $(g / l . h)$ \\
\hline 82 & 15,3 & 1,02 & 1,49 & 0,151 & 0,186 & 0,108 & 1,65 \\
83 & 15,5 & 1,02 & 1,49 & 0,150 & 0,184 & 0,107 & 1,65 \\
84 & 15,6 & 1,02 & 1,49 & 0,148 & 0,182 & 0,099 & 1,54 \\
85 & 15,5 & 1,02 & 1,49 & 0,149 & 0,183 & 0,075 & 1,16 \\
86 & 14,8 & 1,02 & 1,49 & 0,156 & 0,192 & 0,053 & 0,78 \\
87 & 14,2 & 1,02 & 1,49 & 0,163 & 0,200 & 0,075 & 1,07 \\
88 & 14,1 & 1,02 & 1,49 & 0,164 & 0,202 & 0,093 & 1,34 \\
89 & 14,1 & 1,02 & 1,49 & 0,164 & 0,202 & 0,097 & 1,37 \\
90 & 14,1 & 1,02 & 1,49 & 0,164 & 0,202 & 0,097 & 1,37 \\
91 & 14,1 & 1,02 & 1,49 & 0,164 & 0,202 & 0,097 & 1,37 \\
92 & 14,1 & 1,02 & 1,49 & 0,164 & 0,202 & 0,097 & 1,37 \\
93 & 14,1 & 1,02 & 1,49 & 0,164 & 0,202 & 0,097 & 1,37 \\
94 & 14,1 & 1,02 & 1,49 & 0,164 & 0,202 & 0,097 & 1,37 \\
95 & 14,1 & 1,02 & 1,49 & 0,164 & 0,202 & 0,097 & 1,37 \\
96 & 14,1 & 1,02 & 1,49 & 0,164 & 0,202 & 0,097 & 1,37 \\
& & & & & & & \\
\hline
\end{tabular}

* Instante em que foi feita a mudança de $\Phi$. 

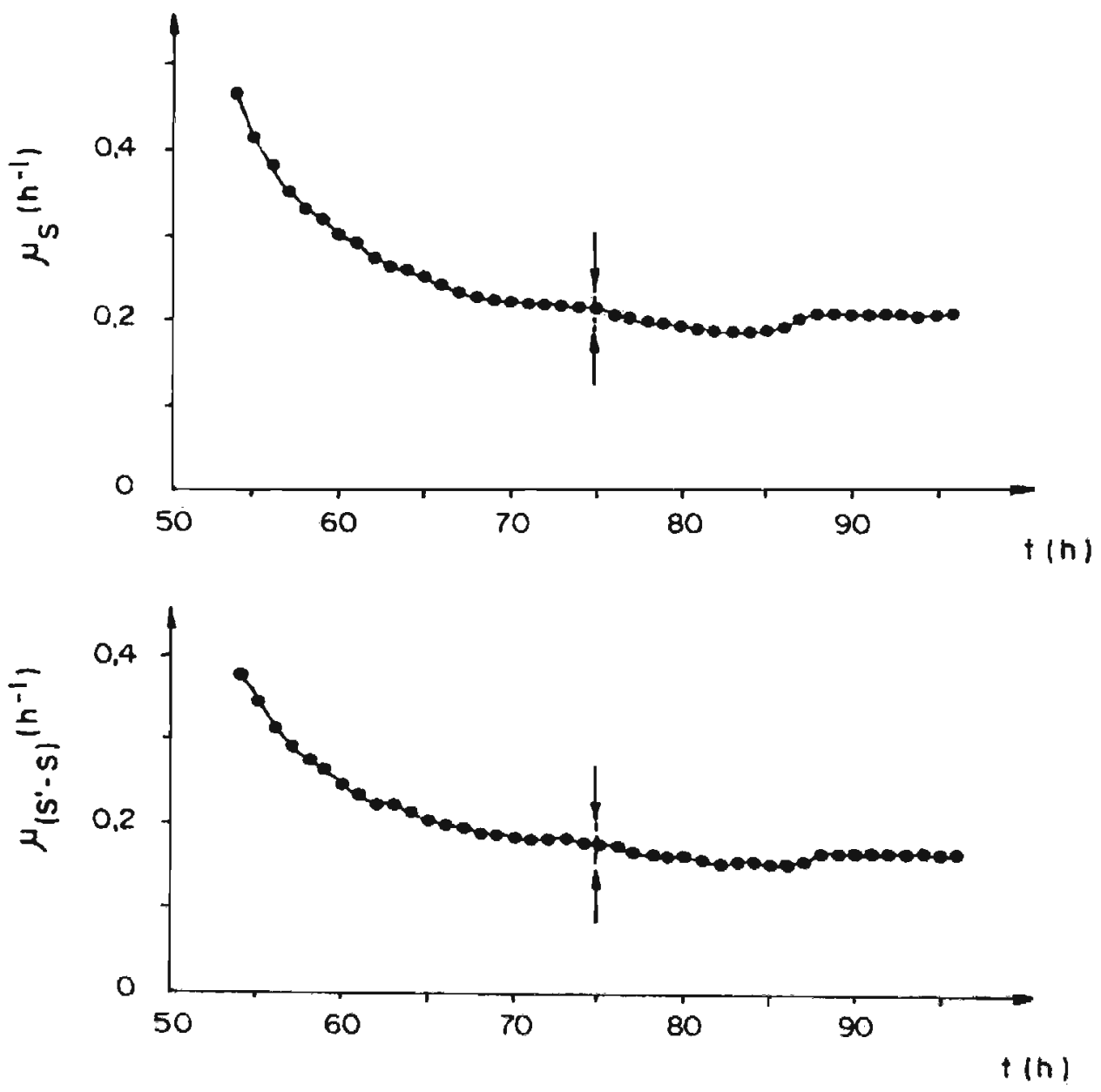

FIGURA 4. IX. Variação com o tempo, das velocidades especîfi cas de consumo de sacarose $\left(\mu\left(S^{\prime}-s\right)\right)$ e de AR ( $\left.\mu_{s}\right)$ referentes as 3 a e 4 a etapas do ensaio रo 5 . 

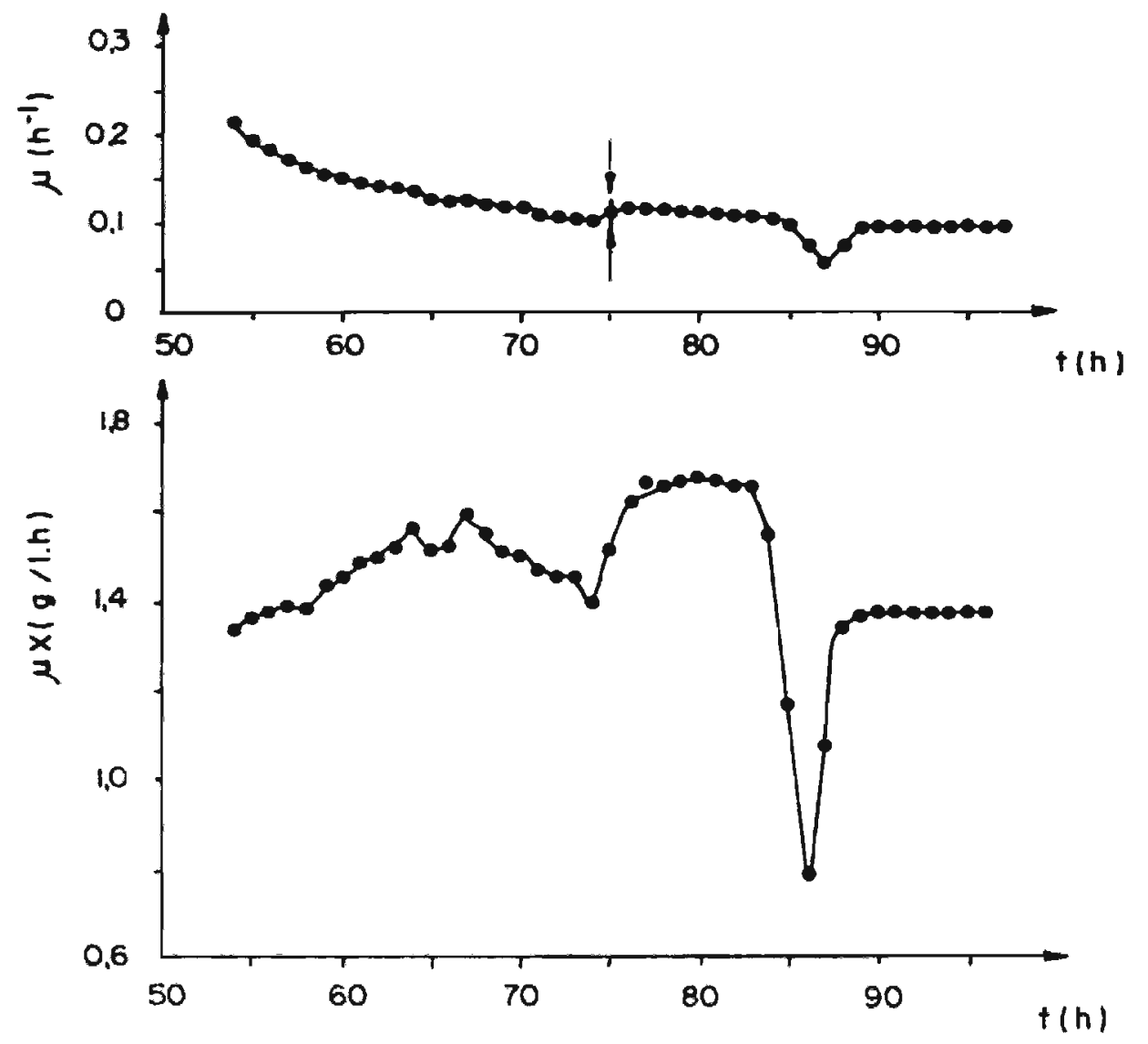

FIgURA 4.X. Variação, com o tempo, da velocidade especiffica de crescimento celular (H) e da produtivida de em células $(\mu X)$ referentes à $3 \stackrel{a}{a}$ e 4 a etapas do ensaio nọ 5 . 


\subsubsection{Ensaio n: 6}

Este ensaio será analisado em 2 etapas. Os resultados são mostrados nas figuras 3.IX, 4.XI e 4.XII e nas tabelas 3.15 e 4.8 .

A) $1 \stackrel{\text { a etapa }}{ }$

A utilização das seguintes condições expe-

rimentais:

$$
F=711 \mathrm{ml} / \mathrm{h} ; \mathrm{D}=0,23 \mathrm{~h}^{-1} ; \Phi=1 \text { l/l.min; } N=500 \mathrm{~min}^{-1}
$$

permitiram o estabelecimento de regime transiente, conforme se pode depreender das figuras $3 . I X$ e $4.12(\mu=f(t))$.

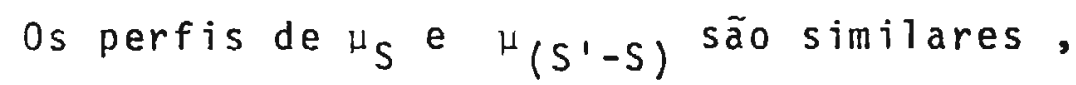
mostrando, tal como na 2 a etapa do ensaio no 5, um acoplamento entre a decomposição da sacarose e a metabolização dos açūcares redutores. Por outro lado $v e{ }^{\prime \prime}\left(S^{\prime}-S\right)$ são funções nitidamente distintas, pois aquela $\bar{e}$ decrescente e esta crescente.

Comparando $v=f(t)$ e $\mu X=f(t)$ nota-se que ambas são funções decrescentes. Associando-se retas de minimos quadrados aos pontos situados entre $t=12 \mathrm{~h}$ e $t=35 \mathrm{~h}$ tanto para $v$ como para $\mu X$, encontrou-se os respectivos valores para $r: 0,94$ e 0,93 . Os correspondentes valores crïticos de $r$ para 99\% de probabilidade são: 0,62 e 0,54 (32).

Entre os instantes $t=35 \mathrm{~h}$ e $t=45 \mathrm{~h}, \quad \mathrm{v}$ e $\mu X$, aparentemente, não apresentam correlação. Não se encon trou justificativa para tal fato.

Pela figura 3 . IX verifica-se que os valores de voscilam ao longo do tempo, sendo O P.O.M. igual a $4,4 \mathrm{~h}$. 
B) $2 \stackrel{\text { a }}{\underline{a}}$ etapa

o uso das seguintes condiçôes experimentais:

$$
\begin{aligned}
& F=704 \mathrm{ml} / \mathrm{h} \\
& D=0,24 \mathrm{~h}^{-1} \\
& M=2 \mathrm{l} / \mathrm{R} \cdot \mathrm{min} \\
& M=700 \mathrm{~min}^{-1}
\end{aligned}
$$

permitiram o estabelecimento de regime transiente, conforme se pode inferir das figuras 3.IX e 4.XII $(\mu=f(t))$. Contudo deve-se ressaltar que a partir do instante $t=60 \mathrm{~h} 0$ sistema parece ter atingido regime estacionário.

A analise comparada dos perfis de $\mu_{S}$, ${ }^{\prime}\left(S^{\prime}-S\right)^{e}$ $\checkmark$ conduzem a resultados análogos aos da etapa anterior.

Considerando o intervalo entre $t=45 \mathrm{~h}$ e $t=60 \mathrm{~h}$ nota-se que $v$ e $\mu X$ são funçöes crescentes, embora não tenha sido possivel ajustar retas de mînimo quadrado que tivessem significado estatistico. 
TABELA 4.8 Velocidades especificas de consumo de AR, de consumo de sacarose, de crescimento celular e produ tividade em cēlulas para o ensaio no 6 .

\begin{tabular}{|c|c|c|c|c|c|c|c|}
\hline $\begin{array}{c}t \\
(h)\end{array}$ & $\begin{array}{c}x \\
(g / e)\end{array}$ & $\begin{array}{c}S \\
(g / 2)\end{array}$ & $\begin{array}{c}S^{\prime} \\
(g / \ell)\end{array}$ & $\begin{array}{c}\mu\left(S^{1}-s\right) \\
\left(h^{-1}\right)\end{array}$ & $\begin{array}{c}\mu_{S} \\
\left(h^{-1}\right)\end{array}$ & $\left(h^{-1}\right)$ & $\begin{array}{c}\mu x \\
(g / \ell \cdot h)\end{array}$ \\
\hline 0 & 3,90 & 1,00 & 1,40 & 1,39 & 1,70 & 0,256 & 0,998 \\
\hline 1 & 4,00 & 1,10 & 1,55 & 1,36 & 1,66 & 0,261 & 1,04 \\
\hline 2 & 4,75 & 1,15 & 1,60 & 1,31 & 1,59 & 0,272 & 1,13 \\
\hline 3 & 4,35 & 1,30 & 1,70 & 1,25 & 1,50 & 0,270 & 1,18 \\
\hline 4 & 4,50 & 1,40 & 1,85 & 1,21 & 1,45 & 0,260 & 1,17 \\
\hline 5 & 4,62 & 1,50 & 1,95 & 1,18 & 1,41 & 0,252 & 1,16 \\
\hline 6 & 4,70 & 1,62 & 2,10 & 1,16 & 1,38 & 0,233 & 1,10 \\
\hline 7 & 4,65 & 1,72 & 2,20 & 1,17 & 1,39 & 0,219 & 1,02 \\
\hline 8 & 4,60 & 1,85 & 2,30 & 1,18 & 1,40 & 0,219 & 1,01 \\
\hline 9 & 4,55 & 2,00 & 2,40 & 1,20 & 1,40 & 0,219 & 0,996 \\
\hline 10 & 4,50 & 2,12 & 2,50 & 1,21 & 1,41 & 0,213 & 0,959 \\
\hline 11 & 4,40 & 2,22 & 2,65 & 1,24 & 1,42 & 0,210 & 0,924 \\
\hline 12 & 4,32 & 2,35 & 2,75 & 1,26 & 1,45 & 0,216 & 0,933 \\
\hline 13 & 4,28 & 2,50 & 2,90 & 1,27 & 1,46 & 0,216 & 0,924 \\
\hline 14 & 4,20 & 2,65 & 3,05 & 1,29 & 1,49 & 0,215 & 0,903 \\
\hline 15 & 4,15 & 2,70 & 3,20 & 1,31 & 1,50 & 0,218 & 0,905 \\
\hline 16 & 4,10 & 2,85 & 3,35 & 1,32 & 1,50 & 0,218 & 0,894 \\
\hline 17 & 4,05 & 3,00 & 3,50 & 1,33 & 1,50 & 0,218 & 0,883 \\
\hline 18 & 4,00 & 3,10 & 3,70 & 1,31 & 1,49 & 0,218 & 0,872 \\
\hline 19 & 3,95 & 3,18 & 3,90 & 1,31 & 1,49 & 0,220 & 0,869 \\
\hline 20 & 3,92 & 3,20 & 4,10 & 1,32 & 1,51 & 0,224 & 0,878 \\
\hline 21 & 3,90 & 3,22 & 4,33 & 1,34 & 1,53 & 0,227 & 0,885 \\
\hline 22 & 3,90 & 3,25 & 4,33 & 1,36 & 1,55 & 0,227 & 0,885 \\
\hline 23 & 3,88 & 3,28 & 4,33 & 1,38 & 1,56 & 0,226 & 0,877 \\
\hline 24 & 3,87 & 3,35 & 4,33 & 1,40 & 1,57 & 0,226 & 0,875 \\
\hline 25 & 3,85 & 3,45 & 4,33 & 1,42 & 1,57 & 0,225 & 0,866 \\
\hline 26 & 3,83 & 3,60 & 4,33 & 1,44 & 1,58 & 0,226 & 0,866 \\
\hline 27 & 3,82 & 3,75 & 4,33 & 1,45 & 1,59 & 0,227 & 0,867 \\
\hline 28 & 3,81 & 3,90 & 4,33 & 1,46 & 1,59 & 0,227 & 0,865 \\
\hline 29 & 3,80 & 3,98 & 4,33 & 1,45 & 1.59 & 0,229 & 0,870 \\
\hline
\end{tabular}


Continuação da Tabela 4.8

\begin{tabular}{|c|c|c|c|c|c|c|c|}
\hline $\begin{array}{c}t \\
(h)\end{array}$ & $\begin{array}{c}x \\
(g / \ell)\end{array}$ & $\begin{array}{c}S \\
(g / \ell)\end{array}$ & $\begin{array}{c}S^{\prime} \\
(g / l)\end{array}$ & $\begin{array}{c}\mu\left(S^{\prime}-S\right) \\
\left(h^{-1}\right)\end{array}$ & $\begin{array}{c}{ }^{\mu} S \\
\left(h^{-1}\right)\end{array}$ & $\left(h^{-1}\right)$ & $\begin{array}{c}\mu x \\
(g / \ell . h)\end{array}$ \\
\hline 30 & 3,80 & 4,00 & 4,33 & 1,44 & 1,59 & 0,227 & 0,863 \\
\hline 31 & 3,78 & 4,05 & 4,37 & 1,44 & 1,59 & 0,226 & 0,854 \\
\hline 32 & 3,77 & 4,05 & 4,40 & 1,44 & 1,60 & 0,226 & 0,852 \\
\hline 33 & 3,75 & 4,05 & 4,42 & 1,44 & 1,60 & 0,223 & 0,836 \\
\hline 34 & 3,72 & 4,02 & 4,50 & 1,43 & 1,60 & 0,225 & 0,837 \\
\hline 35 & 3,71 & 4,00 & 4,52 & 1,43 & 1,60 & 0,227 & 0,842 \\
\hline 36 & 3,70 & 3,90 & 4,60 & 1,41 & 1,61 & 0,229 & 0,847 \\
\hline 37 & 3,70 & 3,80 & 4,65 & 1,41 & 1,61 & 0,229 & 0,847 \\
\hline 38 & 3,69 & 3,72 & 4,69 & 1,41 & 1,60 & 0,223 & 0,823 \\
\hline 39 & 3,65 & 3,70 & 4,75 & 1,43 & 1,62 & 0,218 & 0,796 \\
\hline 40 & 3,60 & 3,70 & 4,80 & 1,47 & 1,64 & 0,223 & 0,803 \\
\hline 41 & 3,60 & 3,85 & 4,90 & 1,51 & 1,63 & 0,223 & 0,803 \\
\hline 42 & 3,55 & 4,10 & 4,95 & 1,54 & 1,65 & 0,216 & 0,767 \\
\hline 43 & 3,50 & 4,20 & 5,01 & - & - & 0,209 & 0,732 \\
\hline 44 & 3,40 & 4,25 & 5,10 & 1,56 & 1,71 & 0,201 & 0,683 \\
\hline $45^{\star}$ & 3,30 & 4,25 & 5,15 & 1,62 & 1,80 & 0,198 & 0,653 \\
\hline 46 & 3,45 & 4,20 & 5,00 & 1,66 & 1,84 & 0,276 & 0,952 \\
\hline 47 & 3,55 & 4,18 & 4,80 & 1,63 & 1,81 & 0,275 & 0,976 \\
\hline 48 & 3,70 & 4,08 & 4,60 & 1,54 & 1,75 & 0,271 & 1,00 \\
\hline 49 & 3,78 & 3,90 & 4,40 & 1,49 & 1,72 & 0,261 & 0,987 \\
\hline 50 & 3,86 & 3,65 & 4,20 & 1,43 & 1,70 & 0,262 & 1,01 \\
\hline 51 & 3,95 & 3,20 & 4,15 & 1,35 & 1,66 & 0,259 & 1,02 \\
\hline 52 & 4,01 & 2,85 & 3,90 & 1,33 & 1,62 & 0,256 & 1,03 \\
\hline 53 & 4,08 & 2,65 & 3,80 & 1,33 & 1,61 & 0,253 & 1,03 \\
\hline 54 & 4,12 & 2,53 & 3,70 & 1,36 & 1,61 & 0,248 & 1,02 \\
\hline 55 & 4,15 & 2,53 & 3,50 & 1,37 & 1,61 & 0,250 & 1,04 \\
\hline 56 & 4,20 & 2,53 & 3,40 & 1,35 & 1,58 & 0,246 & 1,03 \\
\hline 57 & 4,20 & 2,53 & 3,30 & 1,35 & 1,59 & 0,242 & 1,02 \\
\hline 58 & 4,22 & 2,53 & 3,22 & 1,34 & 1,58 & 0,246 & 1,04 \\
\hline 59 & 4,25 & 2,53 & 3,20 & 1,34 & 1,57 & 0,246 & 1,05 \\
\hline 60 & 4,27 & 2,53 & 3,15 & 1,33 & 1.56 & 0,246 & 1,05 \\
\hline 61 & 4,30 & 2,53 & 3,04 & 1,32 & 1,55 & 0,243 & 1,05 \\
\hline 62 & 4,30 & 2,53 & 3,04 & 1,32 & 1,55 & 0,242 & 1,04 \\
\hline 63 & 4,32 & 2,53 & 3,04 & 1,31 & 1,54 & 0,242 & 1,05 \\
\hline
\end{tabular}

Continua 
Continuação da Tabela 4.8

\begin{tabular}{cccccccc}
\hline $\begin{array}{c}\mathrm{t} \\
(\mathrm{h})\end{array}$ & $\begin{array}{c}\mathrm{X} \\
(\mathrm{g} / \mathrm{l})\end{array}$ & $\begin{array}{c}\mathrm{S} \\
(\mathrm{g} / \ell)\end{array}$ & $\begin{array}{c}\mathrm{S} \\
(\mathrm{g} / \ell)\end{array}$ & $\begin{array}{c}\mu\left(\mathrm{S}^{1}-\mathrm{S}\right) \\
\left(\mathrm{h}^{-1}\right)\end{array}$ & $\begin{array}{c}\mu_{S} \\
\left(\mathrm{~h}^{-1}\right)\end{array}$ & $\begin{array}{c}\mu \\
\left(\mathrm{h}^{-1}\right)\end{array}$ & $\begin{array}{c}\mu X \\
(\mathrm{~g} / \ell . \mathrm{h})\end{array}$ \\
\hline 64 & 4,32 & 2,53 & 3,04 & 1,31 & 1,54 & 0,240 & 1,04 \\
65 & 4,32 & 2,53 & 3,04 & 1,31 & 1,54 & 0,240 & 1,04 \\
66 & 4,32 & 2,53 & 3,04 & 1,31 & 1,54 & 0,240 & 1,04 \\
67 & 4,32 & 2,53 & 3,04 & 1,31 & 1,54 & 0,240 & 1,04 \\
68 & 4,32 & 2,53 & 3,04 & 1,31 & 1,54 & 0,240 & 1,04 \\
69 & 4,32 & 2,53 & 3,04 & 1,31 & 1,54 & 0,240 & 1,04 \\
70 & 4,32 & 2,53 & 3,04 & 1,31 & 1,54 & 0,240 & 1,04 \\
71 & 4,32 & 2,53 & 3,04 & 1,37 & 1,54 & 0,240 & 1,04 \\
72 & 4,32 & 2,53 & 3,04 & 1,31 & 1,54 & 0,240 & 1,04 \\
\hline
\end{tabular}



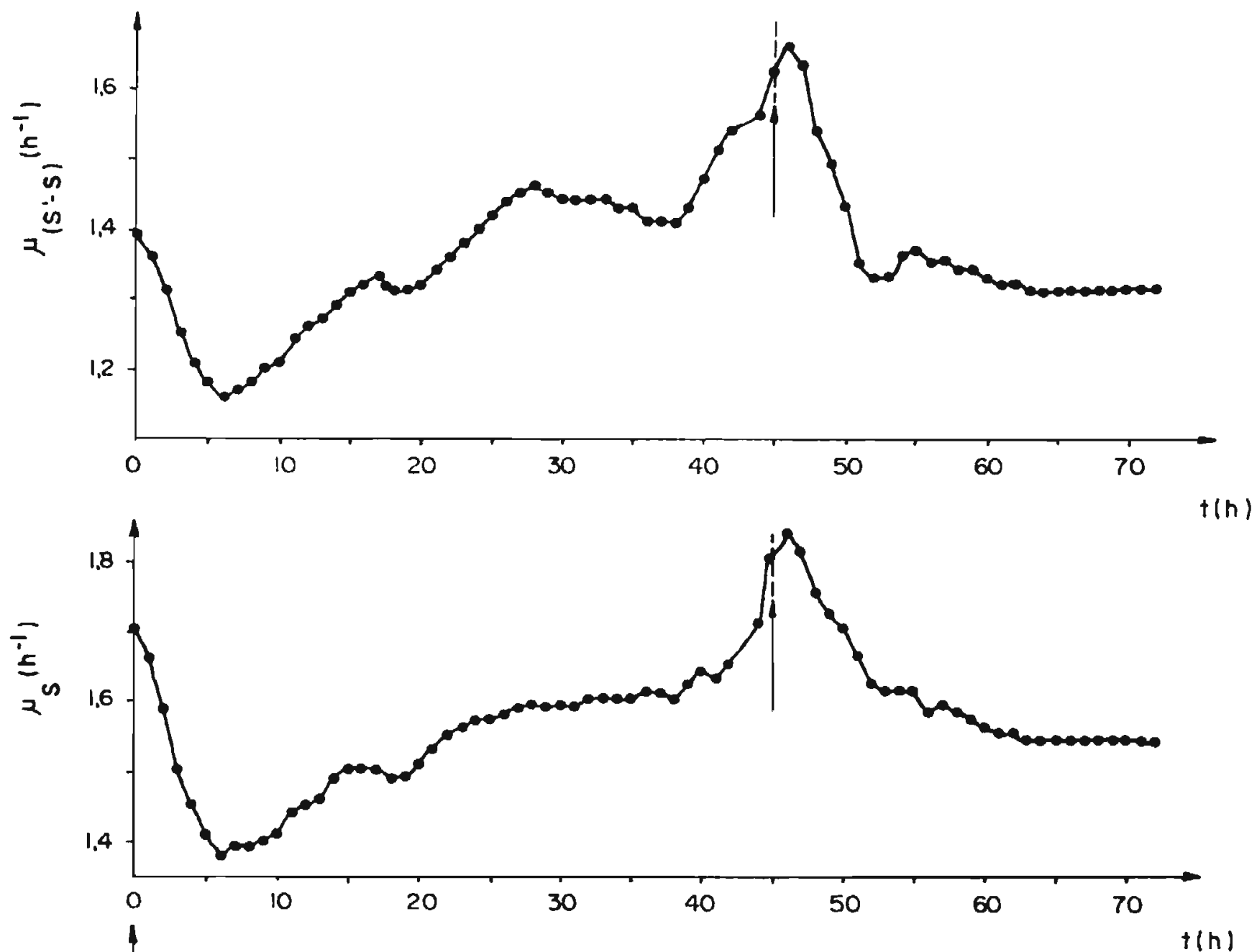

FIGURA 4.XI. Variação, com o tempo, das velocidades especificas de consumo de sacarose ( $\mu(S:-S)$ ) e de AR ( $\mu S)$ refe rentes ao ensaio no 6. O gräfico A mostra o perfiT da curva usada para interpolar os valores de ( $S^{\prime}-S$ ) utilizados para calcular $\mu\left(S^{\prime}-S\right)$. O perfil da curva usado para interpolar os valores de $S$ para 0 cálculo de $\mu_{S}$ e mostrado na figura 3 . IX do item 3.5 .6 . 

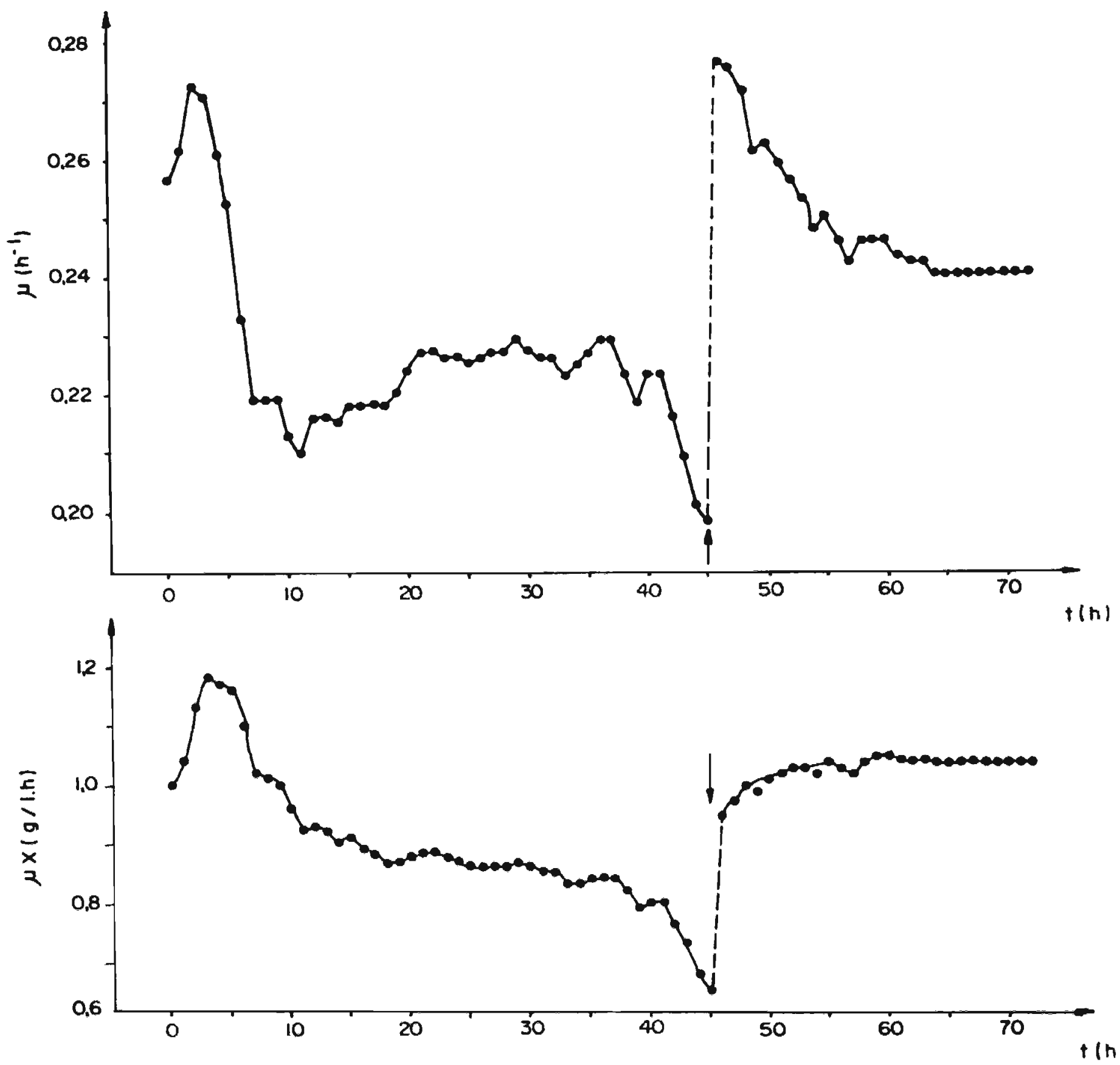

FIGURA 4.XII. Variação, com o tempo, da velocidade especifica de crescimento celular ( $\mu$ ) e da produtivida de em cēlulas ( $11 X$ ) referentes ao ensaio no 6 . 


\subsubsection{Ensaio ne 7}

Pela figura $3 . x$ nota-se claramente que, 0 processo fermentativo continuo realizado nas seguintes condições :

$$
F=725 \mathrm{ml} / \mathrm{h} ; \quad D=0,23 \mathrm{~h}^{-1} ; \quad \Phi=2 \mathrm{l} / \mathrm{l} \cdot \mathrm{min} ; \quad N=700 \mathrm{~min}^{-1}
$$

Permitiu o estabelecimento de regime estacionārio a partir do instante $t=12 \mathrm{~h}$.

0 patamar obtido se manteve por $42 \mathrm{~h}$, com os seguintes valores mëdios:

$$
\begin{array}{ll}
\bar{x}=3,71 \mathrm{~g} / \ell & \bar{s}^{\prime}=6,55 \mathrm{~g} / \ell \\
\bar{s}=5,14 \mathrm{~g} / \ell & \bar{v}=0,161 \mathrm{gART} / \mathrm{g} \mathrm{c} \bar{e} 1 . \mathrm{min}
\end{array}
$$

As velocidades especificas de crescimento celular, de consumo de $A R$ e consumo de sacarose são, respecti vamente, iguais a $0,23 \mathrm{~h}^{-1} ; 1,5 \mathrm{~h}^{-1}$ e $1,41 \mathrm{~h}^{-1}$. A produtivida de em células foi de $0,85 \mathrm{~g} / \mathrm{l} . \mathrm{h}$.

Durante todo o período de duração do patamar o valor de voscilou, sendo O P.O.M. de 4,2 h.

Conforme mostrado na figura $3 . x$, entre os instantes $t=48 \mathrm{~h}$ e $t=51 \mathrm{~h}$ foram feitas amostragens de 0,5 em $0,5 \mathrm{~h}$. Nota-se que neste intervalo de tempo surgiram dois picos, mostrando que, provavelmente, a oscilação observada, fazendo-se amostragem de 1,5 em $1,5 \mathrm{~h}$, nada mais é que o resulta do da somatōria de oscilação mais rāpidas, e cujo periodo médio não foi possivel determinar nas condições deste ensaio. 


\subsubsection{Ensaio nọ 10}

Entre os instantes $t=0 \mathrm{~h}$ e $t=19 \mathrm{~h}$ as condições operacionais foram anālogas às do ensaio nọ 4. os resultados obtidos nesta fase jā foram discutidos no item 4.5.1.6.

A partir de $t=19$ foram provocadas, de 12 em $12 \mathrm{~h}$, perturbações por impulso pela adição de uma só vez à dorna de uma mistura adequada de sais, conforme descrito em 3.5.11. Como consequeñcia o sistema passou a regime transiente, 0 qual estä ilustrado nas figuras 3.XIII e 4.XIV $(\mu=f(t))$.

Em todos os ensaios realizados atē o momento, as perturbações de naturezas diferentes foram feitas de modo descontinuo. Este ensaio, por sua vez, foi idealizado para verificar o comportamento de $v=f(t)$ fren te a perturbações de mesma natureza e provocadas periodicamente.

0 intervalo transcorrido entre duas perturbações consecutivas foi fixado em torno de $12 \mathrm{~h}$, corres pondendo a, aproximadamente, 3 tempos de residéncia. Nestas condições garantiu-se que, ao se provocar nova perturbação, a concentração dos ingredientes adicionados no impul so anterior jä era praticamente desprezīvel.

Pela figura $3 . X I I I$ observa-se que o com portamento de $\vee$ ao longo de todo o ensaio não se altera significativamente. No entanto se olharmos com mais aten- 
ção para os valores de $v$ antes e logo apös o impulso, verifica-se a ocorrēncia de variaçōes da ordem de $70 \%, 56 \%$, $76 \%$ e $79 \%$, respectivamente, para a $1 \stackrel{a}{-}, 2 \stackrel{a}{-} 3 \stackrel{a}{-}$ e $4 \stackrel{a}{a}$ pertur bações.

$$
\text { Considerando-se os perfis de } \mu_{S}, \mu\left(S^{\prime}-S\right) \text {, }
$$

$\checkmark$ e $\mu X$ das figuras 4.XIII e 4.XIV, cujos dados são mostrados na tabela 4.9, depreende-se que não existe corre-

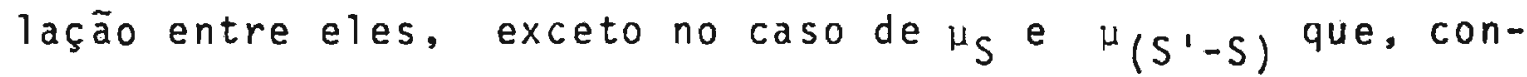
forme já vericado em ensaios anteriores, apresentam certa $\mathbf{j}$ milaridade.

Outrossim deve ser mencionado que os valo res de $v$ oscilaram durante todo o ensaio, sendo o P.O.M. de $4,7 \mathrm{~h}$. 
TABELA 4.9 Velocidades especîficas de consumo de AR, de consumo de sacarose, de crescimento celular e produtividade em células para o ensaio nọ 10.

\begin{tabular}{|c|c|c|c|c|c|c|c|}
\hline $\begin{array}{c}t \\
(h)\end{array}$ & $\begin{array}{c}x \\
(g / \ell)\end{array}$ & $\begin{array}{c}S \\
(g / \ell)\end{array}$ & $\begin{array}{c}S^{\prime} \\
(g / l)\end{array}$ & $\begin{array}{c}\mu\left(S^{\prime}-S\right) \\
\left(h^{-1}\right)\end{array}$ & $\begin{array}{c}\mu_{S} \\
\left(h^{-1}\right)\end{array}$ & $\begin{array}{c}\mu \\
\left(h^{-1}\right)\end{array}$ & $\begin{array}{c}\mu X \\
(g / \ell \cdot h)\end{array}$ \\
\hline 21 & 1,35 & 6,00 & 21,4 & $T, 84$ & 1,94 & 0,230 & 0,311 \\
\hline 22 & 1,35 & 6,00 & 21,1 & 1,89 & 1,99 & 0,249 & 0,336 \\
\hline 23 & 1,40 & 6,00 & 20,8 & 1,87 & 1,97 & 0,255 & 0,357 \\
\hline 24 & 1,42 & 6,00 & 20,3 & 1,96 & 2,06 & 0,265 & 0,376 \\
\hline 25 & 1,50 & 6,00 & 20,0 & 2,00 & 2,10 & 0,283 & 0,425 \\
\hline 26 & 1,58 & 6,00 & 19,5 & 2,01 & 2,10 & 0,277 & 0,438 \\
\hline 27 & 1,65 & 6,00 & 18,9 & 2,04 & 2,09 & 0,282 & 0,465 \\
\hline 28 & 1,75 & 6,70 & 18,3 & 2,04 & 2,06 & 0,273 & 0,478 \\
\hline 29 & 1,80 & 6,18 & 17,7 & 2,13 & 2,15 & 0,266 & 0,479 \\
\hline 30 & 1,88 & 6,20 & 17,0 & 2,18 & 2,16 & 0,257 & 0,483 \\
\hline 31 & 1,90 & 6,45 & 16,2 & 2,22 & 2,07 & 0,243 & 0,462 \\
\hline $32^{*}$ & 1,93 & 6,85 & 16,2 & 1,91 & 1,74 & 0,230 & 0,444 \\
\hline 33 & 1,90 & 7,00 & 16,5 & 1,72 & 1,64 & 0,217 & 0,412 \\
\hline 34 & 1,88 & 7,00 & 16,9 & 1,62 & 1,63 & 0,219 & 0,412 \\
\hline 35 & 1,86 & 6,80 & 17,1 & 1,52 & 1,70 & 0,222 & 0,413 \\
\hline 36 & 1,85 & 6,40 & 17,2 & 7,35 & 1,71 & 0,219 & 0,405 \\
\hline 37 & 1,82 & 5,40 & 17,1 & $T, 37$ & 1,96 & 0,222 & 0,404 \\
\hline 38 & 1,82 & 4,80 & 16,9 & 1,57 & 1,97 & 0,238 & 0,433 \\
\hline 39 & 1,85 & 4,70 & 16,6 & 1,89 & 2,00 & 0,252 & 0,466 \\
\hline 40 & 1,90 & 5,40 & 16,1 & 2,50 & 2,14 & 0,252 & 0,479 \\
\hline 41 & 1,93 & 7,00 & 15,6 & 2,77 & 2,18 & 0,256 & 0,494 \\
\hline $42^{*}$ & 2,00 & 7,50 & 15,0 & 2,21 & 2,07 & 0,268 & 0,536 \\
\hline 43 & 2,08 & 7,20 & 14,6 & 1,84 & 2,03 & 0,259 & 0,539 \\
\hline 44 & 2,12 & 6,30 & 14,3 & 1,64 & 1,98 & 0,247 & 0,524 \\
\hline 45 & 2,15 & 5,90 & 14,1 & 1,72 & 1,91 & 0,249 & 0,535 \\
\hline 46 & 2,20 & 5,80 & 14,1 & 1,71 & 1,82 & 0,246 & 0,541 \\
\hline 47 & 2,22 & 5,78 & 14,1 & 1,69 & 1,78 & 0,241 & 0,535 \\
\hline 48 & 2,25 & 5,78 & 14,2 & 1,67 & 1,79 & 0,243 & 0,547 \\
\hline 49 & 2,28 & 5,60 & 14,0 & 1,82 & 2,00 & 0,241 & 0,549 \\
\hline 50 & 2,30 & 5,40 & 12,8 & 2,21 & 2,35 & - & - \\
\hline
\end{tabular}

Continua 
Continuação da Tabela 4.9

\begin{tabular}{|c|c|c|c|c|c|c|c|}
\hline $\begin{array}{c}t \\
(h)\end{array}$ & $\begin{array}{c}x \\
(g / \ell)\end{array}$ & $\begin{array}{c}S \\
(g / \ell)\end{array}$ & $\begin{array}{c}S^{\prime} \\
(g / \ell)\end{array}$ & $\begin{array}{c}\mu\left(s^{\prime}-s\right) \\
\left(h^{-1}\right)\end{array}$ & $\begin{array}{c}\mu_{S} \\
\left(h^{-1}\right)\end{array}$ & $\begin{array}{c}\mu \\
\left(h^{-1}\right)\end{array}$ & $\begin{array}{c}\mu X \\
(g / \ell \cdot h)\end{array}$ \\
\hline 51 & 2,28 & 5,50 & 11,8 & 2,12 & 2,12 & 0,219 & 0,500 \\
\hline 52 & 2,25 & 5,90 & 12,2 & 1,86 & 1,71 & 0,212 & 0,477 \\
\hline 53 & 2,20 & 6,50 & 13,0 & 1,81 & 1,59 & 0,210 & 0,455 \\
\hline 54 * & 2,15 & 6,90 & 13,6 & 1,77 & 1,58 & 0,210 & 0,445 \\
\hline 55 & 2,10 & 7,20 & 14,4 & 1,72 & 1,54 & 0,194 & 0,407 \\
\hline 56 & 2,00 & 7,40 & 15,1 & 1,70 & 1,54 & 0,180 & 0,360 \\
\hline 57 & 1,90 & 7,50 & 15,8 & 1,67 & - & 0,177 & 0,336 \\
\hline 58 & 1,80 & 7,40 & 16,4 & 1,73 & 1,68 & 0,202 & 0,364 \\
\hline 59 & 1,80 & 7,30 & 16,7 & 1,76 & 1,78 & 0,244 & 0,439 \\
\hline 60 & 1,85 & 7,00 & 16,8 & 1,63 & 1,82 & 0,257 & 0,475 \\
\hline 61 & 1,90 & 6,40 & 16,6 & 1,53 & 1,97 & 0,269 & 0,511 \\
\hline 62 & 2,00 & 5,30 & 16,0 & 1,57 & 2,12 & 0,263 & 0,526 \\
\hline 63 & 2,03 & 4,80 & 15,4 & 1,80 & 2,09 & 0,255 & 0,518 \\
\hline 64 & 2,10 & 4,90 & 14,7 & 2,11 & 2,16 & 0,254 & 0,533 \\
\hline 65 & 2,13 & 5,40 & 14,0 & 2,40 & 2,20 & 0,253 & 0,539 \\
\hline 66 & 2,20 & 6,40 & 13,4 & 2,21 & 1,98 & 0,254 & 0,559 \\
\hline
\end{tabular}

* Instantes em que foram provocados os impulsos. 

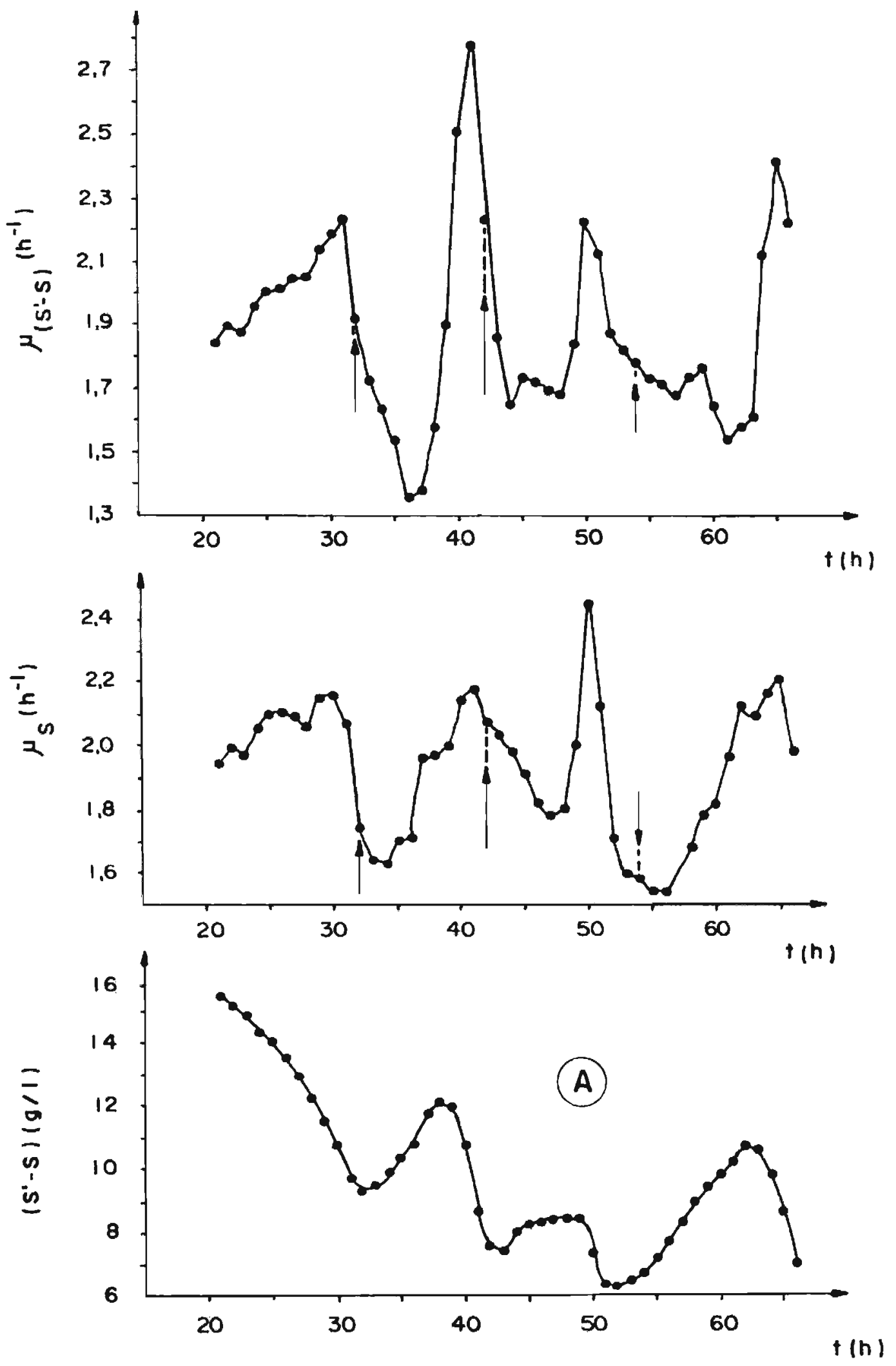

FIGURA 4.XIII. Variação, com o tempo, das velocidades específicas de consumo de sacarose ( $\mu\left(S^{\prime} S\right)$ ) e de $A R$ ( $\mu S$ ) referentes ao ensaio no 10. O perfil do grafico $A$ foi usado para interpolar os va lores de $\left(S^{\prime}-S\right)$ para o calculo de $\mu\left(S^{\prime}-S\right)$. o perfil da curva_uti1 izado para interpolar os valores de $\mathrm{S}$ para o cálculo de $\mu_{\mathrm{S}} \mathrm{e}$ mos trado na figura 3.XIII do item 3.5.11. 

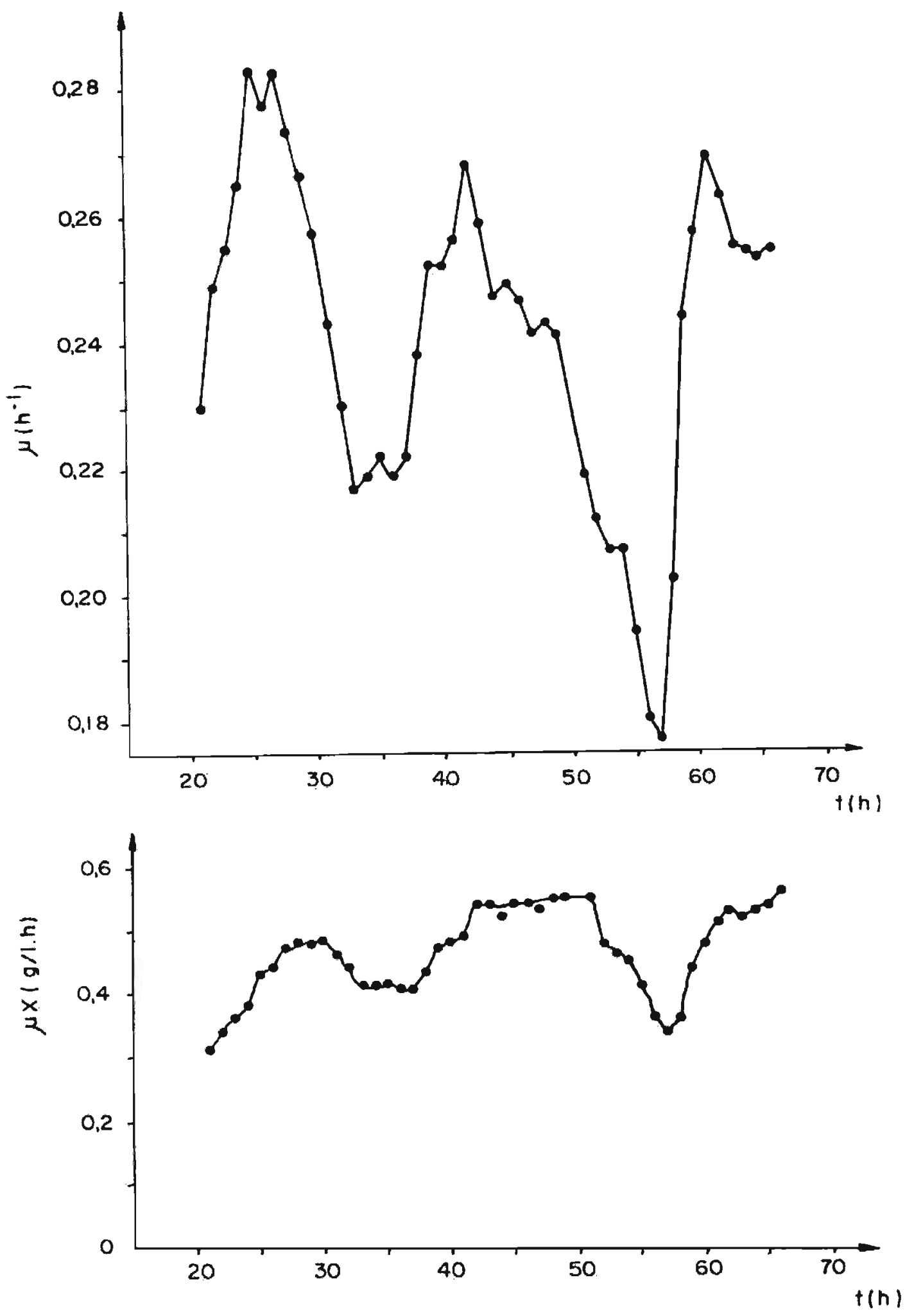

FIGURA 4.XIV. Variação, com o tempo, da velocidade especĩfica de crescimento celular ( $\mu$ ) e da produti $v i d a d e$ em células $(\mu X)$ referentes ao ensaio no 10 . 


\subsubsection{Ensajo n! 11}

Pela figura 3. XIV nota-se nitidamente que, - processo fermentativo continuo realizado nas seguintes condições:

$$
\begin{aligned}
& F=729 \mathrm{ml} / \mathrm{h} \\
& D=0,24 \mathrm{~h}^{-1} \\
& \Phi=2 \mathrm{l} / \mathrm{l} \cdot \mathrm{min} \\
& N=700 \mathrm{~min}^{-1}
\end{aligned}
$$

permitiu o estabelecimento de regime estacionārio a partir do instante $t=18 \mathrm{~h}$.

$$
0 \text { patamar obtido se manteve por } 42 \mathrm{~h} \text {, com os }
$$
seguintes valores médios:

$$
\begin{aligned}
& \bar{x}=3,40 \mathrm{~g} / \mathrm{l} \\
& \overline{\mathrm{S}}=4,50 \mathrm{~g} / \mathrm{l} \\
& \overline{\mathrm{S}}^{\prime}=6,25 \mathrm{~g} / \mathrm{l} \\
& \bar{v}=0,148 \mathrm{gART} / \mathrm{g} \text { cé } 1 . \mathrm{min}
\end{aligned}
$$

As velocidades específicas de crescimento celu lar, de consumo de AR e consumo de sacarose são, respectiva mente, iguais a $0,24 \mathrm{~h}^{-1} ; 1,62 \mathrm{~h}^{-1}$ e $1,54 \mathrm{~h}^{-1}$. A produtivida de em cẻlutas foi de $0,82 \mathrm{~g} / \ell . \mathrm{h}$.

Durante todo o período de duração do patamar o valor de voscilou, sendo o P.0.M. de $6,5 \mathrm{~h}$.

Apōs $t=75 \mathrm{~h}$, quando a alimentação de mosto foi interrompida, nota-se, pela figura $3 . X V$, que 0 sistema mostrou forte tendéncia para retornar ao estado inicial, isto $\bar{e}$, para a fase descontinua do ensaio. Isto mostra que a capacidade funcional das cēlulas, considerada em termos glo- 
bais, sofre pequena ou nenhuma influência pelo fato das mesmas terem sido submetidas ao cultivo contínuo.

Conforme descrito no item 3.5 .12 , entre os instantest $=48 \mathrm{~h}$ e $t=51 \mathrm{~h}$ de processo continuo, fizeram-se amostragens de $10 \mathrm{em} 10 \mathrm{~min}$, sendo os resultados mostrados na tabela 3.27 e no gräfico 3.XVIA. Por conseguinte, cada os cilação dos valores de v observada para intervalos de amostragem mais longos, representaria, na realidade, um conjunto de oscilações mais rápidas, cujo perĩodo não foi possivel detectar nas nossas condições de trabalho.

\subsubsection{Comentārios sobre o ítem 4.5.2}

Analisando o grupo de ensaios realizados com borbulhamento de ar e com mosto suplementado podese dizer:

a) o regime transiente foi obtido nas condiçóes seguintes:

1) $F=692 \mathrm{ml} / \mathrm{h} ; D=0,24 \mathrm{~h}^{-1} ; \Phi=1$ l/l.min; $N=500 \mathrm{~min}^{-1}$.

2) $F=290 \mathrm{ml} / \mathrm{h} ; D=0,10 \mathrm{~h}^{-1} ; \Phi=1$ l/l.min; $N=500 \mathrm{~min}^{-1}$.

3) $F=268 \mathrm{ml} / \mathrm{h} ; D=0,097 \mathrm{~h}^{-1} ; \Phi=2 \mathrm{l} / \ell \cdot \mathrm{min} ; N=500 \mathrm{~min}^{-1}$.

4) $F=711 \mathrm{ml} / \mathrm{h} ; D=0,23 \mathrm{~h}^{-1} ; \Phi=1 \mathrm{l} / \mathrm{l} \cdot \mathrm{min} ; \mathrm{N}=500 \mathrm{~min}^{-1}$.

5) $F=704 \mathrm{ml} / \mathrm{h} ; D=0,24 \mathrm{~h}^{-1} ; \Phi=2$ l/l.min; $N=700 \mathrm{~min}^{-1}$.

6) $F=713 \mathrm{ml} / \mathrm{h} ; D=0,23 \mathrm{~h}^{-1} ; \Phi=1 \mathrm{l} / \mathrm{l} \cdot \mathrm{min} ; \mathrm{N}=500 \mathrm{~min}^{-1}$.

b) O regime estacionário foi obtido nas seguintes condi çổes :

1) $F=725 \mathrm{ml} / \mathrm{h} ; D=0,23 \mathrm{~h}^{-1} ; \Phi=2$ l/l.min; $N=700 \mathrm{~min}^{-1}$.

2) $F=729 \mathrm{ml} / \mathrm{h} ; D=0,24 \mathrm{~h}^{-1} ; \Phi=2 \mathrm{l} / \mathrm{l} \cdot \mathrm{min} ; N=700 \mathrm{~min}^{-1}$. 
c) Em regime transiente, quaisquer que sejam as condições operacionais, os perfis de $\mu_{S}$ e $\mu_{\left(S^{\prime}-s\right)}$ são similares, indicando o provāvel acoplamento entre a decomposição da sacarose e a assimilação dos açūcares redutores, intermediada pela presença da invertase na parede celular da levedura.

d) Em regime transiente não existe correlação aparente entre $v$ e $\mu\left(S^{\prime}-S\right)^{\circ}$

e) De um modo geral, em regime transiente o comportamen to de $v$ e $\mu X$ depende das condiçöes operacionais. Assim, am bas são funções crescentes do tempo para as condições dos ensaios no 5 ( $2 \underline{a}$ etapa) e $n ! 6$ ( 2 a etapa); decrescentes do tempo para o ensaio no 6 ( 1 a etapa); para o ensaio no 5 ( 3 a etapa) $v=f(t)$ e crescente e $\mu X=f(t)$ decrescente. Para os ensaios no 5 ( 4 a etapa) e no 10 (2 $\underline{a}$ etapa) nada se pode dizer sobre a tendēncia geral destes dois parāmetros.

Ressalte-se que, do ponto de vista da produção de invertase, as condiçôes nas quais $v$ e $\mu X$ são crescentes merecem especial atenção. Mesmo nestes casos é importan te notar que um aumento de $\mu X$ näo implica num aumento propor cional de $v$. Assim, para o ensaio no 5 ( 2 a etapa), considerando 0 intervalo entre os instantes $t=27 \mathrm{~h}$ e $t=47 \mathrm{~h}, \quad \mu X$ e v variam cerca de 67 e $30 \%$, respectivamente. Contudo para - ensaio no 6 ( 2 a etapa), levando em conta o intervalo entre os instantes $t=46 \mathrm{~h}$ e $t=60 \mathrm{~h}$, as variaçöes de $\mu \mathrm{X}$ e $\quad v$ são, respectivamente, de 9 e $44 \%$. 
f) Comparando as perturbações provocadas pela adiçäo de nutrientes nos ensaios de no 5 ( $2 \underline{a}$ etapa) e no 10 ( $2 \underline{a}$ etapa), e patente que a perturbação por degrau causa sobre o siste ma um efeito mais intenso do que a perturbação por impulso.

g) Considerando, apenas, as perturbações por degrau, as quais, em principio, podem ser provocadas pela alteração de um ou mais dos diversos parâmetros operacionais, a que apresentou efeito mais intenso sobre $v$ foi a adição de nutrien tes ao mosto.

h) Tanto em regime transiente como no estacionārio os valores de $v$ oscilam. Provavelmente o período de oscilação real näo é superior a $10 \mathrm{~min}$.

i) 0s periodos de oscilação médios (P.O.M.), exceptuando-se a 2 a etapa do ensaio no 6 , são de mesma magnitude tanto para regime transiente como estacionārio.

\subsubsection{Ensaio com mosto não suplementado e sem borbulhamento de ar}

\subsubsection{Ensaio $n$ ? 8}

Pela figura $3 . X I$ nota-se claramente que, - processo fermentativo contínuo realizado nas seguintes con dições:

$$
\begin{aligned}
& F=735 \mathrm{ml} / \mathrm{h} \\
& D=0,24 \mathrm{~h}^{-1} . \\
& N=500 \mathrm{~min}^{-1}
\end{aligned}
$$


permitiu o estabelecimento de regime estacionário a partir do instante $t=3 h$.

$$
0 \text { patamar obtido se manteve durante } 40 \mathrm{~h} \text {, com }
$$

os seguintes valores médios:

$$
\begin{aligned}
& \bar{x}=1,25 \mathrm{~g} / \ell \\
& \bar{s}=4,92 \mathrm{~g} / \ell \\
& \bar{s}^{\prime}=15,3 \mathrm{~g} / \ell \\
& \mu=D=0,24 \mathrm{~h}^{-1} \\
& \mu_{S}=2,96 \mathrm{~h}^{-1} \\
& { }^{\mu}\left(\mathrm{S}^{\prime}-\mathrm{S}\right)=2,71 \mathrm{~h}^{-1} \\
& \mu X=0,30 \mathrm{~g} / \ell \cdot \mathrm{h} \\
& \bar{v}=0,081 \mathrm{gART} / \mathrm{g} \text { cé } 1 . \mathrm{min}
\end{aligned}
$$

Outrossim deve ser destacado que durante todo o período de duração do patamar o valor de v oscilou,sen do o período médio de oscilação igual a $6,1 \mathrm{~h}$.

\subsubsection{Ensaio com mosto suplementado e sem borbulhamento de ar}

\subsubsection{Ensaio n! 9}

Pela figura 3.XII observa-se que as con

dições seguintes:

$$
\begin{aligned}
& F=770 \mathrm{ml} / \mathrm{h} \\
& D=0,26 \mathrm{~h}^{-1} \\
& N=500 \mathrm{~min}^{-1}
\end{aligned}
$$

permitiram o estabelecimento de regime estacionārio a partir do instante $t=9 \mathrm{~h}$. 
O patamar manteve-se durante $36 \mathrm{~h}$, com os seguintes valores médios:

$$
\begin{aligned}
& \bar{x}=1,60 \mathrm{~g} / \mathrm{l} \\
& \overline{\mathrm{s}}=3,52 \mathrm{~g} / \mathrm{l} \\
& \overline{\mathrm{S}}^{\prime}=10,9 \mathrm{~g} / \mathrm{l} \\
& \mu=D=0,26 \mathrm{~h}^{-1} \\
& \mu_{S}=2,73 \mathrm{~h}^{-1} \\
& \mu^{\prime}\left(\mathrm{S}^{\prime}-\mathrm{S}\right)=2,33 \mathrm{~h}^{-1} \\
& \mu X=0,40 \mathrm{~g} / \mathrm{l} \cdot \mathrm{h} . \\
& \bar{v}=0,099 \mathrm{gART} / \mathrm{g} \mathrm{c} \bar{e} 1 . \mathrm{min}
\end{aligned}
$$

Durante todo o perĩodo de duração do patamar os valores de v oscilaram, sendo O P.0.M. de 4,6 h.

\subsection{ENSAIO DESCONTINUO COM MELAÇO SUPLEMENTADO E COM BORBULHAMENTO DE AR}

\subsubsection{Ensaio no 12}

Analisando-se as figuras $3 . X V I I$ e $4 . X V$, cujos dados estão mostrados, respectivamente, nas tabelas 3.30 e 4.10, nota-se:

a) devido à prōpria natureza do ensaio estabeleceu-se no sistema o regime transiente;

b) $\mu\left(S^{\prime}-s\right)$ decresce com o tempo, tornando-se praticamen te desprezivel a partir do instante $t=3 \mathrm{~h}$;

c) $\mu_{S}=f(t) \bar{e}$ uma função que apresenta valores māximos nos instantes $t=1 \mathrm{~h}\left(2,98 \mathrm{~h}^{-1}\right)$ e $t=4 \mathrm{~h}\left(3,16 \mathrm{~h}^{-1}\right)$ e mi nimos em $t=0,5 h\left(0,32 h^{-1}\right)$ e $t=5,5 h\left(0,55 h^{-1}\right)$; 
d) $\mu=f(t)$ atingiu o māximo valor em $t=2 h$. A anālise do perfil mostra que não se estabeleceu uma fase de crescimento exponenciaj;

e) $v=f(t)$, apōs rāpida oscilação entre $t=$ oh e $t=1,5 \mathrm{~h}$, decresceu continuamente atē chegar a um valor mínimo em $t=4 h(0,100 \mathrm{gART} / \mathrm{g}$ cēl.min). A partir deste ins tante passou a crescer atē atingir o valor de $0,700 \mathrm{gART} / \mathrm{g}$ cél.min $(t=6 \mathrm{~h})$, permanecendo, a seguir, praticamente constante.

Pela tabela 4.11 , fica claro que durante todo o ensaio a atividade invertásica especifica sempre foi su perior às demais. Mesmo para $t=4 h$, onde $v \bar{e}$ minima, ela é, respectivamente, cerca de 23 e 2 vēzes superior a $\mu$ e ${ }_{S}$, por exemplo. Isto explica porque, a partir de $t=4 \mathrm{~h}$, apesar de $\mu\left(S^{\prime}-S\right)$ ser desprezivel, a sacarose presente no mosto continua a ser hidrolisada. Por outro lado, como $\mu_{S}>\mu$ sem pre, então, analogamente, pode-se explicar a queda continua da concentração de AR a partir de $t=4 \mathrm{~h}$.

Este quadro conduzirā ao ponto em que a concentraçãa de $S$ no mosto caia abajxo de $10 \mathrm{~g} / \ell$ (após o ins tante $t=4 h)$. Concentrações de $S$ desta ordem de grandeza dejxam de reprimir a biossintese de invertase (23)(34)(44), o que explica o aumento de $v$ observado a partir de $t=4 \mathrm{~h}$.

A partir do instante $t=6 \mathrm{~h}$, quando $S$ e $S^{\prime}$ são muito baixos, o valor de $v$ mantem-se alto $(0,700 \mathrm{gART} / \mathrm{g}$ cēl. min) e, aproximadamente, constante. Isto ocorre porque a invertase presa à parede celular continua ativa,independendo 
do fato dos produtos resultantes de sua ação terem ou não participação no metabolismo celular. Em outros termos, a invertase se acha naturalmente imobilizada na cēlula intacta de levedura.

A técnica utilizada ao longo deste trabalho pa ra medir a atividade invertāsica descrita no îtem 2.5.4,ava lia, na verdade, a atividade total da invertase imobilizada na parede celular e não a parcela da atividade da qual resul tam os açūcares redutores que são efetivamente consumidos pela cēlula.

A variação de $v$ entre os intantes $t=0$ o $e t=$ $1,5 \mathrm{~h}$, provavelmente, seja o resultado da combinação dos seguintes efeitos:

a) adaptação das cēlulas às novas condições;

b) a glicose, inicialmente presente no mosto, teria a capacidade de estimular a biossintese da invertase pela cēlula (35);

c) fenômenos de repressão e desrepressão atuando simultaneamente. 
TABELA 4.10 Velocidades específicas de consumo de $A R$, de consumo de sacarose e de crescimento ce lular para o ensaio no 12.

\begin{tabular}{|c|c|c|c|c|c|c|}
\hline $\begin{array}{c}t \\
(h)\end{array}$ & $\begin{array}{c}x \\
(g / \ell)\end{array}$ & $\begin{array}{c}S \\
(g / \ell)\end{array}$ & $\begin{array}{c}S^{\prime} \\
(g / \ell)\end{array}$ & $\begin{array}{c}\mu\left(S^{\prime}-S\right) \\
\left(h^{-1}\right)\end{array}$ & $\begin{array}{c}{ }^{\mu} S \\
\left(h^{-1}\right)\end{array}$ & $\begin{array}{c}\mu \\
\left(h^{-1}\right)\end{array}$ \\
\hline 0 & 0,85 & 10,3 & 25,0 & 13,9 & 2,12 & 0,235 \\
\hline 0,5 & 0,95 & 15,3 & 24,5 & 7,12 & 0,32 & 0,263 \\
\hline 1 & 1,70 & 18,0 & 23,6 & 4,14 & 2,98 & 0,355 \\
\hline 1,5 & 1,35 & 18,5 & 22,7 & 2,12 & 2,04 & 0,407 \\
\hline 2 & 1,65 & 18,3 & 21,3 & 1,14 & 1,56 & 0,418 \\
\hline 2,5 & 2,05 & 17,5 & 19,5 & 0,78 & 1,70 & 0,390 \\
\hline 3 & 2,45 & 16,3 & 17,6 & 0,56 & 1,71 & 0,347 \\
\hline 3,5 & 2,90 & 14,4 & 15,0 & 0,33 & 1,83 & 0,310 \\
\hline 4 & 3,35 & 11,7 & 11,7 & 1,35 & 3,16 & 0,263 \\
\hline 4,5 & 3,78 & 8,0 & 8,5 & 0 & 1,85 & 0,225 \\
\hline 5 & 4,20 & 4,7 & 5,0 & 0 & 1,21 & 0,169 \\
\hline 5,5 & 4,50 & 2,5 & 3,3 & 0 & 0,55 & 0,144 \\
\hline 6 & 4,85 & 1,5 & 1,5 & 0 & 1,44 & 0,109 \\
\hline 6,5 & 5,05 & - & - & - & - & 0,069 \\
\hline 7 & 5,20 & - & - & - & - & 0,048 \\
\hline 7,5 & 5,30 & - & - & - & - & 0,037 \\
\hline 8 & 5,40 & - & - & - & - & 0,030 \\
\hline
\end{tabular}



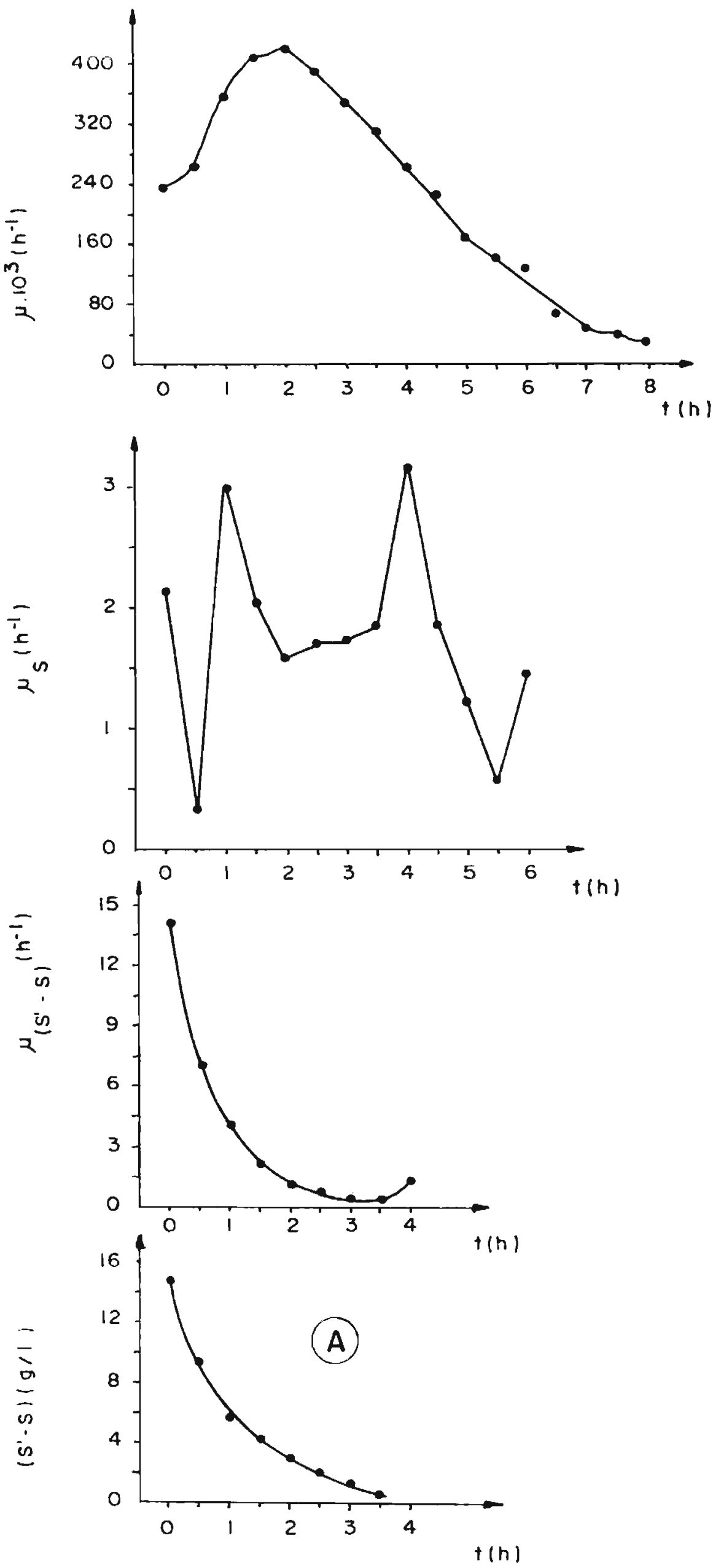

FIGURA 4.XV. Variação, com o tempo, de $(\mu(S:-S))$, $\mu S$ e $\mu$ referentes ao ensaio n! 12. O perfil do grafico A foi usado para interpolar os valores de ( $S^{\prime}-S$ ) para o cálculo de $\mu\left(S^{\prime}-S\right)$. O perfilda cur va usado para interpolar os valores de $S$ para calcular $\mu_{S} \bar{e}$ mostrado na figura $3 . X V I I$. 
TABELA 4.11 Relações entre as atividades especificas: $\mu, \mu_{S}$, $\mu\left(S^{\prime}-S\right)$ e $v$, referentes ao ensaio no 12 .

\begin{tabular}{|c|c|c|c|c|c|c|}
\hline $\begin{array}{c}t \\
(h)\end{array}$ & $v / \mu$ & $v / \mu_{S}$ & $v / \mu\left(S^{\prime}-S\right)$ & $\mu_{s} / \mu$ & $\mu_{s} / \mu\left(s^{\prime}-s\right)$ & $\mu\left(s^{\prime}-s\right) /^{\mu}$ \\
\hline 0 & 139 & 15,4 & 2,3 & 9,0 & 0,15 & 59 \\
\hline 0,5 & 146 & 120 & 5,4 & 1,2 & 0,04 & 27,1 \\
\hline 1 & 81,3 & 9,7 & 7,0 & 8,4 & 0,72 & 11,7 \\
\hline 1,5 & 131 & 26,2 & 25,2 & 5,0 & 0,96 & 5,2 \\
\hline 2 & 39,9 & 10,7 & 14,6 & 3,7 & 1,4 & 2,7 \\
\hline 2,5 & 28,3 & 6,5 & 14,2 & 4,4 & 2,2 & 2 \\
\hline 3 & 24,3 & 5,0 & 15,1 & 4,9 & 3,1 & 1,6 \\
\hline 3,5 & 22,3 & 3,8 & 20,9 & 5,9 & 5,5 & 1,1 \\
\hline 4,0 & 22,8 & 1,9 & - & 12 & - & - \\
\hline 4,5 & 29,3 & 3,4 & - & 8,2 & - & 0 \\
\hline 5 & 72,8 & 10,2 & - & 7,2 & - & 0 \\
\hline 5,5 & 267 & 70 & - & 3,8 & - & 0 \\
\hline 6 & 410 & 31 & - & 13,2 & - & 0 \\
\hline
\end{tabular}




\subsection{ANALISE GERAL DOS ENSAIOS DE FERMENTAÇAO CONTINUA}

\section{4,7.1 Ensaios em regime estacionārio}

O regime estacionārio foi obtido nos ensaios de nūmero: 4, 5 (1 1 a etapa), 7, 8, 9, 10 (1 a etapa) e 11 . 0s paràmetros característicos referentes a cada um deles estão resumidos na tabela 4.12 .

Verifica-se pela tabela 4.12 que $\mu_{S}$ e $\mu\left(S^{\prime}-S\right)$ em cultivo sem borbulhamento de ar são pelo menos, respectivamente, 41 e $33 \%$ superiores aos obtidos em aerobiose, independente do fato do mosto ter sido ou não suplementado. Este resultado respalda-se no jā bem conhecido fato de que em cultivo sem borbulhamento de ar a conversão da glicose em ATP apresenta rendimento inferior à mesma conversão reali zada em aerobiose (39). Assim sendo, a cēlula deve remover AR do meio com maior velocidade, a fim de que ela pos sa ter energia suficiente para manter sua atividade metabō lica. Como consequēncia, observa-se que, tambēm, $\bar{v}$ em cultivo sem borbulhamento de ar é maior do que em aerobiose com mosto não suplementado. Este interrelacionamento não $\vec{e}$ de se estranhar, pois a ünica fonte de reserva de AR disponivel para a levedura é a sacarose presente no meio, a qual só pode ser hidrolisada, nas condiçōes operacionais empregadas, pela invertase.

Por outro lado, $\bar{v}$ em cultivo sem borbulhamen to de ar é menor do que em aerobiose com mosto adicionado de $\mathrm{Na}_{2} \mathrm{HPO}_{4} \cdot 12 \mathrm{H}_{2} \mathrm{O},\left(\mathrm{NH}_{4}\right)_{2} \mathrm{SO}_{4}$ e $\mathrm{MgSO}_{4}$, conforme descrito em 
2.1.4. Este resultado se aproxima daquele encontrado

por DODYK e ROTHSTEIN (21), que mostraram que a atividade invertásica de células intactas de levedura era incrementada pela presença de ions $\mathrm{Mg}^{2+}, \mathrm{NH}_{4}^{+}$e $\mathrm{H}_{2} \mathrm{PO}_{4}^{-}$. Contudo, deve ser salien tado que, embora $\bar{v}$ nas condições referidas tenha aumentado, $\mu\left(S^{\prime}-S\right)$ não aumentou. o único modo de explicar isto $\bar{e}$ admitir que somente uma parcela da atividade invertāsica total è efetivamente usada pela cēlula para decompor a sacarose e suprir suas necessidades em AR. Este resultado reforça o que foi dito por ocasião da anälise do ensajo nọ 12, qual, seja, que a técnica de medida de $v$ empregada,só permite avaliar a atividade total da invertase imobilizada na cêlula intacta de levedura.

o fator de conversão de substrato em microrganismo $(\bar{Y})$ decresce na seguinte ordem: aerobiose com mosto suplementado, aerobiose com mosto não suplementado e anaero biose com e sem suplementaçäo. Em termos globais $\bar{Y}$ reflete os diferentes estados metabólicos em que a levedura se encontra, quando submetida a condições ambientais distintas.

Tendo em vista os ensaios sem borbulhamento de ar nota-se que $\mu_{S}=\mu_{\left(S^{\prime}-S\right)}$, independente do mosto ter sido ou não suplementado, embora a suplementação tenha propiciado um ganho de $22 \%$ em massa celular seca. De outra parte,observase que algo semelhante ocorre entre os ensaios realizados com borbulhamento de ar, exceto que o ganho em massa seca foi de $64 \%$ para o caso en que houve suplementação. Isto demonstra o ja referido acoplamento dentro da dorna entre a decomposição da sacarose e o consumo do AR formado. 
Pela figura 4.XVI fica demonstrado que a ativi dade enzimātica específica é função crescente da velocidade de crescimento celular dentro da dorna em regime permanente. Este resultado corrobora aquele que jā foi observado em vārios ensaios realizados em regime transiente.

A equação da reta ajustada aos pontos do grāf co da figura 4.XVI é:

$$
\begin{aligned}
& \bar{v}=0,54+10,66 \quad D \bar{x} \quad r=0,94 \\
& \text { Procedendo-se da mesma forma para as relações: }
\end{aligned}
$$

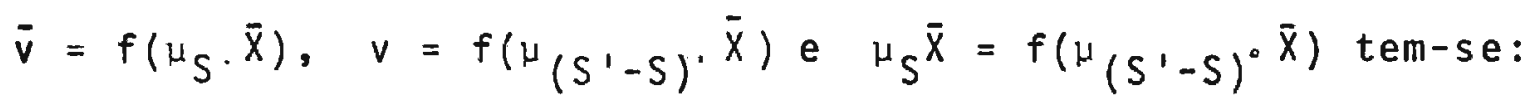

$$
\begin{aligned}
& \bar{v}=-0,96+1,77 \mu_{s} \cdot \bar{x} \quad r=0,95 \\
& \bar{v}=-0,96+1,92 \bar{X}_{0} \mu\left(S^{\prime}-S\right) . \quad r=0,98 \\
& \mu_{S^{\prime}} \bar{X}=0,15+1,04 \bar{X}_{\cdot \mu}\left(S^{\prime}-S\right) \quad r=0,98
\end{aligned}
$$

Os coeficientes de correlação obtidos são estatisticamente significativos, pois o valor de $r$ critico, para $99 \%$ de probabilidade e 5 graus de liberdade, è igual a $0,87(32)$.

Comparando as equações acima, nota-se claramen te, pelo coeficiente angular, que a velocidade de variaça de $\bar{v} \bar{e}$ maior em relação a $D \bar{x}$, ficando demonstrado, portanto, que os valores de $v$ obtidos ao longo deste trabalho relacionam-se com a produtividade em cēlulas. Em outros termos, representam a atividade da invertase naturalmente imobilizada na parede celular, confirmando a evidencia realçada na anālise do ensaio no 12 . 


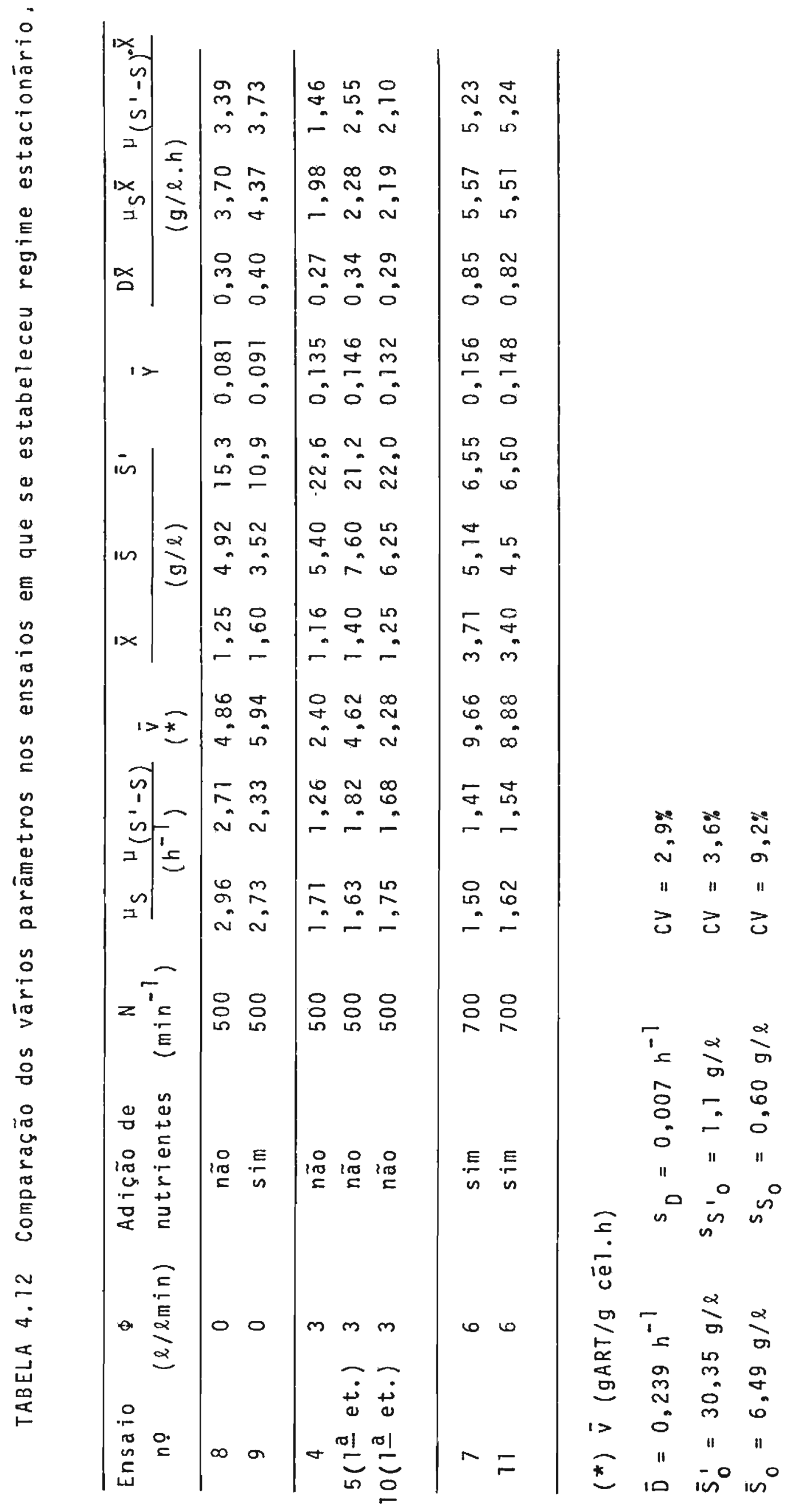




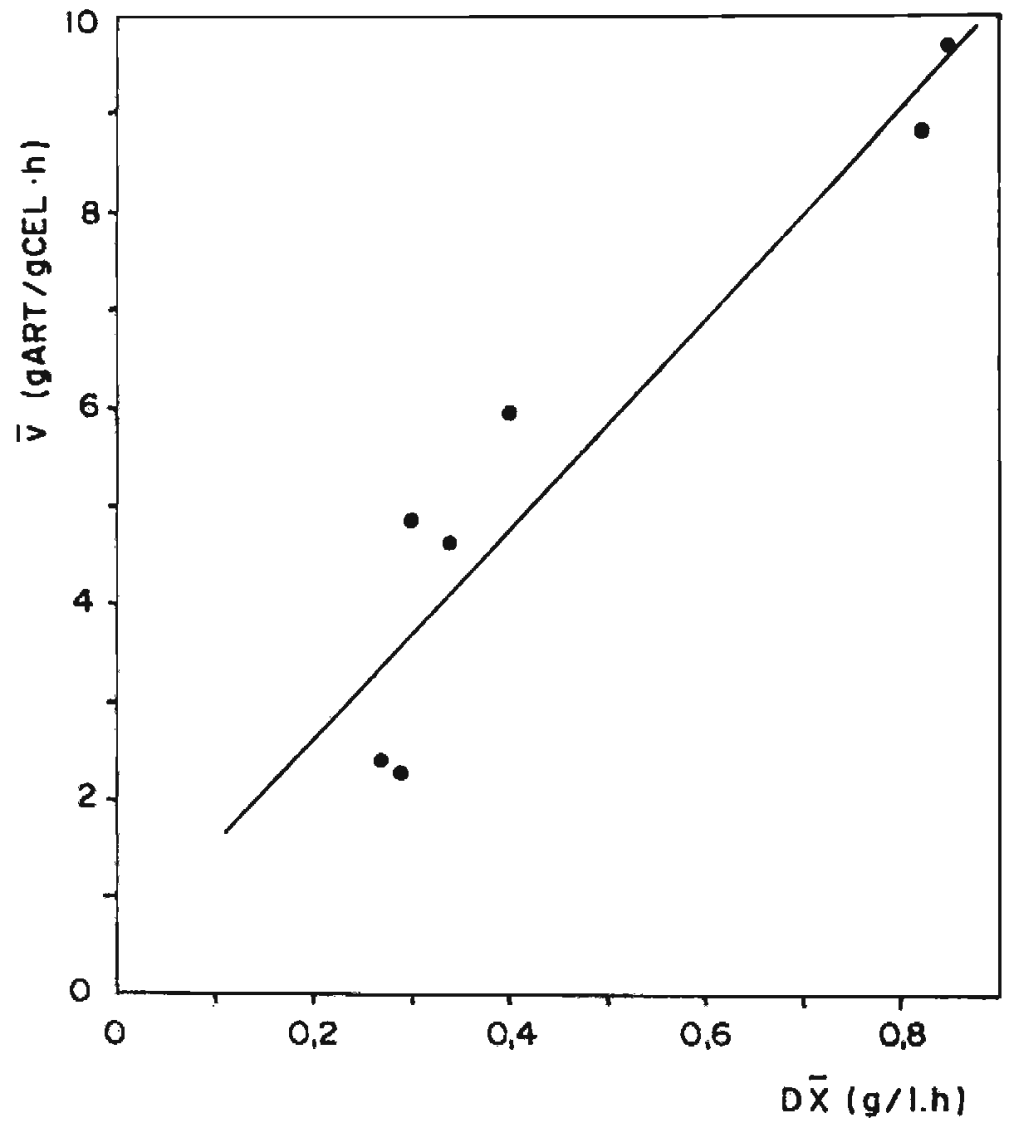

FIGURA 4.XVI. Relação entre a atividade invertāsica especĩfica média e a produtividade celular para os ensaios realizados em regime estacionàrio. 


\subsubsection{Ensaios em regime transiente}

0 estudo quantitativo de um sistema em regime transiente é de difícil execução, pois os parāmetros do sistema (por ex., $X, S, S^{\prime}$ ) variam com o tempo, impossibilitan do o estabelecimento de conclusões com grande amplitude de validez.

No presente trabalho procurou-se analisar um sistema nestas condições atravēs da anājise de velocidades específicas de consumo ou formação de certos constituintes do sistema, por exemplo, transformação de um substrato 1 imi tante.

Atravēs do balanço material, mostrado no ĩtem 1.2, deduziram-se as equações (4.V) a (4.VIII), as quais permitiram calcular parāmetros do tipo $\mu_{S}, \mu_{\left(S^{\prime}-S\right)}$ e $\mu$,que em $\bar{u} 1$ tima anālise estão intimamente relacionados ao metabolis mo celular:

$$
\begin{gathered}
\frac{d\left(S^{\prime}-S\right)_{C}}{d t}=\frac{d\left(S^{\prime}-S\right)}{d t}-D\left[\left(S_{0}^{\prime}-S_{0}\right)-\left(S^{\prime}-S\right)\right] \\
\frac{(d S)_{c}}{d t}=\frac{\frac{d S}{d t}-D\left(S_{0}-S\right)-\frac{(d S)_{p}}{d t}}{d t}=\frac{(d S)_{p}}{d t} \\
\frac{d\left(S^{\prime}-S\right)_{C}}{d t}=-\frac{d x}{d t} \cdot \frac{1}{x}
\end{gathered}
$$

Assim, verificou-se que nos ensaios (nos 1, 2 
e 3) onde o mosto não foi suplementado, tais velocidades específicas mostraram baixo grau de correlação. Outrossim, nos casos em que se usou mosto suplementado (ensaios de no 5,6 e 10) $\mu_{S}$ e $\mu_{\left(S^{\prime}-S\right)}$ apresentaram comportamento similar,evidenci ando alto grau de correlação, que, em ültima instāncia, deve corresponder ao acoplamento entre a decomposição da sacarose e o consumo do AR. Na presença de nutrientes há uma ativaçăo geral do metabolismo, que exigira maior dispēndio de energia, o qual, por sua vez, estimularā a cēlula a aumentar a eficien cia de utilização da fónte de C disponivel.

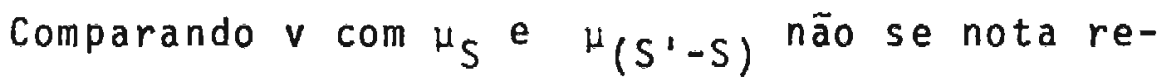
1 ação aparente. Mas confrontando $v=f(t)$ com $\mu X=f(t)$ nos ensaios nọ, 2 (1 $\stackrel{a}{\text { e }}$ 2 a etapas), 5 ( 2 a etapa), 6 (1 a e 2 a eta pas), verifica-se certo grau de correlação. Só foi possĩvel associar retas estatisticamente significativas para os ensaios no 1, 2 (1 1 a etapa) e 6 (1 a etapa), que são:

Ensaio no 1 ( $t=15 \mathrm{~h}$ a $t=54 \mathrm{~h})$ :(ver Figs. 3. IIb e $4.1 \mathrm{I})$

$$
\begin{array}{rlrl}
v & =0,073+0,0024 t & r & =0,96 \\
\mu x & =0,27+0,0028 t & r & =0,81
\end{array}
$$

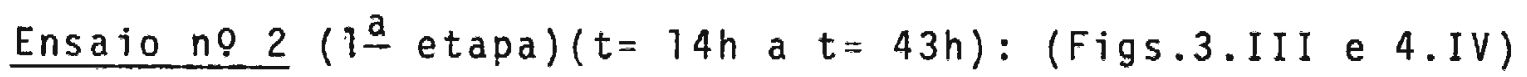

$$
\begin{array}{rlrl}
v & =0,092+0,0026 t & r & =0,86 \\
\mu X & =0,35+0,0054 t & r & =0,91
\end{array}
$$

Ensaio no 6 ( $1 \stackrel{\text { a }}{\text { etapa }) ~}(t=12 \mathrm{~h}$ e $t=35 \mathrm{~h}):$ (Figs.3.IX e $4 . X$ II)

$$
\begin{array}{rlrl}
v & =1,23-0,029 t & r & =0,94 \\
\mu X & =0,95-0,003 t & r & =0,93
\end{array}
$$


A respeito das segundas etapas dos ensaios $n$ ? 2, 5 e 6 a relação crescente de $\nu$ e $\mu X$ ao longo do tempo só pode ser notada pela observação direta das figuras 3.III, 3.VII, 3.IX, 4.IV, 4.VIII e 4.XII.

Com relação aos ensaios no 3, 5 ( 3 a e $4 \stackrel{a}{a}$ etapas) e 10 ( 2 a etapa) nada se pode dizer sobre a eventual correlação entre $v$ e $\mu x$. Porēm, dentre eles o ünico que realmen te apresentou resultado inesperado foi o de $n$ o 3 , pois os demajs, tendo sido submetidos a vārias perturbações, não permitiram o estabelecimento de uma correlação mais nitida entre $v$ e $\mu x$.

Considerando os coeficientes angulares das retas correspondentes aos ensaios nọ 1 e 2 ( 1 a etapa), cuja üni ca diferença residiu na $\Phi$, nota-se,claramente, que $\mu x \bar{e}$ mais sensivel à variação do teor de $0_{2}$ no meio do que $v$. Isto ē compreensivel, pois a cểula tendo mais $0_{2}$ disponível, terá aumentada sua capacidade de gerar energia, a qual poderä ser empregada em reações de biossintntese, trazendo como resultado final maior produtividade em cēlulas.

E interessante ressaltar que no ensaio n95 ao se passar da 2a para a 3 a etapa, cuja perturbação por degrau consistiu na diminuiçäo brusca de $D$, o sistema respondeu com uma queda acentuada de $v$ entre os instantes $t=52,5 \mathrm{~h}$ e $t=63 \mathrm{~h}$. Como o tempo de residencia é da ordem de $10 \mathrm{~h}$ este intervalo de tempo representou a fase de adaptação das cēlulas às novas condições. As retas que se ajustam aos pontos experimentais de $v, \mu_{S}, \mu\left(S^{\prime}-S\right)$ e $\mu X$ no intervalo considerado são:

$$
\begin{array}{rlrl}
v & =12,8-0,195 t & r & =0,98 \\
\mu X & =0,165+0,021 t & r & =0,97
\end{array}
$$




$$
\begin{array}{rlrl}
\mu_{S} & =1,47-0,019 t & r & =0,93 \\
\mu_{\left(S^{\prime}-S\right)}=1,24-0,016 \mathrm{t} & r & =0,91
\end{array}
$$

Pelas inclinações das retas, nota-se que $v$, $\mu_{S}$ e $\mu_{\left(S^{\prime}-S\right)}$ decrescem simultâneamente, porém com variação cerca de 10 vezes mais acentuada para $v$. Este fato vem de encontro àquele jă estabelecido anteriormente, qual seja, de que os valores de $v$ determinados referem-se $\bar{a}$ atividade total da invertase imobilizada na parede celular e não à atividade que realmente supre as necessidades em AR da levedura. Se assim não fosse, seria lögico esperar variações de magnitudes equivalentes para estes parāmetros.

Ressalte-se que as perturbações por degrau pela adição de nutrientes e diminuição de $D$, causam respostas mar cantes do sistema em regime contīnuo de alimentação.

Do ponto de vista da produção de invertase, os resultados obtidos mostram que as melhores condições de traba 1ho são aquelas do ensaio no 5 ( 1 a e $2 \underline{a}$ etapas em conjunto). Assim, o regime estacionärio obtido nas condiçōes: $500 \mathrm{~min}^{-1}$, $1 \ell / \ell, \min , D=0,24 \mathrm{~h}^{-1}$ e sem adição de nutrientes, seguido de uma perturbação por degrau com quantidades não limitantes de $\left(\mathrm{NH}_{4}\right)_{2} \mathrm{SO}_{4}, \mathrm{MgSO}_{4} \cdot 7 \mathrm{H}_{2} \mathrm{O}$ e $\mathrm{Na}_{2} \mathrm{HPO}_{4} \cdot 12 \mathrm{H}_{2} \mathrm{O}$, permitiu obter células de levedura com atividade invertásica total cerca de $46 \%$ maior que a obtida no ensaio $n 9$, onde a perturbação por degrau consistiu da variação da frequência do agitador (de 500 para $700 \mathrm{~min}^{-1}$ ) e da vazão específica do ar (de 1 para 2

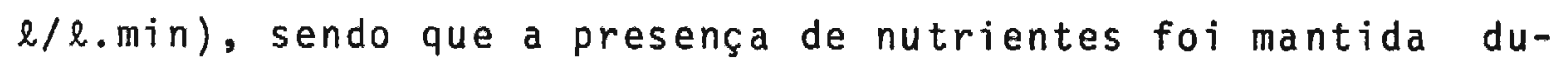
rante todo este ensaio. O resultado obtido no ensaio no 5 foi cerca de $41 \%$ superior ao obtido em regime descontinuo de fermentação (ensaio nọ 12). 
Estudos posteriores serão feitos na tentativa de conseguir regime estacionärio, no qual seja mantido o $n \vec{i}-$ vel de atividade invertásica ao redor de 1,2 gART/g cēi.min, que poderia ser ütil caso se desejasse uma produção contị nua de invertase.

\subsubsection{Considerações finais}

Em todos os ensaios realizados verifica-se,pe la anālise dos gräficos de $v=f(t)$, que os valores de $v$ oscilam, independentemente do regime estabelecido no sistema $e$ das condições operacionais empregadas.

Pela tabela 4.13 nota-se, claramente, que a variação de $v$ não pode ser oriunda de erro experimental por duas razões, sendo uma delas a magnitude da variação e a outra a ocorrēncia do fenómeno em todos os ensajos.

Observando os resultados obtidos por TODA(58) e TODA et al (59) verifica-se que os autores não observaram oscilação nos valores de $v$, assim como não existe correlação aparente entre os valores de $v$ e $\mu X$ por eles apresentados.

Algumas razões que poderiam levar a esta discordāncia, seriam:

a) emprego de espēcies diferentes de levedura;

b) uso de mejos de cultura diferentes;

c) diferentes intervalos de tempo de amostragens consecutivas.

Por outro lado, tendo em vista as peculiaridades de um sistema em regime contĩnuo de alimentação e em esta 
do estacionārio, os dados da tabela 4.13 poderiam indicar que a oscilação seria consequência da defasagem entre o tem po de geração $\left(\theta_{g}\right)$ e o tempo de residēncia, acentuado pela aleatoriedade em relação ao ciclo celular com a qual as amostragens de cēlulas foram feitas. Cumpre lembrar que um sistema desses não ē sincronizado (12) (31) (42) (63), daî não ser necessārio fixar um intervalo de amostragem coincicente com as fases do ciclo de vida da levedura. Mas os resultados obtidos no ensaio no 11 entre os instantes $t=48 \mathrm{~h}$ e $t=51 \mathrm{~h}$, onde as amostragens foram feitas de 10 em $10 \mathrm{~min}$, mostram que a oscilação ocorre a intervalos de tempo bem in feriores ao $\theta_{g}$ e tempo de residéncia, tornando, assim, esta hipōtese improvāvel.

Conforme verificado indiretamente no ensaio ne 12 (regime descontinuo) e pelos dados apresentados por TODA (58), existe evidēncia de um mecanismo de repressão desrepressão da biossintese de invertase governado pela concentração de glicose, presente no mosto. Segundo ELORZA et al (23)(24) e CARLSON et al (15) a repressão catabōlica da invertase pela glicose se dá ao nīvel da transcrição do DNA e da translação do RNA $_{m}$. 0 efeito da glicose seria o de aumentar a velocidade de degradação do RNA $_{m}$ específico para a formação da invertase. Alēm disso, segundo os autores, este fenōmeno não interfere na secreçäo e nem na ativi dade catalitica da invertase. Como nos regimes estacioná rios obtidos verificou-se que a concentração de AR no meio permanecia praticamente inalterada, a oscilação detectada não pode ser explicada por um mecanismo do tipo repressãodesrepressão. 
Foi verificado que em culturas de $\underline{\text { S.cerevisiae }}$ em estado estacionärio o volume celular médio da população, assim como o inîcio da gemulação, estando este ültimo vincula do a um tamanho celular minimo, dependem do valor de D $(40)$.

A duração da fase de brotamento do $\underline{5}$. cerevisiae numa faixa de $D$ compreendida entre $0,66 \mathrm{~h}^{-1}$ e $0,07 \mathrm{~h}^{-1}$ permanece, aproximadamente, constante e è de cerca de $2 h$ (41). Como consequēncia seria de esperar que, para valores baixos de $D\left(\right.$ da ordem de $0,07 \mathrm{~h}^{-1}$ ), a população celular na dorna se ria constituida em sua major parte de cểulas individuais, en quanto que para valores altos de $D$ (da ordem de $0,66 h^{-1}$ ) a população seria, predominantemente, formada por cēlulas com gémulas. E oportuno lembrar que ao longo do nosso trabalho os regimes estacionários foram obtidos com $D$ da ordem de 0,23 $h^{-1}$, o que, possivelmente, permitiu o estabelecimento na dor na de uma população com grau de brotamento ponderāvel.

A gemulação corresponde à fase do ciclo celu lar onde o metabolismo global da cēlula de levedura è mais intenso, conforme se pode depreender do quadro morfogenético descrito resumidamente no item 1.1 .

A parede celular da gêmula em formação estä sü jeita a contīnuas modificações (14), que podem se refletir sobre a atividade catalitica da invertase, a qual se encontra em maior quantidade assocjada a esta estrutura (3)(20) (49). Outrossim, hâa evidēncias de que boa parte da invertase extracitoplasmātica esteja, mais exatamente, localizada no es paço periplásmico (4) (5). Neste caso, então, os efeitos sobre a açäo da invertase deveriam ser mais pronunciados, dada 
a maior possibilidade de variaçāo do volume desta zona. De acordo com CONWAY e DOWNEY (17) o volume do espaço periplās mico e cerca de $11 \%$ do volume celular e, segundo ARNOLD (4) toda a invertase externa poderia se acomodar neste espaço. Alèm disso TKACZ (56) demonstrou que a invertase formada duran te a gemulação é distribuĩda assimetricamente na superfīcie da gêmula. Estes fatores unidos ocasionariam posicionamen tos distintos das moléculas da enzima durante o desenvolvi mento celular, influindo ora mais, ora menos acentuadamente, sobre a interação invertase-sacarose.

o tratamento das amostras, conforme descrito no item 2.4.2, permitiu obter suspensōes de cēlulas intactas, viāvejs e em fase de não crescimento que manteriam, aproximadamente, as mesmas caracteristicas que possuiam dentro do fermentador no momento da amostragem. Assim, a oscilação dos valores de $v$, medidos conforme deserito no item 2.5.4, po deria ser vista como sendo o resultado da maior ou menor dificuldade da invertase em interagir com a sacarose, refletin do os posicionamentos distintos de suas moléculas na zona da parede celular durante os vários estágios do ciclo reproduti vo.

A periodicidade do fenômeno é consequência das cēlutas terem sido formadas em cultivo contīnuo, pois num sistema destes as propriedades se repetem de tempos em tempos $(57)$.

Finalmente, como se depreende da tabela 4.13, - P.O.M. parece estar relacionado de algum modo com D, pois o P.O.M. para $D=0,11 \mathrm{~h}^{-1} \overline{\mathrm{e}}$ superior ao P.O.M. para $D=0,23 \mathrm{~h}^{-1}:$ 
TABELA 4.13 Parâmetros referentes aos ensaios de cultivo contỉnuo em regimes transiente e estacionārio.

\begin{tabular}{|c|c|c|c|c|c|c|c|c|}
\hline $\begin{array}{c}\text { Ensaio } \\
\text { no } \\
\star\end{array}$ & Regime & $\left(h^{-1}\right)$ & $\begin{array}{c}\text { tempo } \\
\text { de } \\
\text { resid. } \\
(h)\end{array}$ & $\begin{array}{l}\text { tempo } \\
\text { de ge } \\
\text { raçao } \\
\text { (h) }\end{array}$ & 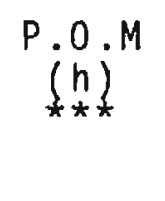 & $\begin{array}{c}\bar{v} \\
\star \star \star \star \star\end{array}$ & $\begin{array}{l}c \quad v \\
\text { para } \\
v(\%) \\
* * * *\end{array}$ & $\begin{array}{l}\text { Adição de } \\
\text { Nutrientes }\end{array}$ \\
\hline 1 & $T * \star$ & 0,11 & 9,1 & - & 7,8 & 0,149 & 23,5 & - \\
\hline $2-I$ & $T$ & 0,11 & 9,1 & - & 11,5 & 0,163 & 14,7 & - \\
\hline $2-I I$ & $T$ & 0,74 & 7,1 & - & 10 & 0,251 & 8,0 & - \\
\hline 3 & $T$ & 0,23 & 4,3 & - & 4,5 & 0,066 & 51,5 & - \\
\hline 4 & $E^{* *}$ & 0,23 & 4,3 & 3 & 5,1 & 0,044 & 31,4 & - \\
\hline $5-I$ & $\mathrm{E}$ & 0,24 & 4,2 & 2,9 & 4,5 & 0,077 & 34,7 & - \\
\hline 5 - I I & T & 0,24 & 4,2 & - & 3,3 & 1,19 & 92,3 & + \\
\hline 5-III & $T$ & 0,10 & 10 & - & 6 & 1,10 & 64,1 & + \\
\hline 5-IV & $T$ & 0,10 & 10 & - & 3,3 & 1,06 & 33,1 & + \\
\hline $6-I$ & $T$ & 0,23 & 4,3 & - & 4,4 & 0,658 & 51,7 & + \\
\hline $6-$ I I & $T$ & 0,24 & 4,2 & - & - & 0,633 & 26,9 & + \\
\hline 7 & E & 0,23 & 4,3 & 3 & 4,4 & 0,161 & 15,6 & + \\
\hline 8 & $\mathrm{E}$ & 0,24 & 4,2 & 2,9 & 6,1 & 0,081 & 18 & - \\
\hline 9 & $E$ & 0,25 & 4 & 2,8 & 4,6 & 0,099 & 26,8 & + \\
\hline $10-I$ & $E$ & 0,23 & 4,3 & 3 & 4,8 & 0,038 & 63,2 & - \\
\hline $10-I^{\Delta}$ & $T$ & 0,23 & 4,3 & - & 4,7 & 0,044 & 46 & + \\
\hline 11 & $E$ & 0,24 & 4,2 & 2,9 & 6,5 & 0,148 & 36,7 & + \\
\hline
\end{tabular}

* O algarismo romano representa a etapa do ensaio.

** $T$ = transiente; $E=$ estacionārio.

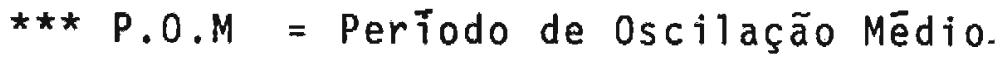

$\star * * * C V=$ Coeficiente de variação

$\bar{v}$ em gART/g cēll.min

$\Delta$ Como na verdade este ensaio é constituído de 5 etapas, sendo a 1 a em regime estacionārio e as demais transiente, os valores de $\bar{V}$ e $C V$ apresentados representam a mēdia destes parāmetros entre as etapas: $2 \stackrel{a}{a}, 3 \stackrel{a}{-}, 4 \stackrel{a}{a}$ e $5 \underline{a}$. Foi feito isto por questão de conveniência (ver texto para maiores detalhes). 


\section{CONCLUSOES}

0s resultados obtidos nas condições experimentais descritas nesta Tese permitem concluir:

1. Para uma dada composição do meio, a técnica adotada no pré paro do inōculo permitiu obter suspensões de leveduras com praticamente mesma concentração celular e mesma atividade invertāsica especīfica.

2. Nas primeiras horas dos ensaios de cultivo continuo, a ati vidade invertásica específica da levedura apresentou acentuado decrēscimo, refletindo provāveis alterações do meta bolismo celular naqueles períodos.

3. A atividade invertásica especīfica da levedura oscilou em todos os ensaios de cultivo continuo.

4. O valor real do perīodo de oscilação da atividade invertāsica especifica da levedura em cultivo continuo não $\bar{e}$ superior a 10 min.

5. Nos ensaios em regime transiente não foi observada corre lação entre a atividade invertāsica específica e a velocidade especiffica de consumo da sacarose. 
6. Nos ensaios, em regime transiente, com borbulhamento de ar e mosto suplementado, os perfís das variações, com o tempo, das velocidades específicas de consumo de AR e de consumo de sacarose foram semelhantes, indicando provável acoplamento entre a hidrōlise da sacarose e a assimilação dos açūcares redutores, intermediada pela presença da invertase na parede celular.

7. Considerando apenas as perturbaçōes do sistema provocadas por adição de nutrientes,verificou-se que a perturbação por degrau causou um efeito mais intenso ra atividade invertäsica especīfica do que a perturbação por impulso.

8. Entre as vārias perturbações por degrau efetuadas, a que apresentou maior influēocia sobre a atividade invertās ca especifica foi a provocada por adição de nutrientes.

9. Nos ensaios em regime estacionārio, a atividade invertās ca especîfica média diminuiu na seguinte sequēncia: a) cul tivo com borbulhamento de ar e mosto suplementado; b) cuI tivo sem borbulhamento de ar e mosto suplementado ou näo; c) cultivo com borbulhamento de ar e mosto näo suplementa do.

10. Em regime permanente, a atividade invertāsica específica média $\vec{e}$ função crescente da velocidade de crescimento celular:

$$
\vec{v}=0,54+10,66 \mathrm{DX} \quad(r=0,94)
$$


11. Em regime permanente, as seguintes eq̣uaçōes foram nbtidas:

$$
\begin{aligned}
\bar{v} & =-0,96+1,77 \mu_{S} \cdot \bar{x} & & (r=0,95) \\
\bar{v} & =-0,96+1,92 \mu_{\left(S^{\prime}-S\right)} \cdot \bar{x} & & (r=0,98) \\
\mu_{S} \cdot \bar{x} & =0,15+1,04 \mu_{\left(S^{\prime}-S\right)} \cdot \bar{x} & & (r=0,98)
\end{aligned}
$$

12. A velocidade de crescimento celular é mais sensivel do que a atividade invertāsica especīfica à velocidade de fornecimento de oxigēnio ao meio.

13. A variação da atividade invertāsica especīfica no decorrer do cultivo descontinuo pode ser atribuida a um mecanismo de repressão-desrepressão relacionado com a concentração de glicose presente no meio.

14. A oscilação da atividade invertásica específica, observada em todos os ensaios de cultivo continuo, pode ser compreendida, pelo menos en parte, como resultante da major ou menor dificuldade de interação entre a invertase e a sacarose, em consequēncia dos distintos posicionamentos das moléculas da enzima na parede celular durante os está gios do ciclo reprodutivo das células.

15. Os maiores valores de atividade invertásica específica fó ram obtidos quando um cultivo continuo, com mosto não suplementado e $\operatorname{com} \Phi=1 \mathrm{l} / \mathrm{l} \cdot \mathrm{min}, \mathrm{D} \cong 0,24 \mathrm{~h}^{-1}$ e $\mathrm{N}=500 \mathrm{~min}^{-1}$, foi submetido a uma perturbaçāo por degrau por adição de nutrientes. 


\section{RESUMO}

Mediu-se a atividade invertāsica de cêlulas intactas de levedura ( $S$. cerevisiae) cultivadas por processo cont $\bar{T}$ nuo em mejo preparado a partir de melaço de cana-de-açūcar,nas seguintes condições:

a) aerobiose, com adição de nutrientes ao meio

$$
\begin{aligned}
& D\left(h^{-1}\right): 0,10 \text { e } 0,24 \\
& \Phi(\ell / \ell \cdot \min ): 1 \text { e } 2 \\
& N\left(\min ^{-1}\right): \quad 500 \text { e } 700
\end{aligned}
$$

b) aerobiose, sem adição de nutrientes ao meio

$$
\begin{aligned}
& D\left(h^{-1}\right): 0,11 ; 0,14 \text { e } 0,23 \\
& \Phi(l / \ell \cdot \min ): 1 \text { e } 2 \\
& N\left(\mathrm{~min}^{-1}\right): 500
\end{aligned}
$$

c) anaerobiose, com e sem adição de nutrientes ao meio

$$
\begin{aligned}
& D\left(h^{-1}\right): 0,24 \\
& N\left(\min ^{-1}\right): 500
\end{aligned}
$$

Nas condições referidas obtiveram-se cultivos continuos em regime permanite e transiente.

Realizou-se, tambēm, cultivo descontinuo de cēlulas (mosto suplementado, $\Phi=2 \mathrm{\ell} / 2 \cdot \mathrm{min}$ e $N=500 \mathrm{~min}^{-1}$ ), constatando-se que a atividade invertāsica específica (v) variava no decorrer do processo. 
A anālise dos resultados deste ensaio permitiu con cluir que a variação de v poderia ser o resultado de um meca nismo de repressão-desrepressão controlado pela concentração de glicose no meio. Outrossim, o valor constante de $v$ no final do processo refletiria o fato de que a enzima na realidade está imobilizada na parede celular.

No caso dos cultivos contínuos foi observado que os valores de $v$, em função do tempo, oscilaram, sendo que o período de oscilação não foi maior que $10 \mathrm{~min}$. Outrossim, deve ser destacado que o P.O.M da atividade invertásica guardou certa dependēncia com as condições operacionais usadas nos ensaios. Assim, no caso de cultivos em aerobiose com mosto não suplementado o P.O.M de $v$ em regime permanente è menor do que em regime transiente. De outra parte, no caso de cultivos em aerobiose com mosto suplementado o P.O.M foi de mesma magnitu de tanto em regime transiente comc permanente.

Atravēs de balanços materiais adequados foi poss $\mathbf{i}$ vel calcular as velocidades especificas de crescimento celular $(\mu)$, de consumo de $A R\left(H_{S}\right)$ e de consumo de sacarose $\left(\mu_{S}{ }_{-S}\right)$ em funçäo do tempo. Em regime transiente näo se encontrou nenhuma lei que correlacionasse estas velocidades especificas entre si. Contudo, nos casos en que foi empregado mosto acrescido de nutrientes, verificou-se graficamente que deve existir uma correlação entre $\mu_{S}$ e $\mu\left(S^{\prime}-S\right)$, o que evidenciaria o acoplamento exis tente entre a decomposição da sacarose e o consumo de AR pelas cétulas, irternediada pelta invertase. Ressalte-se, tanbēm,que $v$ e u(S'-s) não mostrarari correlaçäo aparente, o que é de se estranhar, pois nas condiçōes de trabalho a hidrōlise da sacarose sō poderia se dar por via enzimätica. 
Em regime transiente observou-se que a atividade invertásica específica apresentava alguma ccrrelação com a velocidade de crescimento celular (UX). Dependendo das condições do experimento $v \in u X$ eram funçōes crescentes ou decrescentes com o tempo. Esta correlação ficou bem demonstrada nos cultivos em regime permanente, onde $\bar{v}$ era função crescente de $\mu X$, obedecendo à relação:

$$
\vec{v}=0,54+10,66 \mu x \quad(r=0,94)
$$

Em regime permanente foi verificado, tambēm, que:

a) Hs e $\mu_{\left(S^{\prime}-s\right)}$ para os cultivos em anaerobiose eram superiores àquelas dos cultivos em aerobiose, independente do fato do mosto ter sido ou não suplementado;

b) $\vec{v}$ diminuia, de acordo com as condições operacionais em pregadas, na seguinte ordem: cultivo em aerobiose com mosto su plementado, cultivo em anaerobiose com ou sem mosto suplementa do e cultivo em aerobiose e mosto não suplementado;

c) o fator de conversão de substrato em microrganismo decresceu na seguinte ordem: cultivo em aerobiose e mosto suple mentado, cultivo en aerobiose e mosto não suplementado e culti vo em anaerobiose com e sem mosto suplementado.

A correlação existente el.tre $v$ e $\mu x$ mostrou que os valores de $v$ determinados referem-se à atividade global da invertase imobilizada na parede celular e não àquela parcela da atividade que gerou os açücares redutores realmente consumi dos pela célula. Além disso, do modo como foi feito o tratamento das amostras, è possível admitir que não ocorreram modificações significativas nas caracteristicas morfo-fisiologi- 
cas das cẹlulas, representando estas a populaçăo existente na dorna no momento da amostragem. Por conseguinte a osci1 açäo de v poderia ser vista como sendo uma variaçăo na interação da invertase com a sacarose, devido àos posiciona mentos distintos que as moléculas da enzima teriam na parede celular durante as värias etapas do ciclo celutar. 
SUMMARY

The invertase specific activities of intact yeast cells obtained from continuous cultures on sugar-cane molasse media were determined. The experiments were carried out under the following conditions:

a) aerated and supplemented medium:

$$
\begin{aligned}
& D\left(h^{-1}\right): 0.10 \text { and } 0.24 \\
& \Phi(\ell / \ell \cdot m i n): 1 \text { and } 2 \\
& N\left(\min ^{-1}\right): 500 \text { and } 700
\end{aligned}
$$

b) aerated and non supplemented medium:

$$
\begin{aligned}
& D\left(h^{-1}\right): 0.11,0.14 \text { and } 0.23 \\
& \Phi(\ell / \ell . \min ): 1 \text { and } 2 \\
& N\left(\min ^{-1}\right): 500
\end{aligned}
$$

c) non aerated, supplemented and non supplemented medium: $D\left(h^{-1}\right): 0.24$

$N\left(\min ^{-1}\right): 500$

The above conditions lead to unsteady and to steady-state cultures.

It was observed that the invertase specific activi ty (v) varied during a batch growth experiment carried out under the following conditions: supplemented molasses, $\Phi=2$ e/l.min and $\mathrm{N}=500 \mathrm{~min}^{-1}$. The observed variation was 
probably caused by a repression-desrepression phenomenon on the biosynthesis of invertase, controlled by glucose concentration in the medium. Nevertheless, $v$ was approximately constant at the end of the process, which could be explained as a result of the enzyme immobilization on the cell wall.

It was also observed that in continuous test $v$ oscillated, and the oscillatory period was not greater than 10 min. Otherwise, it must be enhanced that there were some correlations between average oscillatory period and the experimental conditions. Considering the aerated continuous tests carried out with non supplemented medium, it was found that average oscillatory period in steady-state was lower than in unsteady-state. Nevertheless, in aerated continuous cultures carried out with supplemented medium average oscillatory period was the same, regardless if the system would be in unsteady or steady-state.

The following parameters were calculated: specific growth rate of the yeast $(\mu)$, specific consumption rate of reducing sugar $\left(\mu_{S}\right)$ and specific hydrolysing rate of sucrose $\left(\mu_{S}-S\right)$. Such parameters didn't show any correlation among them during unsteady states. Nevertheless, the curves $\mu_{S}=f(t)$ and $\mu_{\left(S^{\prime}-S\right)}=f(t)$, when supplemented molasses were used, show

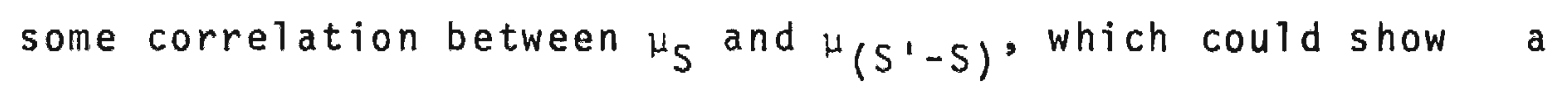
coupling between sucrose hydrolysis and reducing sugar consumption by cells, intermediated by invertase. In spite of the fact that only invertase could hydrolyse sucrose under the experimental conditions used, it wasn't possible to find any correlation between $\mu\left(S^{\prime}-S\right)$ and $v$. 
Otherwise, it was found a correlation between $v$ and $\mu x$ (growth rate) during unsteady-state. Such correlation was well demonstrated in steady-state tests:

$$
\bar{v}=0.54+10.65 \mu X \quad(r=0.94)
$$

The other main features of the experimental results obtained in steady-state continuous experiments are:

a) $\mu_{S}$ and $\mu_{\left(S^{\prime}-S\right)}$, for experiments carried out under anaerobic conditions, were higher than the same parameters for experiments carried out under aerobic conditions, regardless if the molasses had been supplemented or not;

b) $\bar{v}$ varied as follows: (aerated culture with supplemented medium) > (non aerated culture with or without supplemented medium) > (aerobic culture with non supplemented medium);

c) the yield factor varied as follows: (aerated culture with supplemented medium) > (aerated culture with non supple mented medium) > (non-aerated culture with or without supple mented medium).

The correlation between $\vee$ and $\mu X$ was an evidence that the measured values of $v$ represent the total invertase activity of the cell, and has no relation with the fraction of invertase that produced the reducing sugars assimilated by the cells.

Otherwise, it seems possible to assure that the sample manipulation did not affect the cell structure and that, consequently, the measured enzyme activity represents the actual invertase activity of the growing cells. The 
oscillatory phenomena could then be considered as a variation of the invertase-sucrose interaction due to different positions of the invertase molecules on the cell wall during the cell growth. 


\section{REFERENCIAS BIBLIOGRAFICAS*}

1. ABRAMS, B.B.; HACKEL, R.; MIZUNAGA, T.; LAMPEN, 0.J.

Relationship of large and small invertases in Saccharomyces: mutant selectively deficient in small invertase. J.Bacteriol., Baltimore, 135(3):809-17, 1978.

2. AIBA, S.; HUMPHREY, E.A.; MILLIS, F.N. Engenharia bioquímica. Campinas, Editora do ITAL, 1971. p.111-37.

3. ARNOLD, W.N. The structure of the yeast cell wall: solubilization of a marker enzyme (invertase) by the autolytic enzyme system. J.Biol. Chem., Baltimore, 247 (4):1161-9, 1972 .

4. ARNOLD, W.N. Volume and enzyme content of the periplasmic space in yeast. Physiol. Chem. Phys., Portland, $\underline{5}(2)$ : $117-23,1973$.

5. ARNOLD, W.N. Location of acid phosphatase and B-fructofuranosidase within yeast cell envelopes. J.Bacteriol., Baltimore, $112(3): 1346-52,1972$.

6. BABCZINSKI, P. Partial purification, characterization and localization of the membrane-associated invertase of yeast. Biochim. Biophys. Acta, Amsterdam, 614(1): $121-33,1980$.

* De acordo com as normas preconizadas pela ASSOCIAÇAO BRASILEI RA DE NORMAS TECNICAS (ABNT). As abreviaturas dos tītulos dos periōdicos estão de acordo com o Chemical Abstracts Service Source Index, Easton, 1975. 
7. BACILA, M.; VILLELA, G.G.; TASTALDI, H. Técnicas e experimentos de bioquímica. Rio de Janeiro, Guanabara Koo gan, 1972. p.29.

8. BALLOU, C.E. Some aspects of the structure, immunochemis try and genetic control of yeast mannans. Adv. Enzymol., New York, 40:239-70, 1974.

9. BOER, P.; LINNEMANS, W.A.M.; ELBERS, P.F. Localization of acid phosphatase in $\underline{S}$. cerevisiae: a clue to cell wall formation. J. Bacteriol., Baltimore, 131(2):638$44,1977$.

10. BORZANI, W.; LIMA, U.A.; AqUARONE, E. Engenharia bioquímica. São Paulo, Edgard B1ücher, 1975. v.3, p. 112.

11. BORZANI, W.; GREGORI, R.E.; VAIRO, M.L.R. SOme observations on oscillatory changes in the growth rate of $\underline{\text { s. }}$ cerevisiae in aerobic continuous undisturbed cultu re. Biotechnol. Bioeng., New York, 19:1363-74, 1977.

12. BOSTOCK, C.J.; DONACHIE, W.D.; MASTERS, M.; MITCHISON, J. M. Synthesis of enzymes and DNA in synchronous cultu res. Nature, London, 210:808-10, 1966.

13. BULL, A.T. Environmental factors influencing the synthesis and excretion of exocellular macromolecules. App 1. Chem. Biotechnol., London, 22:261-92, 1972.

14. CABIB, B. Molecular aspects of yeast morphogenesis. Annu. Rev. Microbiol., Palo Alto, 29:191-214, 1975. 
15. CARLSON, M. \& BOTSTEIN, D. Two differentialiy regulated mRNAs with different $5^{\prime}$ ends encode secreted and intracellular forms of yeast invertase. Cell, Cambridge, 28: $145-54,1982$.

16. CLARKE, P.H. Methods for studying enzyme regulation. Methods Microbiol., London, 6A:269-326, 1971.

17. CONWAY, E.J. \& DOWNEY, M. An outer metabolic region of the yeast cell. Biochem. J., London, 47:347-55, 1950.

18. DAVIES, A. Invertase formation in S. fragilis. J. Gen. Microbiol., London, 14:109-21, 1956.

19. DEAN, A.C.R. Influence of environment on the control of enzyme synthesis. J.Appl. Chem. Biotechnol., London, $\underline{22}: 245-59,1972$.

20. DEMIS, D.J.; ROTHSTEIN, A.; MEIER, R. The relationship of the cell surface to metabolism. X. The location and function of invertase in the yeast cel1. Arch. Biochem. Biophys., New York, 48:55-62, 1954.

21.DODYK, F. \& ROTHSTEIN, A. Factors influencing the appear ance of invertase in S. cerevisiae. Arch. Biochem. Biophys., New York, 104:478-86, 1964.

22. ELLIOTT, S.G. \& McLAUGHLIN, C.S. Rate of macromolecular synthesis through the cell cycle of the yeast $\underline{s}$. cerevisiae. Proc. Nitl. Acad. Sci. USA., Washington, 75 (9):4384-8, 1978 . 
23. ELORZA, M.V.; VILLANUEVA, J.R.; SENTANDREU, R. The mecha nism of catabolite inhibition of invertase by glucose in $\underline{S}$. cerevisiae. Biochim. Biophys. Acta, Amster dam, $\underline{475}(1): 103-12,1977$.

24. ELORZA, M.V.; LOSTAU, C.M.; VILLANUEVA, J.R.; SENTANDREU, $R$. Invertase messenger ribonucleic acid in $\underline{S}$. cerevisiae: Kinetics of formation and decay. Biochim. Biophys. Acta, Amsterdam, 475(4):638-51, 1977.

25. FALCONE, M. \& MARQUES, A.B. Estudo sobre as condições de hidrōlise pelo àcido cloridrico na dosagem de açūcares redutores totais. Tecnol. Aliment. Bebidas, Säo Paulo, 4: $24-30,1965$.

26. FARKAS, V.; KOVARIK, J.; KOSINOVA, A.; BAUER, S. Autoradiografic study of mannan incorporation into the growing cell walls of $\underline{S}$. cerevisiae. J.Bacteriol. Ba1timore, 117(1):265-9, 1974 .

27. FARREL, P.H. High resolution two-dimensional electrophoresis of proteins. J.Biol. Chem., Baltimore, 250:400721,1975 .

28. GALLILI, G. \& LAMPEN, 0.J. Large and small invertases and the yeast cell cycle. Pattern of synthesis and sensi vity to tunicamycin. Biochim. Biophys. Acta, Amster dam, $\underline{475}(1): 113-22,1977$.

29. GASCON, S.; NEUMAN, N.P.; LAMPEN, 0.J. Purification of the internal invertase of yeast. J.Biol. Chem., Baltimore, 243:1567-72, 1968. 
30. GORDON, C.N. \& ELLIOTT, S.G. Fractionation of S.cerevisiae cell populations by centrifugal elutriation. J. Bacteriol., Baltimore, $\underline{129}(1): 97-100,1977$.

31. GORMAN, J.; TAURO, P.; La BERGE, M.; HALVORSON, H. Timing of enzyme synthesis during synchronous division in yeast. Biochem. Biophys. Res. Commun., New York, 15(1): $43-9,1964$.

32. GRANER, E.A. Como aprender estatística. São Paulo, Melho ramentos, 1952 . p. 119.

33. HARRISON, J.S. Baker's yeast. In: RAINBOW, C. \& ROSE, A.H., ed. Biochemistry of industrial microorganisms. London, Academic Press, 1963. p. 9-30.

34. IGLESIAS, C.F.; MORENO, F.; GASCON, S. Light and intermediate molecular forms of yeast invertase as precursors of the heavy enzyme. FEBS Lett., Amsterdam, 114(1):5760,1980 .

35. ISLAM, M.F. \& LAMPEN, J.0. Invertase secretion and sucrose fermentation by $\underline{s}$. cerevisiae protoplasts. Biochim. Biophys. Acta, Amsterdam, 58:294-302, 1962.

36. JOHNSTON, G.G.; EHRHARDT, C.W.; LORINCZ, A.; CARTER, B.L.A. Regulation of cell size in the yeast $\underline{\mathrm{S}}$. cerevisiae. $\mathrm{J}$. Bacteriol., Baltimore, 137(1):1-5, 1979.

37. L.ACAZ, C.S.; MINAMI, P.T.; PURCHIO, A. O grande mundo dos fungos. São Paulo, EDUSP, 1970. 
38. LAMPEN, J.0.; KUO, S.; CANO, F.R. Structural features in synthesis of external enzymes by yeast. Ferment.Technol. Today, Proc. Int. Ferment. Symp., $4^{\text {th }}, 1972,819-$ 24. Apud: Chem. Abstr., Columbus, $84: 27875 \mathrm{~K}, 1973$.

39. LEHNINGER, A.L. Bioguỉmica. São Paulo, Edgard Blücher, 1976. v.2, p.317.

40. MCMURROUGH, I. \& ROSE, A.H. Effect of growth rate and substrate limitation on the composition and structure of the cell wall of $\underline{S}$. cerevisiae. Biochem. J., London, 105:189-203, 1967 .

41. MEYENBURG, H.K. The budding cycle of $\underline{\mathrm{S}}$. cerevisiae. Pathol. Microbiol., Base1, 31:117-27, 1968.

42. MITCHISON, J.M. Enzyme synthesis in synchronous cultures. Science, Washington, 165:657-63, 1969 .

43. MITCHISON, J.M. The growth of single cells. I. Schizosaccharomyces pombae. Exp. Cell Res., New York, 13(2): $244-62,1957$.

44. MORMENEO, S. \& SENTANDREU, R. Regulation of invertase

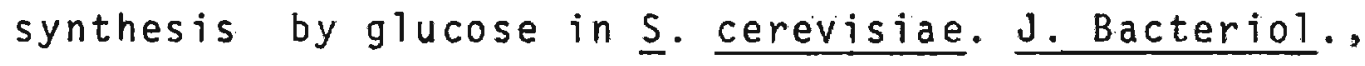
Baltimore, $152(1): 14-8,1982$.

45. NOVICK, P. \& SCHEKMAN, R. Secretion and cell surface growth are blocked in a temperature-sensitive mutant

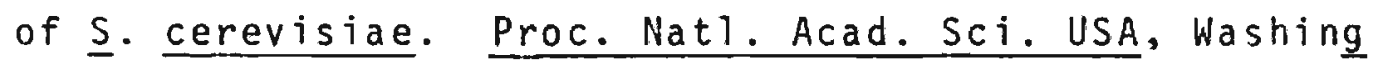
ton, $\underline{76}(4): 1858-62,1979$. 
46. OHWEILER, A.0. Teoria e prätica da anāilise quantitativa inorgānica. Brasilia, Editora Univ. Brasîlia, 1968. v. 1, p. 9 .

47. PEREgo, L. Fermentação alcoōica contínua de mosto de me1aço: influência da concentração do mosto e da vazão especĩfica de alimentaçāo na estabilidade do sistema a $32^{\circ} \mathrm{C}$. São Pauto, FacuTdade de Ciências Farmacêuticas da USP, 1979. |Dissertação - mestrado|.

48. PFAFF, J.H.; MILLER, M.W.; MRAK, E.M. The 1 ife of yeast. 2.ed. Cambridge, Harward University Press, 1968.

49. PREISS, W.J. The localization of invertase in the yeast cell with low voltage electrons. Arch. Biochem. Biophys., New York, 75:156-95, 1958.

50. RODRIGUES, L. Yeast invertase: subcellular distribution and possible relationship between the isoenzymes. Curr. Microbiol., New York, 1(1):41-44, 1978. Apud: Chem. Abstr., Columbus, $89: 159858 \mathrm{v}, 1978$.

51. ROSE, A.H. \& HARRISON, J.S. The yeasts. London, Academic Press, 1971 . $\quad .2$.

52. SAMEJIMA, H.; KIMURA, K.; ADO, Y. Recent development and future directions of enzyme technology in Japan. Biochimie, Paris, 62:299-315, 1980.

53. SANTOS, E.; VillanueVA, J.R.; SENTANDREU, R. - The plasma membrane of $\underline{S}$. cerevisiae: isolation and some properties. Biochim. Biophys. Acta, Amsterdam, 508(1):3954,1978 . 
54. SKINNER, K.J. Enzymes technology. Chem. Eng. News, Washington, 53(33):22-41, 1975 .

55. SOMOGYI, M. Notes on sugar determination. J.Biol.Chem., Baltimore, 195(1):19-23, 1952.

56. TKACZ, J.S. \& LAMPEN, J.0. Surface distribution of invertase on growing Saccharomyces cells. J. Bacteriol., Baltimore, $113(2): 1073-5,1973$.

57. TODA. K. Induction and repression of enzymes in microbial culture. 1. Chem. Technol. Biotechnol., Oxford, $31: 775-90,1981$.

58. TODA, K. Invertase biosynthesis by $\underline{S}$. carlsbergensis in batch and continuous cultures. Biotechnol. Bioeng.. New York, 18:1103-15, 1976.

59. TODA, K.; TAKEUCHI, T.; SANO, H. Growth rate dependence of enzyme synthesis in chemostat cultures: $\alpha$-amylase, $\beta$-galactosidase,acid phosphatase and $\beta$-fructosidase. J. Chem Technol. Biotechnol., Oxford, 29:747-55, 1979.

60. VITOLO, M. Extração de invertase solūvel a partir de 1evedura de panificação ( . cerevisiae). São Paulo, Faculdade de Ciências Farmacēuticas da USP, 1979. |Dissertação - mestradol.

61. Vitolo, M. Tópicos de enzimologia industrial. São Pau10, Edição do autor, 1981. p. 58.

62. WHITE, J. Yeast technology. London, Chapman and Hall, 1954. p. 62. 
63. WILLIAMSON, D.H. \& SCOPES, A.W. A rapid method for. synchronizing division in the yeast $\underline{s}$ cerevisiae. Nature, London, 193:256-7, 1962.

64. ZAJIK, E.J. \& LeDUY, A. A geometrical approach for differentation of an experimental function at a point: applied to growth and product formation. Biotechno1. Bioeng., New York, 15:805-10, 1973. 


\section{APENDICE}

A tabela 8.1 tem o objetivo de ilustrar os vărios passos necessārios para calcular as velocidades específi cas, empregadas na discussão dos resultados desta tese. Estes parâmetros foram calculados atravēs das equações (1-III), (1-VII) e (1-IX), deduzidas no item 1.2, em associação com o mētodo algébrico de cālculo de derivadas preconizado por ZAJIC \& Le DUY (64), utilizado para determinar dS/dt, dX/dt e $d\left(S^{\prime}-S\right) / d t$. 
TABELA 8.1. Parāmetros intermediārios indispensāveis para o cálculo de $\mu, \mu_{S}$ e $\mu_{S^{\prime}-S}$. Os dados mostrados re ferem-se à 2 a etapa do ensaio no 5 .

\begin{tabular}{|c|c|c|c|c|c|c|c|c|c|c|c|c|c|c|c|c|}
\hline \multirow[t]{2}{*}{$\begin{array}{l}: t \\
(n)\end{array}$} & $x$ & 5 & $5^{\prime}$ & $\left(5^{1}+5\right)$ & $\begin{array}{l}\left(5^{\prime}-5\right) \\
\text { interp. }\end{array}$ & $\frac{d\left(5^{1}-5\right)}{d t}$ & $(* *)$ & $\frac{d(5-5)}{d t}$ & $\frac{d s^{*}}{d t}$ & $D\left(5_{0}-5\right)$ & $\frac{(d s) c}{d t}$ & $\mu_{s}$ & $H\left(5^{1}-s\right)$ & $\frac{1}{x} \cdot \frac{d x^{*}}{d t}$ & $\boldsymbol{\mu}$ & \multirow{2}{*}{$\begin{array}{c}\mu x \\
(g / 2, h)\end{array}$} \\
\hline & & & $(g / f)$ & & & \multicolumn{6}{|c|}{$(g / l, h)$} & \multicolumn{4}{|c|}{$h^{-1}$} & \\
\hline 27 & 1,43 & 7.5 & 20.8 & 13.3 & 13,3 & 0 & 2.629 & -2.629 & 0 & $-0,239$ & $-2,39$ & 1.67 & 1.84 & 0.063 & 0,303 & 0.433 \\
\hline 28 & 1,52 & 7,5 & 20.8 & 13.3 & 13,3 & 0 & 2,629 & -2.629 & 0 & -0.239 & -2.39 & 1,57 & 3.73 & 0,063 & 0,303 & 0,461 \\
\hline 29 & 1.62 & 7,5 & 20.8 & 13,3 & 13,3 & $-0,098$ & 2.629 & $-2,727$ & 0 & $-0,239$ & $-2,49$ & 1.54 & 1.68 & 0.059 & 0,299 & 0.484 \\
\hline 30 & 1.71 & 7,5 & 20,6 & 13,1 & 13,1 & $-0,295$ & $2 ., 677$ & $-2,972$ & 0 & $-0,239$ & $-2,73$ & 1.60 & 1,74 & 0,067 & 0,307 & 0.525 \\
\hline 31 & 1,85 & 7,5 & 20,1 & 12,6 & 12,7 & $-0,492$ & 2.772 & $-3,264$ & 0 & $-0,239$ & $-3,03$ & 1.64 & 1.76 & 0,078 & 0,318 & 0.588 \\
\hline 32 & 2,00 & 7.5 & 19,5 & 12.0 & 12,1 & $-0,835$ & 2,940 & $-3,775$ & $-0,050$ & $-0,239$ & $-3,59$ & 1.80 & 1.89 & 0.065 & 0.305 & 0,610 \\
\hline 3.3 & 2.71 & 7.4 & 18.5 & 11.1 & 10,8 & $-i .52$ & 3.227 & -4.747 & -0.100 & $-0,215$ & $-4,63$ & 2,19 & 2.25 & 0,078 & 0,318 & 0.671 \\
\hline 34 & 2,33 & 7,3 & 15.2 & 8,9 & 8,9 & -1.95 & 3.681 & -5.631 & $-0,149$ & $-0,131$ & $-5,59$ & 2,40 & 2,42 & 0.084 & 0.324 & 0,755 \\
\hline 35 & 2,50 & 7,1 & 14.1 & 7.0 & 6,9 & $-1,80$ & 4.159 & $-5,959$ & $-0,373$ & $-0,143$ & $-6,19$ & 2,48 & 2.38 & 0.080 & 0,320 & 0,800 \\
\hline 36 & 2.73 & 6.5 & 12,0 & 5,5 & 5,3 & $-1,55$ & 4,541 & $-6,091$ & -0.762 & 0 & -6.85 & 2,51 & 2,23 & 0,090 & 0.330 & 0,901 \\
\hline 37 & 3,00 & 5,5 & 9.5 & 4,0 & 3,8 & $-1,45$ & 4.900 & -6.350 & -1.024 & 0,239 & $-7,61$ & 2,54 & 2,12 & 0.103 & 0,343 & 1,03 \\
\hline 38 & 3.35 & 4.5 & 7,1 & 2.7 & 2.4 & $-1,23$ & 5,234 & $-6,464$ & $-1,000$ & 0,490 & $-7,95$ & 2,37 & 1,93 & 0.093 & 0,333 & 1,12 \\
\hline 39 & 3,62 & 3,5 & 4,5 & 3,0 & 1,3 & $-0,72$ & 5,497 & -6.207 & $-0,974$ & 0,717 & $-7,90$ & 2.18 & 1,71 & 0.077 & 0,317 & 1.15 \\
\hline 40 & 3,91 & 2.5 & 3,3 & 0,8 & 0.8 & $-0,39$ & 5,617 & $-6,007$ & $-0,750$ & 0,956 & $-7,71$ & 1.97 & 1.54 & 0.068 & 0.308 & 1.20 \\
\hline 41 & 4,15 & 2,0 & 2.5 & 0,45 & 0,5 & $-0,144$ & 5,688 & -5.832 & $-0,448$ & 1.080 & $-7,36$ & 1,77 & 1.41 & 0,053 & 0,293 & 1,22 \\
\hline 42 & 4.35 & 1.6 & 2,1 & 0,5 & 0,5 & 0 & 5.688 & $-5,688$ & $-0,212$ & 1,171 & -7.07 & 1.63 & 1.31 & 0.044 & 0,284 & 1.24 \\
\hline 43 & 4,53 & 1.6 & 2.0 & 0.5 & 0,5 & 0 & 5,688 & $-5,688$ & $-0,050$ & 1.183 & $-6,92$ & $1,53$. & 1.26 & 0,036 & 0.276 & 1.25 \\
\hline 44 & 4,68 & 1,5 & 2,0 & 0.5 & 0.5 & 0 & 5.688 & $-5,688$ & $-0,025$ & 1.195 & $-6,91$ & 1,48 & 1.22 & 0,027 & 0,267 & 1.25 \\
\hline 45 & 4.78 & 1,5 & 2,0 & 0.5 & 0.5 & 0 & 5,688 & $-5,688$ & o & 1.195 & $-6,88$ & 1.44 & 1.19 & 0.026 & 0.266 & 1.27 \\
\hline 46 & 4,93 & 3.5 & 2,0 & 0,5 & 0.5 & 0 & 5,688 & $-5,688$ & 0 & 1.195 & $-6,88$ & 1,40 & 1.15 & 0,027 & 0,267 & 1,32 \\
\hline 47 & 5.05 & 1.5 & 2.0 & 0,5 & 0.5 & 0 & 5,688 & $-5,688$ & 0 & 1.195 & -6.88 & $i, 36$ & 1.13 & 0,024 & 0,264 & 1.33 \\
\hline 48 & 5,17 & 1,5 & 2.0 & 0,5 & 0,5 & 0 & 5.688 & $-5,688$ & 0 & 1.195 & $-6,88$ & 9,33 & 1.10 & 0,016 & 0,256 & 1,32 \\
\hline 49 & 5.22 & 1.5 & 2.0 & 0.5 & 0,5 & 0 & 5,688 & $-5,688$ & 0 & 1,195 & $-6,88$ & 1.32 & 1.09 & 0,006 & 0.246 & 1.28 \\
\hline 50 & 5,23 & 1,5 & 2,0 & 0,5 & 0,5 & 0 & 5.688 & $-5,688$ & 0 & 1.195 & $-6,88$ & 1,32 & 1.09 & 0.003 & 0,243 & 1.27 \\
\hline 51 & 5,25 & 1,5 & 2,0 & 0.5 & 0.5 & 0 & 5.688 & -5.688 & 0 & 1,195 & $-6,8 B$ & 1.31 & 1.08 & 0,003 & 0,243 & 1,28 \\
\hline
\end{tabular}

* Calculados através do mêtodo algëbrico preconizado por Le Duy e Zajic (64) $*=0,239\left[24,3-\left(5^{\prime}-5\right)\right]$. 